\title{
PROTON EXCHANGE MEMBRANE (PEM) FUEL CELL PARAMETRIC STUDY VIA MATHEMATICAL MODELING AND NUMERICAL SIMULATION
}

\author{
By \\ Rihab Jaralla \\ B.Eng., University of Technology, Baghdad, Iraq, 1993 \\ MASc., Ryerson University, Toronto, Canada, 2009 \\ A dissertation presented to \\ Ryerson University \\ in partially fulfillment of the \\ requirements for the degree of \\ Doctor of Philosophy \\ in the Program of \\ Mechanical Engineering
}

Toronto, Ontario, Canada, 2015

C Rihab Jaralla 2015 


\section{AUTHOR'S DECLARATION FOR ELECTRONIC SUBMISSION OF A DISSERTATION}

I hereby declare that I am the sole author of this dissertation. This is a true copy of the dissertation, including any required final revisions, as accepted by my examiners.

I authorize Ryerson University to lend this dissertation to other institutions or individuals for the purpose of scholarly research

I further authorize Ryerson University to reproduce this thesis by photocopying or by other means, in total or in part, at the request of other institutions or individuals for the purpose of scholarly research.

I understand that my dissertation may be made electronically available to the public 


\title{
ABSTRACT \\ Proton Exchange Membrane (PEM) Fuel Cell Parametric Study via Mathematical Modeling and Numerical Simulation
}

\author{
Rihab Jaralla \\ Doctor of Philosophy, Ryerson University \\ Department of Mechanical and Industrial Engineering, 2015
}

In the proton exchange membrane (PEM) fuel cell study, numerical analysis of complex and coupled multi-disciplinary processes involving the subjects of fluid dynamics, heat transfer, mass transport, and electrochemistry has been attempted over the past few decades. However, many resulting models are, in spite of fancier functionalities such as three-dimensionality, too complex to implement on account of the digital hardware requirement as well as computation time consumption. On the other hand, three-dimensional analytical models reported in literature look much simple, but they are embedded by a number of fairly unrealistic assumptions and, hence, lead to significantly weakened usability.

In this thesis, a set of detailed two-dimensional non-isothermal computational models for PEM fuel cells in $x-y$ and $y-z$ planes are developed, which aims at the equivalency with the 3D PEM fuel cell model and, moreover, gains more insights with significantly reduced computational cost. The complete model consisting of the equations of continuity, momentum, energy, species concentrations, and electric potentials in different regions of a PEM fuel cell are numerically solved using the finite element method implemented into a commercial CFD (COMSOL) code. A comprehensive comparison with the experimental data has been performed to validate the $2 \mathrm{D}$ models developed in this study. On the basis of simulations of various flow and transport phenomena in an operational PEMFC, a systematic parametric study is conducted using the present developed PEM fuel cell models. A number of operating and design parameters are examined, 
including the operating pressure, ambient temperature, relative humidity, the porosity of the gas diffusion layer (GDL), the effective porosity of catalyst layer (CL), the porosity of membrane (M), the proton conductivity and the air inlet velocity at cathode side .

The obtained results of this study revealed that the membrane porosity, and air inlet velocity have considerable effects on the water content in the membrane, thus it is essential to select the proper values of these parameters to improve water management in the cell and avoid dehydration the membrane or flooding the electrode. Also, it is found that increasing air velocity at the inlet of the cathode gas channel has a significant effect on the temperature distribution in PEM fuel cell, as the temperature a noticeably dropped with higher inlet air velocity. The numerically results also found that with higher porosities of gas diffusion layers (GDLs) and catalyst layers (CLs), the performance of PEM fuel cell improved. In addition, it found that a higher performance can be achieved when fuel cell operated with reasonably higher operating temperature, operating pressure, proton conductivity and ensuring a full hydration of the reactants.

The outcome of this study demonstrates that the present developed PEM fuel cell models can serve as a useful tool for understanding of transport and electrochemical phenomena in PEM fuel cell as well as for optimization of cell design and operating conditions. 


\section{ACKNOWLEDGEMENTS}

I am gratefully thankful to my supervisor, Dr. Jun Cao for his constant encouragement and valuable guidance throughout this study. The completion of this thesis would not have been possible, without his guidance, great support and suggestions. Also, I would like to thank Dr. Alan Fung for allowing use of his laboratory during my study.

I would like to thank my examination committee members: Dr. Ziad Saghir, Dr. Alan Fung, Dr. Jeff Xi, and Dr. Huaxiong Huang for their valuable suggestions. Special thanks go to Dr. Ahmad Ghasempoor, the Director of Graduate Studies.

I acknowledge the financial support of the National Science and Engineering Research Council of Canada (NSERC) and Ryerson University.

I would like to express my deepest thanks to my husband, Dr. Tawfiq Jaber, for his unconditional emotional support, patience and understanding. My special most sincere thanks to my mother, without her and her unconditional love which she gives to me, this would never have been possible, and last but not least, I would like to express my thanks to my children, Mohamad, Ali and Hussain for their support and understanding during my study. 


\section{TABLE OF CONTENTS}

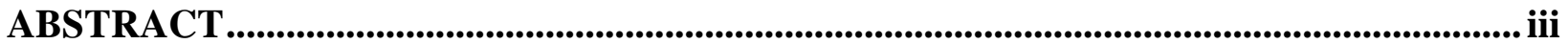

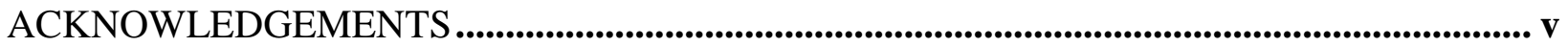

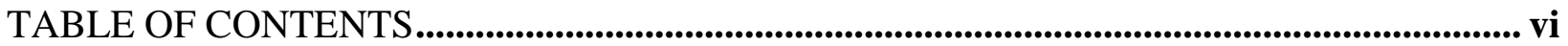

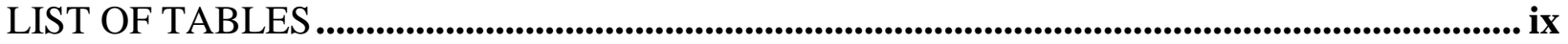

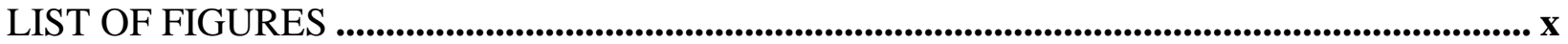

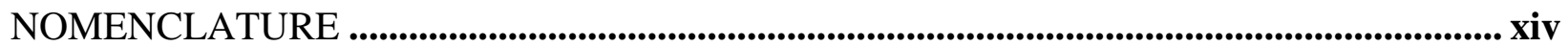

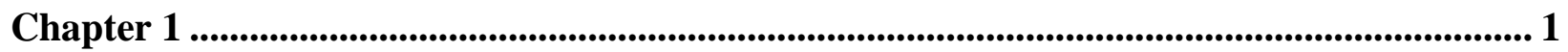

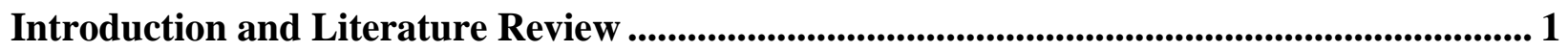

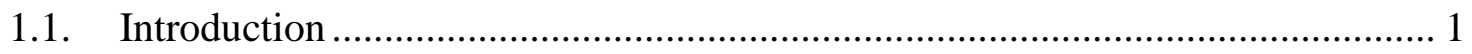

1.2. PEM Fuel Cell Principle and Components ................................................ 13

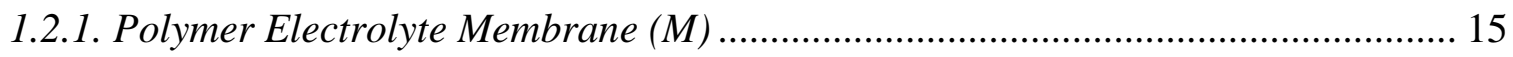

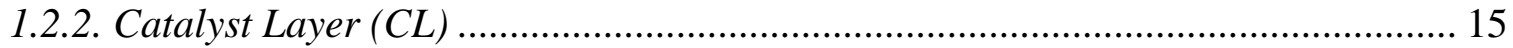

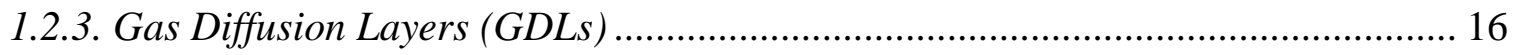

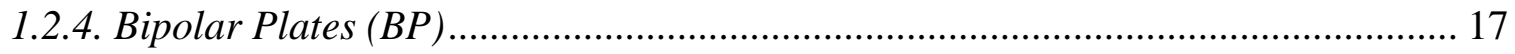

1.3. Fuel Cell Efficiencies ........................................................................... 17

1.4. PEM Modeling Literature Review ........................................................ 20

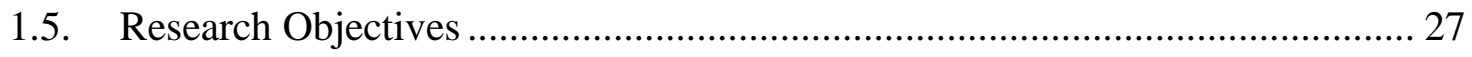

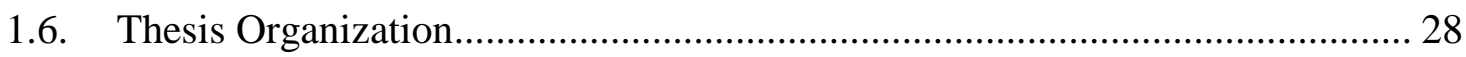

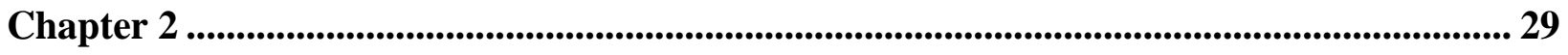

Two-Dimensional Model of PEM Fuel Cell........................................................................... 29

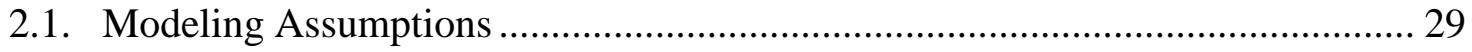

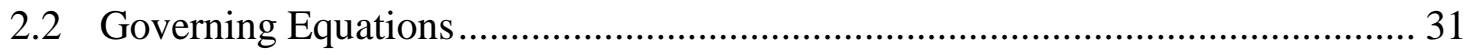

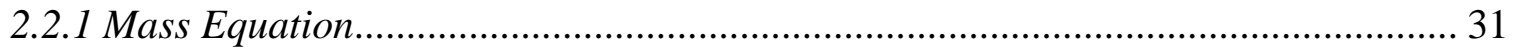

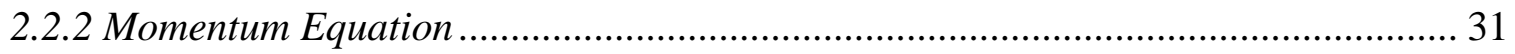


2.2.3 Mass Transfer Equation................................................................................. 33

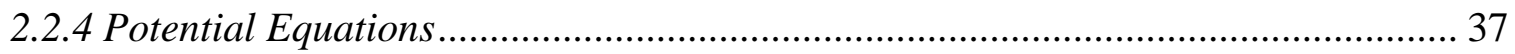

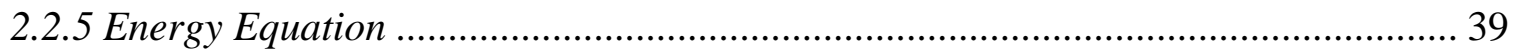

2.2.6 Water and Proton Transport Model ................................................................ 41

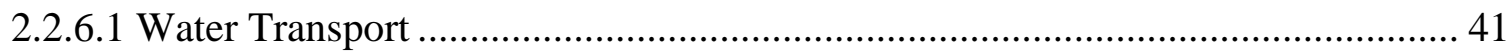

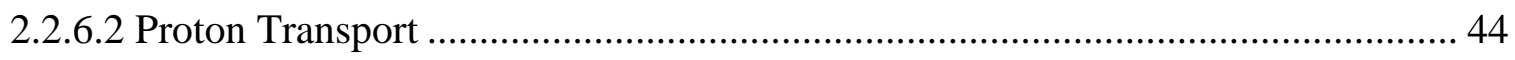

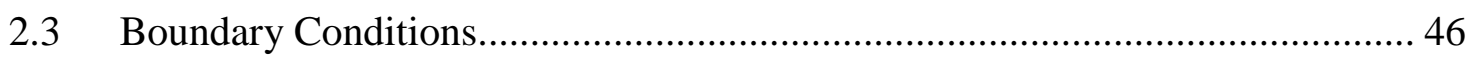

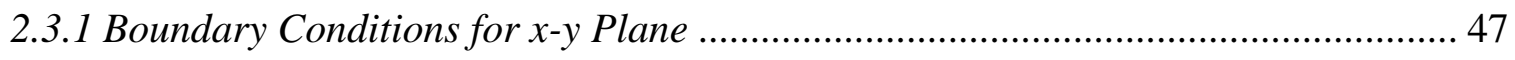

2.3.1.1 Boundary Conditions for Flow Field Model ....................................................... 47

2.3.1.2 Boundary Conditions for Species Transport Model ............................................ 48

2.3.1.3 Boundary Conditions for Energy Equations ....................................................... 49

2.3.1.4 Boundary Conditions for Water Transport in the Membrane.............................. 49

2.3.1.5 Boundary Conditions for Electron and Proton Transport Models ...................... 50

2.3.2 Boundary Conditions for $y$-z Plane .................................................................... 50

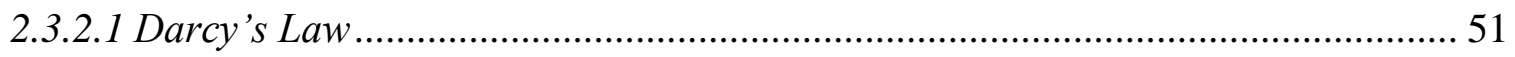

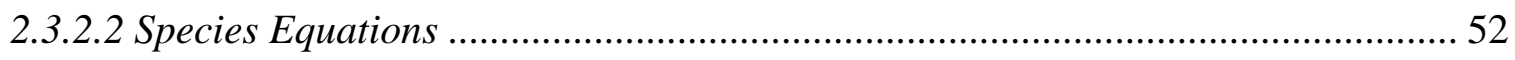

2.3.2.3 Solid-Phase Potential Equation ………………………………………….... 53

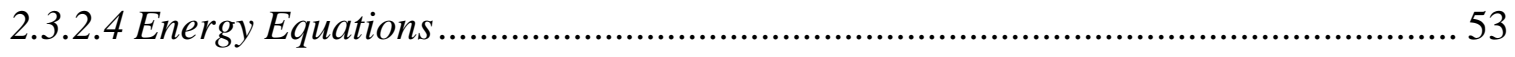

2.3.2.5 Boundary Conditions for Water and Proton Transport Model ........................... 53

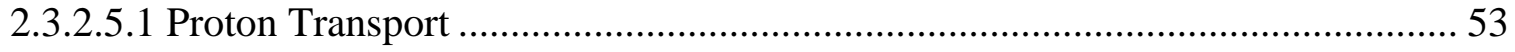

2.3.2.5.2 Water Transport in the Membrane ……………….......................................... 53

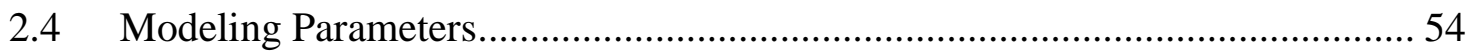

2.5 Numerical Solution Technique...................................................................... 57

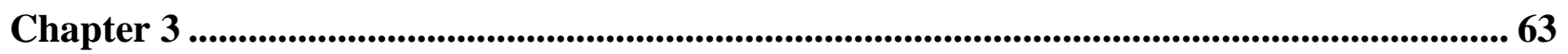

Base Case Results for $x-y$ and $y-z$ Planes................................................................................................ 63 


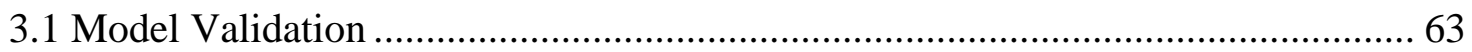

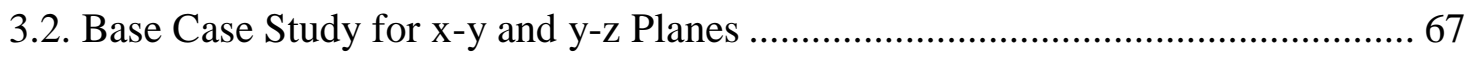

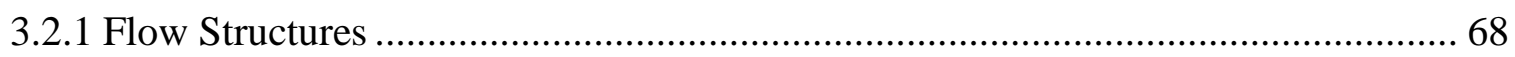

3.2.2 Distribution of Reactants and Products................................................................. 70

3.2.3 Water Content in Membrane .................................................................................. 76

3.2.4 Membrane-Phase Potential Loss ........................................................................ 78

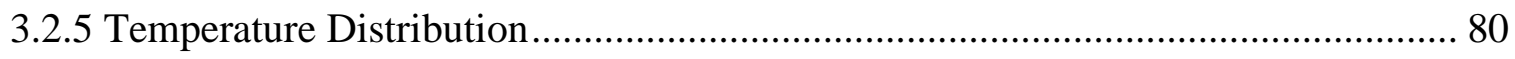

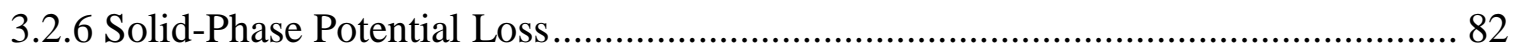

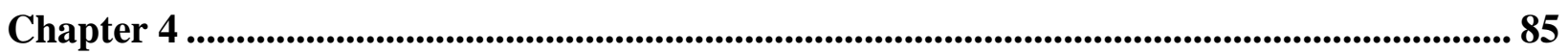

Parametric Study for $x-y$ Plane ........................................................................................................... 85

4.1 Effect of Inlet Reactant Relative Humidity .......................................................... 85

4.2 Effect of Operating Temperature ...................................................................... 90

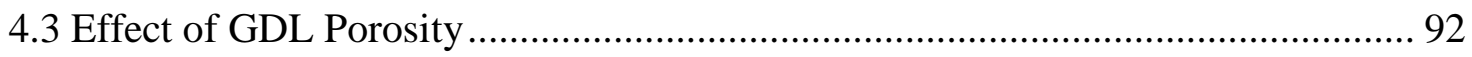

4.4 The Effect of the Effective Porosity of the Catalyst Layer...................................... 96

4.5 Effect of Proton Conductivity ……………………........................................... 99

4.6 Effect of Operating Pressure ………………………………………………. 102

4.7 The Effect of Membrane (M) Porosity ……………………….......................... 108

4.8 Effects of Air Inlet Velocity at Cathode Side ........................................................ 114

4.9 The optimization model ................................................................................ 120

Chapter 5 ....................................................................................................................................................... 122

Conclusions and Recommendations.................................................................................................. 122

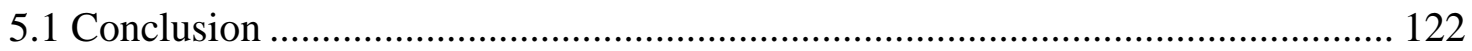

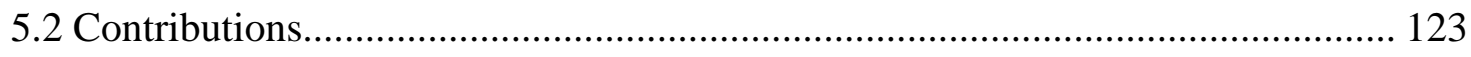

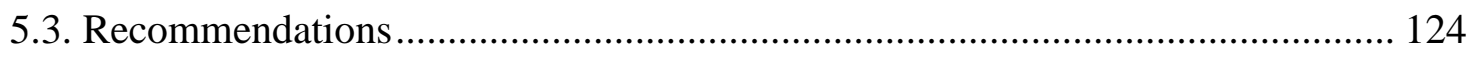




\section{LIST OF TABLES}

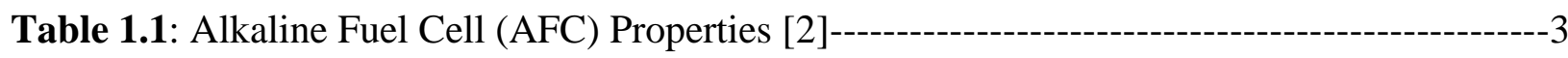

Table 1.2: Solid Oxide Fuel Cells (SOFC) Properties [2]---

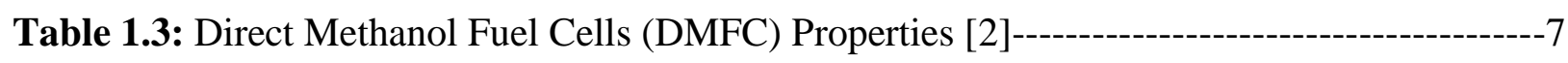

Table 1.4: Phosphoric Acid Fuel Cells (PAFCs) Properties [2]--------------------------------9

Table 1.5: Molten Carbonate Fuel Cell (MCFC) Properties [2]----------

Table 1.6: Polymer Electrolyte Membrane Fuel Cells (PEMFC) Properties [2]----------------13

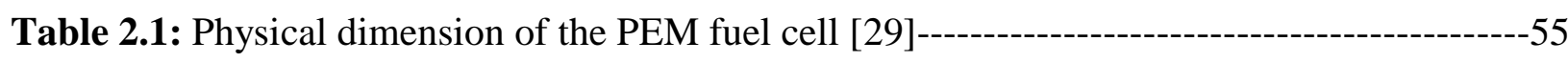

Table 2.2: Operating parameters for a PEM fuel cell under a base case computation,-----------55

Table 2.3: Electrode and membrane properties ---

Table 2.4: Electrochemical properties of a PEM fuel cell----------------------------57

Table 2.5: Binary diffusivities at 1atm and reference temperatures [32]------------------57

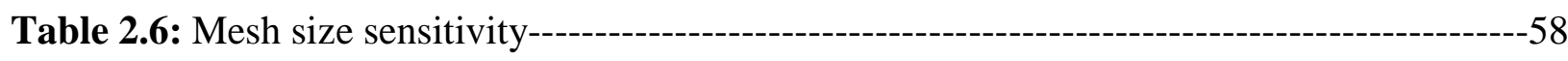

Table 4.1: The Current density corresponding to the Optimum Parameters at Cell Voltage of 0.7 (V)---10 121 


\section{LIST OF FIGURES}

Figure 1.1 Alkaline Fuel Cell Diagram [3] -----------------------------------------------2

Figure 1.2 Solid Oxide Fuel Cell (SOFC) Diagram [3] -----

Figure 1.3 Direct Methanol Fuel Cell (DMFC) Diagram [5] ---------

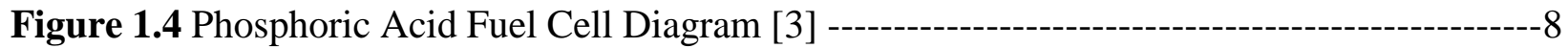

Figure 1.5 Molten Carbonate Fuel Cell (MCFCs) Diagram [3] --------

Figure 1.6 Proton Exchange Membrane (PEM) Fuel Cell Diagram [3] --------------------12

Figure 1.7 The polymer electrolyte fuel cell (PEMFC) [12] ---------------------------14

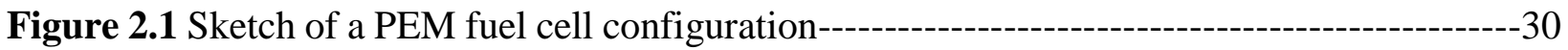

Figure 2.2 Schematic diagram of computation model of a PEM fuel cell in $x-y$ and $y-z$ planes-30

Figure 2.3 Transport paths of protons and electrons within a PEM fuel cell------------------------38

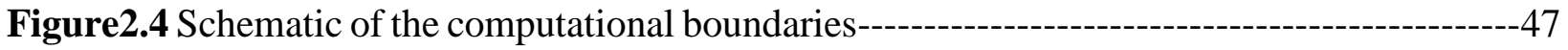

Figure2.5 Schematic diagram of computation model of a PEM fuel cell in y-z plane. -----------51

Figure 2.6 Mesh of the computational domain for $x-y$ plane (top) and y-z plane (bottom) -------60

Figure 2.7 Flow chart of the solution procedure for x-y plane-----------------------------61

Figure 2.8 Flow chart of the solution procedure for y-z plane----------

Figure 3.1 Comparison of modeling results for (a) $x-y$ and (b) $y-z$ plans with experimental data by Ju and Wang

Figure3.2 Power curve resulting from the fuel cell polarization curve ------------------------65

Figure 3.3 Power curve resulting from the fuel cell polarization curve. ----------------------67

Figure 3.4 Velocity distribution in the PEM fuel cells for $x-y$ plane (top) and y-z plane (bottom)-

Figure 3.5 Oxygen mole fraction distribution at cathode side for $x-y$ plane on the top and $y-z$ plane on the bottom $-72$

Figure 3.6 Water vapour mole fraction at the cathode side for $x-y$ plane top and $y-z$ plane in the bottom for cell voltage $0.7 \mathrm{~V}$

Figure 3.7 Hydrogen mole fraction at anode side for $x-y$ plane top and $y-z$ in the bottom for cell voltage $0.7 \mathrm{~V}$ $-74$

Figure 3.8 Water vapour mole fraction at the anode side for $x-y$ plane top and $y-z$ plane in the bottom for cell voltage $0.7 \mathrm{~V}$ $-75$ 
Figure 3.9 Water content distribution in membrane in $x-y$ plane top and $y-z$ plane on the bottom

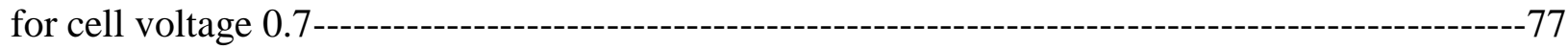

Figure 3.10 Membrane-phase potential distribution in MEA $x-y$ plane top and $y-z$ plane on the bottom for the cell voltage 0.7

Figure 3.11 Temperature distribution in $x-y$ plane top and $y-z$ plane in the bottom for cell voltage $0.7 \mathrm{~V}-$ $-81$

Figure 3.12 Solid-phase potential at the cathode in $x-y$ plane top and $y-z$ plane on the bottom for cell voltage $0.7 \mathrm{~V}$ $-83$

Figure 3.13 Solid-phase potential at the anode side for $x-y$ plane top and $y-z$ plane on the bottom for cell voltage $0.7 \mathrm{~V}$ $-84$

Figure 4.1 Polarization curves corresponding to different relative humidity$-86$

Figure 4.2 water content at cell voltage 0.7V: for Relative humidity $\mathrm{RH}=50 \%$ (top) and $\mathrm{RH}=100 \%$ (bottom) $-88$

Figure 4.3 membrane-phase potential losses at cell voltage $0.7 \mathrm{~V}$ : for Relative humidity $\mathrm{RH}=50 \%$ (top) and $\mathrm{RH}=100 \%$ (bottom) $-89$

Figure 4.4 Polarization curves corresponding to different operating temperature$-90$

Figure 4.5 water content at cell voltage $0.4 \mathrm{~V}$ : for Temperature $\mathrm{T}=333 \mathrm{~K}$ (top) and $\mathrm{T}=353 \mathrm{~K}$ (bottom) $-91$

Figure 4.6 Effects of GDL porosity on PEM fuel cell performance.

Figure 4.7 Oxygen mole fraction distribution inside fuel cells with different GDL porosities: $\varepsilon_{g}=0.2$ (top), and (b) $\varepsilon_{g}=0.4$ (bottom), at cell voltage $0.4 \mathrm{~V}$. $-94$

Figure 4.8 Oxygen mole fraction distribution inside cathode catalyst layer with different GDL porosities: $\varepsilon_{g}=0.2$ (top) and $\varepsilon_{g}=0.2$ (bottom) at cell voltage $0.4 \mathrm{~V}$ $-95$

Figure 4.9 The influence of effective porosity of catalyst layer on the performance of the PEM fuel cell$-96$

Figure 4.10 Oxygen mole fraction distribution inside cathode catalyst layer with different effective porosity of the catalyst layer: $\varepsilon_{c l}=0.034$ (top), and $\varepsilon_{c l}=0.102$ (bottom) at cell voltage 0.6V-98 Figure 4.11 Effect of proton conductivity on PEM fuel cell performance. $-99$

Figure 4.12 Membrane-phase potential losses for different proton conductivities: $11 \mathrm{~S} / \mathrm{m}$ (top) and $14 \mathrm{~S} / \mathrm{m}$ (bottom), at cell voltage $0.6 \mathrm{~V}$ $-101$ 
Figure 4.13 Membrane-phase potential losses for different proton conductivities: at $\mathrm{x}=0.0118 \mathrm{~m}$, for cell voltage $0.6 \mathrm{~V}$

Figure 4.14 Cell performance at different operating pressure loading $-103$

Figure 4.15 Hydrogen mole fraction distribution at anode side under different operating pressure conditions: $\mathrm{P}(1-3)$ top and $\mathrm{P}$ (3-5) bottom, at the cell voltage $0.6 \mathrm{~V}-$ $-104$

Figure 4.16 Water vapor mole fraction distribution at anode side under different operating pressure conditions: $\mathrm{P}(1-3)$ top and $\mathrm{P}(3-5)$ bottom, at the cell voltage $0.6 \mathrm{~V}$ $-105$

Figure 4.17 Oxygen mole fraction distribution at cathode side under different operating pressure conditions: $\mathrm{P}$ (1-3) top and $\mathrm{P}(3-5)$ bottom, at the cell voltage $0.6 \mathrm{~V}$ $-106$

Figure4.18 Water vapor mole fraction distribution at cathode side under different operating pressure conditions: $\mathrm{P}(1-3)$ top and $\mathrm{P}(3-5)$ bottom, at the cell voltage $0.6 \mathrm{~V}$ $-107$

Figure 4.19 Effects of Membrane porosity on PEM fuel cell performance$-109$

Figure 4.20 Oxygen mole fraction distribution inside fuel cells with different $M$ porosities: $\varepsilon_{m}=0.17$ (top), and $\varepsilon_{m}=0.28$ (bottom), at cell voltage $0.6 \mathrm{~V}$ $-110$

Figure 4.21 Water vapor mole fraction distribution at the cathode side with different M porosities: $\varepsilon_{m}=0.17$ (top), and $\varepsilon_{m}=0.28$ (bottom), at cell voltage $0.6 \mathrm{~V}$ $-111$

Figure 4.22 Water content at cell voltage $0.6 \mathrm{~V}$ with different $\mathrm{M}$ porosities: $\varepsilon_{m}=0.17$ (top), and $\varepsilon_{m}=0.28$ (bottom)

Figure 4.23 Membrane-phase potential loss for different membrane porosities: $\varepsilon_{m}=0.17$ (top), and $\varepsilon_{m}=0.28$ (bottom), at cell voltage $0.6 \mathrm{~V}$ $-113$

Figure 4.24 Effect of air inlet velocity on PEM fuel cell performance $-114$

Figure 4.25 Temperature distribution (surface plot) and convective heat flux (arrow plot) in the fuel cell with different air inlet velocity $U_{c}=0.1185 \mathrm{~m} / \mathrm{s}$ (top), and $U_{c}=1.45 \mathrm{~m} / \mathrm{s}$ (bottom), operating at cell voltage $0.6 \mathrm{~V}$ $-116$ Figure 4.26 Temperature distribution (surface plot) and conductive heat flux (arrow plot) in the fuel cell with different air inlet velocity $U_{c}=0.1185 \mathrm{~m} / \mathrm{s}$ (top), and $U_{c}=1.45 \mathrm{~m} / \mathrm{s}$ (bottom), operating at cell voltage $0.6 \mathrm{~V}$ $-117$ 
Figure 4.27 Oxygen mole fraction distribution at the cathode side with different air inlet velocity $U_{c}=0.1185 \mathrm{~m} / \mathrm{s}$ (top), and $U_{c}=1.45 \mathrm{~m} / \mathrm{s}$ (bottom), at cell voltage 0.6V-----------------------118 Figure 4.28 Water content distribution inside fuel cell with different air inlet velocity $U_{c}=0.1185 \mathrm{~m} / \mathrm{s}$ (top), and $U_{c}=1.45 \mathrm{~m} / \mathrm{s}$ (bottom), at cell voltage 0.6V---------------------119 Figure 4.29 The Polarization Curves of the New and Old Models --------------------------------120 


\section{NOMENCLATURE}

$A_{M E A} \quad$ Full active of MEA area, $\left[\mathrm{m}^{2}\right]$

$a \quad$ Catalyst surface area per unit volume, $\left[\mathrm{m}^{2} \cdot \mathrm{m}^{-3}\right]$

C Electric charge, [C]

$c \quad$ Concentration, $\left[\mathrm{mol} \cdot \mathrm{m}^{-3}\right]$

$c_{p} \quad$ Specific heat capacity at constant pressure, $\left[\mathrm{J} . \mathrm{kg}^{-1} \cdot K^{-1}\right]$

$D \quad$ Diffusion coefficient, $\left[\mathrm{m}^{2} \cdot \mathrm{s}^{-1}\right]$

E Potential, [Volt]

$E W_{m}$ Equivalent molecular weight of the membrane, $\left[\mathrm{kg} \cdot \mathrm{mol}^{-1}\right]$

$e \quad$ Membrane constant, $\left[\mathrm{mol} \cdot \mathrm{m}^{-3}\right]$

F Faraday's constant, [96487 $\left.\mathrm{C} \cdot \mathrm{mol}^{-1}\right]$

$f \quad$ Swelling coefficient of membrane, [-]

I Current, $[A]$

$i \quad$ Current density, $\left[A \cdot m^{-2}\right]$

$j_{0}^{r e f} \quad$ Exchange current density, $\left[A \cdot m^{-2}\right]$

$k \quad$ Thermal conductivity, $\left[W \cdot m^{-1} \cdot K^{-1}\right]$

$k_{\phi} \quad$ Electro-kinetic permeability, $\left[\mathrm{m}^{2}\right]$

$k_{h} \quad$ Hydraulic permeability, $\left[\mathrm{m}^{2}\right]$

$k_{p} \quad$ Permeability of electrode/membrane, $\left[\mathrm{m}^{2}\right]$

$M \quad$ Molecular weight, $\left[\mathrm{kg} \cdot \mathrm{mol}^{-1}\right]$

$N \quad$ Molar flux, $\left[\mathrm{mol} \cdot \mathrm{m}^{-2} \cdot \mathrm{s}^{-1}\right]$

$n \quad$ Molar number of electrons transferred, [-]

$n_{d} \quad$ Electro-osmotic drag coefficient [-]

$P \quad$ Pressure, $[\mathrm{Pa}$ ]

$R \quad$ Universal gas constant, $\left[8.3145 \mathrm{~J} \cdot \mathrm{mol}^{-1} \cdot \mathrm{K}^{-1}\right.$ ]

RH Relative humidity, [\%]

$S \quad$ Mass source/sink, $\left[\mathrm{kg} \cdot \mathrm{m}^{-3} \cdot \mathrm{s}^{-1}\right.$ ]

$T \quad$ Temperature, $[K]$ 


$\begin{array}{ll}V & \text { Cell potential (voltage), [Volt }] \\ \vec{V} & \text { Velocity vector, }\left[\mathrm{m} \cdot \mathrm{s}^{-1}\right] \\ W & \text { Power, }[\mathrm{W}] \\ x & \text { Molar fraction, }\left[\mathrm{mol} \cdot \mathrm{m}^{-3}\right] \\ x & \mathrm{x} \text { axis, }[\mathrm{m}] \\ y & \text { y axis, }[\mathrm{m}] \\ Z & \text { Charge number, }[-] \\ z & \mathrm{z} \text { axis, }[\mathrm{m}]\end{array}$

\section{Greek Symbols}

$\alpha \quad$ Transfer coefficient, [-]

$\varepsilon$ Porosity, [-]

$\varepsilon_{w}^{m} \quad$ Volume fraction of water, [-]

$\eta \quad$ Overpotential, [Volt $]$

$\lambda \quad$ Membrane water content, [-]

$\mu \quad$ Viscosity, $\left[\mathrm{kg} \cdot \mathrm{m}^{-1} \cdot \mathrm{s}^{-1}\right]$

$\rho \quad$ Density, $\left[\mathrm{kg} \cdot \mathrm{m}^{-3}\right]$

w Mass fraction, [-]

$\phi \quad$ Electric potential, [Volt]

$\theta \quad$ Volume fraction of membrane in the catalyst layer, [-]

$\chi \quad$ Cell efficiency, [-]

$\sigma \quad$ Electrical or ionic conductivity, $\left[\Omega^{-1} m^{-1}\right]$

\section{Subscripts}

( ) a Anode

( ) act Activation

( ) Cathode

( ) e Equilibrium state

( ) $f \quad$ Fixed charge 
( ) $\quad$ Gas phase

( ) i i). Internal, ii). species $i$;

( ) $i j \quad$ Gas pair $i, j$ in a mixture

( ) mem Membrane

( ) $l \quad$ Liquid phase

( ) ohm Ohmic

( ) $\mathrm{m} \quad$ Membrane phase

( ) rev Reversible

( ) $\quad$ Solid phase

( ) $w \quad$ Water

\section{Superscripts}

()$^{0} \quad$ Reference conditions

( ) eff Effective value of parameter

( ) $)^{\text {ref }}$ Reference value

()$^{\text {sat }}$ Saturation state

( ) $)^{T}$ Thermal

( ) $)^{0} \quad$ Standard state
Abbreviations
CL Catalyst layer
GDL Gas diffusion layer
GC Gas channel
M Membrane
MEA Membrane electrode assembly
PEM Proton exchange membrane
PEMFC Proton exchange membrane fuel cell
HOR hydrogen oxidation reaction 


\section{Chapter 1 \\ Introduction and Literature Review}

\subsection{Introduction}

The interest of clean environmentally friendlier and more efficient energy sources leads to the increase of interest in fuel cells, as it has no production other than water and heat. Fuel cells are electrochemical devices that are designed to directly convert, with high efficiency, the chemical energy from the reaction of the fuel (hydrogen in case of PEMFC) and an oxidant (oxygen) into electricity. Fuel cells are considered to be one of the most potentially clean alternative power supplies for remote, vehicle and stationary generation. In addition, many scientists and energy experts consider hydrogen as the fuel of the future. Since it has been commercially available unlike fossil fuels that can serve the world energy request for a limited time. Fuel cells could play an important part in the hydrogen economy.

Typically, a variety of steps were followed into generate electricity in steam turbine power generation such as: combustion of the fuel produces heat, followed by conversion of steam from water by utilizing the generated heat. Finally the steam is used to operate a turbine to convert thermal energy into mechanical energy, which transformed into electrical energy by a power generator. A fuel cell in a single step generates electricity avoiding all previous steps and it does not involve any moving parts [1]. Fuel cells are in some characteristics comparable to batteries, as they both produce electricity via electrochemical reactions that involve an electrolyte and two electrodes with a positive and negative charger respectively. However unlike batteries, fuel cells continue to supply power without replacement or recharging as long as fuel/hydrogen and oxygen/air is to be supplied continuously, whereas batteries will stop generating electrical power as soon as the materials that are involved in the electrochemical reaction is finished, and therefore it requires to be replaced or recharged.

Fuel cells have many characteristic that make them one of most attractive energy conversion technologies, as they have higher efficiency, low emissions, simple structures with no moving parts, and can be assembled in different sizes and weights to produce energy from microwatts to megawatts which suits all kinds of applications such as: automobiles, scooters and bicycles, space, distributed power generation, utility vehicles, portable power, airplanes, locomotives, boats and 
underwater vehicles (submarines) [1]. There are many kinds of fuel cells that could be classified based on the electrolyte or/and fuel employed in fuel cell. Also, based on the operation temperature, fuel cells can be classified as low temperature such as Proton Exchange Membrane Fuel cells (PEMFCs) and high temperature such as Solid Oxide Fuel Cells (SOFCs).

The most common fuel cell types are:

\section{1) Alkaline Fuel Cells (AFCs)}

The alkaline fuel cell (AFC), first developed on 1930s by Francis Bacon. AFC uses potassium hydroxide as an alkaline electrolyte to operate at low temperature. One of the main challenges for AFC is that, alkaline electrolyte has the ability to become poisonous if carbon dioxide is presented in the gas streams. To avoid or to reduce this poisoning effect, the electrolyte system may be static to be replaced regularly or circulating. Moreover, a scrubber on the inlet air stream may be incorporated to remove carbon dioxide [2].

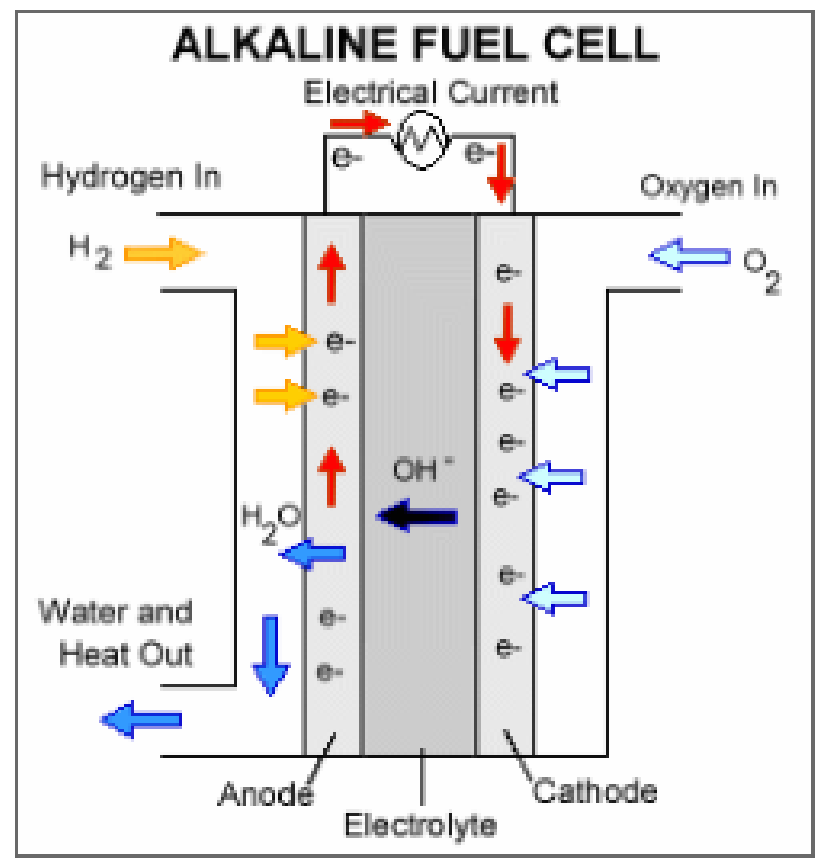

Figure 1.1 Alkaline Fuel Cell Diagram [3]

The basic schematic of an alkaline fuel cell is shown in Figure 1.1. Alkaline fuel cells are attractive for its low-cost cell components and for its improvements in the electrolyte management. Also, 
another advantage of AFC is, it has high performance and that is why it is considered to be the best option for space programs where there is no worry of operating on pure oxygen. The properties of AFC are shown in Table 1.1.

Table 1.1: Alkaline Fuel Cell (AFC) Properties [2]

\begin{tabular}{|c|c|}
\hline Electrolyte & $\begin{array}{l}\text { Aqueous Solution of Potassium Hydroxide } \\
\text { Immersed in a Matrix }\end{array}$ \\
\hline Temperature $\left[{ }^{\circ} \mathrm{C}\right]$ & $65-220$ \\
\hline System Output [W] & $10 \mathrm{k}-100 \mathrm{k}$ \\
\hline Electrical Efficiency & $60 \%$ \\
\hline Power and Heat (CHP) Efficiency & $>80 \%$ (minimum level of heat waste) \\
\hline Anode Reaction & $\mathrm{H}_{2}+2 \mathrm{OH}^{-} \rightarrow \mathrm{H}_{2} \mathrm{O}+2 e^{-}$ \\
\hline Cathode Reaction & $1 / 2 \mathrm{O}_{2}+\mathrm{H}_{2} \mathrm{O}+2 e^{-} \rightarrow 2 e^{-}$ \\
\hline Overall Reaction & $\mathrm{H}_{2}+1 / 2 \mathrm{O}_{2} \rightarrow \mathrm{H}_{2} \mathrm{O}$ \\
\hline Carrier & $\mathrm{OH}^{-}$ \\
\hline Usable Fuels & Pure Hydrogen \\
\hline Advantages & $\begin{array}{ll}\text { - } & \text { Operate fast at low temperature } \\
\text { - } & \text { High efficiency } \\
\text { - } & \text { No corrosion problems } \\
\text { - } & \text { Simple operation } \\
\text { - } & \text { Low volume and weight }\end{array}$ \\
\hline Disadvantages & $\begin{array}{l}\text { - Shows intolerance to } \mathrm{CO} \text { and very intolerant } \\
\text { to } \mathrm{CO}_{2} \text { (up to } 350 \mathrm{ppm} \text { ). } \\
\text { - } \text { Pure oxygen for oxidant or no } \mathrm{CO}_{2} \text { in air } \\
\text { - } \text { Pure hydrogen for fuel } \\
\text { - Handling problems due to liquid electrolyte } \\
\text { - Relatively short lifetime } \\
\end{array}$ \\
\hline Applications & $\begin{array}{l}\text { - Military } \\
\text { - Space }\end{array}$ \\
\hline
\end{tabular}

\section{2) Solid Oxide Fuel Cells (SOFCs)}

Solid oxide fuel cells operate at high temperature in the range of $800-1000^{\circ} \mathrm{C}$. The SOFC consisted of an anode and a cathode that are separated by an electrolyte. The electrolyte is a solid ceramic, such as zirconium oxide stabilised with yttrium oxide [3] . The basic schematic of a solid 
oxide fuel cell is shown Figure 1.2. There are two SOFC basic design in use: planar design, as the components are in flat stacks assembly where air and hydrogen flow through channels attached to the anode and cathode, and tubular design where the air is supplied to the inside of an extended tube that sealed at one end while fuel flows around it. SOFC has high efficiency that reaches up to $60 \%$, due to the high operating temperature that allows direct internal fuel, such as natural gas, processing. The properties of SOFC are shown in Table 1.2.

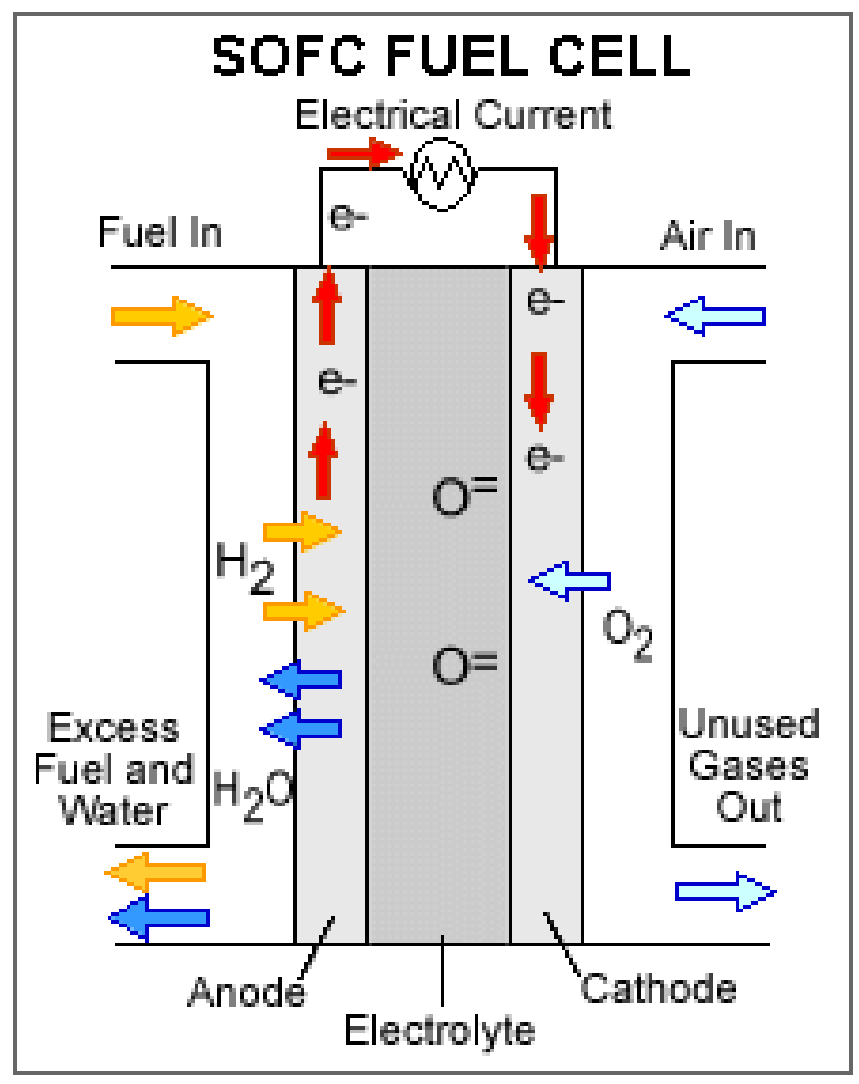

Figure 1.2 Solid Oxide Fuel Cell (SOFC) Diagram [3] 
Table 1.2: Solid Oxide Fuel Cells (SOFC) Properties [2]

\begin{tabular}{|c|c|}
\hline Electrolyte & Yttria Stabilized Zirconia \\
\hline Temperature $\left[{ }^{\circ} \mathrm{C}\right]$ & $600-1000$ \\
\hline System Output [W] & $<1 \mathrm{k}-3 \mathrm{M}$ \\
\hline Electrical Efficiency & $35 \%-43 \%$ \\
\hline $\begin{array}{l}\text { Combined Heat and Power (CHP) } \\
\text { Efficiency }\end{array}$ & $<90 \%$ \\
\hline Anode Reaction & $\mathrm{H}_{2}+\mathrm{O}^{2-} \rightarrow \mathrm{H}_{2} \mathrm{O}+2 e^{-}$ \\
\hline Cathode Reaction & $1 / 2 O_{2}+2 e^{-} \rightarrow O^{2-}$ \\
\hline Overall Reaction & $\mathrm{H}_{2}+1 / 2 \mathrm{O}_{2} \rightarrow \mathrm{H}_{2} \mathrm{O}$ \\
\hline Carrier & $O^{2-}$ \\
\hline Usable Fuels & $\begin{array}{ll}\text { - } & \text { Coal } \\
\text { - } & \text { Natural Gas } \\
\text { - } & \text { Methanol } \\
\text { - } & \text { Petroleum } \\
\end{array}$ \\
\hline Advantages & $\begin{array}{l}\text { - Allows reforming internal fuel } \\
\text { spontaneously. Due to the migration of the } \\
\text { oxide ions along the electrolyte } \\
\text { - Any combustible gas can be oxidize in fuel } \\
\text { cell } \\
\text { - Produces lots of heat; suitable for CHP } \\
\text { - Faster chemical reactions } \\
\text { - High efficiency } \\
\text { - Higher current densities then molten } \\
\text { - } \text { carbonate fuel cells } \\
\text { - } \text { is solid } \\
\text { - No need of noble metal catalysts } \\
\end{array}$ \\
\hline Disadvantages & $\begin{array}{l}\text { For economical production, one needs } \\
\text { materials that remain solid when operate at } \\
\text { high temperatures, with good mechanical } \\
\text { resistance and conductivity } \\
\text { - Sulphur }(50 \mathrm{ppm}) \text { moderate intolerance } \\
\end{array}$ \\
\hline Applications & $\begin{array}{ll}\text { - } & \text { Auxiliary Power } \\
\text { - } & \text { Electric Utility } \\
\text { - } & \text { Large Distributed Generation }\end{array}$ \\
\hline
\end{tabular}




\section{3) Direct Methanol Fuel Cells (DMFCs)}

The direct methanol fuel cell DMFC (see Figure 1.3) was invented in the mid of 1990s to be used for light-duty vehicle propulsion, however a few years later, it becomes as one of the main technologies that being used for personal electronic fuel cells like computers, laptops and mobiles phones [4]. DMFC is similar to the PEMFC as it has the same internal structure and they both use a polymer membrane as an electrolyte. Nevertheless it uses different type of fuel, thus the waste production from the reaction of DMFC include carbon dioxide. The properties of DMFC are shown in Table 1.3.

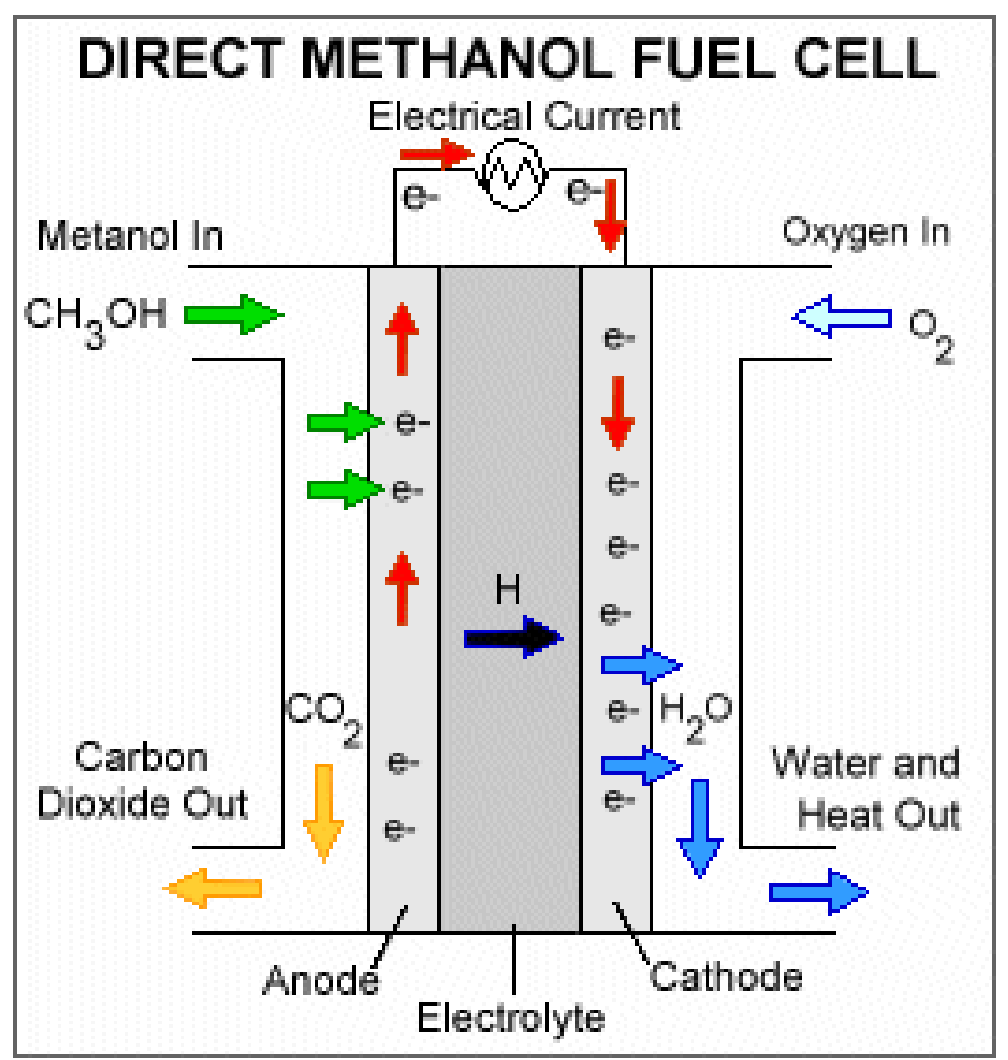

Figure 1.3 Direct Methanol Fuel Cell (DMFC) Diagram [5] 
Table 1.3: Direct Methanol Fuel Cells (DMFC) Properties [2]

\begin{tabular}{|c|c|}
\hline Electrolyte & Polymer Membrane \\
\hline Temperature $\left[{ }^{\circ} \mathrm{C}\right]$ & Around 130 \\
\hline System Output [W] & $\sim 0.1 \sim 10$ \\
\hline Anode Reaction & $\mathrm{CH}_{3} \mathrm{OH}+\mathrm{H}_{2} \mathrm{O} \rightarrow \mathrm{CO}_{2}+6 \mathrm{H}^{+}+6 e^{-}$ \\
\hline Cathode Reaction & $3 / 2 \mathrm{O}_{2}+6 \mathrm{H}^{+}+6 e^{-} \rightarrow 3 \mathrm{H}_{2} \mathrm{O}$ \\
\hline Overall Reaction & $\mathrm{CH}_{3} \mathrm{OH}+3 / 2 \mathrm{O}_{2} \rightarrow \mathrm{CO}_{2}+2 \mathrm{H}_{2} \mathrm{O}$ \\
\hline Carrier & $\mathrm{H}^{+}$ \\
\hline Usable Fuels & Methanol \\
\hline Advantages & $\begin{array}{l}\text { - Fuel is liquid with small deposits size that is } \\
\text { make it suitable for infrastructure } \\
\text { - No reforming process } \\
\text { - Same type of electrolyte as the PEM fuel } \\
\text { cell. This kind of electrolyte increases the } \\
\text { security because eliminates the handling of } \\
\text { acid or any other corrosive. } \\
\text { - less handling problem with liquids due to } \\
\text { solid nature }\end{array}$ \\
\hline Disadvantages & $\begin{array}{l}\text { - hydrogen cells have better efficiency than } \\
\text { this cell } \\
\text { - Needs for noble metal for anodic catalyst } \\
\text { layer where the electro-oxidation of } \\
\text { methanol occurs at the surface of it. }\end{array}$ \\
\hline Applications & $\begin{array}{l}\text { - } 3 \mathrm{C}(\text { Computers/Cameras/Cell-phones }) \\
\text { products } \\
\text { - Consumer Electronics }\end{array}$ \\
\hline
\end{tabular}

\section{4) Phosphoric Acid Fuel Cells (PAFCs)}

Phosphoric acid fuel cells (PAFCs), see Figure 1.4, are ideal to be used in large stationary applications due to their high production of electricity and heat. PAFCs have been around for a long time however the interest in PAFCs became less in late the 1990s due to the production of a large number of intermediate-power PC-25 and the installation of several megawatt-sized power plants, as well as the insufficient operating reliability in the long term usage [6]. A PAFC consists of an anode and a cathode made of a finely dispersed platinum catalyst on carbon and a silicon carbide structure that holds the phosphoric acid electrolyte [3]. The properties of PAFC are shown in Table 1.4. 


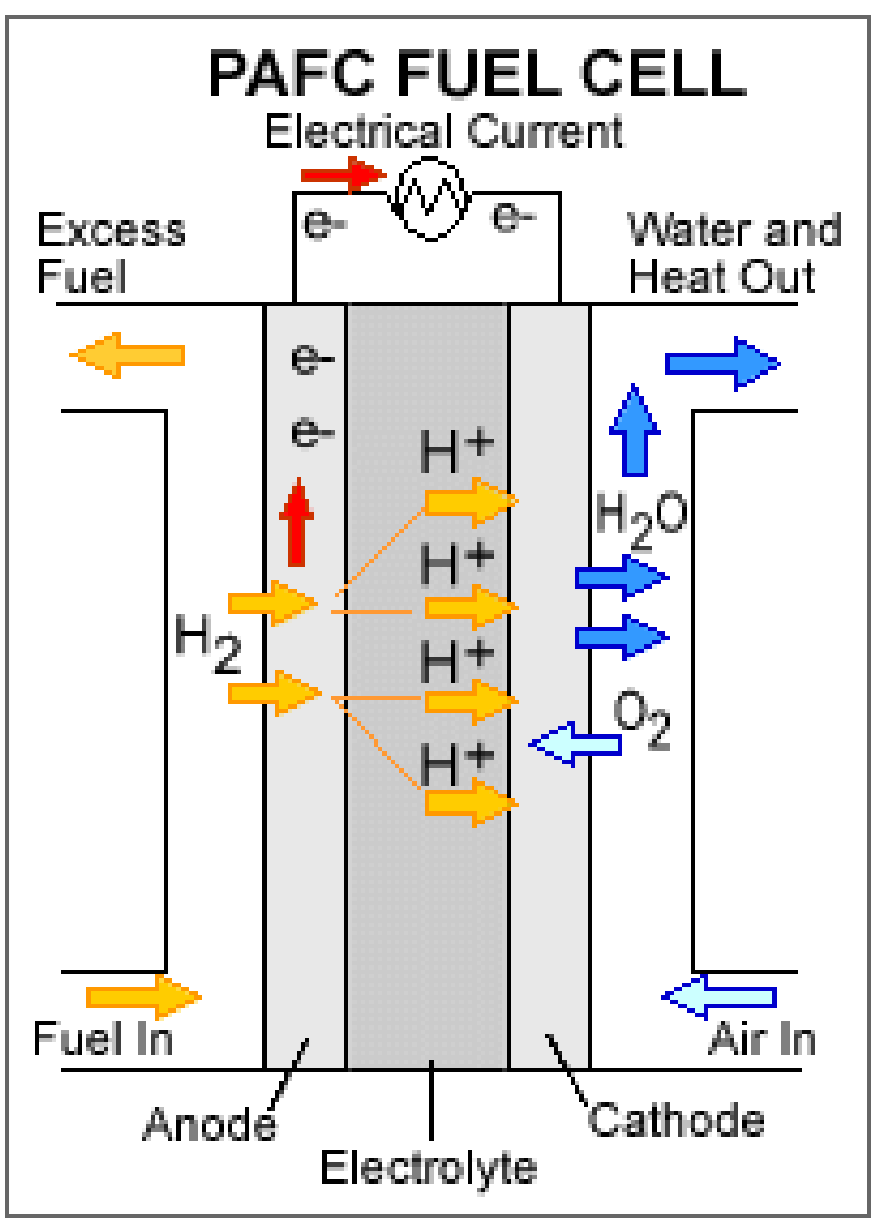

Figure 1.4 Phosphoric Acid Fuel Cell Diagram [3] 
Table 1.4: Phosphoric Acid Fuel Cells (PAFCs) Properties [2]

\begin{tabular}{|c|c|}
\hline Electrolyte & Liquid phosphoric acid soaked in a matrix \\
\hline Temperature $\left[{ }^{\circ} \mathrm{C}\right]$ & $150-200$ \\
\hline System Output [W] & $\sim 200 \mathrm{k}$ \\
\hline Electrical Efficiency & $>40 \%$ \\
\hline $\begin{array}{c}\text { Power and Heat (CHP) } \\
\text { Efficiency }\end{array}$ & $>85 \%$ \\
\hline Anode Reaction & $H_{2} \rightarrow 2 H^{+}+2 e^{-}$ \\
\hline Cathode Reaction & $1 / 2 \mathrm{O}_{2}+2 \mathrm{H}^{+}+2 e^{-} \rightarrow \mathrm{H}_{2} \mathrm{O}$ \\
\hline Overall Reaction & $\mathrm{H}_{2}+1 / 2 \mathrm{O}_{2} \rightarrow \mathrm{H}_{2} \mathrm{O}$ \\
\hline Carrier & $H^{+}$ \\
\hline Usable Fuels & $\begin{array}{ll}\text { - } & \text { Naphtha } \\
\text { - } & \text { Natural Gas } \\
\text { - } & \text { Methanol }\end{array}$ \\
\hline Advantages & $\begin{array}{l}\text { - Uses air directly from the atmosphere, } \\
\text { because it tolerates up to } 30 \% \mathrm{CO}_{2} \\
\text { - Higher overall efficiency with } \mathrm{CHP} \\
\text { (Combined Heat and Power) } \\
\text { - Stable electrolyte at higher temperatures }\end{array}$ \\
\hline Disadvantages & $\begin{array}{l}\text { - } 2 \% \text { tolerance of CO } \\
\text { - Dilution of acid electrolyte due to allowed } \\
\text { entry of water } \\
\text { - Not easy handling with safety issues due to } \\
\text { the use of liquid and corrosive electrolyte }\end{array}$ \\
\hline Applications & - Distributed Generation \\
\hline
\end{tabular}

\section{5) Molten Carbonate Fuel Cell (MCFCs)}

Molten carbonate fuel cells (MCFCs) along with the solid oxide fuel cells (SOFCs) are represented the high temperature class of fuel cells. MCFCs are one of the most important fuel cell technologies for stationary applications. A general schematic of a molten carbonate fuel cell is given in Figure 1.5. It can operate at high temperature, approximately more than $600{ }^{\circ} \mathrm{C}[14]$ and there are several advantages of high temperature as shown in Table 1.5 which also list the properties of MCFC. 


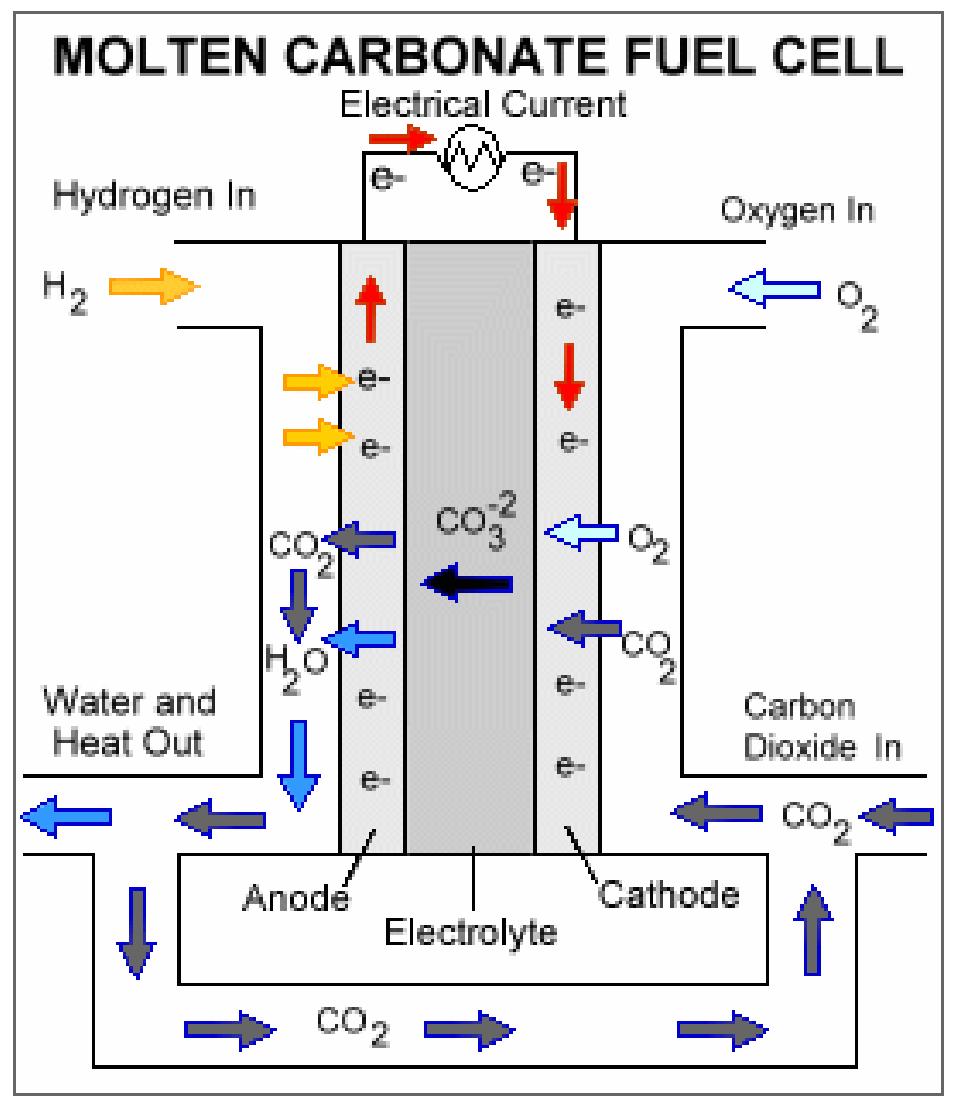

Figure 1.5 Molten Carbonate Fuel Cell (MCFCs) Diagram [3] 
Table 1.5: Molten Carbonate Fuel Cell (MCFC) Properties [2]

\begin{tabular}{|c|c|}
\hline Electrolyte & $\begin{array}{l}\text { Liquid solution of lithium, sodium and/or } \\
\text { potassium carbonates, soaked in a matrix }\end{array}$ \\
\hline Temperature $\left[{ }^{\circ} \mathrm{C}\right]$ & $600-650$ \\
\hline System Output [W] & $\sim 500 \mathrm{k}$ \\
\hline Electrical Efficiency & $45 \%-47 \%$ \\
\hline Power and Heat (CHP) Efficiency & $>80 \%$ \\
\hline Anode Reaction & $\mathrm{H}_{2}+\mathrm{CO}_{3}^{2-} \rightarrow \mathrm{H}_{2} \mathrm{O}+\mathrm{CO}_{2}+2 e^{-}$ \\
\hline Cathode Reaction & $1 / 2 \mathrm{O}_{2}+\mathrm{CO}_{2}+2 e^{-} \rightarrow \mathrm{CO}_{3}^{2-}$ \\
\hline Overall Reaction & $\mathrm{H}_{2}+1 / 2 \mathrm{O}_{2} \rightarrow \mathrm{H}_{2} \mathrm{O}$ \\
\hline Carrier & $\mathrm{CO}_{3}^{2-}$ \\
\hline Usable Fuels & $\begin{array}{ll}\text { - } & \text { Hydrogen } \\
\text { - Natural Gas } \\
\text { - Carbon Oxides }\end{array}$ \\
\hline Advantages & $\begin{array}{ll}\text { - } & \text { Allow spontaneous internal reforming } \\
\text { - Fuel flexibility } \\
\text { - High-speed reactions and efficiency }\end{array}$ \\
\hline Disadvantages & $\begin{array}{l}\text { Malfunction problem results from the } \\
\text { dissolving of the nickel oxide catalyst } \\
\text { cathode in the electrolyte } \\
\text { - Distortion problem due to dimensional } \\
\text { instability that leads } \\
\text { - Handling problems due to the corrosive } \\
\text { liquid electrolyte } \\
\text { - Requires preheating before starting work }\end{array}$ \\
\hline Applications & $\begin{array}{ll}\text { - } & \text { Large Distributed Generation } \\
\text { - } & \text { Electric Utility }\end{array}$ \\
\hline
\end{tabular}

\section{6) Proton Exchange Membrane Fuel Cell (PEMFC)}

Proton exchange membrane fuel cell, also is commonly called polymer electrolyte membrane fuel cell (PEMFC) and it is considered to be an ideal source of power which is suitable for mobile and stationary applications [7], owing to their high energy efficiency and environmental friendliness [8]. PEMFC started to intensively develop around worldwide in the 1990s at Ballard (Canada) [4]. This work mainly has emphasis on the Proton Exchange Membrane (PEM) Fuel Cell that depicted schematically in Figure 1.6. Proton exchange membrane (PEM) fuel cells are extraordinary energy 
conversion devices, efficiently generating electric voltage from chemical reactants without combustion. The properties of PEMFC are given in Table 1.6.

PEM fuel cells are considered to be the best type of fuel cells as they can be used for a lot of applications starting from mobile phones and computers which require a few watts to operate, to a few kilowatts that are needed to run boat engines and domestic systems, to tens of kilowatt for cars, to hundreds of kilowatts for buses and industrial systems [9]. PEMFC is one of the fuel cells that can operate at temperatures less than $100^{\circ} \mathrm{C}$, to deliver high power densities and to enable rapid start-up as well as to produces almost zero emissions. Despite all the benefit that PEMFCs have, there are some disadvantages that is related to the high cost of manufacturing, especially the high cost of catalyst layer (platinum) and polymer membrane (Nafion material), also the cost of humidification units that need to humidify the reactive gases before entering the cell. The total cost of a PEMFC is around 500-600\$/kW, as the total cost for the car that made with using this system, and it is 10 times more than a traditional car with an internal combustion engine (ICE) [10].

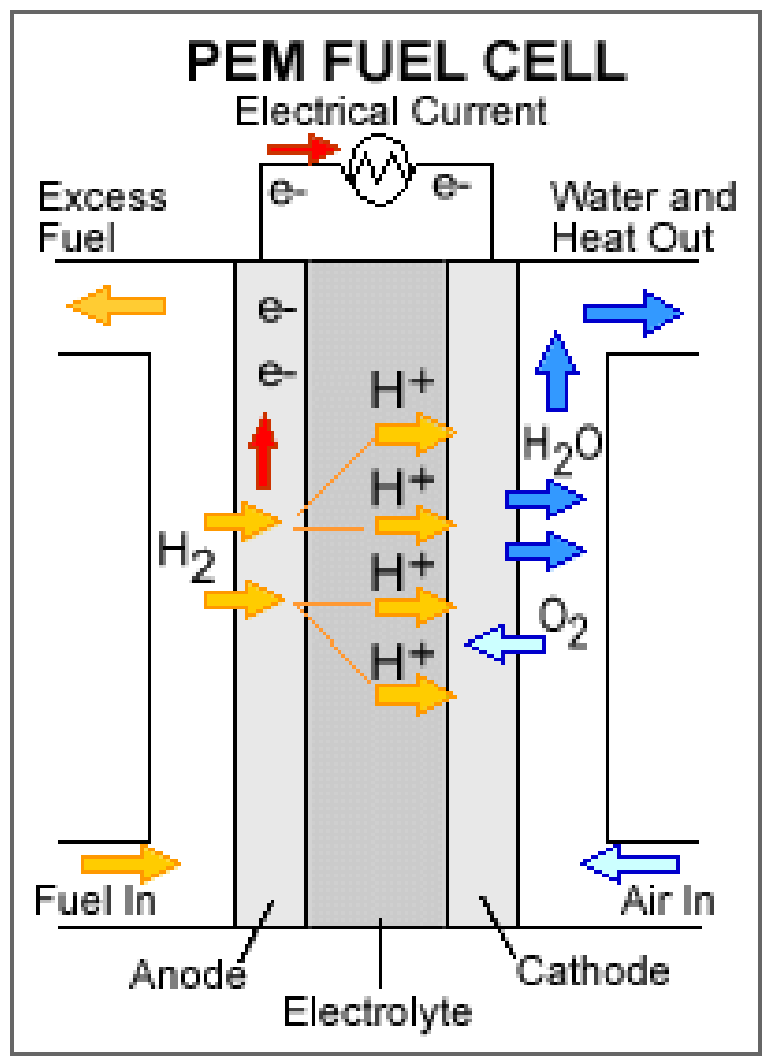

Figure 1.6 Proton Exchange Membrane (PEM) Fuel Cell Diagram [3] 
Table 1.6: Polymer Electrolyte Membrane Fuel Cells (PEMFC) Properties [2]

\begin{tabular}{|c|c|}
\hline Electrolyte & Polymer Membrane \\
\hline Temperature $\left[{ }^{\circ} \mathrm{C}\right]$ & $30-100$ \\
\hline System Output [W] & $1 \mathrm{k}-200 \mathrm{k}$ \\
\hline Electrical Efficiency & $\begin{array}{ll}\text { (stationary) } & 25 \%-35 \% \\
\text { (transportation) } & 53 \%-58 \%\end{array}$ \\
\hline Power and Heat (CHP) Efficiency & (minimum level of heat waste) $70 \%-90 \%$ \\
\hline Anode Reaction & $\mathrm{H}_{2} \rightarrow 2 \mathrm{H}^{+}+2 e^{-}$ \\
\hline Cathode Reaction & $1 / 2 \mathrm{O}_{2}+2 \mathrm{H}^{+}+2 e^{-} \rightarrow \mathrm{H}_{2} \mathrm{O}$ \\
\hline Overall Reaction & $\mathrm{H}_{2}+1 / 2 \mathrm{O}_{2} \rightarrow \mathrm{H}_{2} \mathrm{O}$ \\
\hline Carrier & $\left(\mathrm{H}_{2} \mathrm{O}\right)_{n}$ \\
\hline Usable Fuels & $\begin{array}{ll}\text { - } & \mathrm{H}_{2} \\
\text { - } & \text { Natural Gas } \\
\text { - } & \text { Methanol } \\
\end{array}$ \\
\hline Applications & $\begin{array}{ll}\text { - } & \text { Backup Power } \\
\text { - } & \text { Small Stationary } \\
\text { - Portable Power }\end{array}$ \\
\hline
\end{tabular}

\subsection{PEM Fuel Cell Principle and Components}

A PEM fuel cell uses a permeable polymeric membrane that covered on both side of it with a thin platinum catalyzer layer and a gas-permeable electrode made of graphite paper. At the anode side humidified hydrogen fuel mixture flows into the gas channel layer and diffuses through the anode gas diffusion layer (GDL), then an electrochemical reaction HOR (hydrogen oxidation reaction) takes place at the anode catalyst layer (CL) produces hydrogen electrons and protons. The electrons will flow through the bipolar plate to the external circuit providing useful electrical power; meanwhile protons migrate through the membrane $(\mathrm{M})$ towards the cathode catalyst layer (CL) where they react with the humidified oxygen that diffuses through the cathode gas diffusion layer (GDL) and with electrons arriving through the external circuit, to produce water and heat as shown in Figure 1.7. 
The reactions at the electrodes are:

Anode: $\quad \mathrm{H}_{2(g)} \rightarrow 2 \mathrm{H}_{(\mathrm{aq})}^{+}+2 \mathrm{e}^{-}$

Cathode: $\quad{ }^{1} / \mathrm{O}_{2(\mathrm{~g})}+2 \mathrm{H}_{(\mathrm{aq})}^{+}+2 \mathrm{e}^{-} \rightarrow \mathrm{H}_{2} \mathrm{O}_{(l)}$

Overall: $\quad \mathrm{H}_{2(\mathrm{~g})}+{ }^{1 /}{ }_{2} \mathrm{O}_{2(g)} \rightarrow \mathrm{H}_{2} \mathrm{O}_{(l)}$

where " $(\mathrm{g})$ "refers to the gaseous state, “(aq)" stands for a substance in the aqueous phase that is dissolved in water [11], and " $(l)$ " denotes the liquid state.

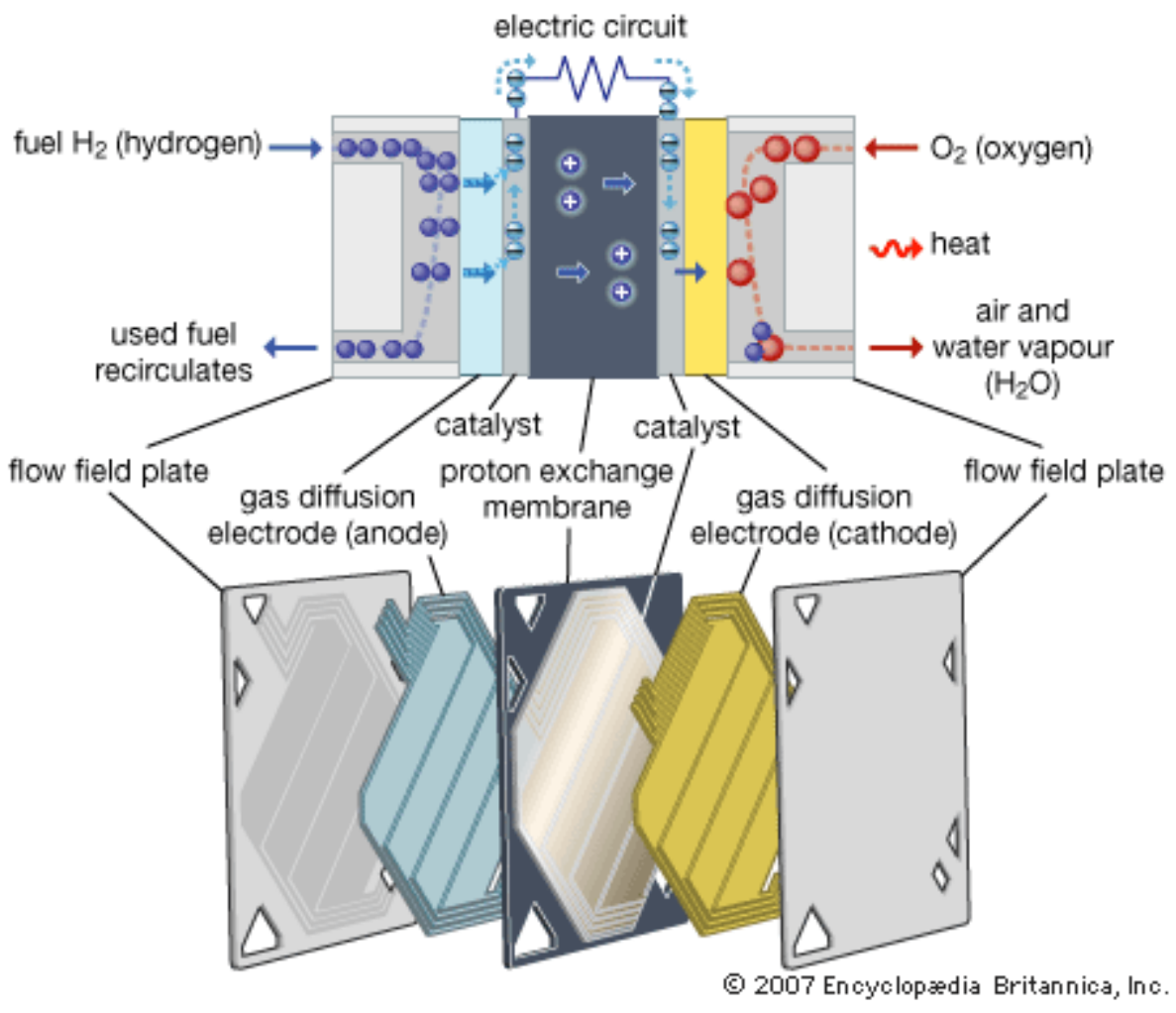

Figure 1.7 The Polymer Electrolyte Fuel Cell (PEMFC) [12].

A PEMFC consists of an anode electrode (negative), a cathode electrode (positive), an electrolyte membrane, and bipolar plate as shown in Figure 1.7 


\subsubsection{Polymer Electrolyte Membrane (M)}

The fuel cell membrane is considered to be the heart of the PEM fuel, in which hydrogen protons transport from the anode catalyst layer (CL) to the cathode catalyst layer (CL). The membrane functions to isolate the hydrogen/fuel and oxygen, thus, it must electronically insulate the cathode from the anode [13]. Also, since the hydrogen protons migrate along the membrane, the membrane need to have a relatively high proton conductivity, as well as it must be chemically and mechanically stable in the fuel cell environment [1].The most typical membrane is perfluorocarbon-sulfonic acid ionomer (PSA). The Nafion family made by DuPont, the best material for the membrane, is based on a sulfonated tetrafluoroethylene-based fluoropolymercopolymer [13]. Understanding the exact mechanism of the proton movement is an area of active research. Developing hydrocarbon-based membranes, is the goal for many researchers, in order to reduce the cost of using fluorine. It is essential to maintain a fully humidified membrane for proton conductivity since the water produced during the electrochemical reactions is insufficient to maintain the required humidification level in the membrane. In addition, the dry reactant gases, and the effects of the electro-osmotic drag that brings water molecules with protons that move from the anode to the cathode can result in an under-humidified state. Thus it is preferable to humidify the inlet gas streams before entering the cell to maintain the desired humidification level in the membrane and to reduce the membrane humidification requirements that leads to reduce system cost, volume, and complexity [13].

\subsubsection{Catalyst Layer (CL)}

In the structure of PEM fuel cell there are two catalyst layers bonded on either side of membrane. These catalyst layers are located between the membrane and gas diffusion layers (GDLs) at the anode and the cathode sides respectively. The electrochemical reactions occurs on the surface of the catalyst layer. The electrochemically active catalyst sites require the three-phase interface [13]:

- Pt catalyst surface, electrically connected to the external path to provide electron transport paths;

- Ionomer or electrolyte contact to transport protons; and

- Reactant gas phase access. 
Catalyst layers are made highly porous, thus their active surface areas are orders of magnitudes greater than their geometrical ones. The requirements of a catalyst layer are: high intrinsic activity, large active surface area, high ionic and electric conductivities, highly porous for reactant access and product removal, and stability [15]. Typically Pt-based is used for the catalysts in PEM fuel cells due to the high stability and reactivity of Pt. Pt alloys may also be introduced to further increase kinetic activity, improve stability, and improve tolerance to contaminants on the anode for use in reformed fuel [13]. Since the cost of Pt is high, it requires a maximum utilization and it is usually in the form of very small particles of about 2 to $8 \mathrm{~nm}$ diameters to supported on larger carbon particles that provide a high surface area support structure to enhance the dispersion of the catalyst particles as well as provide an electrical and thermal pathway from the reaction site toward the external circuit. A similar proton of exchange material is used in the membrane (ionomer) to be mixed into the catalyst layer as small particles to provide proton pathways. The mix of carbon particles and ionomer must provide sufficient porosity in the catalyst layer for reactant gas access to the catalyst reaction [13].

\subsubsection{Gas Diffusion Layers (GDLs)}

Gas diffusion layers is on the side of each catalyst layers at anode and at cathode sides. Typically GDLs are made of hydrophobic carbon fiber paper or cloth, called the substrate. It has a hydrophobic microporous layer (MPL) applied to the catalyst side, made of carbon particles with a hydrophobic binder [13]. The hydrophobicity is typically achieved through application of PTFE (Poly Tetra Fluoro Ethylene) to the substrate and by mixing PTFE with carbon particles in a carbon ink to be coated on the substrate. The GDLs serve several important functions $[16,13]$ :

- It serves as a pathway for transport of the reactant gases from the flow field channels to the catalyst layer, allowing them access to the entire active area (not just to those adjacent to the channels).

- It serves as a pathway for removal of product water from the catalyst layer to the flow field channels.

- It serves as a heat conductor.

- It electrically connects the catalyst layer to the bipolar plate, allowing the electrons to complete the electrical circuit. 
- It mechanical supports of membrane and catalyst layers to span flow field channels

The membrane electrode assembly (MEA) is the term that usually used to name the combination of membrane (M), catalyst layers (CLs) and gas diffusion layers (GDLs) in the literature.

\subsubsection{Bipolar Plates (BP)}

The bipolar or flow field plates are assembled on either side of the GDLs, and the entire unit is comprised of stacked unit cell of the fuel cells. BPs are usually made out of carbon- or graphitepolymer composite materials or metals [13]. The main functions of the bipolar plates are [13]:

- To transport the incoming reactants gases to the GDLs, and remove the exhaust gases and product water.

- To transfer electrons and heat;

- To provide mechanical structure

To provide all these functions the bipolar plates must be chemically stable under the operation conditions of fuel cell environment, electrically and thermally conductive, mechanically robust and free of contamination [13].

\subsection{Fuel Cell Efficiencies}

The enthalpy of the hydrogen that participate in the electrochemical reactions that occur at the electrodes (refer to Eq.1.3), is equal to the enthalpy of the water formation [17]. The hydrogen has a chemical energy that's called heating value. All the efficiencies of the fuel cell are described based on the lower heating value (LHV) or higher heating value (HHV) of hydrogen, as product water is produced either as liquid or gaseous phase [17]:

$$
\begin{array}{ll}
\mathrm{H}_{2}+\frac{1}{2} \mathrm{O}_{2} \rightarrow \mathrm{H}_{2} \mathrm{O}_{(\mathrm{g})} & -\Delta_{f} \mathrm{H}_{\mathrm{H}_{2} \mathrm{O}_{(g)}}=L H V=241.82 \frac{\mathrm{kJ}}{\mathrm{mol}} \\
\mathrm{H}_{2}+\frac{1}{2} \mathrm{O}_{2} \rightarrow \mathrm{H}_{2} \mathrm{O}_{(l)} & -\Delta_{f} H_{\mathrm{H}_{2} \mathrm{O}_{(l)}}=L H V=285.83 \frac{\mathrm{kJ}}{\mathrm{mol}}
\end{array}
$$

where $\Delta_{f} H_{\mathrm{H}_{2} \mathrm{O}}$ is the enthalpy of water formation which is equal to the reaction enthalpy and have a negative sign, whereas the HHV and LHV have positive signs. At $25^{\circ} \mathrm{C}$ a difference of 44.01 $\mathrm{kJ} / \mathrm{mol}$ can be found between LHV and HHV, which is equal to the molar latent heat of water. In 
general the cell efficiency is higher with LHV, and the general form of the energy conversion efficiency can be defined as:

$$
\eta=\frac{\text { (useful) energy output }}{\text { energy input }}=\frac{\text { (useful) power output }}{\text { power input }}
$$

Temperature, pressure and the fuel concentration are vitally important in the efficiency of the fuel cell [18]. It is important to know the differences between the efficiencies for fuel cells since in the literature many definitions and terms are used.

1- Thermodynamic efficiency: also known as the maximum or ideal efficiency, it is the ratio between heating value (enthalpy $\Delta H$ ) and Gibbs free enthalpy, it is given by [17]:

$\eta_{e l, \max }=\frac{\Delta G}{\Delta H}$

where $\Delta G$ is the available energy that used for external work

2- Electric efficiency: also, known as load efficiency, voltage efficiency, cell efficiency and stack sub- system efficiency; it is the ratio between the electric of the stack (power) to the consumed fuel power, it is defined as [17]:

$$
\eta_{e l}=\frac{P_{e l}}{P_{\text {fuel,consumed }}}
$$

where $P_{e l}$ is the stack electric power and $P_{\text {fuel,consumed }}$ is the consumed fuel power. According to LHV and HHV the electric efficiency can be defined as:

$$
\begin{aligned}
& \eta_{\mathrm{el}, \mathrm{LHV}}=\frac{\text { AveCell }}{1.253 \mathrm{~V}} \\
& \eta_{\mathrm{el}, \mathrm{HHV}}=\frac{\text { AveCell }}{1.481 \mathrm{~V}}
\end{aligned}
$$

where AveCell is the average single cell voltage, and $\mathrm{V}$ is the cell voltage

3- Fuel electric efficiency: also, known as simply efficiency (of either LHV or HHV), and net cell efficiency; it the ratio between the stack gross power and the amount of hydrogen feed to the stack. It is given as [17]: 
$\eta_{f u e l, e l}=\frac{P_{e l}}{P_{\text {fuel,feed }}}$

where $P_{e l}$ is the stack electric gross power, and $P_{\text {fuel,feed }}$ is the fuel feed power. According to LHV and HHV the fuel electric efficiency can be defined as:

$$
\begin{aligned}
& \eta_{\text {fuel, el, LHV }}=\frac{\text { AveCell }}{1.253 \mathrm{~V} \cdot \lambda \text { anode }} \\
& \eta_{\text {fuel, el, HHV }}=\frac{\text { AveCell }}{1.481 \mathrm{~V} \cdot \lambda \text { anode }}
\end{aligned}
$$

The anode stoichiometry $\lambda$ represent the relation between $\eta_{\text {fuel, el }}$ and is $\eta_{e l}$.

$$
\eta_{\text {fuel, el }}=\frac{\eta_{e l}}{\lambda \text { anode }}
$$

4- Voltage efficiency: is the ratio between average and reversible cell voltage $E^{o}$, it can be defined as [17]:

$\eta_{\text {voltage }}=\frac{\text { AveCell }}{E^{o}}$

Generally the voltage efficiency is given based on free enthalpies of liquid water formation

$$
\begin{aligned}
& \left(\Delta_{f} G_{H_{2} O_{(l)}}=-237.13 \mathrm{~kJ} / \mathrm{mol}\right) \text { as: } \\
& \eta_{\text {voltage }}=\frac{\text { AveCell }}{E_{l}^{o}}=\frac{\text { AveCell }}{1.229 \mathrm{~V}} \\
& \eta_{\text {voltage }}=\eta_{\mathrm{el}, \mathrm{HHV}} \cdot \eta_{\mathrm{el}, \mathrm{TD}, \mathrm{HHV}}=\frac{\text { AveCell }}{1.481 \mathrm{~V}} \cdot 83.1 \%
\end{aligned}
$$

5- Thermal efficiency : according the electric efficiency, the thermal efficiency can be calculated as follows [17]:

$$
\eta_{\text {therm }}=\frac{P_{\text {therm }}}{P_{\text {fuel, consumed }}}
$$

Based on HHV, the thermal efficiency can be defined as:

$$
\eta_{\text {therm,HHV }}=\frac{1.481 \mathrm{~V}-\text { AveCell }}{1.481 \mathrm{~V}}
$$


6- Recovered heat efficiency: it can be calculated based on the fact that not all thermal power is transferred into the coolant [17].

$$
\eta_{\text {recovered heat }}=\frac{P_{\text {recovered heat }}}{P_{\text {therm }}}
$$

Based on HHV, the recovered heat efficiency can be calculated as:

$\eta_{\text {recovered heat }}=\frac{P_{\text {recovered heat }}}{P_{\text {therm,HHV }}}=\frac{\dot{\mathrm{V}} \cdot c p \cdot \Delta T \cdot \rho}{(1.481 \mathrm{~V}-\text { AveCell }) \cdot N \cdot I}$

where $\dot{\mathrm{V}}$ is the volume flow , $c p$ is the heat capacity, $\Delta T$ is the temperature increase, $\rho$ is the density, $N$ is the amount of single cells (cell count.) and $I$ is the stack load (electric current)

Overall stack efficiency is:

$\eta_{\text {overall }}=\frac{P_{e l}+P_{\text {therm }}}{P_{\text {fuel, consumed }}}=1$

This overall thermodynamic efficiency $\eta_{\text {overall }}=1$, due to complete consumption of the hydrogen that convert its chemical energy to the eclectic and thermal power:

$P_{\text {fuel, consumed }}=P_{e l}+P_{\text {therm }}$

And,

$\eta_{\text {overall }}=\eta_{e l}+\eta_{\text {therm }}$

The total efficiency of the stack can be reasonably defined as [17]:

$$
\eta_{\text {total }}=\frac{P_{e l}+P_{\text {recovered heat }}}{P_{\text {fuel, feed }}}<1
$$

the $\eta_{\text {total }}$ in above equation is less than one as a result of :

$$
P_{\text {recovered heat }}<P_{\text {therm }} \text { and } P_{\text {fule, feed }}>P_{\text {fuel, consumed }}
$$

\subsection{PEM Modeling Literature Review}

The proton exchange membrane (PEM) fuel cell uses a solid polymer membrane as its electrolyte to separate the anode electrode and cathode electrode electrically and mechanically yet allowing 
for hydrogen proton migration [19]. The use of a solid polymer electrolyte results in a cell that is able to operate at lower temperatures without causing many reliability issues that occur with liquid electrolytes. During the PEMFC operation, critical properties, such as the fluid flow pattern, species concentration variation, temperature distribution, and local current densities, are often fairly difficult to achieve by in-situ measurements. Much effort has been directed toward PEMFC modeling as insights can be achieved through mathematical modeling and numerical simulations. The processes occurring inside a PEMFC can be simulated by using the mathematical model that is used to achieve better performance of new PEM fuel cell designs. Fortunately, the development of digital computers enables fuel cell researchers to investigate, through numerical solution of mathematical modeling equations, sophisticated flow features and complex transport mechanisms that might be experimentally unobservable. The simulation results are then used to optimize the PEMFC design and develop fuel cell stacks with higher efficiency and lower manufacturing cost. Mathematical modeling of PEMFCs has been carried out by several groups.

In nineteenth century Sir William Grove discovered the fuel cell. Grove built what he called a gas battery in 1839, he combined hydrogen and oxygen in a device to generate electricity. The fuel cell was a subject of high interest for scientific research for nearly a century. In 1937, the use of alkali electrolyte was investigated by British engineer Francis T. Bacon. He settled on the use of potassium hydroxide that he used as the electrolyte in 1959 , to develop a $5 \mathrm{~kW}$ stationary fuel cell [13].

The first applications of fuel cells were used in the U.S. Space Program. Also, the fuel cells were used by the Apollo Space Program to create electricity for life support, guidance and communications. Based on license taken on Bacon's patents, the fuel cells were built by Pratt and Whitney. General Motors experimented with a fuel cell powered van by the mid-1960s, meanwhile the U.S. Space Program have continued to successfully use fuel cells up to today. By the end of century the use of fuel cell technologies can be found in the car businesses that maintained by the U.S. Department of Energy, and almost every car industrialist had built and established a fuel cell powered vehicle [13].

In the 1960 s the industry began to recognize that the fuel cells had the commercial potential to be used for other areas, however due to high manufacturing cost and technical obstacles, fuel cells 
were not be able to commercially competitive with current power supplies. In the 1980s, the Canadian Government funded the initial development work of fuel cells that carried by Ballard Power Systems, that originally founded to conduct research and development on high-energy lithium batteries. Latter in 1989, the company decided to focus on fuel cell systems in general and precisely in PEM fuel cells [13].

The most prominent earlier work (1990s), presented by Barnardi et al. [20], [21] established a onedimensional isothermal proton exchange membrane fuel cell model to study the water management in the membrane, they assumed a constant value for water content in it. Meanwhile Springer et $a l$. [22] find an empirical relations for membrane resistance and water contents in some of Nafion® membrane. He presented an empirical relations for the resistance of the proton flow in the membrane in conjunction with the change of operating pressure and temperature and he assumed a constant water content in the membrane. Further studies by Fuller et al. [23], Nguyen and White [24] provide more insight into the transport phenomena of the reactants in PEM fuel cell. They developed pseudo-two-dimensional models that they set the concentration as a boundary conditions at the GC/GDL interfaces, or at the CL/GDL interfaces. Also, they consider that the oxygen can transport by diffusion mechanism only.

Studies by Yi et al. [25, 26] examined the water management in the membrane and take into consideration the convection effects of water transport across the membrane with related to the pressure gradient and the convection effects in removing heat form the cell. Also, their studies provided insight into the temperature distribution in the solid phase. By using a mechanistic approach, Amphlett et al. [27] presented a thermal model for the Ballard Mark IV PEM fuel cell stack, and a number of parameters were selected to suit the empirical results of the single Ballard Mark IV cell. The relationship between the energy generated by the stack to the stack temperature and the amount of heat removed from the stack was investigated in this study. Correspondingly, Kim et al. [28] developed an empirical equation to clarify the PEM fuel cell performance results under various operation parameters and he found better approach of the polarisation curves.

A Computational Fluid Dynamics (CFD) framework was involved in complex two-dimensional steady-state model for PEMFC that developed by Gurau et al. [29] to solve the governing equations 
of the continuity, momentum, energy, and species concentration in the membrane electrode assembly (MEA) and in the gas channels at the anode and cathode sides with special consideration to the porous medium. This study reduced the need of prescribing boundary conditions at the interfaces between the subdomains of the PEMFC. This study approve that the oxygen distribution along the GC is nonlinear which is unlike the assumption of earlier [23]. A similar CFD model was offered by Um et al. [30], that used the Henry's law with special consideration to the difference of oxygen concentration due to phase change at the interface of GDL/CL at cathode side. The two-phase flow and transport in the cathode side of PEM fuel cell was investigated by Wang et al. [31]. Wang studied the distribution of both single-phase and two-phase water within the cathode side where the air is feed as an oxidant in the gas channel. The results of this model provide interesting insight about the transport of two-phase flow in cathode side of PEM fuel cell.

Berning et al. [32] developed a comprehensive, single-phase, non-isothermal, three-dimensional computational model that account for the heat management issue and transport phenomena. Their model includes all components of PEM fuel cell that is: gas channels GCs, gas diffusion layers GDs, catalyst layers with real thickness CLs and membrane M. Following the same modeling approach, Dutta et al. [33, 35], used the mathematical model that was implemented within the framework of commercial CFD codes to solve the governing equations and obtained results as well as to examine the process within MEA. A three-dimensional dynamics model for cathode side was developed by Um et al. [35]. The straight and interdigitated flow field designs computational models were carried out to explain the connections between electrochemical kinetics and mass transport in PEM fuel cells and to demonstrate the current and species distribution.

Mathematical modeling of two-phase transport in PEMFCs has been carried out by several groups. Wang [36] provided valuable fundamental bases for the available two-phase flow models for PEM fuel cells. A two-phase flow model for the cathode of a PEM fuel cell was presented by You et al. $[37,38]$. The model was used to describe the two-phase flow and transport species in cathode side as well as the influences of operating temperature and the humidification temperatures on the liquid saturations and the water transport in membrane. Mazumder et al. [39] carried out a 3D multiphase mixture model $\left(\mathrm{M}^{2}\right)$, to determine the distribution of liquid water in the PEM fuel cell. 
Berning et al. [40] also developed a 3D multiphase, model for gas diffusion layers GDLs and gas channel GCs in anode and cathode sides with considering the heat and mass transfer. Chang et al. [41] developed a two-phase flow model based on multiphase mixture concept to examine the influences of transport phenomena in the gas diffusion layer (GDL) of a proton exchange membrane fuel cell (PEMFC) on cell performance. A pseudo-two-dimensional analytical model is proposed by Bansode et al. [42] to predict the inception of two-phase flow along the gas diffusion the gas channel at cathode side. This study assume that the diffusion of the water takes place only across the gas diffusion layer (GDL). The effects of the channel length, GDL thickness, air inlet velocity, the cell temperature, and relative humidity of air at the channel inlet on the threshold current density are predicted. Thus, for given design and operating parameters, this computational work can help to predict the inception of two-phase flow, and set the design and operating parameters in such a way that the flooding can be avoided. With a reasonable accuracy the results of this model is able to predict the threshold current density as well as predicting the two-phase flow.

A three-dimensional CFD model that include the catalyst layer with a finite thickness is presented by Zhou et al. [43] using the commercial CFD package CFX. In this numerical model, the effect of the transport of liquid phase of water in the membrane is not consider, while the electrochemical reactions at cathode and anode catalyst layers are consider with adding the suitable sources/sink terms in the species and charge equations. Zhou et al. [44] expanded their model by considering the electronic resistance of the GDL that was neglecting in some of earlier CFD work [45], [15]. They obtained a non-uniform distribution of overpotential in the GDL unlike the previous assumption of a uniform electronic-phase potential distribution in the GDL that results from neglecting the potential resistance in the gas diffusion layer.

In 2005, Cao et al. [46] developed a partially hydrated membrane model for PEM fuel cells that featured the inclusion of the membrane swelling effects as well as the effect of water transport in the membrane. A general detailed non-isothermal, two-dimensional CFD model including two finite-thickness catalysts is presented by Yin et al. [47]. The simulation results of this model clarify the distribution of the species, potential and temperature inside the entire PEM fuel cell including the catalyst layer with finite thickens. Another general detailed novel mathematical model for an 
entire PEM fuel cell is developed by Jaralla et al. [48, 49] with focus placed on the modeling and assessment of the role of thermodiffusion that has been neglected in previous fuel cell research work. The simulation results demonstrate that the thermodiffusion has a noticeable impact on transport of species in an operational PEM fuel cell. The model assigns a finite thickness for catalyst layers, allowing for a more realistic description of electrochemical reaction kinetics arising in the operational PEM fuel cell.

The fluid flow and cell performance in cathode side of a proton exchange membrane (PEM) fuel cell were numerically analyzed by Gulan et al. [50]. The model allows obtaining the distributions of velocity, oxygen concentration, current density, and power density in the cathode side of the PEM fuel cell for different values of inlet Reynolds number and inlet oxygen mole fraction at different operation temperatures. The simulations showed that the oxygen concentration in gas diffusion layer and catalyst layer decreases with decreasing Reynolds number. It is also observed that increasing inlet Reynolds number increases the power density and the current density of the cell. The increasing inlet oxygen mole fraction results in increases in the power density and current density of the cell. It is also observed that that current density and power density of the PEM fuel cell increases with increasing operation temperature.

A three-dimensional computational model for PEM fuel cell with advanced dynamics code have been carried out by Sui et al. [51]. The results of the study illustrated transport of species along the channel and couple energy equation with the mass transfer equation. The model use a commercial CFD code, CFD-ACE+ to solve the governing equations of momentum, mass, potential and energy as well as the liquid water transport in membrane. Other examples of the PEM fuel cell modeling studies can be found in the recently published reviews. One-dimensional transient thermal model for proton exchange membrane fuel cell (PEMFC) was presented by Khemili et al. [52] that investigate the heat generating mechanisms and the effects of various factors on the transient phenomena in the PEMFC. Another transient model have been carried out by Verma et al. [53] to examine some of selected operating parameters to improve fuel cell performance. 
A three dimensional fluid dynamics model of PEM fuel cell has been simulated by Ahmadi et al [54]. They investigate the effect of inlet gases humidity on the polymer exchange membrane fuel cell performance. The results of this study found that to improve the PEM fuel cell performance is necessary to control the inlet gases humidity with proper water content in the membrane. Another three dimensional and steady state model was developed by Jian et al. [55] to examine the effects of increasing fuel gas humidification from $25 \%$ to $100 \%$, on cell performance for two kinds of flow design: conventional and interdigitated flow fields in PEM fuel cells.

More studies for the design of flow field are carried out by Sheung et al. [56].

The effect of the membrane thermal conductivity on the performance of a polymer electrolyte membrane fuel cell was investigated by Iranzol et al. [57]. The governing equations in this model was solved by using the framework of CFD analysis. The results reveal that the membrane thermal conductivity has a big influence on the performance of PEM fuel cell. Maggiolo et al. [58] developed a three-dimensional lattice Boltzmann multiphase model to study the water cumulation at the interface between gas channel and gas diffusion layer at the anode side of a PEM fuel cell. Despite of neglecting the species and thermal diffusion, this study is considered to be the first effort to realise the mechanism of water cumulation in PEMFCs in microscopic level.

In literature there are many studies on proton exchange membrane fuel cell (PEMFC) performance. Numerical analyses of complex and coupled processes such as flow, heat and mass transports, reaction kinetics, and charge transport have been attempted over the past three decades to develop the performance of PEM fuel cell. Most of the aforementioned numerical studies focused on the conservation equations in general PEM fuel cell related microscopic and macroscopic heat and mass transfer in particular. These models provided useful insight and fundamental understanding of the transport phenomena in fuel cells. However, detailed analysis of transport phenomena and electrochemical reaction in realistic and complex geometries requires further investigation to account all the processes taking place inside a fuel cell.

In the present study, a two-dimensional model is developed in $x-y$ and $y-z$ planes to analyze the processes at the PEMFC in detail. The development of a model for the PEM fuel cell is intended to realise some of the properties that are important in the design. Precisely, the properties of the 
gas diffusion layer, membrane and catalyst layers. All the physical and electrochemical processes occurring in an operational PEM fuel cell are incorporated into a complete non-isothermal model that consists of all the components including two catalyst layers with finite thickness and a membrane under the full hydration condition. This model can be used for further optimization by varying the design parameters and operation conditions to improve the performance of PEM fuel cell.

\subsection{Research Objectives}

The purpose of this work is to develop a comprehensive non-isothermal two-dimensional CFD model of PEM fuel cells, which is capable of investigating electrochemical and transport phenomena in all seven regions of a PEMFC, namely, the anode/cathode gas channels (GCs), two gas diffusion layers (GDLs), two catalyst layers (CLs) in finite thickness, and a membrane allowing for partial and full hydration. This model is implemented into the finite element CFD commercial software package COMSOL, which provides a platform for simulating all important transport phenomena and electrochemical kinetics through solving the governing equations for transport processes involving the mixture gas flow, multi-component transport, heat transfer, water content, proton, and electron transport. Based on a given cell voltage, the cell current in the present model will be predicted, followed by a validation through comparison with available experimental results. The fully validated model will be used in a series of parametric studies. A number of operating parameters and design parameters are picked, including operating pressure, operating temperature, relative humidity, effective porosity of catalyst layer, membrane porosity, porosity of the gas diffusion layers (GDLs), the proton conductivity and air inlet velocity at cathode side. The performance characteristics of the fuel cell based on a selected parameter can be obtained by varying one parameter while keeping the others unchanged, to gain valuable insight and guidance for identifying the PEM fuel cell's possible failure mechanisms, and achieving its performance optimization as well as reducing the manufacturing cost. 


\subsection{Thesis Organization}

This thesis consists of five chapters and it is organized as follows:

- Chapter one presents an introduction to the fuel cell and literature review.

- Chapter two exhibits a model description and governing equations which are used to solve the problem. Also, the full model and the boundary conditions are described in detail. Finally, the finite element analysis is explained.

- Chapter three deals with a series of numerical experiments, including a base case study, and a validation of the numerical model through comparison of overall cell performance against experimental data obtained from other literature.

- Chapter four includes a systematic set of parametric studies.

- Finally, Chapter five presents the conclusions and recommendations. 


\section{Chapter 2 \\ Two-Dimensional Model of PEM Fuel Cell}

A two-dimensional model for a single PEM fuel cell is modeled in the $\mathrm{x}-\mathrm{y}$ and $\mathrm{y}-\mathrm{z}$ planes. The model consists of seven subregions (from the top to the bottom as schematically shown in Figures 2.1 and 2.2: for $x-y$ plan: the gas channel, gas diffusion layer (GDL) and catalyst layer (CL) on the anode side; the ionomeric membrane; and the catalyst layer, gas diffusion layer and gas channel on the cathode side; and as shown in Figure 2.2, the PEMFC components involved in the y-z plane include seven subdomains, namely: on the anode side, the collector plate, gas diffusion layer (GDL) and catalyst layer (CL); the ionomeric membrane; the catalyst layer, gas diffusion layer, and collector plate on the cathode side.

In the y-z plane, additional components, the current plate/current collectors, are involved in the two-dimensional model, while the anode/cathode gas channels may be extracted from the computational domains since the cross flow within the channels is insignificant. While in $x-y$ plane the current plate/current collectors are not involved.

\subsection{Modeling Assumptions}

The specific assumptions made in this work include:

1. The transport processes are steady-state.

2.The flow in the gas-distribution channels is laminar.

3. The gravity effect is negligible.

4. Though heat generation due to the electrochemical reaction is considered, the fluid properties are assumed to be independent of temperature.

5. The membrane is assumed to be impermeable for the gas-phase, for which a fairly small permeability for gases is employed to ensure nil gas concentration in the membrane. 


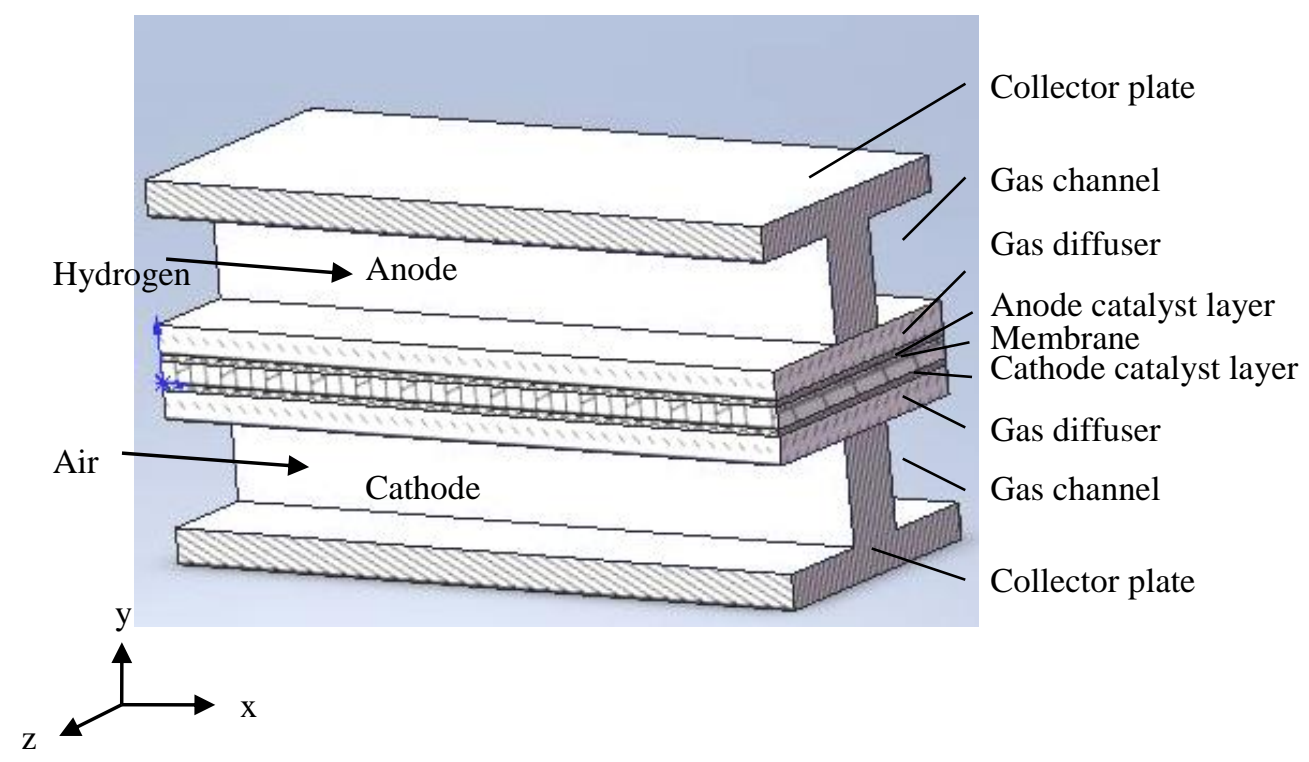

Figure 2.1 Sketch of a PEM Fuel Cell Configuration [77]

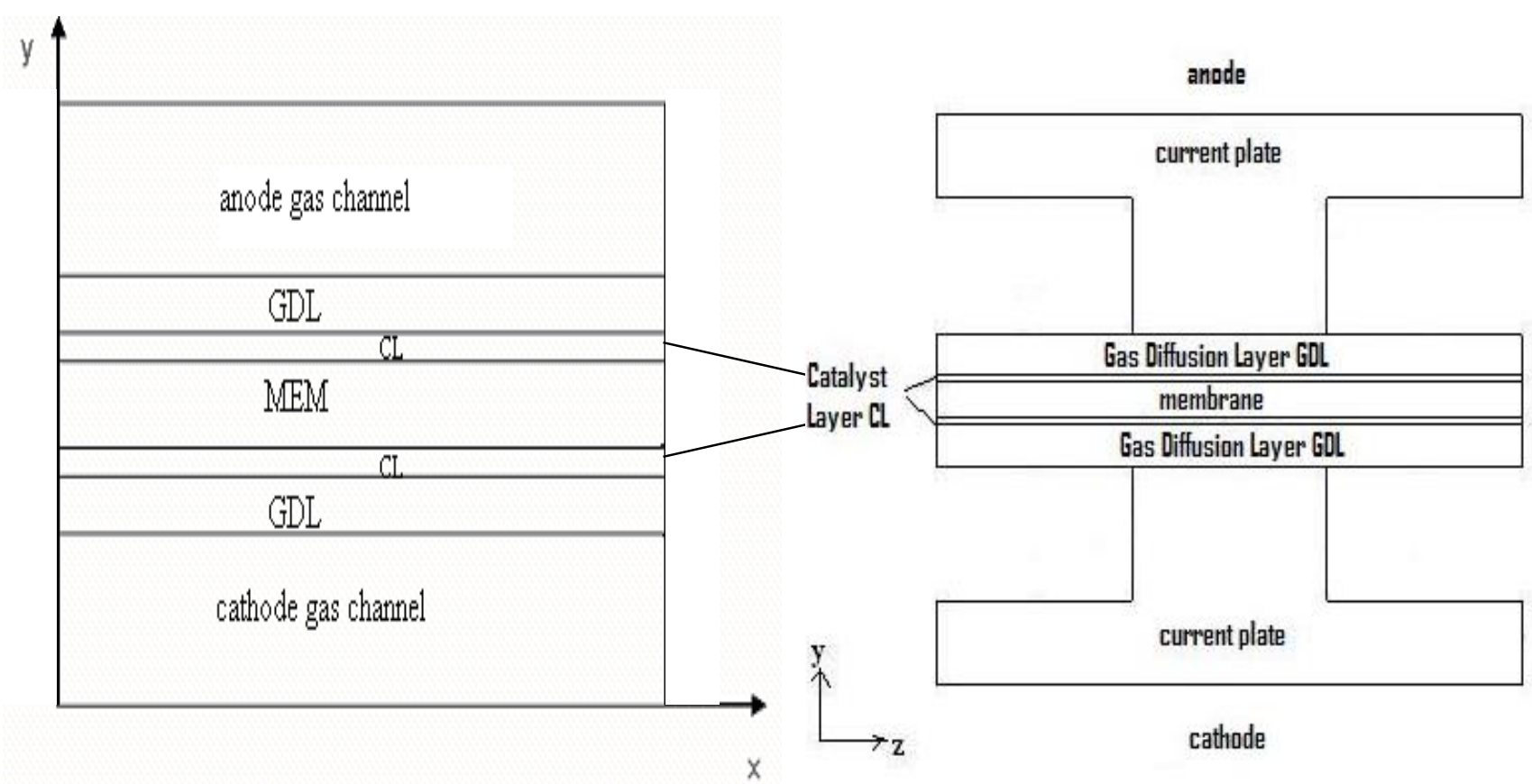

Figure 2.2 Schematic Diagram of Computation Model of a PEM Fuel Cell in x-y and y-z Planes 
6. The gas diffusers, the catalyst layers, and the membrane are all considered as isotropic and homogeneous porous media.

7. On the cathode side, the gas mixture consists of oxygen $\mathrm{O}_{2}$, nitrogen $\mathrm{N}_{2}$ and vapor water $\mathrm{H}_{2} \mathrm{O}$ (g), whereas on the anode side, the gas mixture consists of hydrogen $\mathrm{H}_{2}$, carbon dioxide $\mathrm{CO}_{2}$ and $\mathrm{H}_{2} \mathrm{O}(\mathrm{g})$, all of these gasses are assumed to be ideal gases and the gas mixture is incompressible.

8. Within the gas channels, the gas diffusers, and the catalyst layers, water is purely in the form of vapor or over-saturated vapor, while in the membrane water exist in the liquid phase and exhibits a linear variation in its pressure.

9. No water phase change is considered within each subdomain except that all water vapor at each interface between the catalyst layer and the membrane is entirely transformed to liquid water.

\subsection{Governing Equations}

\subsubsection{Mass Equation}

The continuity equation describing the conservation of mass is used for the entire fuel cell.

$\vec{\nabla} \cdot \varepsilon \rho \vec{V}=0$

with $\rho$ denoting the density of fluid mixture, $\vec{V}$ is the velocity of the fluid mixture and $\varepsilon_{\varepsilon}$ is the porosity $\left(\varepsilon=\varepsilon_{c t}\right.$ at CLs , $\varepsilon=\varepsilon_{g}$ at $\mathrm{GDL}_{\mathrm{s}} \varepsilon=\varepsilon_{m}$ at membrane, and $\varepsilon=1$ at GCs $)$.

\subsubsection{Momentum Equation}

For x-y plane, in the gas channels (GCs), the Navier-Stokes equations are employed to describe the conservation of the mass and momentum.

$\rho(\vec{V} \cdot \nabla) \vec{V}=-\vec{\nabla} p+\mu \Delta \vec{V} \quad$ (in GCs)

where $\mu, \rho, \vec{V}$ and $p$ are the dynamic viscosity, density, velocity, and pressure of the gas mixture, respectively. Here, it is noted that the density is assumed to be a constant for the gas 
mixture since the incompressibility condition is taken into account. To describe the momentum conservation in porous media, the gas mixture flow in the porous electrodes is governed by Darcy's law with the pressure gradient as the driving force. Darcy's law can be used to describe the conservation of the mass and momentum for the GDLs; as, the gas channels in which the flow fields were governed by the Navier-Stokes equations, are not involved in the y-z plane model; otherwise, it is important to consider the average viscous stress terms in the outer boundary of a porous medium where the macroscopic velocity varies rapidly in space [19]. The Darcy's law in its revised version:

$$
\begin{aligned}
& \vec{V}=-\frac{k_{p}}{r^{(2)} \mu} \vec{\nabla} p \quad \text { (in GDLs) } \\
& \vec{V}=-\frac{k_{h}}{r^{(2)} \mu} \vec{\nabla} p \quad \text { (in CLs ) }
\end{aligned}
$$

where $p$ is the operating pressure and $p=p_{a}$ at anode side, and $p=p_{c}$ at the cathode sides, respectively. $k_{p}$ and $k_{h}$ are the permeability of the porous electrode and the hydraulic permeability, respectively; $\mu$ is the viscosity of the fluid; and $r^{(2)}$ is a coefficient describing the effect of the porosity of the medium to the viscous force. The coefficient $r^{(2)}$ can be determined using [21]:

$$
\begin{aligned}
& \left.r^{(2)}=2.25 \frac{\left(1-\varepsilon_{g}\right)^{2}}{\varepsilon_{g}^{2}} \quad \text { (in GDLs }\right) \\
& r^{(2)}=2.25 \frac{\left(1-\varepsilon_{c t}\right)^{2}}{\varepsilon_{c t}^{2}} \quad(\text { in CLs })
\end{aligned}
$$

where $\varepsilon_{g}$ is the porosity of the gas diffusers, $\varepsilon_{c t}$ is the effective porosity of the catalyst layer which can be calculated by:

$$
\varepsilon_{c t}=\varepsilon_{m} \cdot \theta_{m c}
$$

with $\varepsilon_{m}$ and $\theta_{m c}$ denoting the porosity of the membrane and the volume fraction of the membrane in the catalyst layer, respectively. It is obvious that Eqs. (2.3) and (2.4) reduce to Darcy's law when $r^{(2)}=1$. 


\subsubsection{Mass Transfer Equation}

In multicomponent diffusion, the movement of any species is different than that for the binary diffusion where the movement is from higher concentration to the lower one; and interesting things can arise in multicomponent diffusion such that (i) the species can move against its concentration gradient which is known as reversed diffusion; (ii) the species can move in the absence of its concentration gradient, which is called osmotic diffusion; and (iii) the species may not diffuse regardless of the present of the concentration gradient, which is called nonzero diffusion.

Maxwell-Stefan equations are shown to be a very good approximation for multicomponent diffusion in gases at low density [16, 27]. Curtiss and Bird revised the Maxwell-Stefan equations by using different diffusivities to validate the equations for dense gases, liquids and polymers. Unlike the conventional one, their formulation incorporates the pressure dependence and the temperature dependence of the concentration gradient of the species. The formulation is adopted in this study, and briefly explained as follows:

The mass balance for each species, except one, in a solution is given by the general transport equation:

$\frac{\partial}{\partial t}\left(\rho w_{i}\right)+\nabla \cdot\left(j_{i}+\rho w_{i} u\right)=R_{i}$

where $w_{i}$ is the mass fraction of the species and $R_{i}$ is the reaction rate. The second term in this equation is the combined mass flux consisting of molecular mass flux vector $j_{i}$ and the convective mass flux vector with the velocity vector $u$. $j_{i}$ describes the diffusion-driven transport, which is the property investigated by Curtiss and Bird. They derived their description of the molecular mass flux from Jaumann's entropy-balance equation [31] and were able to describe diffusion transport as a function of temperature and a diffusion driving force $d_{j}$. Hence, with the thermodynamics of irreversible processes, $j_{i}$ is defined as:

$$
j_{i}=-D_{i}^{T} \nabla(\ln T)-\rho w_{i} \sum_{j=1}^{N} D_{i j} d_{j} \quad(\mathrm{i}=1,2, \ldots \ldots \mathrm{N})
$$


where $D^{T}$ is the thermal diffusion coefficient (in this work is neglected $=0$ ), $T$ is the temperature, $D_{i j}$ are the symmetric diffusivities proposed by Curtiss, and $d_{j}$ is the diffusion driving force for the species $j$, which is defined as:

$$
d_{i}=\frac{1}{c R T}\left(\nabla p_{i}-w_{i} \nabla p-\rho w_{i} g_{i}+w_{i} \sum_{j=1}^{N} \rho w_{j} g_{j}\right)
$$

where $c$ is the concentration of the mixture, $R$ is the universal gas constant and $g_{i}$ is the force per unit mass acting on the $i^{\text {th }}$ species. The first two terms on the right side of Eq. (2.10) define the effects of the intermolecular forces, and the effects of the external forces is describe in the last two terms which will cancel each other if the only external force is the gravity. Noting that from the ideal gas law $p=c R T$ and the mole fraction of the species $i$ is

$x_{i}=\frac{p_{i}}{p}$

Eq. (2.10) can then be written as:

$d_{i}=\left(\nabla x_{i}+\left(x_{i}-w_{i}\right) \frac{\nabla p}{p}-\rho w_{i} g_{i}+w_{i} \sum_{j=1}^{N} \rho w_{j} g_{j}\right)$

With the assumptions that the transport processes are steady-state and there is no external force acting on the species apart from the gravity, by substituting Eqs. (2.9) and (2.12) into Eq. (2.8), the resulting mass balance in the mass fractions reads:

$\nabla \cdot\left[\rho w_{i} \vec{V}-\rho w_{i} \sum_{j=1}^{n} D_{i j}\left\{\nabla x_{j}+\left(x_{j}-w_{j}\right) \frac{\nabla p}{p}\right\}-D_{i}^{T} \frac{\nabla T}{T}\right]=R_{i}$

where $x_{j}$ and $w_{j}$ represent the mole and mass fraction of the species $j$ in the mixture, that is on the anode side, the subscripts $i$ and $j$ are applied to denote hydrogen, water vapour, carbon dioxide; while, on the cathode side, $i$ and $j$ are applied to denote oxygen, water vapor, and nitrogen; $x_{i}$ is the mole fraction of the component $i ; N_{i}$ is the molar flux of the componenti; $c$ stands for the concentration;

It is possible to express the molar fraction $x_{i}$ in the term of mass fraction $w_{i}$ by [29]: 


$$
x_{i}=\frac{\frac{w_{i}}{M_{i}}}{\sum_{j=1}^{n} \frac{w_{j}}{M_{j}}}
$$

the above equation can also be written as:

$$
w_{i}=\frac{x_{i} M_{i}}{\sum_{j=1}^{n} x_{j} M_{j}}=\frac{x_{i} M_{i}}{M}
$$

where $M$ stands for the total mole mass of the mixture calculated using:

$$
M=\sum_{i=1}^{n} M_{i} x_{i}
$$

and $M_{i}$ indicates the mole mass of the species $i$. Assumption 7 implies the applicability of the state equation, which relates density, temperature and pressure. That is, for each species $i$ contained in the ternary system, such as the mixture of $\mathrm{O}_{2}, \mathrm{~N}_{2}$ and $\mathrm{H}_{2} \mathrm{O}_{(\mathrm{g})}$ at the cathode side and the mixture of $\mathrm{H}_{2}, \mathrm{CO}_{2}$ and $\mathrm{H}_{2} \mathrm{O}(\mathrm{g})$ at the anode side, the following relationship holds:

$$
\rho_{i}=M_{i} \frac{p_{g}}{R T_{g}}
$$

Though, theoretically Eq. (2.13) can be used for each species in the gas mixture, the mass and molar fractions for $\mathrm{CO}_{2}$ on the anode side and $\mathrm{N}_{2}$ on the cathode side are practically calculated by using:

$$
\begin{aligned}
& w_{n}=1-\sum_{i=1}^{n-1} w_{i} \\
& x_{n}=1-\sum_{i=1}^{n-1} x_{i}
\end{aligned}
$$

which ensures the conservation of mass on both sides. Therefore, the Maxwell-Stefan diffusion and convection equation applies only to 2 species out of the 3 species on one electrode side, that is: oxygen and water vapour at cathode side, and hydrogen and water vapour at anode side. The final species is solved through the fact that:

$$
\sum_{i=1}^{n} w_{i}=1
$$

The $D_{i j}$ in Eq.(2.13) represents the binary diffusivity of species $i$ and $j$. On the cathode side, the 
ternary mixture of three species is viewed in three species pairs: $\mathrm{O}_{2}-\mathrm{N}_{2}, \mathrm{~N}_{2}-\mathrm{H}_{2} \mathrm{O}_{(g)}$, and $\mathrm{O}_{2}$ $\mathrm{H}_{2} \mathrm{O}_{(g)}$, while on the anode sides, the three species pairs are: $\mathrm{H}_{2}-\mathrm{CO}_{2}, \mathrm{CO}_{2}-\mathrm{H}_{2} \mathrm{O}_{(g)}$, and $\mathrm{H}_{2} \mathrm{O}_{(g)}$ $-H_{2}$. The binary diffusivities $D_{i j}$ are usually obtained by experiment at the atmospheric pressure $p_{a t m}$ and reference temperature $T_{0}$; according to [32], $D_{i j}^{0}$ can then be scaled to the operating temperature and pressure as follows:

$D_{i j}=D_{i j}^{0}\left(T_{0}, p_{0}\right) \frac{p_{0}}{p}\left(\frac{T}{T_{0}}\right)^{1.5}$

where $D_{i j}^{0}, T_{0}, p_{0}$ are the reference experimentally binary diffusivities, temperature and pressure, respectively.

Due to the porous nature of the gas diffusers and catalyst layers, the binary diffusivity correction is taken for the porous media. The resulting species equations becomes:

$\vec{\nabla} \cdot\left[\rho w_{i} \vec{V}-\rho w_{i} \sum_{j=1}^{n} D_{i j}^{e f f}\left\{\vec{\nabla} x_{j}+\left(x_{j}-w_{j}\right) \frac{\vec{\nabla} p}{p}\right\}-D_{i}^{T} \frac{\vec{\nabla} T}{T}\right]=0$

By using the so-called Bruggemann correction formula [43], the binary diffusivities $D_{i j}$ are corrected for the flow in porous media:

$D_{i j}^{e f f}=D_{i j} \varepsilon^{1.5}$

Based on the Maxwell-Stefan equations in the form developed by [29], the transport model for the multi-gases passing through the GDLs, GCs and CLs accounts for both diffusion and convection: $\vec{\nabla} \cdot\left[-\rho w_{i} \sum_{j=1}^{n} D_{i j}^{e f f}\left\{\vec{\nabla} x_{j}+\left(x_{j}-w_{j}\right) \frac{\vec{\nabla} p}{p}\right\}-D_{i}^{T} \frac{\vec{\nabla} T}{T}\right]=-\rho \vec{V} \cdot \vec{\nabla} w_{i}+ \begin{cases}0 & \text { GDLs \& GCs } \\ S_{\mathrm{k}} & \text { CLs }\end{cases}$

As indicated in Eq. (2.24), the right hand side corresponding to the GDLs vanishes because there is no reaction on the sites; but a sink term at the anodic CL must be prescribed:

$$
\begin{aligned}
& S_{H_{2}}=-\frac{j_{a}}{2 F} M_{H_{2}} \\
& S_{H_{2} \mathrm{O}}=0
\end{aligned}
$$

Due to the oxidization of hydrogen, and meanwhile a sink term for oxygen and a source term for 
water should be considered at the cathodic CL representing the oxygen reduction reaction:

$$
\begin{gathered}
S_{O_{2}}=\frac{j_{c}}{4 F} M_{O_{2}} \\
S_{H_{2} O}=-\frac{j_{c}}{2 F} M_{H_{2} O}
\end{gathered}
$$

In the above source/sink terms, $M$ is the molecular weight of the species, $j_{a}$ and $j_{c}$ are the anodic and cathodic exchange current densities, respectively, which can be modeled by the Butler-Volmer equations [35]:

$$
\begin{aligned}
& j_{a}=\left(a j_{0}^{r e f}\right)_{a}\left(\frac{c_{\mathrm{H}_{2}}}{c_{\mathrm{H}_{2}, \text { ref }}}\right)^{1 / 2}\left[\exp \left(\frac{\alpha_{a}^{a} F}{R T} \eta_{a}\right)-\exp \left(-\frac{\alpha_{c}^{e} F}{R T} \eta_{a}\right)\right] \\
& j_{c}=\left(a j_{0}^{r e f}\right)_{c}\left(\frac{c_{O_{2}}}{c_{O_{2}, \text { ref }}}\right)\left[\exp \left(\frac{\alpha_{a}^{c} F}{R T} \eta_{c}\right)-\exp \left(-\frac{\alpha_{c}^{c} F}{R T} \eta_{c}\right)\right]
\end{aligned}
$$

The surface overpotential for an electrochemical reaction, $\eta$ is considered the driving force for an electrochemical reaction, and can be described as:

$$
\begin{cases}\eta_{a}=\phi_{s}-\phi_{p} & \text { at anode } \\ \eta_{c}=\phi_{s}-\phi_{p}-E_{0} & \text { at cathode }\end{cases}
$$

where $\phi_{s}$ is the solid-phase potential, $\phi_{p}$ is membrane-phase potential, and $E_{0}$ is the thermodynamic open circuit potential for overall reaction, which is expressed by the Nernst equation [60] as a function of the reactant and product concentrations at the interface:

$$
E_{0}=1.23-0.9 \times 10^{-3}(T-298)+2.3 \frac{R T}{4 F} \log \left(p_{H_{2}}^{2} p_{O_{2}}\right)
$$

\subsubsection{Potential Equations}

At the low operating temperature of the PEM fuel cell, the electrochemical reactions Eqs. (1.1) and (1.2) would occur very slowly at the catalyst layers surface, where fuel and oxidant react 
electrochemically to produce electrical power. Hydrogen fed to the anode side diffuses through the porous gas diffusion layer (GDL), hydrogen flows to the anode side and split into protons (hydrogen ions) and electrons at the anodic catalyst layer. Electrons travel over an external circuit to the cathode side, consequently providing usable current or energy, while the hydrogen ions travel through the membrane to the cathode catalyst layer. Due to the movement of the protons through the membrane from anode side to cathode side, a voltage difference will builds up. For example, when the electrodes are connected, the voltage difference produces a straight electric energy that can operate an engine. In the cathodic catalyst layer, protons mix with electrons and oxygen to produce water and heat at the cathode. The reaction is driven by the electrochemical energy stored in the reactants. Figure 2.3 shows the movement of protons and electrons through the cell to produce an electrical power.

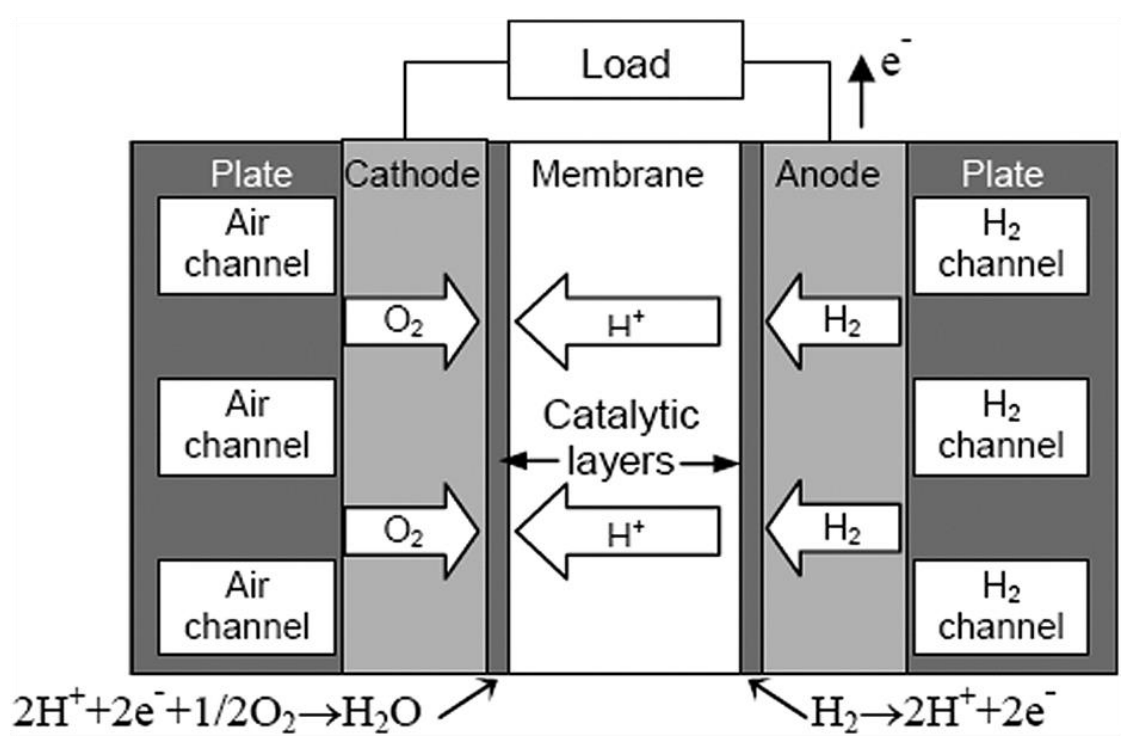

Figure 2.3 Transport Paths of Protons and Electrons within a PEM Fuel Cell [16]

To describe the fuel cell potential distribution, two kinds of potentials are modeled. One is the membrane-phase potential, which is obtained by solving the equation of proton transport in the catalyst layer and membrane: 
$\vec{\nabla} \cdot\left(-\sigma^{p} \vec{\nabla} \phi_{p}\right)= \begin{cases}j_{a} & \text { in anode catalyst layer } \\ \text { Function }\left(T, p_{l}, c_{w}, \ldots\right) & \text { in membrane } \\ j_{c} & \text { in cathode catalyst layer }\end{cases}$

where $\phi_{p}$ is the ionic potential, and $\sigma^{p}$ is the ionic conductivity.

The second kind of potential in the model is the solid-phase potential which results from the solution to the equation of electron transport in the catalyst layers, gas diffusers and collector plates:

$\vec{\nabla} \cdot\left(-\sigma^{e} \vec{\nabla} \phi_{e}\right)= \begin{cases}-j_{a} & \text { in anode catalyst layer } \\ 0 & \text { in GDLs and collector plates } \\ -j_{c} & \text { in cathode catalyst layer }\end{cases}$

where $\phi_{e}$ is the electric potential, and $\sigma^{e}$ is electrical conductivity. In the present model, the value of $\sigma^{e}$ is assumed to be $20000 \mathrm{~S} / \mathrm{m}$ [61]. The right hand side corresponding to the GDLs vanishes since there is no electron produced in gas diffusion layers, as the GDL works as a bridge between the current-collecting land and catalyst layer to provide electron lateral conduction. The electron current density $\vec{i}_{e}$ in the gas diffusers satisfies:

$\vec{\nabla} \cdot \overrightarrow{i_{e}}=0$

where the electron current density $\vec{i}_{e}$ can be described by:

$\overrightarrow{i_{e}}=-\sigma_{G D L}^{e} \vec{\nabla} \phi_{s}$

where $\sigma_{G D L}^{e}$ is the electrical conductivity of the gas diffuser.

By substituting Eq. (2.36) into Eq. (2.35) the solid-phase potential in the gas diffusion layers can be obtained by solving:

$\vec{\nabla} \cdot\left(-\sigma_{G D L}^{e} \vec{\nabla} \phi_{s}\right)=0$.

\subsubsection{Energy Equation}

The general mechanism of water transport in PEM fuel cell is more complicated due to the effects of the electrochemical reaction that happens in the catalyst layers during the operation of PEM fuel cell. As a results of the heat generation and ohmic heating in the membrane, the membrane 
dehydrate as the water evaporation rates increases at the cathode side. The temperature distribution can be obtained by solving the following energy equation in the GCs, GDLs, CLs and membrane of a PEM fuel cell:

$$
\rho C_{p}(\vec{V} \cdot \nabla T)=k_{e f f} \Delta T+ \begin{cases}0 & \text { in GCs } \\ \frac{\vec{i}_{e}^{2}}{\sigma_{G D L}^{e}} & \text { in GDLs } \\ \frac{\vec{i}_{p}^{2}}{\sigma_{m}^{p}} & \text { in membrane } \\ \frac{\vec{i}_{p}^{2}}{\sigma_{c t}^{m}}+\frac{\vec{i}_{e}^{2}}{\sigma_{c t}^{e}}+\eta_{a} j_{a} & \text { in anode catalyst layer } \\ \frac{\vec{i}_{p}^{2}}{\sigma_{c t}^{m}}+\frac{\vec{i}_{e}^{2}}{\sigma_{c t}^{e}}+\eta_{c} j_{c} & \text { in cathode catalyst layer }\end{cases}
$$

At GDLs, the term $\frac{\vec{i}_{e}^{2}}{\sigma_{G D L}^{e}}$, is the heat source term that produced as a result of the ohmic heating of electron current, $i_{e}$, as there is an electronic resistances through the gas diffusers. In the membrane an additional Joule heating source, $\frac{\vec{i}_{p}^{2}}{\sigma_{m}^{p}}$, arising from protonic resistances through the membrane has been added to the energy equation, $\sigma_{m}^{p}$ appears in the Joule heating source term representing the ionic conductivity in the membrane. At the catalyst layers, on the right hand side of the above equation, the second and third terms describe the ohmic heating of both proton current $\vec{i}_{p}$ and electron current $\vec{i}_{e}$ within catalyst layers; and the last term represents the heat generation or absorption because of electrochemical reaction at the catalyst.

For the fluid and solid phase in the overall averaging of the energy equations, the effective conductivity satisfies $[29,77]$ :

$$
k_{e f f}=-2 k_{g r}+\frac{1}{\frac{\varepsilon_{g}}{2 k_{g r}+k_{g a s}}+\frac{1-\varepsilon_{g}}{3 k_{g r}}}
$$


where $k_{\text {gas }}$ is the thermal conductivities of the gas mixture, and $k_{g r}$ is the graphite solid matrix.

\subsubsection{Water and Proton Transport Model}

The effect of membrane swelling on water content and potential loss within the membrane is examined in this study. Liquid water and protons are considered to be the only species that allowed to transport through the membrane while the membrane is assumed to be impermeable for the gasphase as stated in assumption 5. Although the exact and complete mechanism of water transport behavior in the membrane is still under investigation, an updated model is formulated by Cao et al [46] to investigate the effects of the partial hydration condition of reactants on the fuel cell performance.

$$
\vec{\nabla} \cdot \vec{N}_{w}=0
$$

and

$$
\vec{\nabla} \cdot \vec{N}_{p}=0
$$

where $\vec{N}_{w}$ and $\vec{N}_{p}$ are the molar fluxes of water and protons, respectively. As sign conventions, positive values for $\vec{N}_{w}$ or $\vec{N}_{p}$ mean net water flux or protons flux from the anode to the cathode, while negative values are from the cathode to the anode.

\subsubsection{Water Transport}

Water transport in the membrane is driven by: i) the electro-osmotic drag that results from moving protons, ii) diffusion that induced by concentration difference, iii) and hydraulic permeation, that results from the pressure difference between the two sides of the membrane. A good water management procedure aims at balancing these water fluxes to avoid flooding the electrodes or dehydrating the membrane.

The net water flux in the membrane satisfies:

$\overrightarrow{N_{w}}=-D_{w} \vec{\nabla} c_{w}-c_{w} \varepsilon_{m}^{w} \frac{k_{h}}{\mu_{l}} \vec{\nabla} p_{l}+\frac{n_{d} \overrightarrow{i_{p}}}{F}$ 
where $\vec{N}_{w}$ is the molar flux of water, $c_{w}$ denotes the molar concentration of water, ${ }_{m}^{w}$ the volume fraction of water in the membrane, $D_{w}$ the diffusion coefficient, $k_{h}$ the hydraulic permeability of the membrane, $\mu_{l}$ the liquid water viscosity, $n_{d}$ the elector-osmotic drag coefficient, $F$ Faraday's constant, $p_{l}$ the water pressure, and $\vec{i}_{p}$ is the proton current density that equals the local current density $\vec{i}$ in the membrane, as there is no electron transport in the membrane. This equation accounts for back diffusion processes induced by the water concentration gradient, which provides the model with improved capability of predicting humidification schemes.

Taking into account the current density conservation:

$\vec{\nabla} \cdot \vec{i}=0$

along with the linear profile of pressure:

$\nabla^{2} p_{l}=0$

the divergence of $\vec{N}_{w}$ can be expressed as:

$\vec{\nabla} \cdot \vec{N}_{w}=-D_{w} \nabla^{2} c_{w}-\varepsilon_{w}^{m} \frac{k_{h}}{\mu_{l}}\left(\vec{\nabla} c_{w} \cdot \vec{\nabla} p_{l}\right)+\frac{\vec{\nabla} n_{d} \cdot \vec{i}}{F}$

Combination of Eq. (2.40) and Eq. (2.45) yields:

$-D_{w} \nabla^{2} c_{w}-\varepsilon_{w}^{m} \frac{k_{h}}{\mu_{l}}\left(\vec{\nabla} c_{w} \cdot \vec{\nabla} p_{l}\right)+\frac{\vec{\nabla} n_{d} \cdot \vec{i}}{F}=0$

Based on the experiments using Nafion117, Springer et al. [22] proposed a simple linear relationship between the electro-osmotic drag coefficient, $n_{d}$ and the water content in the membrane:

$n_{d}=\frac{2.5}{22} \lambda$

where $\lambda$ is the hydration index, the numeric value 2.5 represents the number of water molecules dragged by each migrating $H^{+}$ion and 22 correspond to the possible maximum hydration index. Springer et al. [22] expanded the dry membrane thickness dimensions by the factor $(1+f \lambda)$ to account for membrane swelling, and presented an empirical formula relating $c_{w}$ to $\lambda$ as follows:

$c_{w}=\frac{e \lambda}{f \lambda+1}$ 
where $f$ is the membrane swelling coefficient experimentally determined through the measured thicknesses of the dry and fully hydrated Nafion 117 membranes, and $e$ is a constant ratio for Nafion 117 expressed as:

$e=\frac{\rho_{m}^{d r y}}{E W_{m}}$

where $E W_{m}$ is the equivalent molecular weight of the membrane, and $\rho_{m}^{d r y}$ is the dry membrane density.

Since the water content of the membrane and temperature are related to the membrane water diffusivity, its formula of empirical nature is satisfied by [22]:

$D_{w}=10^{-6} \exp \left[2416\left(\frac{1}{303}-\frac{1}{T}\right)\right]\left(2.563-0.33 \lambda+0.0264 \lambda^{2}-0.000671 \lambda^{3}\right)$

Re-arranging Eq. (2.48) leads to:

$\lambda=\frac{c_{w}}{e-f c_{w}}$

The electro-osmotic drag coefficient $n_{d}$ for Nafion117 expressed in Eq. (2.47) can now be rewritten as a function of water concentration:

$n_{d}=\frac{2.5}{22} \frac{c_{w}}{e-f c_{w}}$

Substituting Eq. (2.52) into Eq. (2.46), the water transport equation can be expressed as:

$$
-D_{w} \nabla^{2} c_{w}-\varepsilon_{w}^{m} \frac{k_{h}}{\mu_{l}}\left(\vec{\nabla} c_{w} \cdot \vec{\nabla} p_{l}\right)+\frac{5}{44} \frac{e}{F\left(e-f c_{w}\right)^{2}}\left(\vec{\nabla} c_{w} \cdot \vec{i}\right)=0
$$

which is a complete mathematical description of water concentration, $c_{w}$, distribution in the membrane. Eq. (2.53) is a nonlinear partial differential equation of $c_{w}$ with the known pressure profile $p_{l}$ and current density $\vec{i}$ in the membrane, 


\subsubsection{Proton Transport}

The Nernst-Planck equation can be used to determine the flux of protons through the membrane, the net molar flux of protons:

$$
\vec{N}_{p}=-Z_{p} \frac{F}{R T} D_{p} c_{p} \vec{\nabla} \phi_{p}-D_{p} \vec{\nabla} c_{p}+c_{p} \vec{V}_{l}
$$

where $V_{l}$ is the convective velocity of the liquid water, $Z_{p}$ is the charge number of ion, $c_{p}$ is the molar concentration of protons, $D_{p}$ is the diffusion coefficient, and , $\phi_{p}$ is the electric potential i.e. membrane-phase potential.

The velocity of liquid water in the pores of the membrane can be estimated by the Schliögl equation $[64,15]$ :

$\vec{V}_{l}=\varepsilon_{w}^{m}\left(\frac{k_{\phi}}{\mu_{l}} Z_{f} c_{f} F \vec{\nabla} \phi-\frac{k_{h}}{\mu_{l}} \vec{\nabla} p_{l}\right)$

where $k_{\phi}$ and $k_{h}$ are the electric and hydraulic permeabilities of the membrane, respectively, $c_{f}$ is the fixed-charged concentration, and $Z_{f}$ is the charge number of the fixed charges.

Since the electric current results from the flux of charge species, the current density in the membrane can be expressed as:

$$
\vec{i}=F \sum Z_{j} \vec{N}_{j}=F \vec{N}_{p}
$$

where $Z_{j}$ is the charge number of charged mobile ion of species $j$, and $Z_{j}=1$ for the sole mobile ions of hydrogen in this situation, $\vec{N}_{j}$ is the molar flux of ions. Therefore, Eq. (2.56) can reduce to:

$$
\vec{N}_{p}=\frac{\vec{i}}{F}
$$

The membrane ionic conductivity is generally defined as:

$$
\sigma_{m}^{p}=\frac{F^{2}}{R T} \sum Z_{j}^{2} D_{j} c_{j}
$$

The electro-neutrality condition signifies that no net charge should exist in the membrane:

$$
Z_{f} c_{f}+\sum Z_{j} c_{j}=0
$$


Since, the sole charged mobile ion in the membrane is proton, and for $\mathrm{H}^{+}, Z_{p}=1$. Hence Eq. (2.58) can be reduced to:

$\sigma_{m}^{p}=\frac{F^{2}}{R T} D_{p} c_{p}$

and, Eq. (2.59) becomes:

$Z_{f} c_{f}=-c_{p}$

Substituting Eq.(2.61) into Eq. (2.54) and (2.55) results in:

$\vec{N}_{p}=-\frac{F}{R T} D_{p} c_{p} \vec{\nabla} \phi_{p}-D_{p} \vec{\nabla} c_{p}+c_{p} \vec{V}_{l}$

and

$\vec{V}_{l}=\varepsilon_{w}^{m}\left(\frac{k_{\phi}}{\mu_{l}} c_{p} F \vec{\nabla} \phi-\frac{k_{h}}{\mu_{l}} \vec{\nabla} p_{l}\right)$

Substituting Eq. (2.63) and (2.57) into Eq. (2.57) gives:

$-\Delta \phi_{p}=-\frac{1}{\sigma_{m}^{p}}\left[\vec{\nabla}\left(\ln c_{p}\right) \cdot \vec{i}\right]+\frac{R T}{F} \vec{\nabla} \cdot\left[\vec{\nabla}\left(\ln c_{p}\right)\right] c_{p}$

where $c_{p}$ is a function of hydration. Unlike the unrealistic assumption of a constant $c_{p}$ as employed in many other previous studies, the concentration of protons is now allowed to vary in response to the swelling or drying of the membrane due to the change of internal liquid water. For Nafion 117 , the proton concentration can be expressed as:

$c_{p}=\frac{c_{w}}{\lambda}$

Substituting Eq. (2.48) into (2.65) leads to:

$c_{p}=\frac{e}{f \lambda+1}$

Substitution Eq. (2.51) in Eq. (2.66) leads to:

$c_{p}=e-f c_{w}$

Substituting Eq. (2.67) into Eq. (2.64), the electrical membrane-phase potential expression in the membrane in terms of water concentration $c_{w}$ : 


$$
\begin{aligned}
-\Delta \phi_{p}= & -\frac{1}{\sigma_{m}^{p}} \frac{f}{e-f c_{w}}\left(\vec{\nabla} c_{w} \cdot \vec{i}\right)-\frac{R T e}{F} \frac{f}{e-f c_{w}} \Delta c_{w} \\
& -\frac{R T}{F}\left(\frac{f}{e-f c_{w}}\right)^{2}\left(\vec{\nabla} c_{w} \cdot \vec{\nabla} c_{w}\right)
\end{aligned}
$$

In order to eliminate $\Delta c_{w}$, i.e $\nabla^{2} c_{w}$, Eq. (2.53) is substituted into Eq. (2.68) and the electric potential equation in the membrane accounting for swelling effect is eventually written as:

$$
\begin{aligned}
-\Delta \phi_{p}= & -\frac{f}{e-f c_{w}}\left(\frac{1}{\sigma_{m}^{p}}-\frac{5}{44} \frac{R T e}{D_{w} F^{2}\left(e-f c_{w}\right)^{2}}\right)\left(\vec{\nabla} c_{w} \cdot \vec{i}\right) \\
& +\frac{R T}{F} \frac{f}{e-f c_{w}} \frac{\varepsilon_{w}^{m}}{D_{w} \mu_{l}}\left(\vec{\nabla} c_{w} \cdot \vec{\nabla} p_{l}\right) \\
& -\frac{R T}{F}\left(\frac{f}{e-f c_{w}}\right)^{2}\left(\vec{\nabla} c_{w} \cdot \vec{\nabla} c_{w}\right)
\end{aligned}
$$

For the ionic conductivity of a Nafion 117 proton exchange membrane, an empirical expression presented by Springe et al. [22] as:

$$
\sigma_{m}^{r e f}=0.5139 \lambda-0.326 \text { if } \lambda \geq 1
$$

where $\sigma_{m}^{r e f}$ is the reference ionic conductivity measured at $303 \mathrm{~K}$. The reference ionic conductivity is assumed constant for the values of membrane water content, $\lambda$ less than 1 [22]. At other temperatures, it is corrected to be a function of operating temperature $T$ [22]:

$$
\sigma_{m}^{p}=\sigma_{m}^{r e f} \exp \left[1268\left(\frac{1}{303}-\frac{1}{T}\right)\right] \text {. }
$$

\subsection{Boundary Conditions}

An entire PEM fuel cell consists of a number of subdomains. Corresponding to the equation of systems, in practice, some subdomains may be grouped to be subjected to an identical governing equation. For example, for $x-y$ plane, the oxygen is transported in the cathode gas channel (GC), diffusion layer (GDL), and catalyst layer (CL); then, the Maxwell-Stefan equation for the oxygen transport applies to all these three subdomains. Accordingly, the boundary conditions for the mass fraction of oxygen are required only at the border of the grouped subdomains, while no 
specification of interfacial conditions is required between neighboring subdomains in the group. The boundary conditions for $\mathrm{x}-\mathrm{y}$ and $\mathrm{y}-\mathrm{z}$ plane are explained in details in the following sections.

\subsubsection{Boundary Conditions for $x-y$ Plane}

The $x-y$ plane for the PEM fuel cell is consisting of seven subregions (from the top to the bottom): the gas channel (GC), gas diffusion layer (GDL) and catalyst layer (CL) are on the anode side; the ionomeric membrane; and the catalyst layer, gas diffusion layer and gas channel are on the cathode side. Figure 2.4 shown all the boundaries of a 2D PEM fuel cell model in the $x-y$ plane:

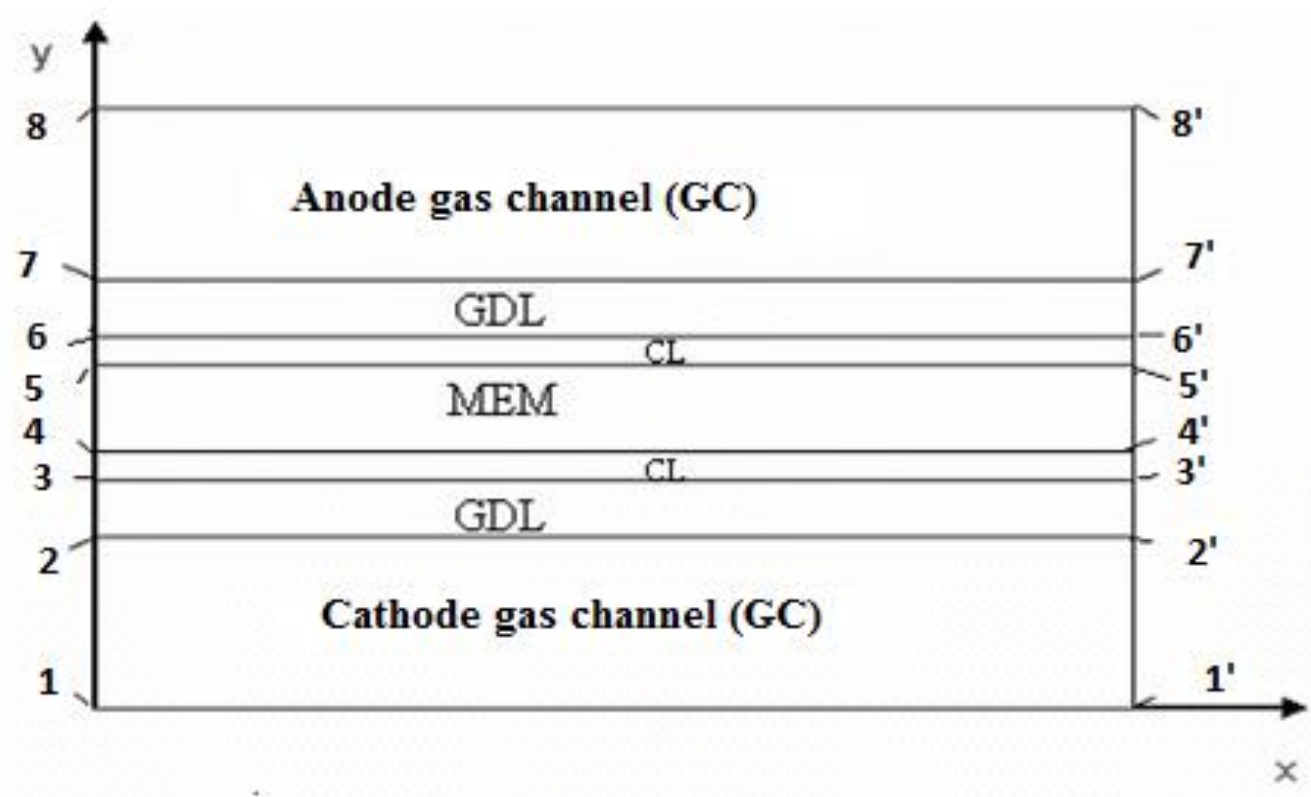

Figure 2.4 Schematic of the Computational Boundaries

\subsubsection{Boundary Conditions for Flow Field Model}

At the inlets of both flow channels (segments 12,78 in Fig. 2.4), the mass flow rates are demonstrated in related with a fully developed laminar flow profiles. The boundary values of the anode/cathode inlet velocities are prescribed from the stoichiometric flow rate and reactant concentration [77]:

$V_{a, \text { in }}=\zeta_{a} \frac{i_{\text {ref }}}{2 F c_{H_{2}}} \frac{A_{\text {react }}}{A_{a, \text { in }}}$ 
$V_{c, \text { in }}=\zeta_{c} \frac{i_{r e f}}{4 F c_{O_{2}}} \frac{A_{\text {react }}}{A_{c, \text { in }}}$

where $\zeta_{a}$ and $\zeta_{c}$ are the anode and cathode stoichiometric flow ratios, respectively, $i_{\text {ref }}$, and $A_{\text {react }}$ is the fully active MEA area. The pressures at both outlet flow channels (segments 7' 8', $1^{\prime} 2^{\prime}$ in Fig. 2.4) also need to be prescribed. All other boundaries (lines 8 8', 6 6', 3 3', $11^{\prime}$ ' and segments $67,6^{\prime} 7^{\prime}, 23,2^{\prime} 3^{\prime}$ in Fig. 2.4) use the no slip condition for the velocity.

Darcy's law is applied in the catalyst layers and gas diffusion layers, the operating pressures need to be imposed at the interfaces between the anode/cathode gas diffusers and gas channels, i.e., lines $77^{\prime}$ and $22^{\prime}$ in Fig. 2.4, respectively. Insulation condition is specified at boundary segments 36 and 3 '6' in Fig. 2.4.

\subsubsection{Boundary Conditions for Species Transport Model}

The Maxwell-Stephan equations are applied to describe the species transport in the whole fuel cell unit except the membrane. At the anode and cathode inlet gas channels (segments 7 8, 12 in Fig. 2.4), the mass fraction of $\mathrm{H}_{2}$ and $\mathrm{O}_{2}$ are prescribed using constant values; the mass fractions of water vapor at the anode and cathode sides are respectively calculated by the equations [77]:

$$
w_{\mathrm{H}_{2} \mathrm{O}, a}=R H \frac{p^{\text {sat }} M_{\mathrm{H}_{2} \mathrm{O}}}{p_{a} M}
$$

and

$$
w_{\mathrm{H}_{2} \mathrm{O}, \mathrm{c}}=R H \frac{p^{s a t} M_{\mathrm{H}_{2} \mathrm{O}}}{p_{c} M}
$$

where $R H$ is the relative humidity, $p_{a}$ and $p_{c}$ are the operating pressures at the anode and cathode sides; $p^{\text {sat }}$ is the saturated water partial pressure calculated using the following empirical equation [62]:

$\log _{10} p^{\text {sat }}=-2.1794+0.02953 T-9.1837 \times 10^{-5} T^{2}+1.4454 \times 10^{-7} T^{3}$

The outlet mass fractions are fully developed, i.e., the gradient of mass fraction of each specie is 
zero. Also, homogeneous Neumann boundary conditions apply along the gas channel walls (lines 1 1', 8 8' in Fig. 2.4) and along the interface between the catalyst layers and the membrane (lines 5 5', 4 4' in Fig. 2.4), representing the gas-impermeable condition in the membrane.

\subsubsection{Boundary Conditions for Energy Equations}

According to the cooling techniques, different boundary conditions can be used for the energy equation. In this research work, a constant temperature, i.e., the ambient temperature $T_{a m}$, is applied to the gas channel outer walls (lines $88^{\prime}, 11^{\prime}$ in Fig. 2.4).

At anode and at cathode gas inlet segment (segments12,78 in Fig. 2.4), convective flux conditions are employed as well as along the anode and at cathode gas outlets (segments 7'8', 1'2' in Fig. 2.4). Otherwise, the thermal insulation conditions are used for the boundary segments 27 and $2 ' 7^{\prime}$ in Fig. 2.4.

\subsubsection{Boundary Conditions for Water Transport in the Membrane}

Liquid water can enter the membrane from both sides of anode and cathode through the interfaces with the catalyst layers, hence, boundary conditions should be carefully set up along lines 44' and 55' in Fig. 2.4. An equilibrium is assumed in this research study, between the gas phase and liquid water phase in the membrane. Hence, the water content at the interface (lines 44', 55' in Fig. $2.4)$ is determined using [22]:

$$
\lambda=0.043+17.8 a-39.85 a^{2}+36 a^{3} \quad \text { for } \quad 0<a \leq 1
$$

where $a$ is the activity of water vapor defined as:

$$
a=\frac{x_{H_{2} O} p}{p^{s a t}}
$$

A linear relation is assumed between the water content and water activity when the water mole fraction exceeds saturation [22]:

$\lambda=14+1.4(a-1) \quad$ for $\quad 1<a \leq 3$

and, furthermore, the water content is assumed to be a constant [22]:

$\lambda=16.8 \quad$ for $\quad a>3$

The above calculated water content is used in conjunction with Eq. (2.48) to determine the 
concentration of water at the interfaces between the anode/cathode catalyst layers and the membrane. At the left and right boundary sides of the membrane (segments $45,4^{\prime} 5^{\prime}$ in Fig. 2.4), the Neumann boundary condition is used:

$$
\vec{n} \cdot \vec{\nabla} c_{w}=0
$$

where $\vec{n}$ denotes the unit vector normal to the boundaries.

\subsubsection{Boundary Conditions for Electron and Proton Transport Models}

Protons cannot go through the gas diffusion layer (GDL), thus the proton current density at the interface between the catalyst layer (CL) and the GDL is set to zero. Also, the electron current density at interface between the catalyst layers and the membrane is set to be zero since electrons cannot cross the membrane.

Therefore, the solid-phase potential equation is applied in the anode and cathode GDLs and in the catalyst layers. In the present model, the boundary conditions are assigned as: nil $\phi_{s}$ along the anode GDL edge (line 77' in Fig. 2.4); along the cathode GDL edge (line 22' in Fig. 2.4), the solidphase potential $\phi_{s}$ is the cell voltage; the Neumann boundary conditions are applied at the other side boundaries (lines 55', $44^{\prime}$ and segment 5 7, 5'7', 2 4, 2'4' in Fig. 2.4).

Similarly, membrane-phase potential boundary conditions are required at the edges of MEA, i.e : a zero value of proton potential is specified at the interface between the anode catalyst layer and membrane (line 6'6 in Fig. 2.4); Neumann boundary conditions are applied at the other side boundaries (line 3 '3 and segments 36, 3'6' in Fig. 2.4).

\subsubsection{Boundary Conditions for $y-z$ Plane}

A two dimensional model for a single PEM fuel cell is modeled in the $y-z$ plane. The model is consisting of seven computational sub-domains (from the top to the bottom as schematically shown 
in Figure 2.5): on the anode side, the collector plate, gas diffusion layer (GDLa) and catalyst layer $\left(\mathrm{CL}_{\mathrm{a}}\right)$; the ionomeric membrane; the catalyst layer $\left(\mathrm{CL}_{\mathrm{c}}\right)$, gas diffusion layer $\left(\mathrm{GDL}_{\mathrm{c}}\right)$, and collector plate on the cathode side.

For convenience, all boundaries in the model are named as \#1,\#1' etc. In the y-z plane, additional components, the current plate/current collectors, are involved in the two-dimensional model, while the anode/cathode gas channels may be extracted from the computational domains since the cross flow within the channels is insignificant.

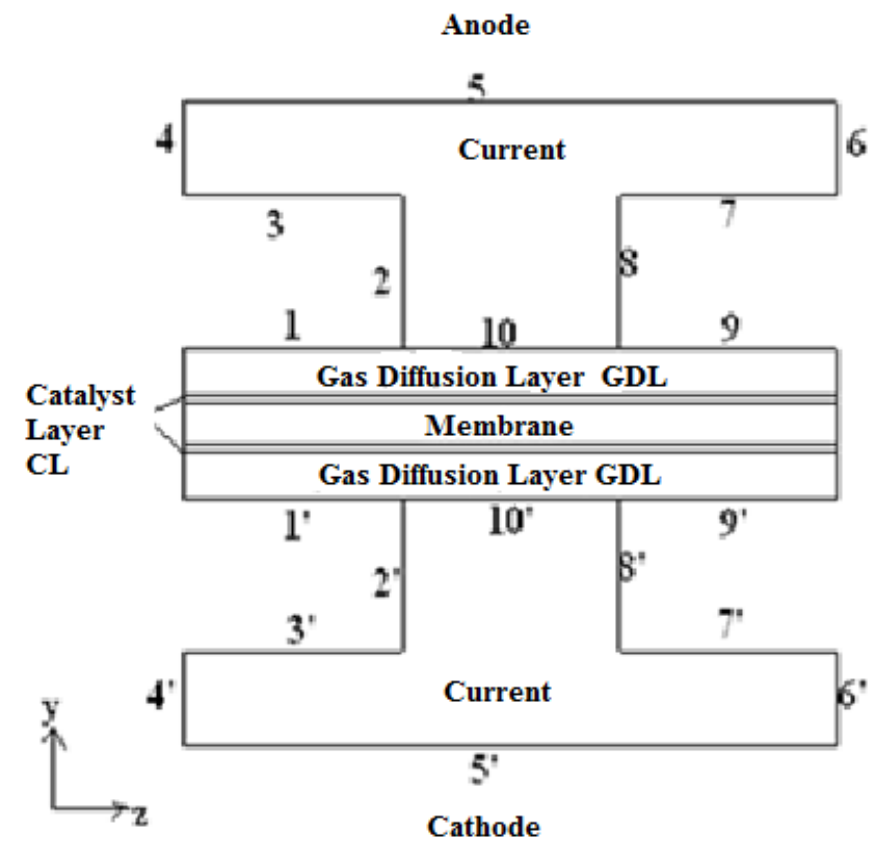

Figure 2.5 Schematic Diagram of Computation Model of a PEM Fuel Cell in y-z Plane.

\subsubsection{Darcy's Law}

Since gas diffusion layers (GDLs), catalyst layers (CLs) and the membrane domains are porous structure, Darcy's law can be apply within these entire domains. The pressure boundary values are prescribed at the operating pressures for the interfaces between the gas channels and GDLs for both anode and cathode sides. That is:

For Boundaries \#1, \#9: $\quad p=p_{a}$ 
For Boundaries \#1', \#9', $\quad p=p_{c}$

where $\mathrm{p}$ is the local pressure, $p_{a}$ and $p_{c}$ are the operating pressures at the anode and cathode sides, respectively. For both anode and cathode sides, insulation condition are specified at the interfaces between the GDLs and collector plate as well as at the inlet and outlet for both GDLs and catalyst layers CLs.

\subsubsection{Species Equations}

To describe the species transport in the gas diffusion layers (GDLs) and catalyst layers; the Maxwell-Stephan equations are applied. At the anodic and cathodic interfaces between the gas channels and GDLs, i.e., boundaries \#1,\#1',\#9, and \#9' (as shown in Figure 2.5), each of the mass fractions of $\mathrm{H}_{2}, \mathrm{O}_{2}$ is prescribed using a constant inlet value. The mass fractions of water vapor at the anode and cathode sides can determine as follow respectively:

$$
\begin{gathered}
w_{\mathrm{H}_{2} \mathrm{O}, \mathrm{a}}=R H \frac{p^{\text {sat }} M_{\mathrm{H}_{2} \mathrm{O}}}{p_{a} M} \\
w_{\mathrm{H}_{2} \mathrm{O}, \mathrm{c}}=R H \frac{p^{\text {sat }} M_{\mathrm{H}_{2} \mathrm{O}}}{p_{c} M}
\end{gathered}
$$

where $R H$ is the relative humidity, $p_{a}$ and $p_{c}$ are the operating pressures at the anode and cathode sides; $p^{\text {sat }}$ is the saturated water partial pressure calculated using the following empirical equation [22]:

$\log _{10} p^{\text {sat }}=-2.1794+0.02953 T-9.1837 \times 10^{-5} T^{2}+1.4454 \times 10^{-7} T^{3}$

A convective flux boundary condition was specified for the oxygen mass fraction equation, at the interface between the cathode catalyst layer and the membrane to keep the oxygen from entering the membrane. As well, a convective flux boundary condition was applied at the interface between the anode catalyst layer and the membrane to prevent hydrogen from entering the membrane. 


\subsubsection{Solid-Phase Potential Equation}

Neumann and Dirichlet boundary conditions are used to solve the electronic and protonic potential equations. The solid-phase potential equation is applied in the anode and cathode GDLs and catalyst layers and to account for electron transport in current plates as well. The solid-phase

potential $\phi_{s}$ is the cell voltage; the value of solid-phase potential along the cathode collector plate edge, i.e., Boundary \#5', is prescribed while the value of the cell voltage along the anode current plate edge, i.e., Boundary \#5, is assumed to be zero. To represent that no electron current passes through the boundaries, i.e, Boundaries \#1, \#2, \#3, \#4, \#6, \#7, \#8, \#9 and Boundaries \#1', \#2', \#3', $\# 4$ ', \#6', \#7', \#8', \#9'; Homogeneous Neumann boundary conditions are applied at these boundaries.

\subsubsection{Energy Equations}

In this model, a constant temperature, i.e., the ambient temperature $T_{\text {atm }}$ is applied to the interface between the collector plate and gas diffusion layers at the anode and cathode side, i.e., boundaries $\# 10$, and \#10'. The value of temperature along the boundaries \#1, \#9 and \#1', \#9', at anode and cathode side respectively are prescribed; noting that the temperature is higher at cathode than anode side; as well as, it's higher at boundaries \#1' , \#9' than boundaries \#1, \#9 and. Convective flux conditions are employed at the inlet and outlet of MEA. Otherwise, the thermal insulation conditions are used.

\subsubsection{Boundary Conditions for Water and Proton Transport Model}

\subsection{Proton Transport}

Proton transport through proton-conductive polymer membrane only; thus the proton current density at the interface between the catalyst layers and the GDL is set zero, as protons cannot go along the gas diffusion layer. Dirichlet boundary conditions are used to solve the protonic potential equations at the interface between the membrane and catalyst layers at anode and cathode sides. Elsewhere; homogeneous Neumann boundary conditions are applied.

\subsection{Water Transport in the Membrane}

In this model; equilibrium is assumed between the gas phase and the liquid water phase in the Nafion membrane. As the water can be transported through the catalyst layers to the membrane; 
Dirichlet boundary conditions should be applied at the interface between the membrane and the catalyst layers at the anode and cathode sides. And the water content at these interfaces can be calculated using [22]:

$\lambda=0.043+17.8 a-39.85 a^{2}+36 a^{3}$ for $\quad 0<a \leq 1$ in catalyst layers

where a is the activity of water vapor defined as:

$$
a=\frac{x_{H_{2} O} p}{p^{\text {sat }}}
$$

A linear relation is assumed between the water content and water activity when water mole fraction exceeds saturation, [22]:

$\lambda=14+1.4(a-1)$ for $1<a \leq 3 \quad$ in the membrane

the Neumann boundary condition is applied at the left and right sides of the membrane:

$$
\vec{n} \cdot \vec{\nabla} c_{w}=0
$$

where $\vec{n}$ denotes the unit vector normal to the boundaries.

\subsection{Modeling Parameters}

Choosing the right modeling parameters is very important and it is difficult in establishing the fully PEM fuel cell computational model for numerical simulation. A very limited experimental results are available in the literature with detailed specification of the cell geometry and experimental conditions. Most of the physical parameters present here and for base case operation conditions are taken from the modeling work of Gurau et al. [29] other available original references are quoted when employed.

The basic physical dimensions of the computational domain are shown in Table 2.1. Only half length of a PEM fuel cell unit is taken due to the limitation of available computation devices. All values in Table 2.1 refer to both anode and cathode sides. Table 2.2 lists the base case operational parameters for the current model. Operational parameters have great effects on fuel cell performance and parametric studies will be performed and discussed in details in chapter three. 
Table 2.1: Physical Dimension of the PEM Fuel Cell [29]

\begin{tabular}{|l|l|l|}
\hline PARAMETER & VALUE & UNIT \\
\hline Gas channel length (half) (x-direction) & 0.025 & $\mathrm{~m}$ \\
\hline Gas channel height (y-direction) & $8.0 \times 10^{-4}$ & $\mathrm{~m}$ \\
\hline Gas channel width (z-direction) & $10 \times 10^{-4}$ & $\mathrm{~m}$ \\
\hline Gas diffuser height (y-direction) & $2.0 \times 10^{-4}$ & $\mathrm{~m}$ \\
\hline Catalyst layer thickness & $0.3 \times 10^{-4}$ & $\mathrm{~m}$ \\
\hline Membrane thickness (y-direction) & $2.3 \times 10^{-4}$ & $\mathrm{~m}$ \\
\hline Collector width & $1.3 \times 10^{-3}$ & $\mathrm{~m}$ \\
\hline
\end{tabular}

Table 2.2: Operating Parameters for a PEM Fuel Cell under a Base Case Computation, [29].

\begin{tabular}{||l|l|c|}
\hline DESCRIPTION & VALUE & UNIT \\
\hline$T:$ fuel cell (ambient) temperature & 333 & $\mathrm{~K}$ \\
\hline$\zeta_{a}:$ stoichiometric ratio at anode & 1.3 & - \\
\hline$\zeta_{c}:$ stoichiometric ratio at cathode & 3 & - \\
\hline$p_{a}:$ fuel inlet pressure at anode & 1 & $\mathrm{~atm}$ \\
\hline$p_{c}:$ air inlet pressure at cathode & 3 & $\mathrm{~atm}$ \\
\hline$R H:$ relative humidity of inlet gas mixture & 100 & $\%$ \\
\hline
\end{tabular}

The properties for the membrane are required to model various transport phenomena across the membrane. A proper choice of membrane properties will directly improve the accuracy of the modeling work; Table 2.3 lists the electrode and membrane properties for the base case. And, Table 2.4 groups the electrochemical parameters chosen for this modeling study. 
Table 2.3: Electrode and Membrane Properties

\begin{tabular}{|l|l|l|l|}
\hline DESCRIPTION & VALUE & UNIT & REF. \\
\hline \hline$\varepsilon_{g}:$ gas diffuser porosity & 0.17 & - & {$[29]$} \\
\hline$\varepsilon_{m}:$ membrane porosity & 0.17 & - & {$[29]$} \\
\hline$\theta_{m c}:$ volume fraction membrane in catalyst layer & 0.2 & - & {$[29]$} \\
\hline$k_{p}:$ permeability to air in the gas diffuser & $1.76 \times 10^{-11}$ & $\mathrm{~m}^{2}$ & {$[29]$} \\
\hline$k_{h}:$ hydraulic permeability of the membrane & $1.58 \times 10^{-18}$ & $\mathrm{~m}^{2}$ & {$[29]$} \\
\hline$k_{\Phi}:$ electrokinetic permeability of membrane & $1.13 \times 10^{-19}$ & $\mathrm{~m}^{2}$ & {$[29]$} \\
\hline$k_{\text {air }}:$ air thermal conductivity & $3.0 \times 10^{-2}$ & $\mathrm{~W} / \mathrm{m} / \mathrm{K}$ & {$[29]$} \\
\hline$k_{g r}:$ thermal conduc. of matrix of gas diffuser & 150.6 & $\mathrm{~W} / \mathrm{m} / \mathrm{K}$ & {$[29]$} \\
\hline$k_{m, d r y}:$ thermal conductivity of dry membrane & 100 & $\mathrm{~W} / \mathrm{m} / \mathrm{K}$ & {$[29]$} \\
\hline$c_{p, a i r}:$ air specific heat at constant pressure & 1008 & $\mathrm{~J} / \mathrm{kg} / \mathrm{K}$ & {$[29]$} \\
\hline$c_{f}:$ fixed charged site concentration in memb. & $1.2 \times 10^{3}$ & $\mathrm{~mol} / \mathrm{m}^{3}$ & {$[29]$} \\
\hline$z_{f}:$ charge of sulfonate site in memb. & -1 & - & {$[29]$} \\
\hline$\rho_{m}^{\text {dry }}:$ membrane solid dry mass density & 1980 & $\mathrm{~kg} / \mathrm{m}^{3}$ & {$[29]$} \\
\hline$E W_{m}:$ equivalent membrane weight & 1.1 & $\mathrm{~kg} / \mathrm{mol}$ & {$[22]$} \\
\hline$f:$ membrane swelling coefficient & 0.0126 & - & {$[22]$} \\
\hline \hline
\end{tabular}

Table 2.5 listed the values of binary diffusivities involved in Maxwell-Stephan equations (2.21). These values are determined experimentally under the specific reference temperature at $1 \mathrm{~atm}$ pressure and the testing conditions should be converted to actual operating conditions used in this study by conversion Eq. (2.22). 
Table 2.4: Electrochemical Properties of a PEM Fuel Cell

\begin{tabular}{|l|l|l|l|}
\hline \multicolumn{1}{|c|}{ DESCRIPTION } & VALUE & UNIT & REF. \\
\hline \hline$a j_{0, a}^{\text {ref }}:$ reference exchange current density & $1.0 \times 10^{9}$ & $\mathrm{~A} / \mathrm{m}^{3}$ & {$[46]$} \\
\hline$a j_{0, a}^{r e f}:$ reference exchange current density & $2.5 \times 10^{3}$ & $\mathrm{~A} / \mathrm{m}^{3}$ & {$[46]$} \\
\hline$c_{H_{2}, \text { ref }}: H_{2}$ reference molar concentration & 40.88 & $\mathrm{~mol} / \mathrm{m}^{3}$ & {$[46]$} \\
\hline$c_{O_{2}, \text { ref }}: O_{2}$ reference molar concentration & 40.88 & $\mathrm{~mol} / \mathrm{m}^{3}$ & {$[46]$} \\
\hline$\alpha_{a}^{c}:$ anodic transfer coefficient at cathode & 0 & - & {$[46]$} \\
\hline$\alpha_{c}^{c}:$ cathodic transfer coefficient at cathode & 1.2 & - & {$[29]$} \\
\hline$\alpha_{c}^{a}:$ cathodic transfer coefficient at anode & $1 / 2$ & - & {$[29]$} \\
\hline$\alpha_{a}^{a}:$ anodic transfer coefficient at anode & $1 / 2$ & - & {$[29]$} \\
\hline
\end{tabular}

Table 2.5: Binary diffusivities at 1atm and Reference Temperatures [32]

\begin{tabular}{|l|c|c|}
\hline GAS & REFERENCE TEMPERATURE & BINARY \\
PAIR & $T_{0}[\mathrm{~K}]$ & $\begin{array}{c}\text { DIFFUSIVITY } \\
D_{i j}\left(\mathrm{~m}^{-2}\right)\end{array}$ \\
\hline \hline$D_{\mathrm{H}_{2}-\mathrm{H}_{2} \mathrm{O}}^{0}$ & 307.1 & $9.15 \times 10^{-5}$ \\
\hline$D_{\mathrm{H}_{2}-\mathrm{CO}_{2}}^{0}$ & 298.0 & $6.46 \times 10^{-5}$ \\
\hline$D_{\mathrm{H}_{2} \mathrm{O}-\mathrm{CO}_{2}}^{0}$ & 307.5 & $2.02 \times 10^{-5}$ \\
\hline$D_{\mathrm{O}_{2}-\mathrm{H}_{2} \mathrm{O}}^{0}$ & 308.1 & $2.8 \times 10^{-5}$ \\
\hline$D_{\mathrm{O}_{2}-\mathrm{N}_{2}}^{0}$ & 293.2 & $2.2 \times 10^{-5}$ \\
\hline$D_{\mathrm{H}_{2} \mathrm{O}-\mathrm{N}_{2}}^{0}$ & 307.5 & $2.56 \times 10^{-5}$ \\
\hline
\end{tabular}

\subsection{Numerical Solution Technique}

The PEM fuel cell modeling equations describing fluid flow, multi-species transport, heat transfer, and electric potentials are strongly nonlinear and coupled with each other. To numerically solve this large set of nonlinear equations, a commercial finite element computational fluid dynamics package, (COMSOL) was used for the implementation of all transport phenomena in the model. 
Some physics application modules in COMSOL Multiphysics along with the PDE-application mode and COMSOL Chemical Engineering Module are also employed in different computational subdomains. In this study, the coupled set of equations was computed iteratively until the relative error in each field variable achieved $1 \times 10^{-6}$.

The COMSOL software offers good and flexible mesh technique. For the current 2D geometry, a mesh with purely conventional unstructured triangular elements was chosen. The rectangular physical domain is divided into a uniform grid in direction of flow ( $\mathrm{x}$ and $\mathrm{z}$-directions). Along the y-direction, as different domains have dramatically varying sizes, the element sizes have to be changed accordingly.

In finite element analyses, it is often necessary to resolve the geometry in more detail for more accuracy, thus, a locally refined mesh was employed. The numerical results for base case geometry showed that there is no significant difference in the result between the three refined meshes that shown in Table 2.6, thus the refine mesh 1 has been chosen for $\mathrm{x}-\mathrm{y}$ and $\mathrm{y}-\mathrm{z}$ planes respectively. Therefore, a finer mesh is not needed to improve numerical accuracy. In the current simulation, the total number of elements shown in Figure 2.6 is 17494 and 13,264 for $\mathrm{x}-\mathrm{y}$ and $\mathrm{y}-\mathrm{z}$ planes respectively, and the total associated degrees of freedom are 224427 and 106,135 for $x-y$ and $y-z$ planes respectively. In this simulation, a stationary non-linear COMSOL solver is used in connection with the Direct (UMFPACK) linear system solver.

Table 2.6: Mesh Size Sensitivity

\begin{tabular}{|c|c|c|c|c|}
\hline Mesh Types & $\begin{array}{l}\text { Number of } \\
\text { elements }\end{array}$ & $\begin{array}{l}\text { Current density } \\
\left(\mathrm{A} / \mathrm{cm}^{2}\right)\end{array}$ & $\begin{array}{l}\text { Oxygen mole } \\
\text { fraction }\end{array}$ & $\begin{array}{l}\text { Hydrogen mole } \\
\text { fraction }\end{array}$ \\
\hline \multicolumn{5}{|c|}{$(x-y)$ plane } \\
\hline Refine mesh 1 & 17494 & 0.1341 & $0.0962 \min -0.131 \max$ & $0.659 \min -0.669 \max$ \\
\hline Refine mesh 2 & 52599 & 0.1342 & $0.0963 \min -0.131 \mathrm{max}$ & $0.659 \mathrm{~min}-0.669 \mathrm{max}$ \\
\hline Refine mesh 3 & 69976 & 0.1343 & $0.0964 \min -0.131 \max$ & $0.658 \min -0.669 \max$ \\
\hline \multicolumn{5}{|c|}{$(y-z)$ plane } \\
\hline Refine mesh 1 & 13264 & 0.2015 & $0.0476 \mathrm{~min}-0.123 \mathrm{max}$ & $0.400 \min -0.419 \max$ \\
\hline Refine mesh 2 & 53056 & 0.2014 & $0.0476 \min -0.123 \max$ & $0.399 \min -0.419 \max$ \\
\hline Refine mesh 3 & 212224 & 0.2012 & $0.0475 \min -0.123 \max$ & $0.399 \min -0.419 \max$ \\
\hline
\end{tabular}


To overcome the limitation of the computer memory, the entire set of governing equations cannot be solved simultaneously, thus a properly designed iteration strategy is employed in this numerical solution. The flow charts of the computation procedure are shown in Figures (2.7 and 2.8) for $x-y$ and y-z planes respectively, which are designed in a Gauss-Seidel method to ensure an efficient decoupling of the flow, potentials, energy, species transport and potentials from each other in the course of computation. Overall, theses algorithms feature predicting the cell current density distribution (output) from a specified cell operating voltage value (input), which are completely different from the current-to-voltage strategy that inevitably depends on the artificially averaged current value as well as some formulae of empirical nature for cell voltage calculation. 

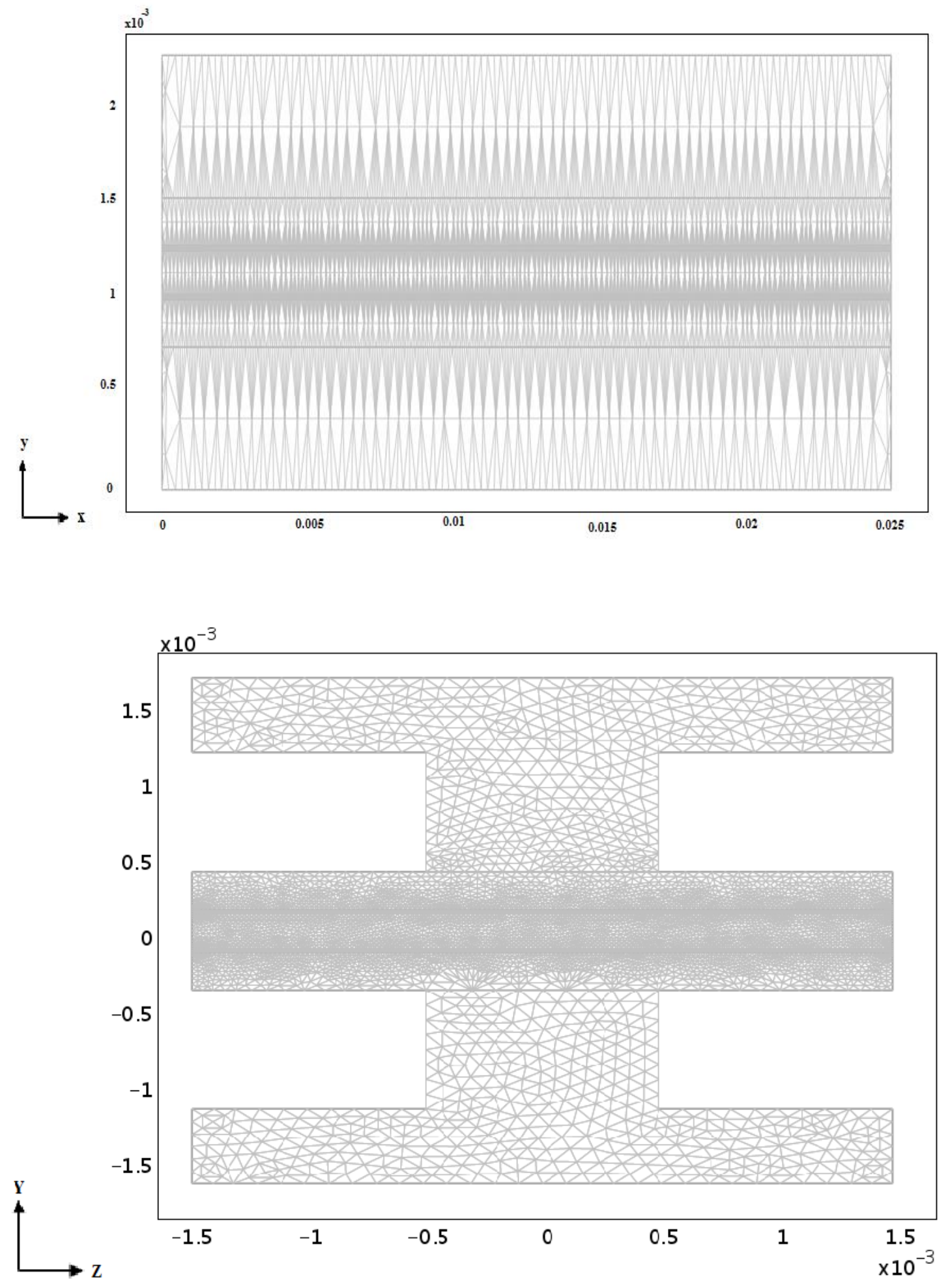

Figure 2.6 Mesh of the Computational Domain for $x-y$ Plane on Top and y-z Plane on the Bottom 


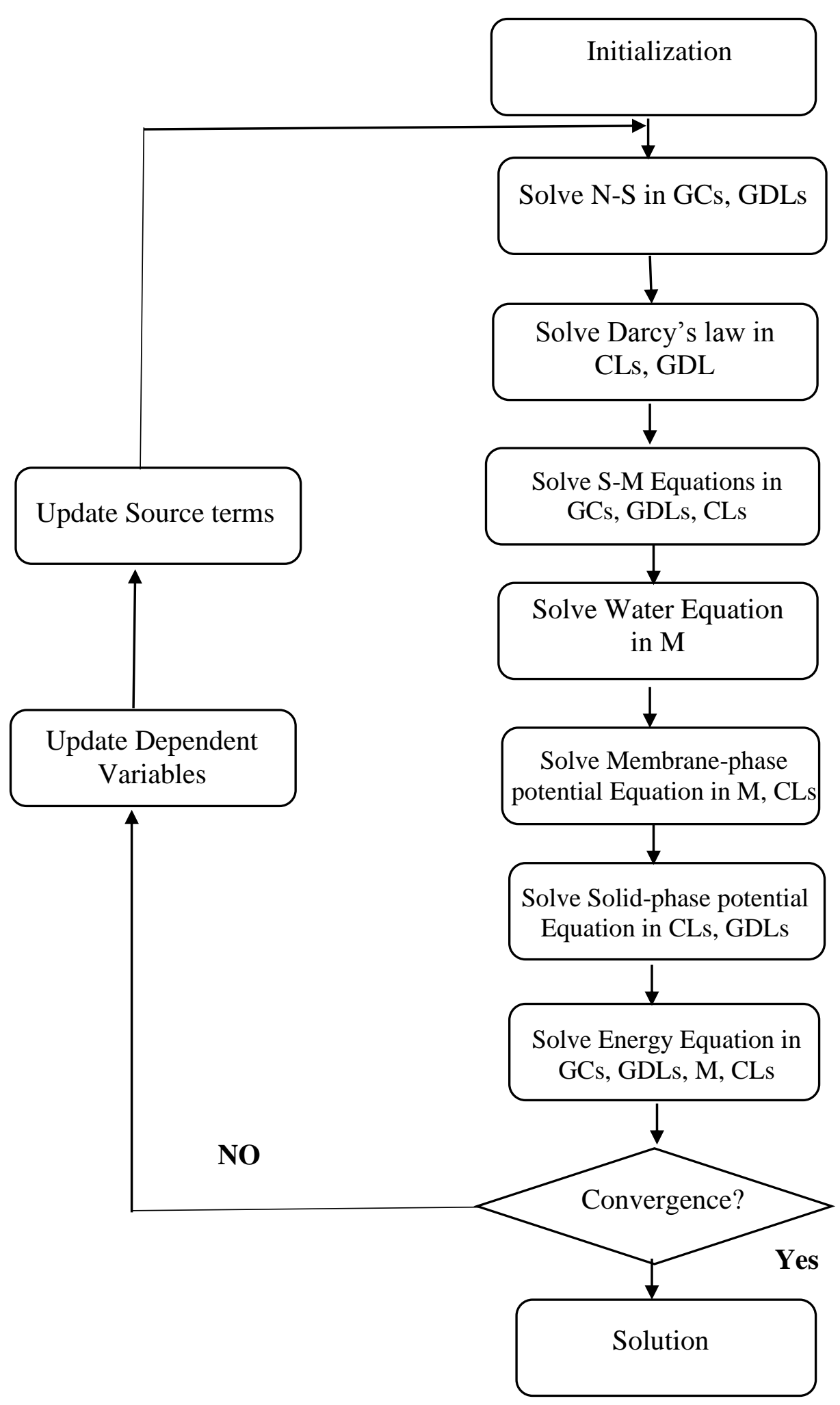

Figure 2.7 Flow Chart of the Solution Procedure for x-y Plane 


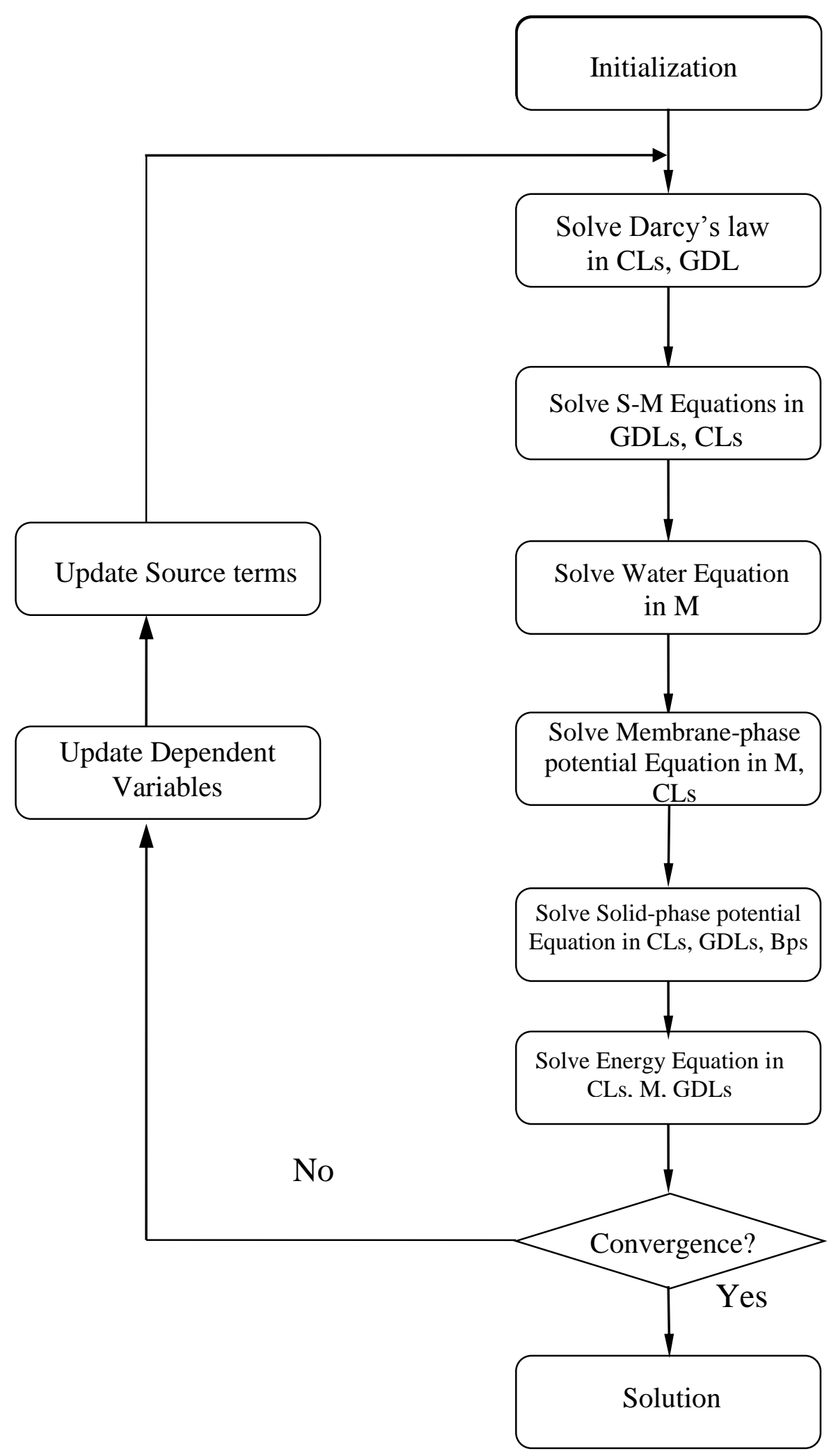

Figure 2.8 Flow Chart of the Solution Procedure for y-z Plane 


\section{Chapter 3 \\ Base Case Results for $x-y$ and $y-z$ Planes}

\subsection{Model Validation}

To validate the model established in this study, comparisons have to be made between the simulation results corresponding to the base case conditions (Table 2.2) and the experimental data obtained by [63]; where, the output is the polarization curve, i.e., cell voltage vs. current density curves. Polarization curves are highly related to the distributions of the each species in a PEM fuel cell and also can be measured directly and accurately through experiments.

Corresponding to the base case conditions with the experimental data a good agreement is seen between the two sets of results throughout the current density ranges observed as shown form Figure 3.1, for both planes: $x-y$ and $y-z$. For $x-y$ plane that shown in Figure 3.1a, the activation region $0 \leq|\vec{i}| \leq 0.2 \mathrm{~A} / \mathrm{cm}^{2}$ ), a slight nonlinearity can be observed in this region as the slope of the polarization curve looks steeper. The region $\left(0.2 \mathrm{~A} / \mathrm{cm}^{2} \leq|\vec{i}| \leq 0.6 \mathrm{~A} / \mathrm{cm}^{2}\right)$ is this case the ohmic loss region where the current density increases and the cell voltages drops clearly in a linear fashion. For the mass transport limited region $\left(|\vec{i}|>0.6 \mathrm{~A} / \mathrm{cm}^{2}\right.$ in this case), where higher current densities, no linear relationship persists due to the fact that the stronger electrochemical reaction is a response to a higher current density will consume approximately all oxygen that has migrated to the reaction site, leading to a limitation of cell voltage output thus the steep drop of the cell voltage in this region can be demonstrated.

Apart from polarization curve, the evolution of the power density, which is product of cell voltage and current density, along with varying current density is another commonly used curve in fuel cell technology. The curve of power density vs. current density is plotted in Figure 3.2, for x-y plane. Figure 3.2 illustrates the maximum power density that the cell can reach. 
(a)

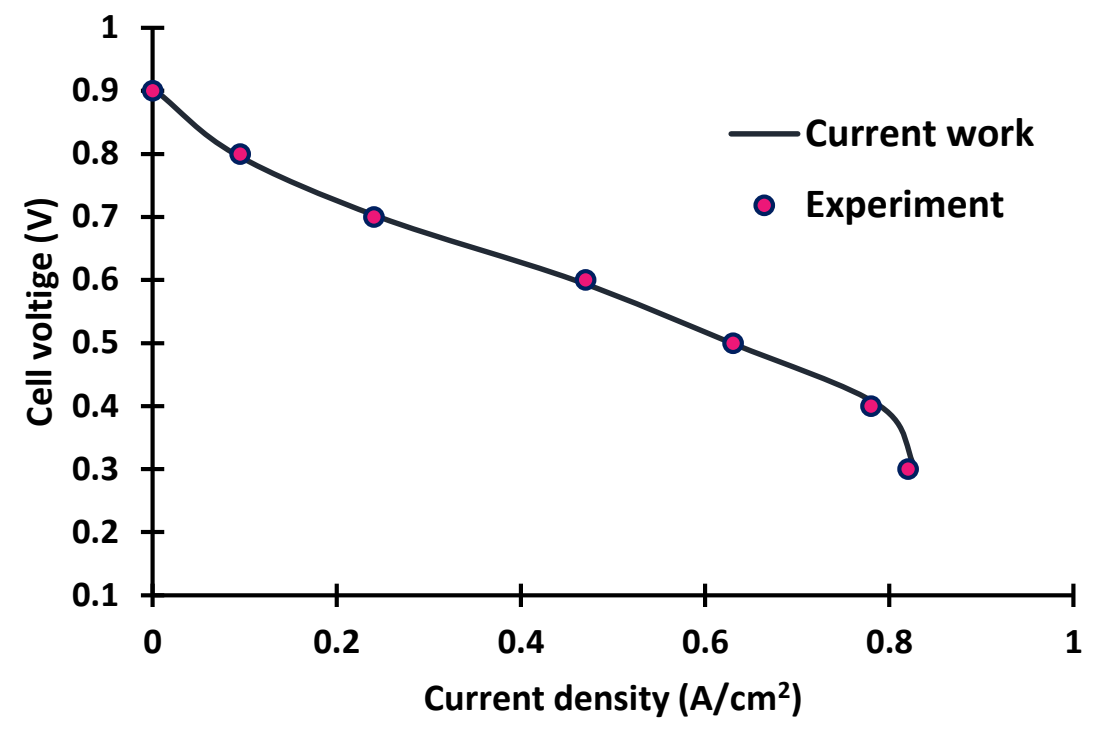

(b)

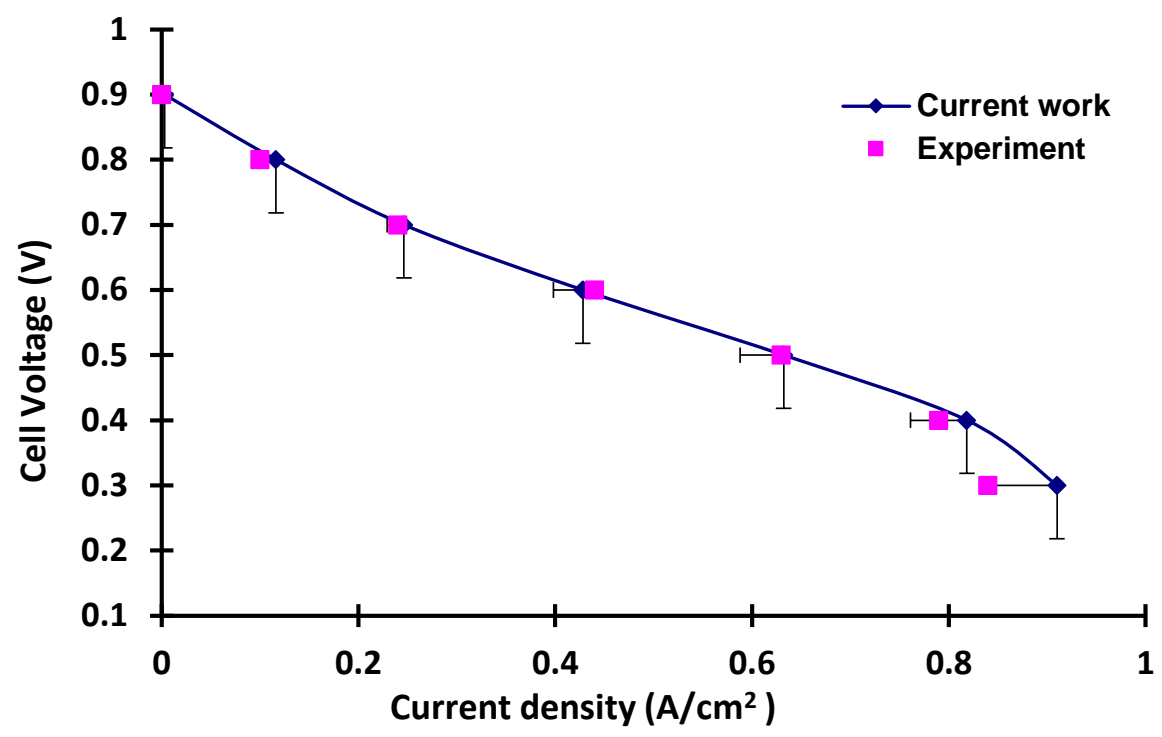

Figure 3.1 Comparison of Modeling Results for (a) x-y and (b) y-z Plans with Average Experimental Data by Ju and Wang [63] 
The maximum power density may be obtained at either a lower current and a higher potential or a higher current density and a lower potential as the power density is product of cell voltage and current density.

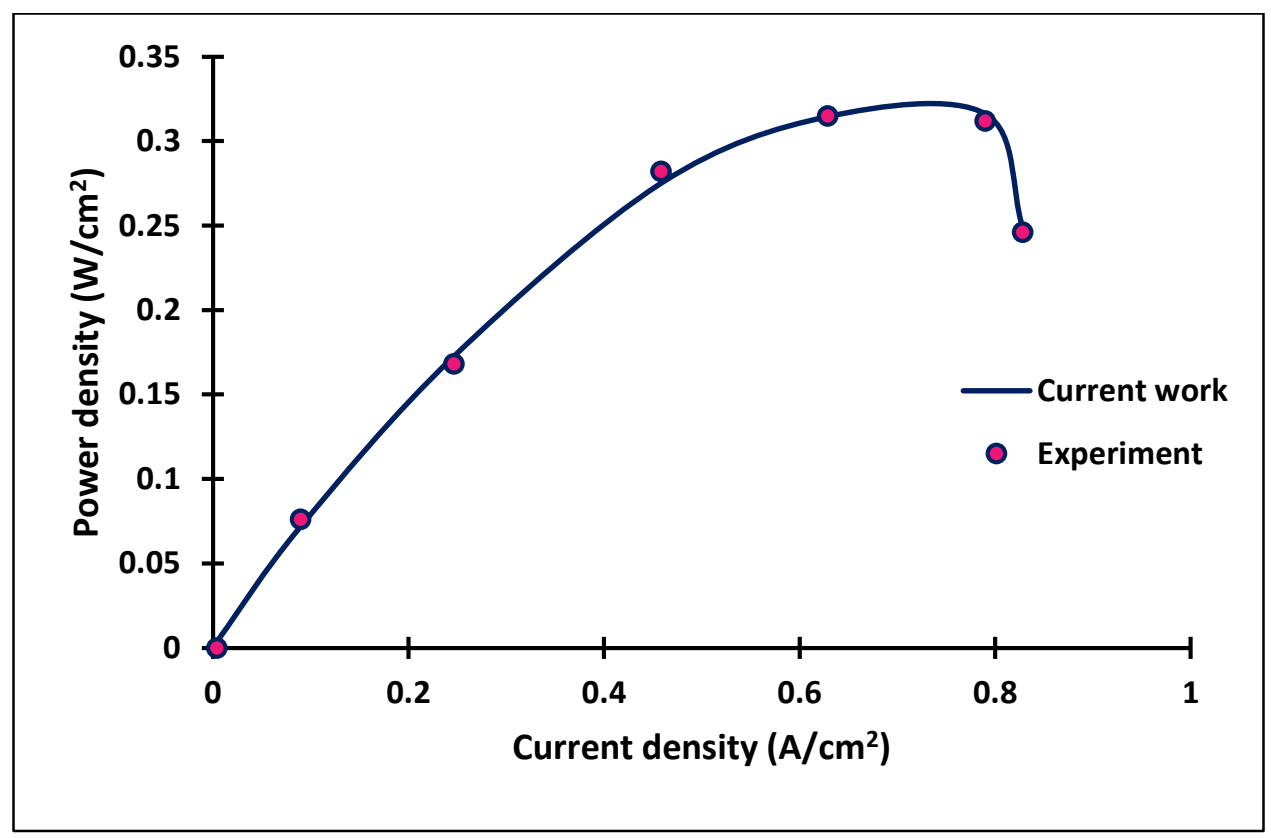

Figure3.2 Power Curve Resulting from the Fuel Cell Polarization Curve

As shown in Figure. 3.1b for y-z plane, the slope of the polarization curve is steeper and exhibits slight nonlinearity in the range of $0 \leq|\vec{i}| \leq 0.2 \mathrm{~A} / \mathrm{cm}^{2}$, which represents the activation region. Then, the two sets of results have a good agreement at intermediate current densities $0.2 \mathrm{~A} / \mathrm{cm}^{2} \leq|\vec{i}| \leq 0.6 \mathrm{~A} / \mathrm{cm}^{2}$, showing the cell voltage drops clearly in a linear trend as the current density increases within this ohmic loss region. However, due to lack of an established mathematical model to accurately quantify the effect of mass transport losses, a noticeable discrepancy is found for high current densities $\left(|\vec{i}| \geq 0.6 \mathrm{~A} / \mathrm{cm}^{2}\right)$, however the error bars represent that the difference in the current densities between the current model and the experimental model 
is within $7 \%$ only . This is due to the increased of strength of electrochemical reaction in response to the desired higher current density. Under such a circumstance, the available oxygen that has migrated to the reaction site cannot afford a fully effective electrochemical reaction, causing a limitation of cell voltage output. Thus, the model is unable to replicate the experimental data at high current densities. Another reason that may lead to the discrepancy between the simulation results and the experimental results for the present $y-z$ model is two dimensional while the experiment is of three dimensional natures. As of today, most of existing fuel cell models underestimate the mass-transport limitation. The limiting current density effect can be practically observed in the numerical results by examining the starting point of a new steeper drop of cell voltage following the generally linear ohmic loss region. As shown in Figure 3.1b, the limiting current density captured from the simulation results is about $0.8 \mathrm{~A} / \mathrm{cm}^{2}$, which is in fairly good agreement with the finding through experiments. In spite of this discrepancy related to the limiting current density, the $y-z$ plane model can efficiently predict the overall performance of an operational fuel cell under its normal working conditions.

The results obtained from the present computer model and experiments in the literature for the $y$ z plane are plotted in Figure 3.3 and it shows good agreement between the two sets of results persists up to a current density of $0.6 \mathrm{~A} / \mathrm{cm}^{2}$. For high current densities $\left(|\vec{i}| \geq 0.6 \mathrm{~A} / \mathrm{cm}^{2}\right)$, increasing discrepancy is observed. This is again due to the concentration losses caused by the reactant transport limitation in the region near and beyond the limiting current density. The power curve resulting from the fuel cell model helps identify the limiting current density. The error bars in Figure 3.3 and plotted by using Excel, indicate that the difference in the current densities between the current model and the experiment data is not exceeding 9\%. Also, Figure 3.3 for $y-z$ 
plane shows that there is a maximum power density $\left(0.32 \mathrm{~W} / \mathrm{cm}^{2}\right)$ when employing a fuel cell. Hence, it does not make sense to pursue the operation of fuel cell beyond its maximum power point; instead, optimal fuel cell performance takes place at a combination of a lower current and a higher cell voltage.

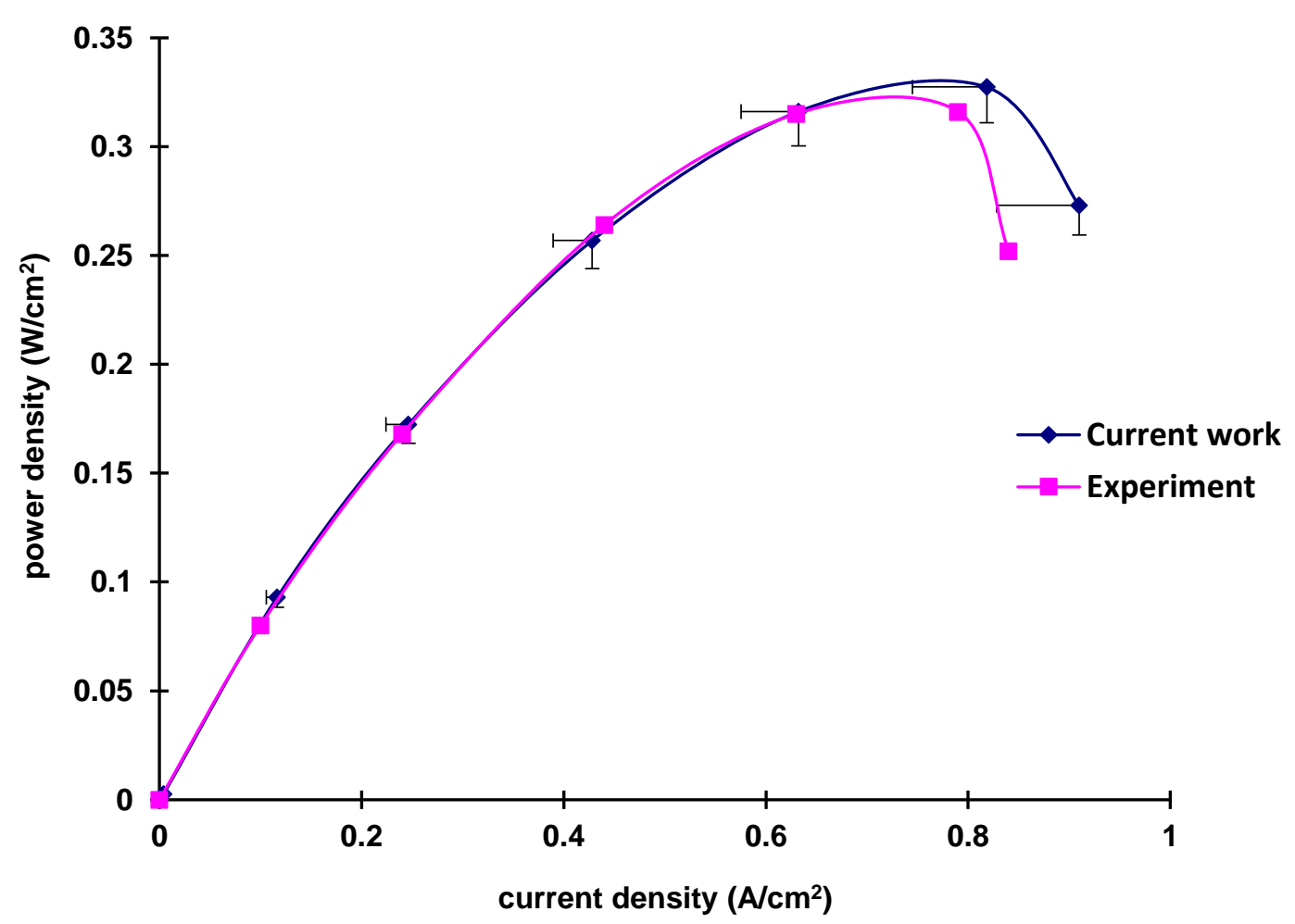

Figure 3.3 Power Curve Resulting from the Fuel Cell Polarization Curve.

\subsection{Base Case Study for $x-y$ and $y-z$ Planes}

The objective of the study is to develop a mathematical model in the $x-y$ and $y-z$ planes (refer to Figure2.2 for the coordinate system employed throughout this study) for PEM fuel cells designs so as to evaluate the cell performances corresponding to both plane. This will allow for discussions of the numerical results obtained here in the $\mathrm{x}-\mathrm{y}$ plane in conjunction with those obtained in the $\mathrm{y}-$ 
$\mathrm{z}$ plane. The numerical simulation employs fuel cell operational conditions that corresponds to the base case operational conditions as described in Table 2.3. Numerical results, including the distributions of mole fractions of reactant gases, temperature, various potentials, and water concentration in membrane, will be examined in the subsequent sections.

\subsubsection{Flow Structures}

Figure 3.4 illustrates two-dimensional flow fields in the $x-y$ plane (top) and y-z plane (bottom) for conventional flow channel patterns. Figure 3.4 for $(x-y)$ plane (top) illustrates the fluid flow behavior in the gas channels and GDLs at both anode and cathode sides. It can be noticed that the velocity is highest in the gas channels for $\mathrm{x}-\mathrm{y}$ plane, in the GDL the velocities are generally low. A fully developed field is observed in the channels and keeps a laminar pattern till the end of channel. In this case, the Reynold Number, $R e$, in the channel is around 10 only, where the channel height is employed as the characteristic length.

Figure 3.4 depicts the flow fields in the anode/cathode GDLs for $y-z$ plane (bottom). It can be clearly observed that the y-direction velocity components are smaller than those in the z-direction. This forced convection mechanism in the GDLs enhances the mass transport near the reaction surface and thus improves the cell performance as shown in subsequent sections. 

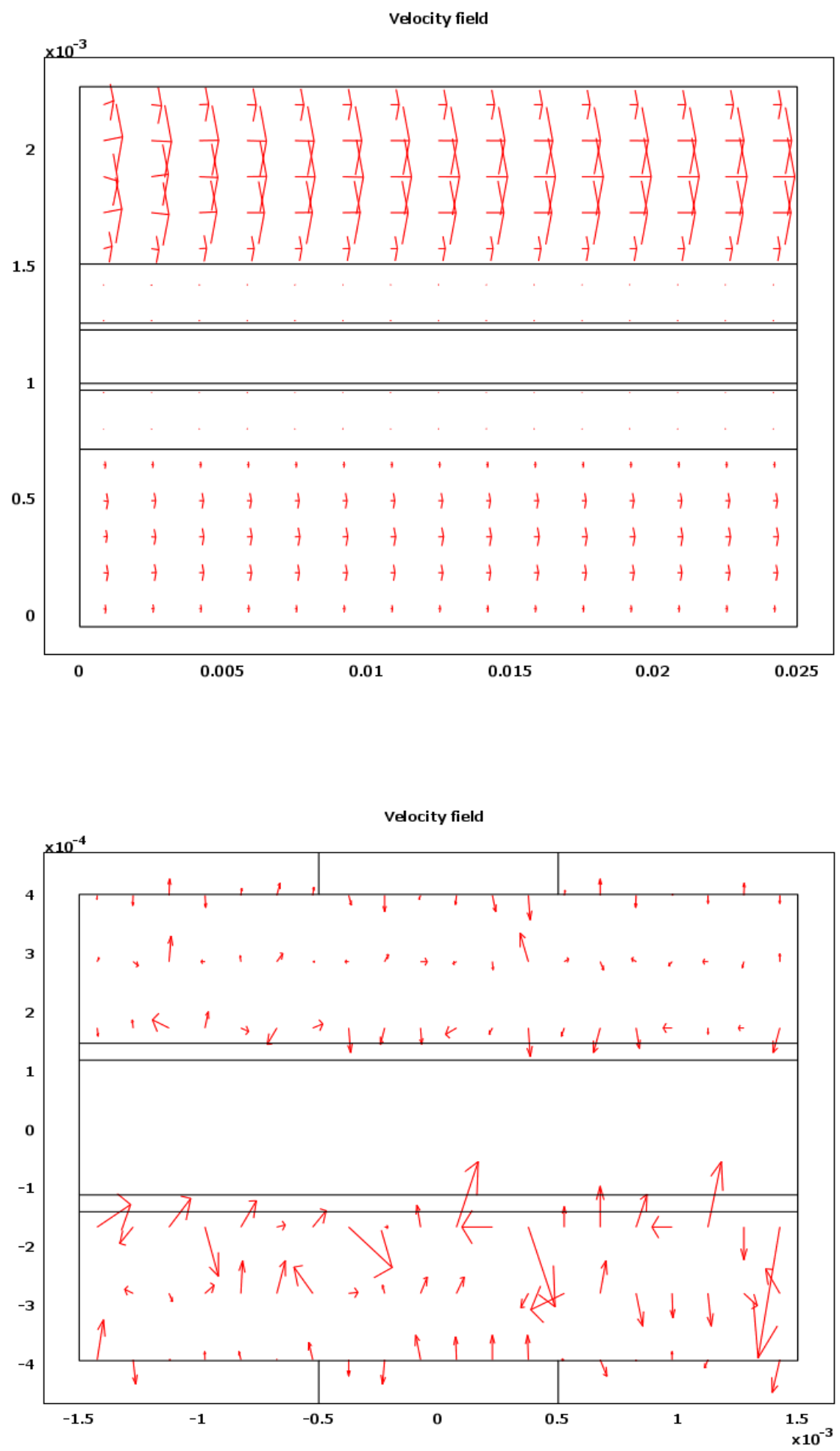

Figure 3.4 Velocity Distribution in the PEM Fuel Cells for x-y Plane (Top) and y-z Plane (Bottom) 


\subsubsection{Distribution of Reactants and Products}

Figure 3.5 - Figure 3.8 illustrate the oxygen mole fraction, water vapour mole fraction distribution at the cathode side, hydrogen mole fraction and water vapour mole fraction distribution at the anode side respectively, at $0.7 \mathrm{~V}$ cell voltage for the $\mathrm{x}-\mathrm{y}$ plane (top) and $\mathrm{y}-\mathrm{z}$ plane (bottom) for PEM fuel cells. In the $x-y$ plane the resulting oxygen and hydrogen distribution can be shown on the top of Figures 3.5 and 3.7, which are very different from the case of the y-z plane that shown on the bottom of Figures 3.5 and 3.7. A higher oxygen and hydrogen concentration is observed near the entrance of each reactant; however, the lowest are close to the reaction surface. In addition, the oxygen mole fraction is greater in $x-y$ plane than in the $y-z$ plane case, indicating an increased consumption of the oxygen in y-z plane due to improvements in the oxygen distribution over the reacting region. In general, the hydrogen and oxygen concentrations decrease gradually from inlet to outlet due to the consumption of reactant gases through the oxidation reaction in the anodic and cathodic catalyst layers. Also the oxygen and hydrogen mole fractions decrease slowly within the gas channels due to convection, while the decrease rate is higher in GDLs due to lack of convection and lower diffusivity on the sites. Because of the relatively low diffusivity of the oxygen compared to the hydrogen and the low concentration of oxygen in ambient air, the oxygen depletion is noticeable.

Figures 3.5 and 3.7 for $y-z$ plane (bottom), demonstrate oxygen and hydrogen mole fraction distributions respectively; since diffusion is the only mass transport mechanism, the oxygen and hydrogen decrease linearly in the direction toward the reaction surface and the profile is symmetrical about its vertical central line due to the symmetrical geometry and flow employed. Besides, as expected, due to the presence of the current plate in the gas channel, there exists a concentration gradient in the z-direction within the GDL and catalyst layer, which could not be observed in the x-y plane simulation results, and a minimum value of oxygen and hydrogen concentrations can be found in the centre of the domain as shown in Figures 3.5 and 3.7 (bottom).

Figures 3.6 and 3.8 depict the water mole fraction distribution in the cathode and anode sides respectively for $\mathrm{x}-\mathrm{y}$ plane (top) and y-z plane (bottom). For x-y plane (top) the water mole fraction increase linearly in the direction of the flow towards the reaction layers, and reach its maximum at the catalyst layers where the production of water is enriched, which is in consistency with the 
noticeably increased consumption of reactants as shown in Figures 3.5 and 3.7 (top). Figures 3.6 and 3.8 (top) illustrate that the concentration increase as a result to water production at the cathode catalyst layer is much larger than the effect of removing hydrogen from the gas stream at the anode side for these flow and current levels. In addition, the water mole fraction distribution at the anode and cathodes sides for $\mathrm{x}-\mathrm{y}$ plane (top) are different from the case of the $\mathrm{y}-\mathrm{z}$ plane (bottom) that shown in Figures 3.6 and 3.8. Since the consumption of the reactants are greater in y-z plane (bottom) than $\mathrm{x}$-y plane (top) as shown in Figures 3.5 and 3.7, the water productions are lower in $\mathrm{x}-\mathrm{y}$ plane than the $\mathrm{y}-\mathrm{z}$ plane (bottom) as shown in Figures 3.6 and 3.8.

Figures 3.6 and 3.8, for y-z plane (bottom), illustrate that the water increases linearly in the direction toward the reaction surface, and the profile is symmetric about its vertical central line due to the symmetric geometry and flow employed. In addition, it is noticed that the maximum value of the water vapour mole fraction within anode and cathode catalyst layers, precisely in the same position as shown in Figures 3.5 and 3.7 (bottom) where the minimum value of oxygen and hydrogen concentrations can be found at the centre of the domain, consistent with each other, the more oxygen and hydrogen is depleted, the higher water vapour concentration is produced. However the water vapor mole fraction at the anode side is greater than cathode side due to the effect of the electroosmotic drag of water in the membrane. 

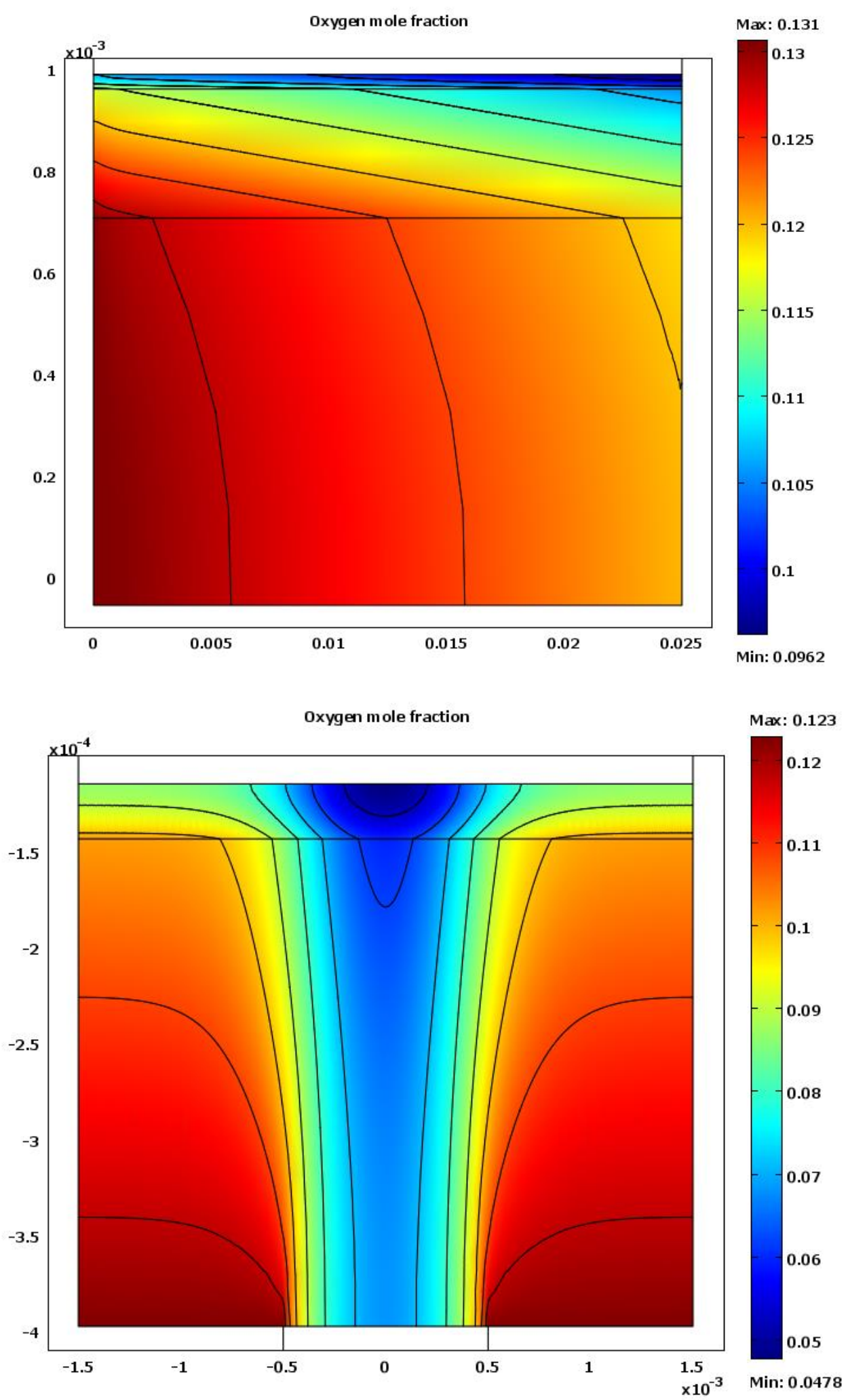

Figure 3.5 Oxygen Mole Fraction Distribution at Cathode Side for x-y Plane on the Top and y-z Plane on the Bottom 

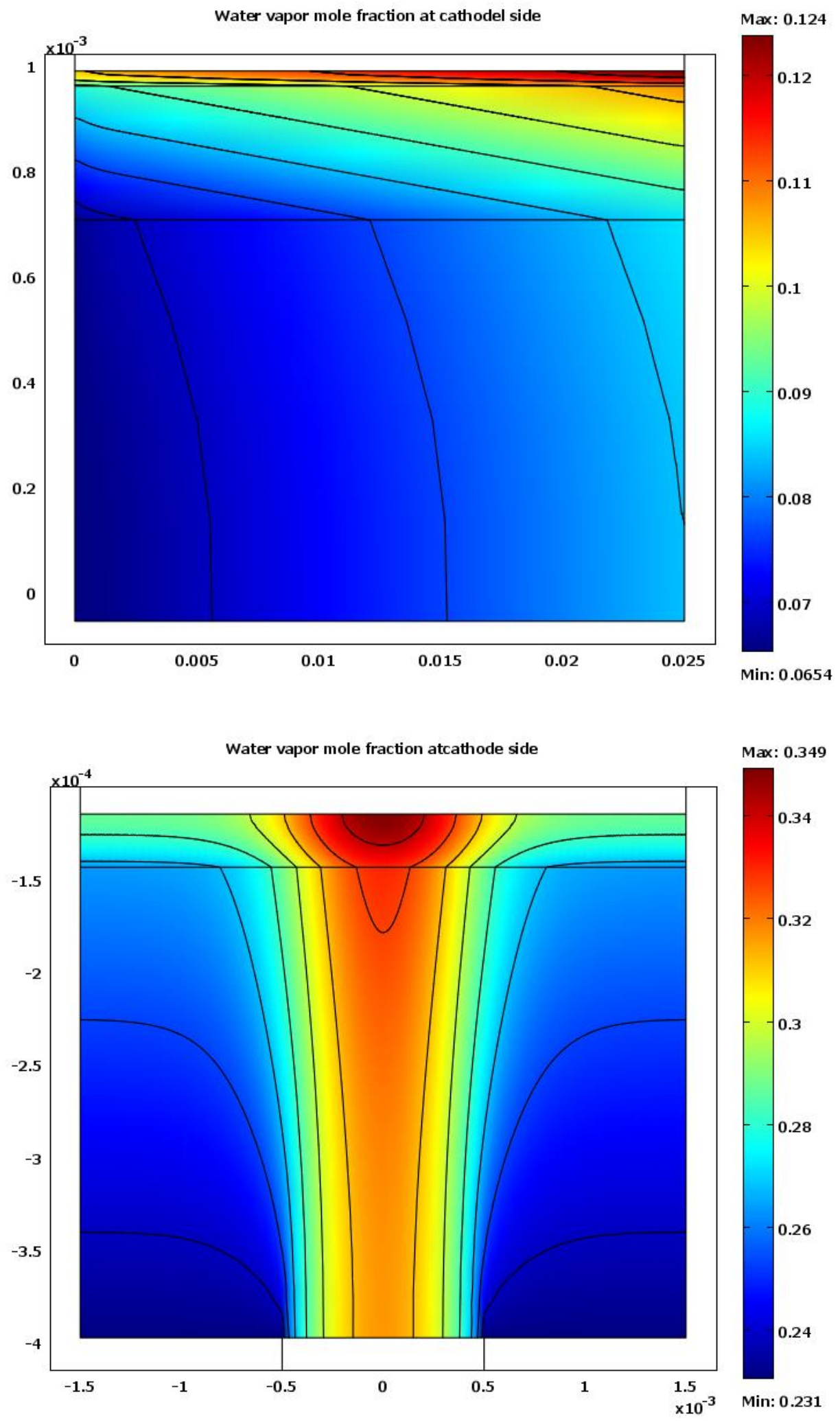

Figure 3.6 Water Vapour Mole Fraction at the Cathode Side for x-y Plane (Top) and y-z Plane in the Bottom for Cell Voltage of $0.7 \mathrm{~V}$ 

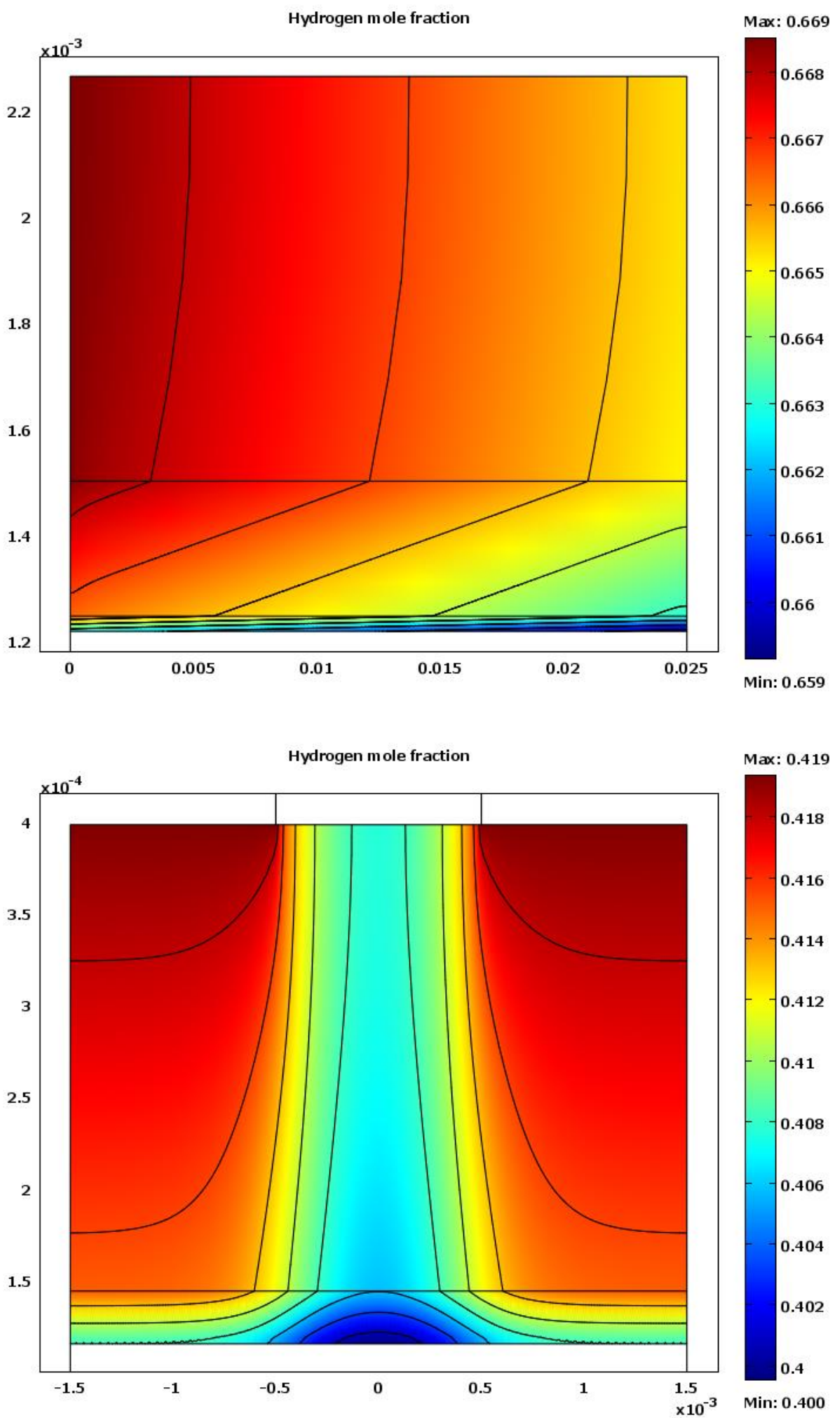

Figure 3.7 Hydrogen Mole Fraction at Anode Side for x-y Plane Top and y-z Plan in the Bottom for Cell Voltage of $0.7 \mathrm{~V}$ 


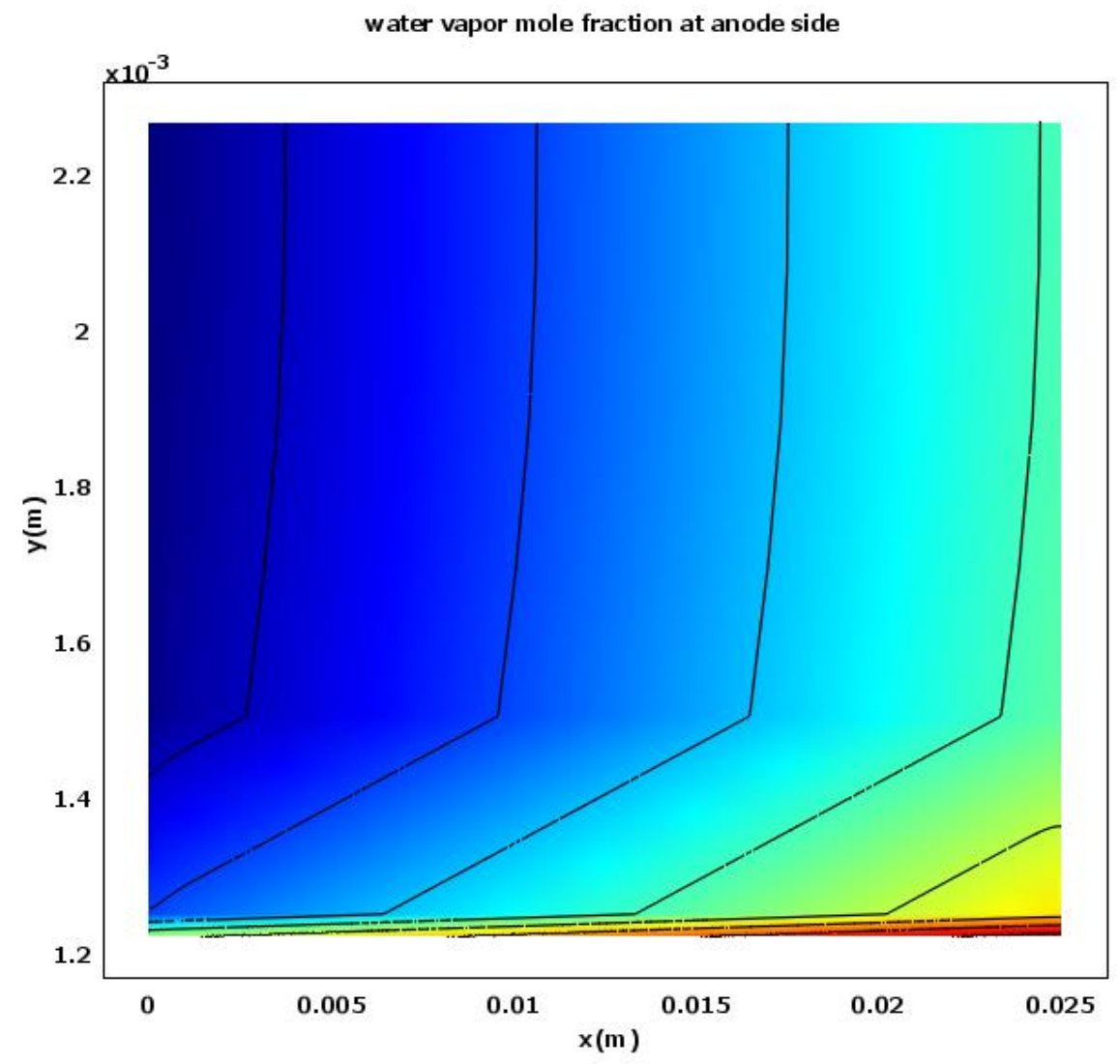

Max: 0.100

0.1

0.1

0.1

0.099

0.099

0.099

0.099

0.099

0.098

0.098

Min: 0.0982

Water vapor mole fraction at anode side

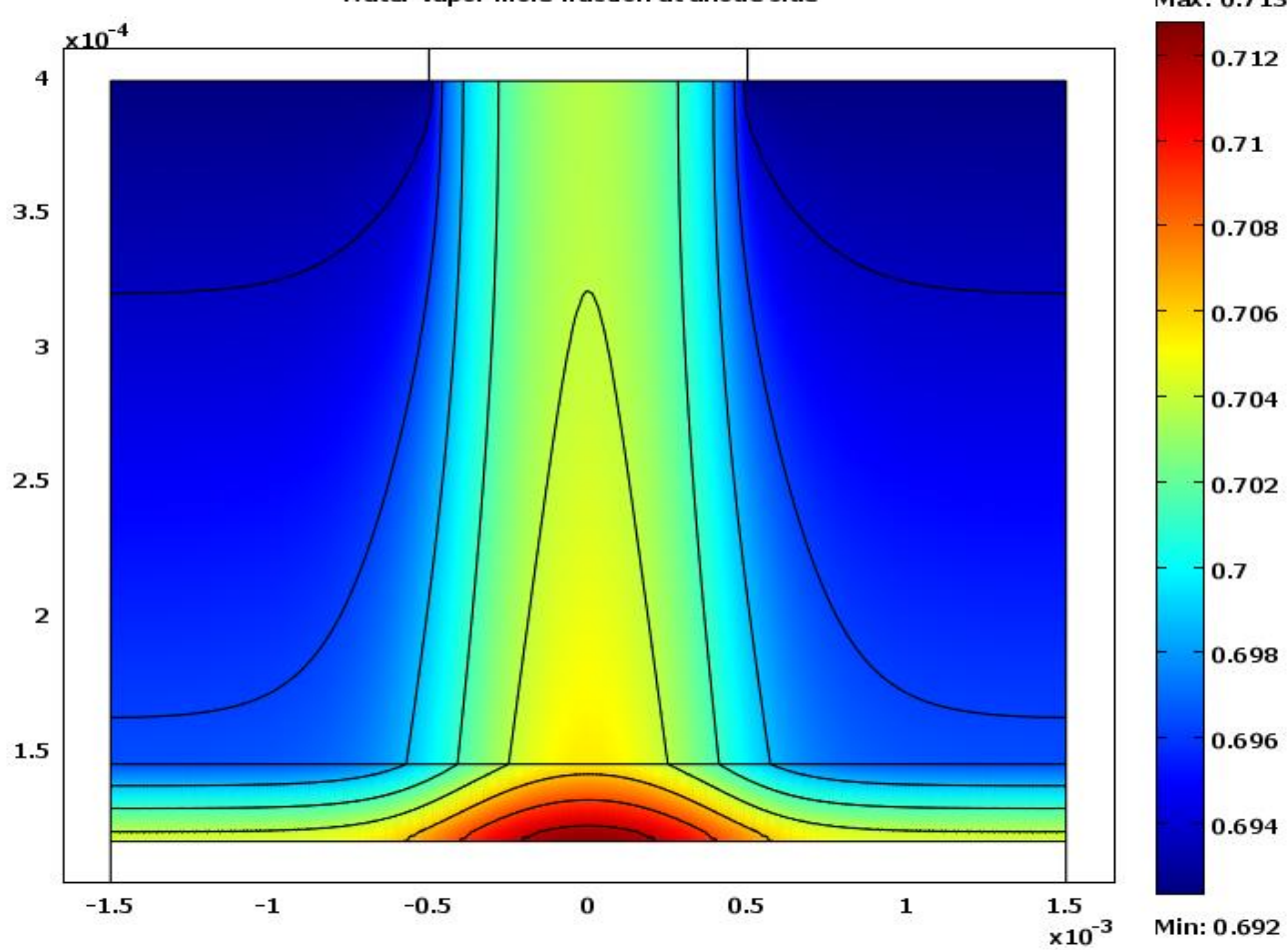

Figure 3.8 Water Vapour Mole Fraction at the Anode Side for x-y Plane Top and y-z Plane in the Bottom for Cell Voltage of $0.7 \mathrm{~V}$ 


\subsubsection{Water Content in Membrane}

Liquid water transport in the membrane due to elector-osmotic drag, concentration gradient and pressure gradient.The water content can be calculated using the liquid water concentration distribution. Figure 3.9 demonstrates the water content in the membrane for the base case for $x-y$ plane (top) and y-z plane (bottom) for cell voltage $0.7(\mathrm{~V})$.

Generally, within the membrane, the water content at the anode side is lower than that at the cathode side. This is due to the electro-osmotic drag that prevents the liquid phase of water from migrating from the anode side to the cathode side, and the insufficient back-diffusion to the anode side from the cathode side, where water is produced.

Figure 3.9 illustrates the uniformly transits distribution of water content across the membrane in $\mathrm{x}-\mathrm{y}$ plane (top) which is different from the $\mathrm{y}$-z plane (bottom) where the profile is symmetric about its vertical central line due to the symmetric geometry. The water content for $y-z$ plane increases linearly in the direction toward the cathode catalyst layer, and it reach its maximum value in the center of the cathode catalyst layer near the current collector's position, this is due to more complete reduction reaction occurs there, that generate a significantly large amount of water that overwhelms the increasing of water accumulation along the catalyst layer. In addition, it is noticed that for a given cell voltage $0.7 \mathrm{~V}$, the electro-osmotic drag drives less water from anode to the cathode for $y-z$ plane (bottom), while for $x-y$ plane (top) the water content is higher, due to the electro-osmotic drag drives more water from the anode side to the cathode side and results in a lower water content at the anode side while a higher water content at the cathode side. It can be observed for Figure 3.9, that the water content at cathode side rise form 14.704 for y-z plane to 15.247 for $\mathrm{x}-\mathrm{y}$ plane, while that at anode side decreases form 14.024 for $\mathrm{y}-\mathrm{z}$ plane to 3.512 for $\mathrm{x}-$ y plane. 

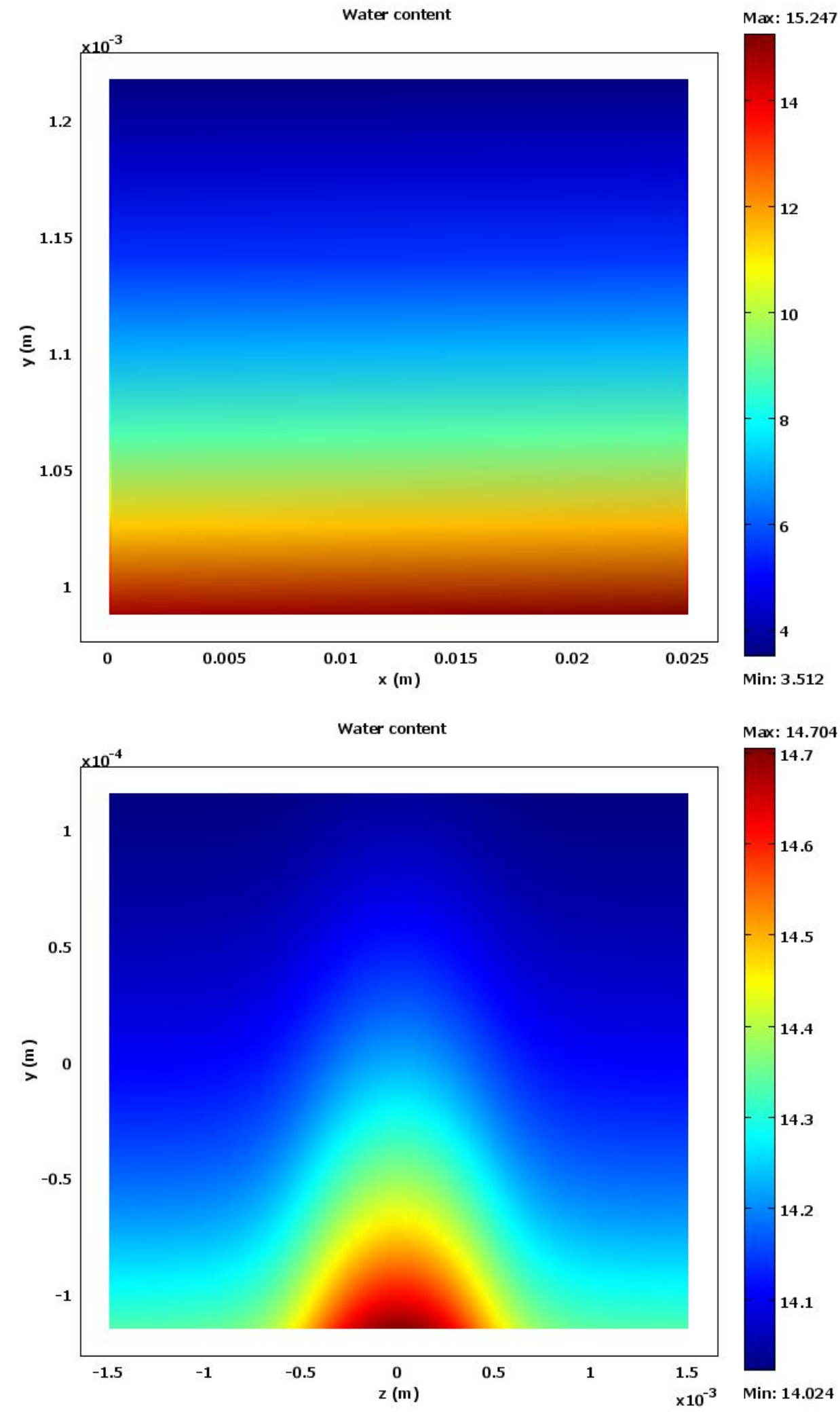

Figure 3.9 Water Content Distribution in Membrane in $x-y$ Plane Top and $y-z$ Plane on the Bottom for Cell Voltage of 0.7 


\subsubsection{Membrane-Phase Potential Loss}

The resistance to proton mobility through the membrane from the anode catalyst layer to the cathode catalyst layer is called the membrane-phase potential. Protons produced when hydrogen reach the anodic catalyst layer then split into electrons and protons. Protons try to pass along the membrane to reach cathodic catalyst layer to be consumed. The magnitude of this potential loss depend on the operating conditions and the material used for the structure of PEMFCs. For instance, fully humidified reactants streams which ensure a hydrated inomer membrane, thus increasing water content in the membrane as well as the membrane conductivity which helps reducing the membrane-phase potential loss.

Figure 3.10 shows the membrane-phase potential loss distribution for $x-y$ plane (top) and y-z plane (bottom) for a given cell voltage $0.7(\mathrm{~V})$. For both planes, the membrane-phase potential is assumed 0 at the anode side for convenience of computational simulation. The equipotential lines indicate that the membrane-phase potential loss is not uniform along the longitudinal direction as shown in Figure 3.10 for $x-y$ plane (top). This potential loss reaches its maximum at the inlet of anode catalyst layer, where protons are consumed fastest, leading to the highest rate of electrochemical reaction whereas the lowest value of membrane-phase potential loss can be found near the outlet surface of cathode catalyst layer.

There is no significant different in the membrane- potential loss between $x-y$ and $y-z$ planes, however, the distribution of the membrane-phase potential is different. The profile of the membrane-potential distribution for the y-z plane (bottom) is symmetric about its vertical central line due to the symmetric geometry as exposed in Figure 3.10. A large rise of membrane-phase potential can be found near the current plate in y-z plane owing to the drops in membrane-phase potential due to the movement from the anode side to the cathode side. The maximum potential loss can be found in the inlet of the membrane, whereas the minimum potential loss can be found at the center of the cathode catalyst layer due to the highest water content in this area that yields to increase the membrane conductivity and least potential loss. 

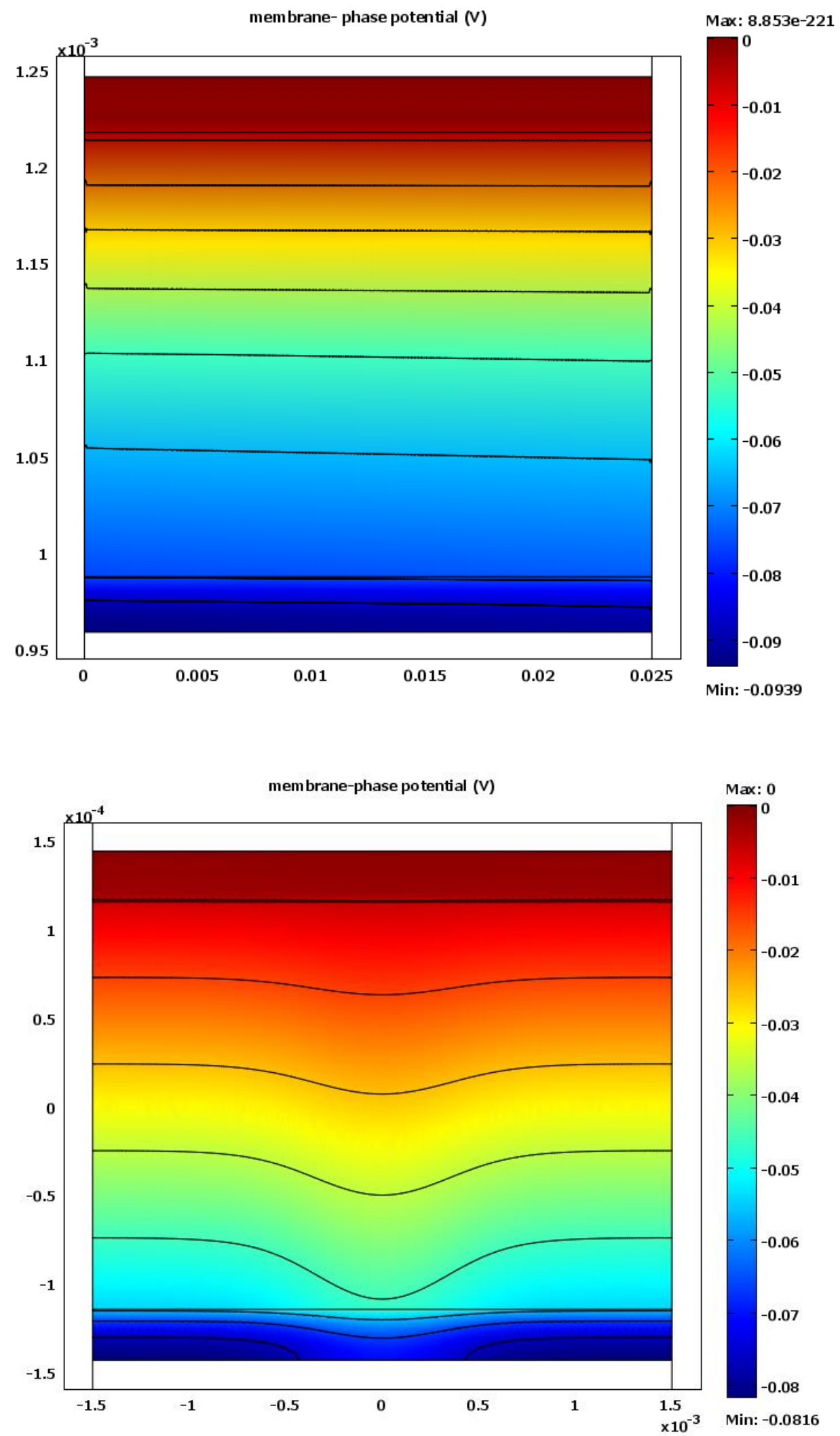

Figure 3.10 Membrane-Phase Potential Distribution in MEA for $x-y$ Plane Top and $y-z$ Plane on the Bottom for the Cell Voltage of 0.7 


\subsubsection{Temperature Distribution}

For higher performance and durability of a PEM fuel cell, a good thermal and excellent heat management is essential. Heat generation in PEM fuel cell is produced from the electrochemical reaction, ohmic resistance and entropic heat of reactions. The distribution of the temperature inside a PEMFCs has significant influences on all transport phenomena. Figure 3.11 illustrates the temperature distribution in the $\mathrm{x}-\mathrm{y}$ plane (top) and y-z plane (bottom) for PEM fuel cells. For $\mathrm{x}-\mathrm{y}$ plane (top) the highest temperature is obtained only at the inlet-side cathode catalyst layer, where the chemical reaction rate is highest, and the temperature in the GDLs is not very low because the forced convection helps heat transfer in the GDLs. In addition the temperature at the cathode side is slightly higher than at the anode side; this is for air at the cathode side is closer to the major heat source. The temperature change over the whole cell is small as about $2.026 \mathrm{~K}$ for a given cell voltage of $0.7 \mathrm{~V}$.

For y-z plane that shown in the bottom of Figure 3.11, the current plates works as a medium of cooling that makes the temperature gradient along the z-direction, which cannot be observed in the $x-y$ plane simulation results. Also, there are significant temperature peaks present at the corners of the gas diffusion channel (GDL) at the cathode side for the y-z plane. It can be clearly seen that the temperature distribution in the $y-z$ plane is symmetric about its vertical central line due to the symmetry of flow field. The temperature change over the whole cell for y-z plane is small as about $1.8 \mathrm{~K}$ that is smaller than the $\mathrm{x}-\mathrm{y}$ plane.

The high degree of temperature non-uniformity along the catalyst layer for the $x-y$ plane, and along the GDL at cathode side for the y-z plane; revealed through the numerical simulation suggests that a redistribution of the catalyst deposition is demanded to reform the current density distribution and, accordingly, effectively control the temperature distribution. 


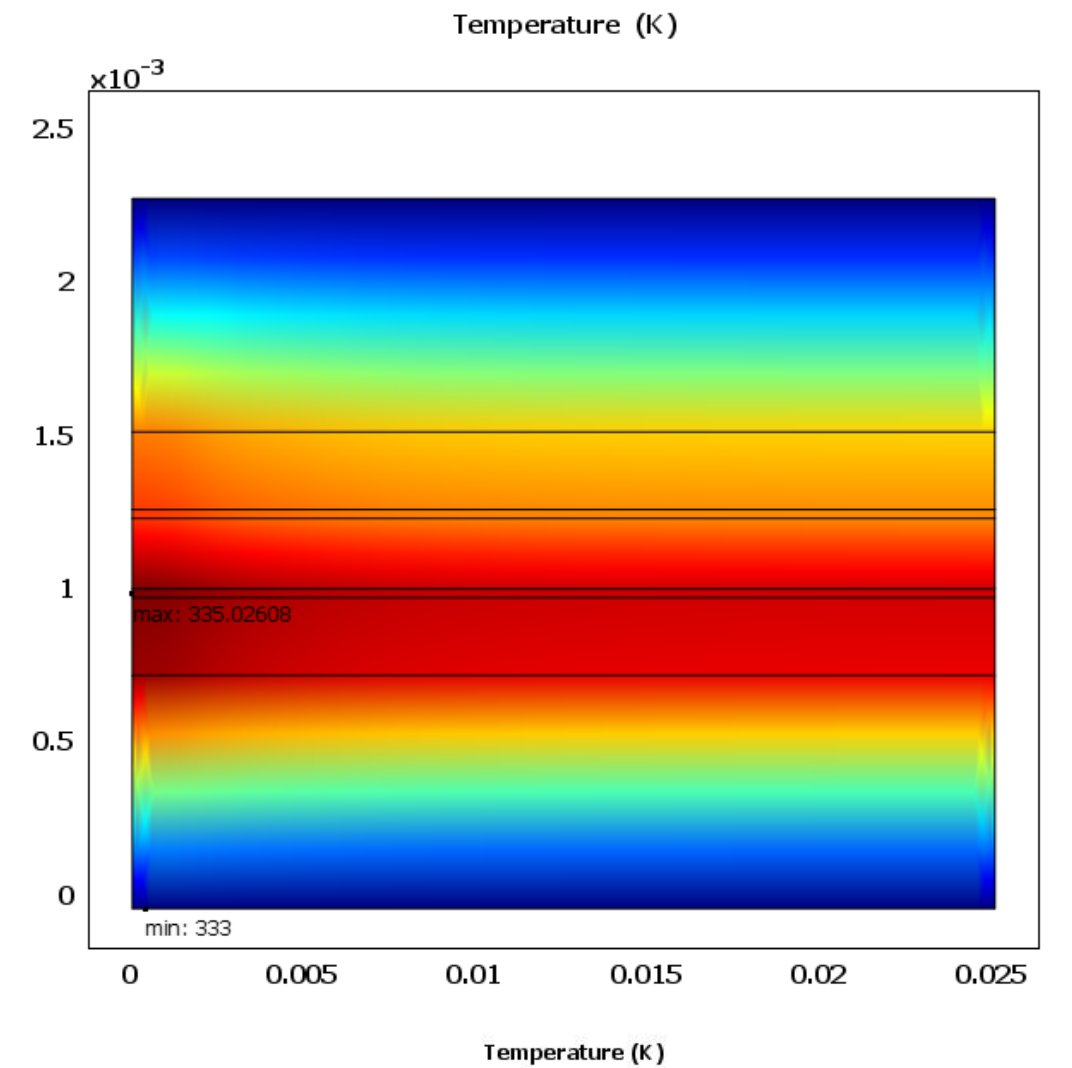

Max: 335.026
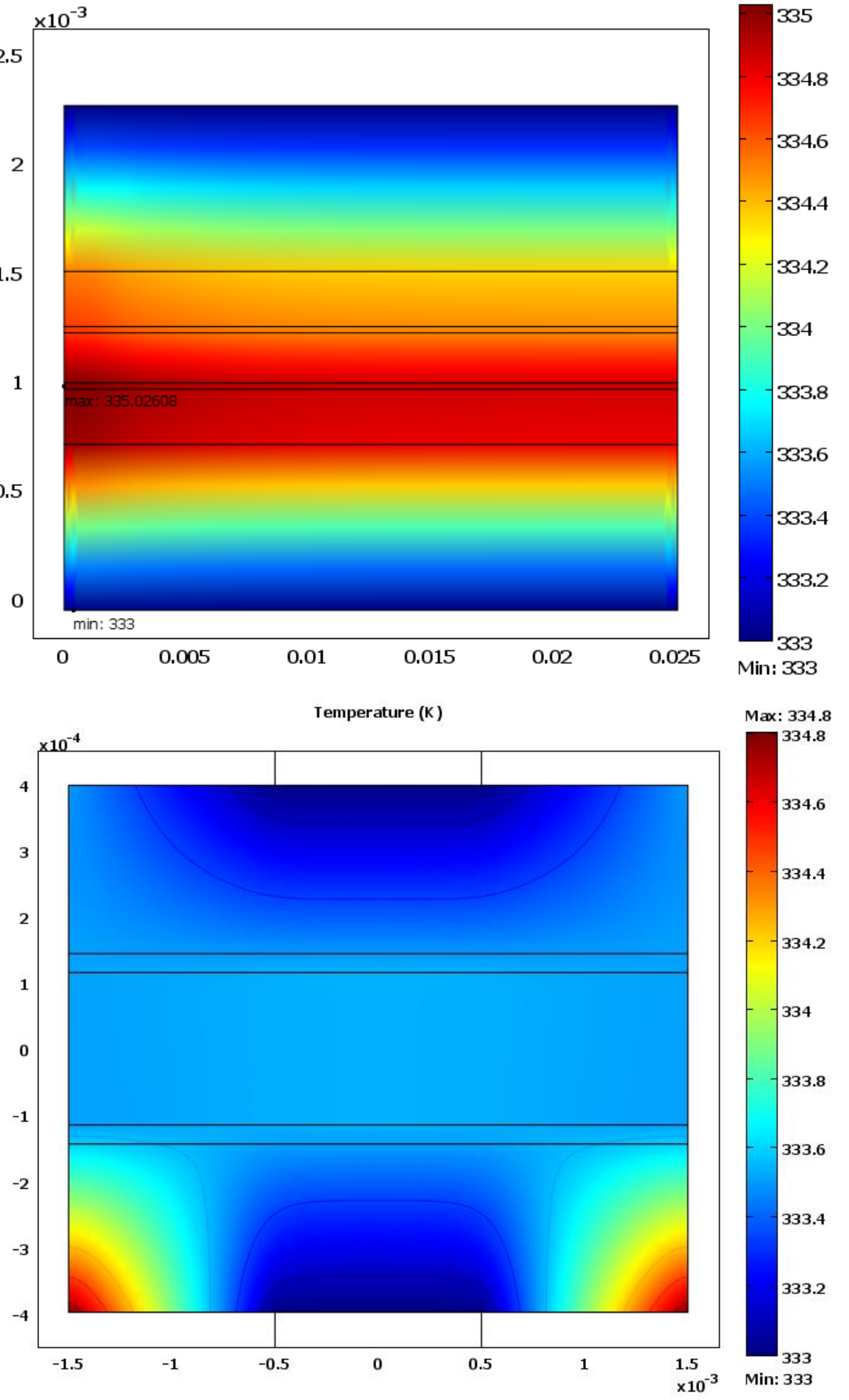

Figure 3.11 Temperature Distribution in x-y Plane Top and y-z Plane in the Bottom for Cell Voltage of $0.7 \mathrm{~V}$ 


\subsubsection{Solid-Phase Potential Loss}

The 2D simulations in the y-z plane can show the solid-phase potential in detailed, which is directly related to the electron flow, unlike the $\mathrm{x}-\mathrm{y}$ plane simulation. The electron flow direction is perpendicular to the solid-phase potential contours, and the magnitude is proportional to the gradient of the solid-phase potential. Figures 3.12 and 3.13 demonstrate the solid-phase potential distribution in the collector plates, gas diffusion layers and catalyst layer across the $y-z$ plane (bottom); and within catalyst layer and gas diffusion layers across the $\mathrm{x}$-y plane (top), at cathode and anode sides, respectively. In general the electrons produced in the anode catalyst layer, then move along the anode gas diffusion layer, are collected in the current plate. Electrons move through outer circuit to reach the cathode side and pass through the current plate, to participate in the electrochemical reaction that occurs at the cathode catalyst layer.

Figure 3.12 illustrates the solid- phase potential at cathode side for $\mathrm{x}-\mathrm{y}$ plane (top) and $\mathrm{y}-\mathrm{z}$ plane (bottom). The solid-phase potential loss is higher within the catalyst layer for the $\mathrm{x}$-y plane (top) and it is reach its lowest value at the GDL. The same trend can be observed for the y-z (bottom) plane as the solid- phase potential loss increase with the direction of flow of electrons from its lowest value at the current plate to the highest value in the catalyst layer precisely in the sides of collector plate as it is flow in symmetrical path due to the symmetrical geometry.

The solid-phase potential loss at the anode side increases with the flow direction of elections as shown in Figure 3.13. As mentioned above the electrons generated at the surface of anodic catalyst layer where the minimum value of solid- phase potential loss can be seen and gradually increases in their flow way to reach its highest at the GDL for the x-y plane (top) and at the current plate for y-z plane (bottom). From Figures 3.12 and 3.13, it can clearly observed that the maximum solidphase potential loss can be found at the cathode catalyst layer due to the consumption of electrons in the electrochemical reaction, while the minimum solid- phase loss can be found at the anode catalyst layer where the electrons are generated. 

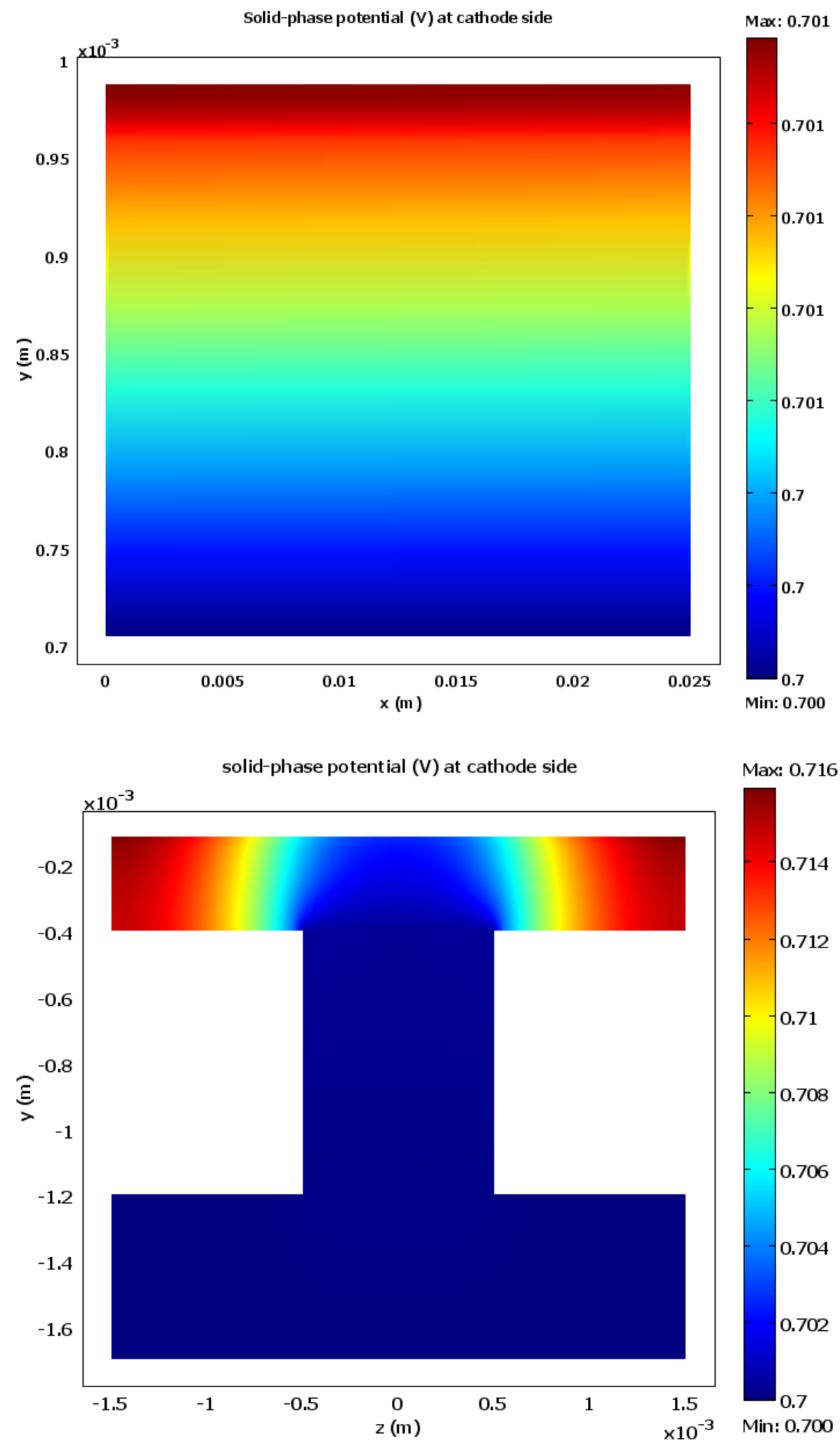

Figure 3.12 Solid-Phase Potential at the Cathode in x-y Plane Top and y-z Plane on the Bottom for Cell Voltage of $0.7 \mathrm{~V}$ 

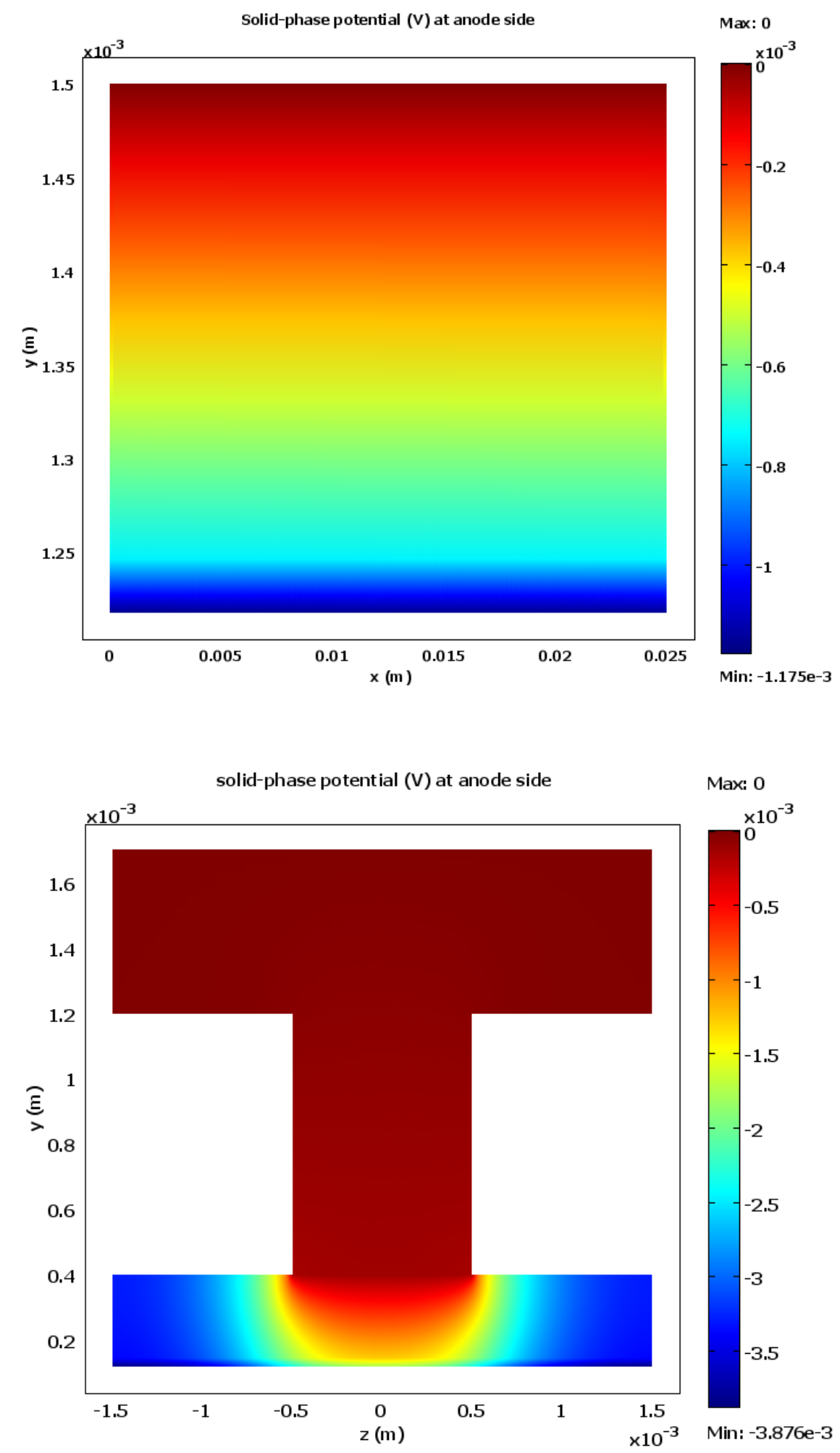

Figure 3.13 Solid-Phase Potential at the Anode Side for x-y Plane Top and y-z Plane on the Bottom for Cell Voltage $0.7 \mathrm{~V}$ 


\section{Chapter 4 \\ Parametric Study for $x-y$ Plane}

In the previous chapter, validation through some base case studies has been performed, and a good agreement with available experiment results testifies to the reliability of the current model. In this chapter, a series of parametric studies will be carried out by using this model for $x-y$ plane. Various working conditions and design parameters will be examined to exhibit the effects of: inlet reactant relative humidity, operating temperature, gas diffusion layer (GDL) porosity, effective porosity of catalyst layer (CL), proton conductivity, operating pressures, membrane (M) porosity, and the air inlet velocity at cathode side, on fuel cell performance. It is necessary to realize the effects of these parameters on fuel cell operations in order to improve fuel cell performances. To assess the effect of each individual parameter on the overall performance of the fuel cell, in each case study, only one parameter is allowed to vary while all others are kept unchanged. The results are presented in the form of polarization curve. The model base conditions are taken from the literature, which are given in Table 2.2.

\subsection{Effect of Inlet Reactant Relative Humidity}

Relative humidity is the ratio of the partial pressure due to water vapour to the saturation pressure, which is the maximum amount of water vapour that can be found in gas for given conditions [65], [69]. The reactant gases need to be humidified before entering cell for high ionic conductivity of the membrane in the PEM fuel cell [75]. Managing the hydration level in the membrane to avoid flooding is one of the key success in the PEM fuel cells and it is extensively studied in the research of PEM fuel cell. The liquid water in the cell is produced at the cathode catalyst layer due to the electrochemical reaction expressed in Eq. (1.3), or due to humidified reactant gases that is called inlet relative humidity of the reactant.

To study the effect of relative humidity, numerical simulations under different relative humidity are implemented and their polarization curves for different inlet reactant relative humidity, ranging from $30 \%$ to $100 \%$ for both oxygen and hydrogen, are shown in Figure 4.1. A significant increase in the current density from $0.4095 \mathrm{~A} / \mathrm{cm}^{2}$ to $0.5815 \mathrm{~A} / \mathrm{cm}^{2}$ is achieved when the RH increases 
from $30 \%$ to $100 \%$. The best performance is obtained when the relative humidity reaches $100 \%$, while at the condition of relative humidity equal to $30 \%$ the performance is lower. Consequently, at lower RHs, fuel cell cannot work towards a higher current density.

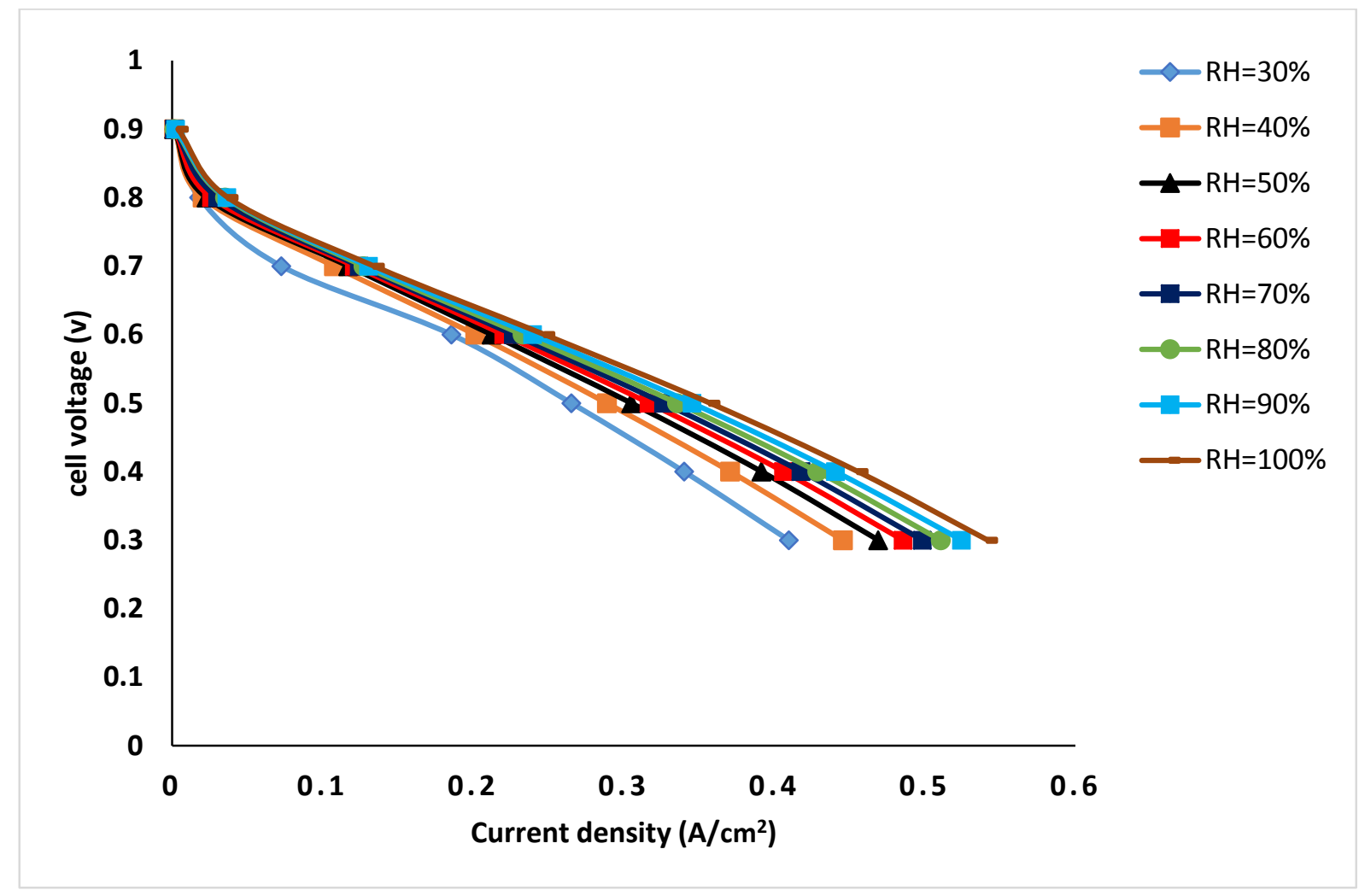

Figure 4.1 Polarization Curves Corresponding to Different Relative Humidity

Figure 4.2 shows that the water content in the membrane increases with higher relative humidity. At high relative humidity $(\mathrm{RH})$, increasing in water content leads to increase the ionic conductivity of a Nafion117 proton exchange membrane as suggested by Eq. (2.70), which helps reduce the membrane-phase potential loss as demonstrated in Figure 4.3. The membrane-phase potential intensely depends on the water content inside the membrane and operating temperature as described in Eq. (2.69).

Figures 4.2 and 4.3 demonstrate the water content and membrane potential loss at a cell voltage of $0.7 \mathrm{~V}$ for $\mathrm{RH}$ at $50 \%$ and $100 \%$, respectively. At this cell voltage, it is easily realized that the water content decreases and the membrane-phase potential loss increases in response to the reduction of 
RH. Consistently, a re-visit can be paid to Figure 4.1, on which the average current density goes up from $0.4690 \mathrm{~A} / \mathrm{cm}^{2}$ to $0.5815 \mathrm{~A}^{-\mathrm{cm}^{2}}$ when the $\mathrm{RH}$ is increasing from $50 \%$ to $100 \%$. Significant accumulation of liquid water can be seen clearly from Figures 4.2 and 4.3, over the reactive surface of cathode catalyst layer where less membrane-phase potential loss can be found. The mass transport of the reactant gases in the cathode catalyst layer may severely been effected by this accumulated water due to covering up the reactive surface area and blocking the gas pores [70]. To avoid cathode flooding, in this case a greater rate of water removal from the diffusion layer is require for higher current densities and thus better PEM fuel cell performance [71].

The result suggests that maintaining the reactant gases as fully humidified as possible may help reduce the membrane-phase potential loss and increase the current density. However, extra parasitic volume and power are required for externally full humidification of the reactant gases in a fuel cell system [36]. Thus, this study suggest a proper balance in the membrane, water content to reduce system cost. 

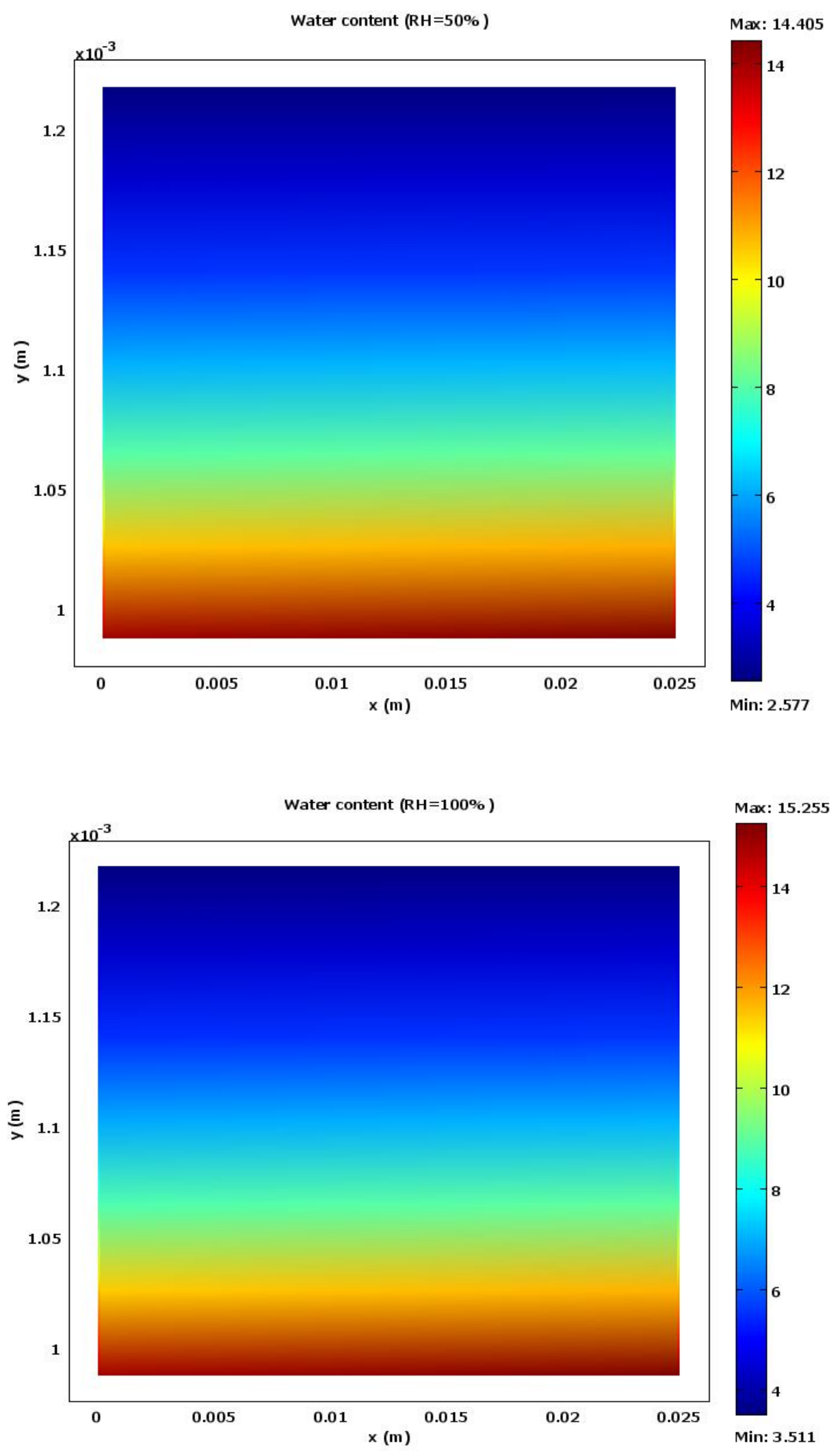

Figure 4.2 Water Content at Cell Voltage 0.7V: for Relative Humidity RH=50\% (Top) and RH=100\% (Bottom) 

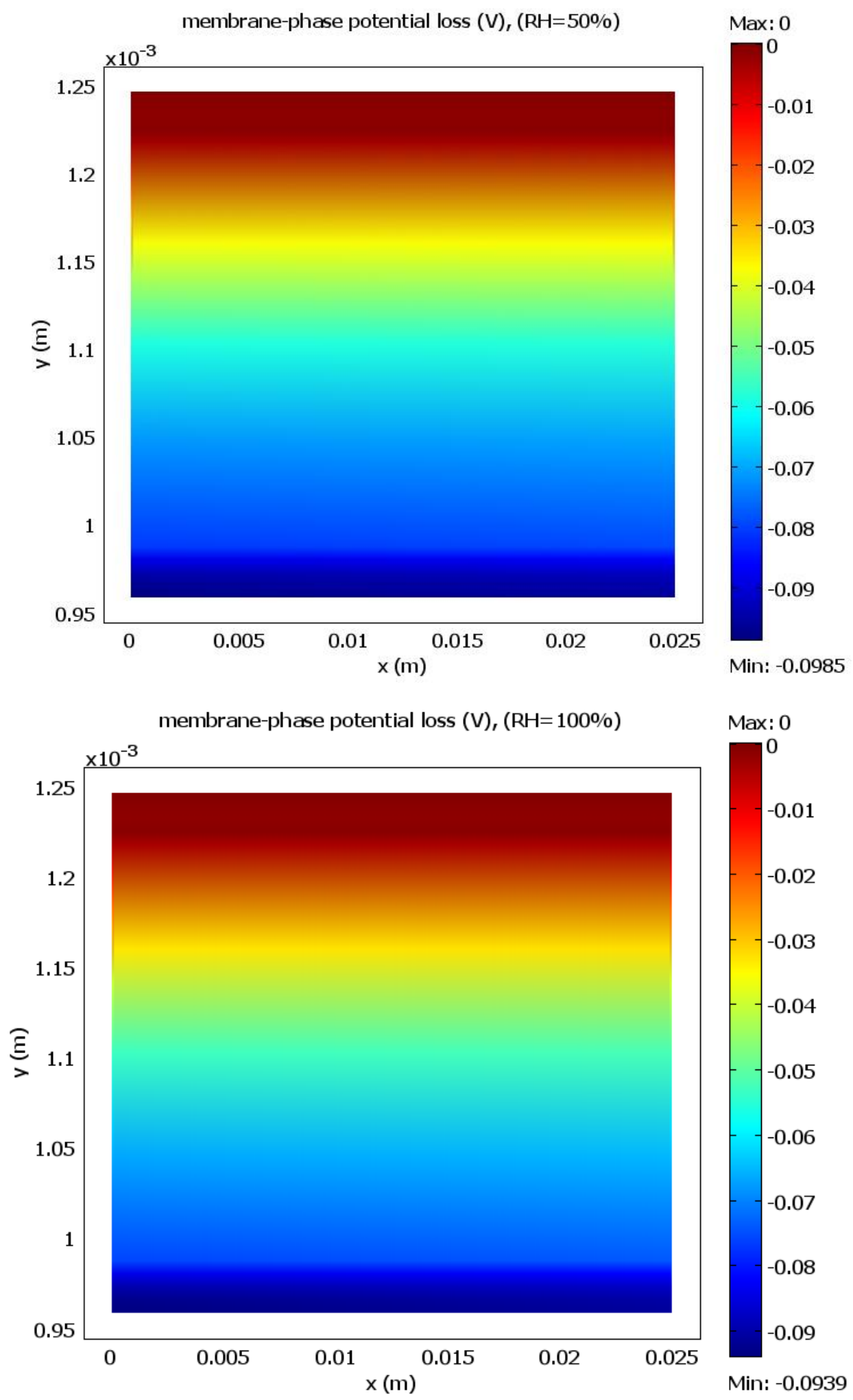

Figure 4.3 Membrane-Phase Potential Losses at Cell Voltage 0.7V: for Relative Humidity RH=50\% (Top) and $\mathrm{RH}=100 \%$ (Bottom) 


\subsection{Effect of Operating Temperature}

In this study, the effect of operating temperature on PEM performance had been studied. The change in temperature will cause in turn the changes in the gas diffusion coefficients, the exchange current densities at anode and cathode sides, and the proton conductivity, which can be calculated using Eqs. (2.21), (2.29), (2.30), and (2.71), respectively. The effect of operating temperature on the polarization curves is shown in Figure 4.4. The operating temperatures vary from 323K to $353 \mathrm{~K}$. The results show that increasing operating temperature leads to improvement in cell performance, due to increase membrane conductivity and gas diffusivity with higher operating temperature that result in better mass transport and thus better limiting current densities. This trend is consistent with the experimental work of [65], [66]. Wang et al [65] concluded that the performance of the PEM fuel cell improves with the increase of operating temperature, if sufficient humidification is ensured.

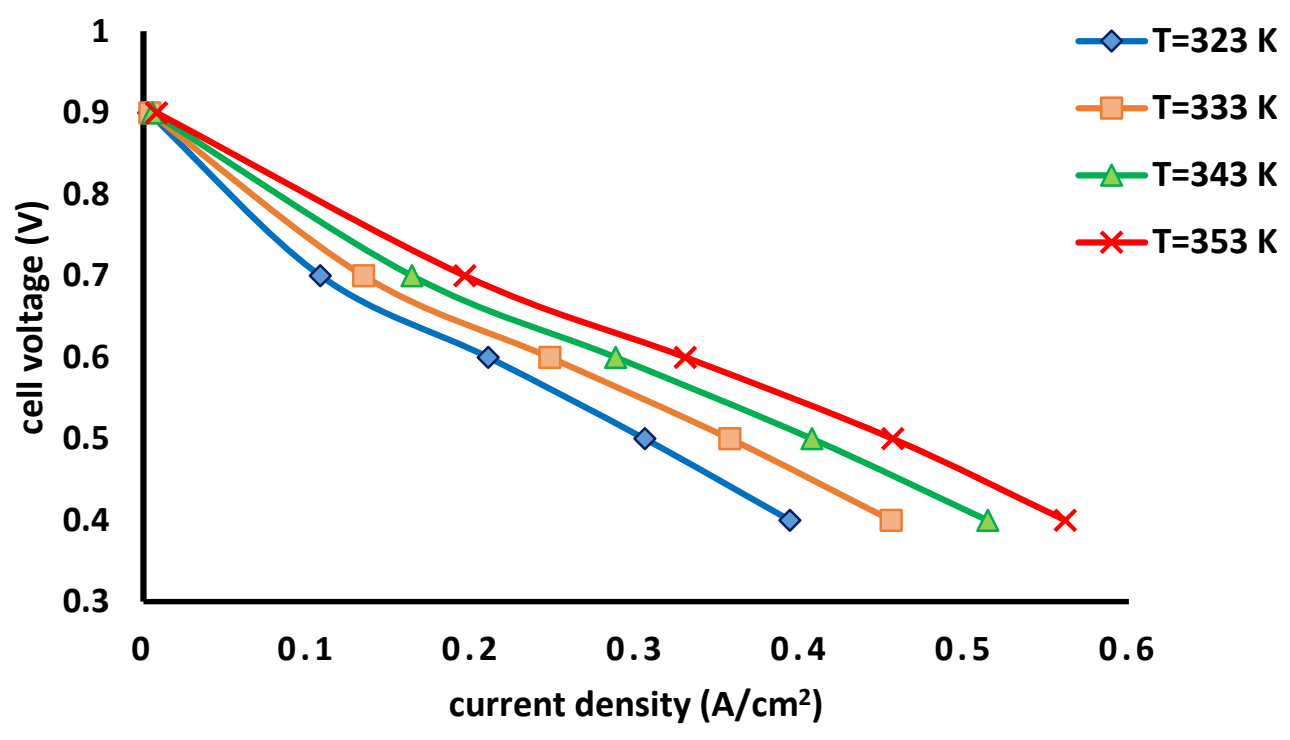

Figure 4.4 Polarization Curves Corresponding to Different Operating Temperature 


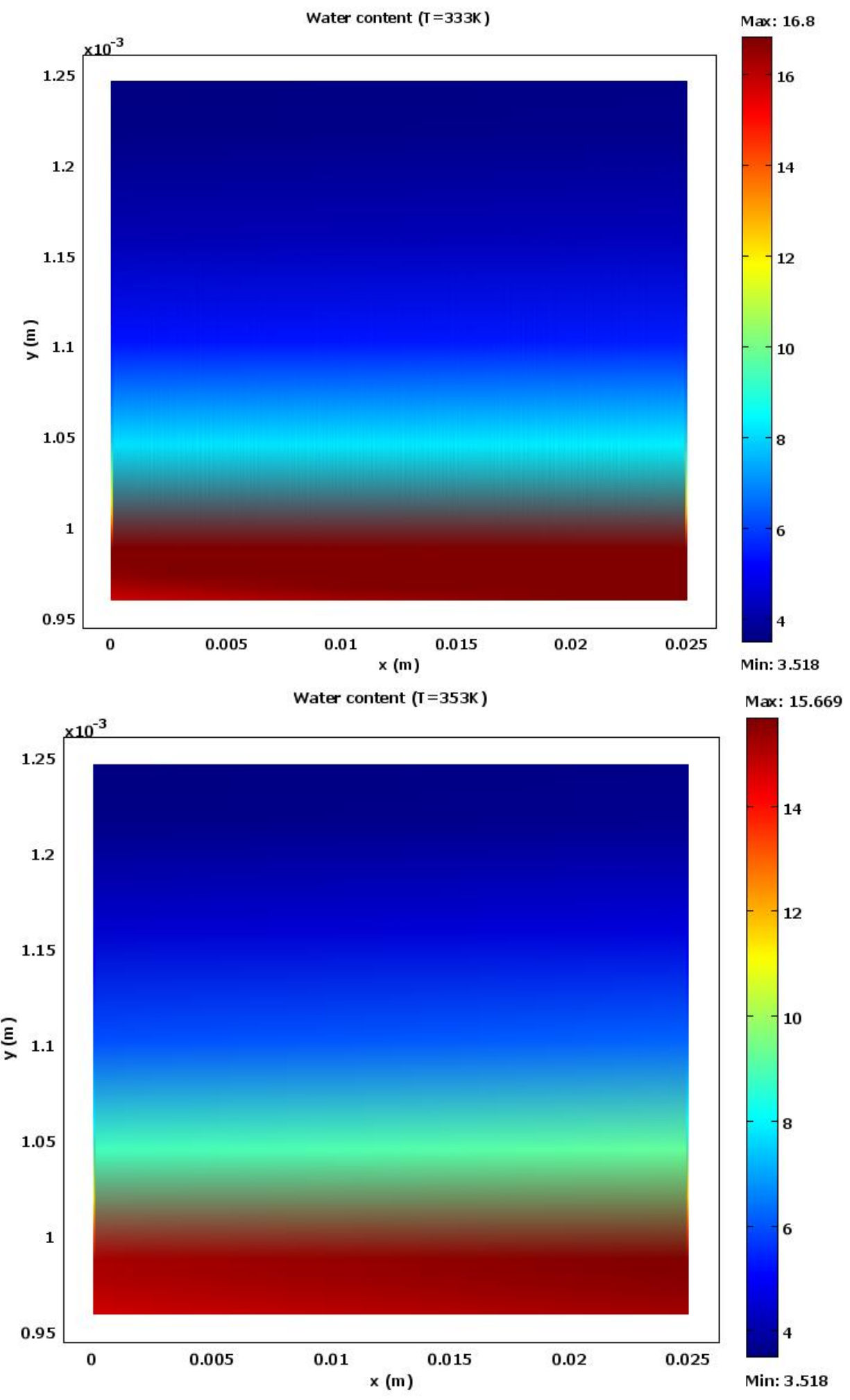

Figure 4.5 Water Content at Cell Voltage 0.4V: for Temperature $\mathrm{T}=333 \mathrm{~K}$ (Top) and $\mathrm{T}=353 \mathrm{~K}$ (Bottom) 
Operating PEM fuel cell at relatively high temperature provides benefit that include easier management of water due to more vaporization of water product, leading more waste heat to the formation of latent heat and less liquid water removal from the fuel cell. On the contrary, due to liquid phase of water at a lower temperature, flooding could occurs in the cathode catalyst layer and gas diffusion layer which will adversely affect gas diffusivity. Figure 4.5 demonstrates the water content inside catalyst layers and the membrane at different temperatures. It is clearly showed that less water content can be found at higher temperature. At the same time, with relatively high temperatures water content in the membrane may decrease leading to reduction in the membrane conductivity, as a results of that the performance drops quickly if overheated. In general, higher cell potential may be achieved with a reasonably raised in operating temperature. However, at higher cell temperatures, the degradation of fuel cell components is accelerated causing in shortened cell lifetimes [67].

\subsection{Effect of GDL Porosity}

The properties of the gas diffusion layer (GDL) effects the optimum performance of the electrode and the catalyst layer [72]. The GDLs are porous media that allows the reactant gases to transport from gas channels (GCs) towards the catalyst layer (CLs). Gas diffusion layers are an essential part of the PEM fuel cell and the porosity of this layer has a noticeable effect on the performance of PEM fuel cell. In this study, the effects of porosity in the gas diffusion coefficients can be expressed by Bruggemann correction expressed in Eq. (2.23).

The effects of GDL porosity on fuel cell performance are shown via polarization curves in Figure 4.6 for three different GDL porosities of $0.17,0.2$ and 0.4 . It is shown that the porosity variation in the gas diffusion layers has no significant influence with low current density, unlike at higher current density, it is evident that the fuel cell with a higher GDL porosity enlarges the limitation of current density through diffusion and more reactant gases towards the reactive areas. 


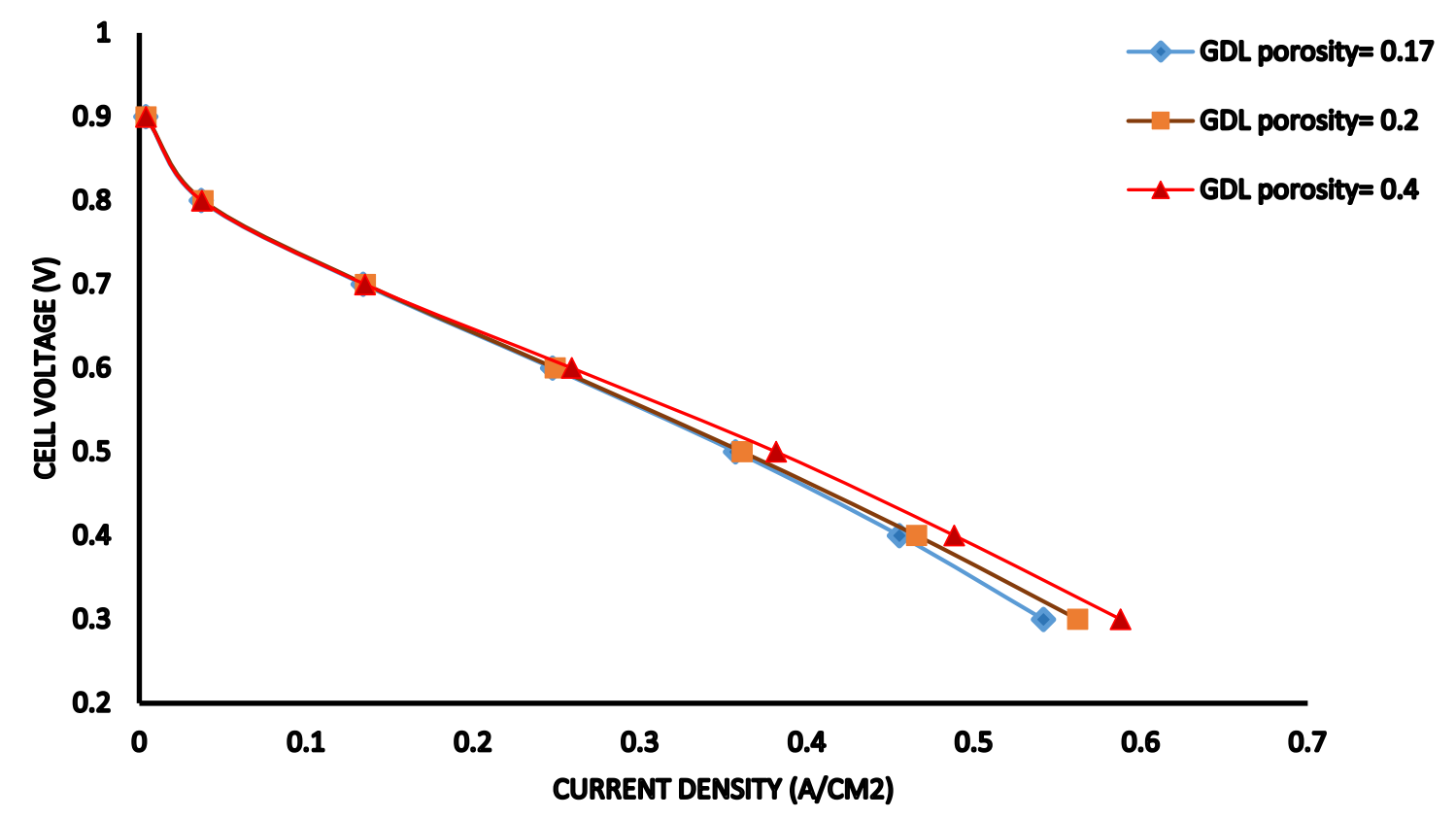

Figure 4.6 Effects of GDL Porosity on PEM Fuel Cell Performance.

Figure 4.6 reveals again that a higher GDL porosity results in a higher limit current density, as a lower current density is produced with a lower porosity due to the reduction in oxygen consumption. Higher volume porosity has positive effects on the mass transport of the oxygen on the cathode side as well as the hydrogen on the anode side. Figure 4.7 shows the oxygen mole fraction distribution inside the cathode side with different porosities of GDL, and Figure 4.8 focuses on this reactant distribution inside the cathodic catalyst layer precisely. The oxygen mole fraction increases with higher GDL porosity (0.4) compared to the case with a porosity of (0.2), since increased volume porosity provides less resistance to mass transport, thus allowing for a more complete electrochemical reaction. The results of this study are agree with the work of [73]. 


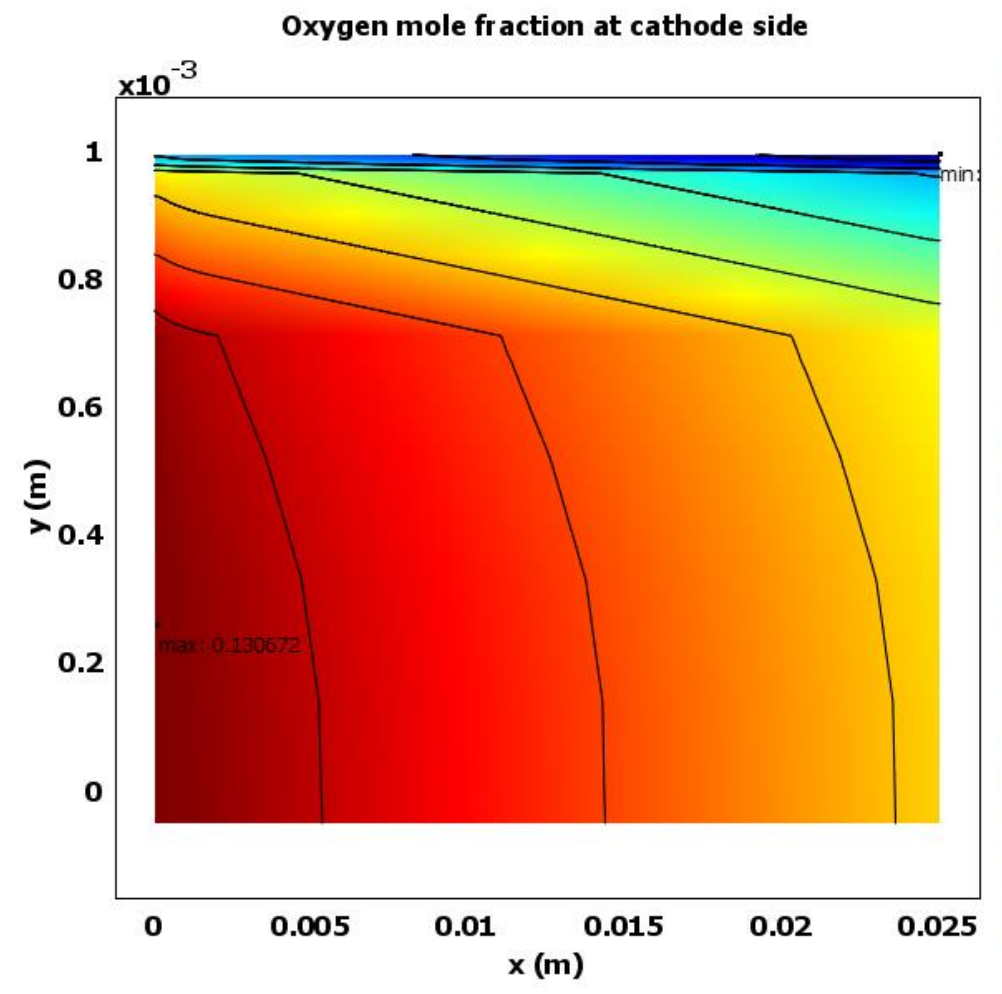

Max: 0.131
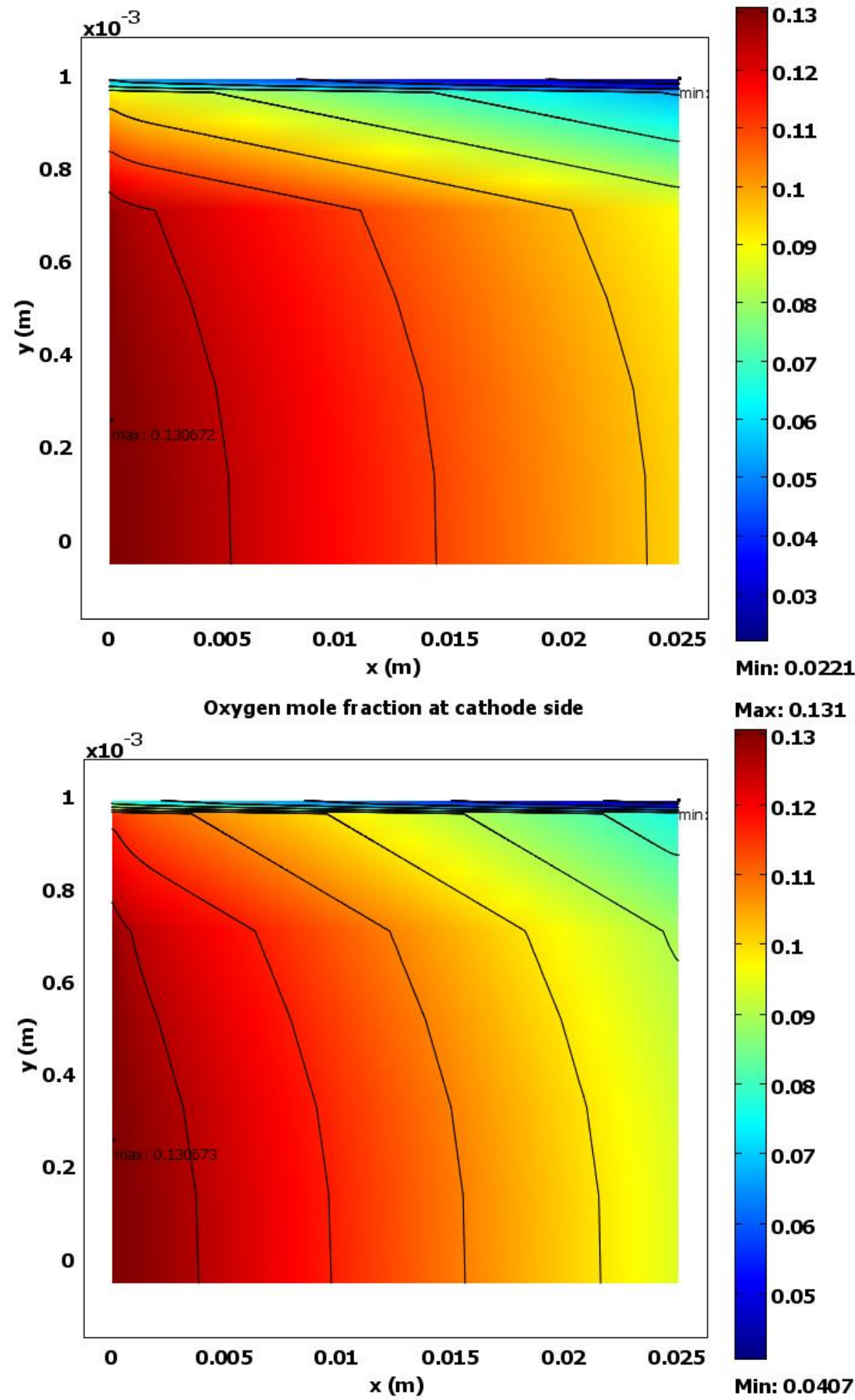

Max: 0.131

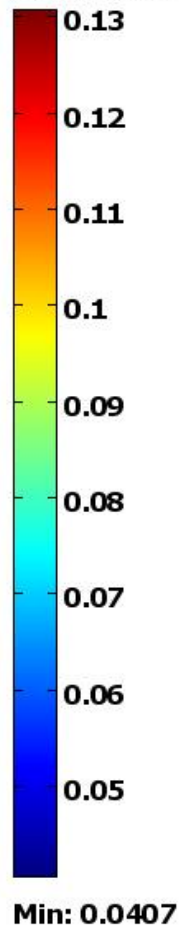

Figure 4.7 Oxygen Mole Fraction Distribution Inside Fuel Cells with Different GDL Porosities: $\varepsilon_{g}=0.2$ (Top), and $\varepsilon_{g}=0.4$ (Bottom), at Cell Voltage of $0.4 \mathrm{~V}$. 


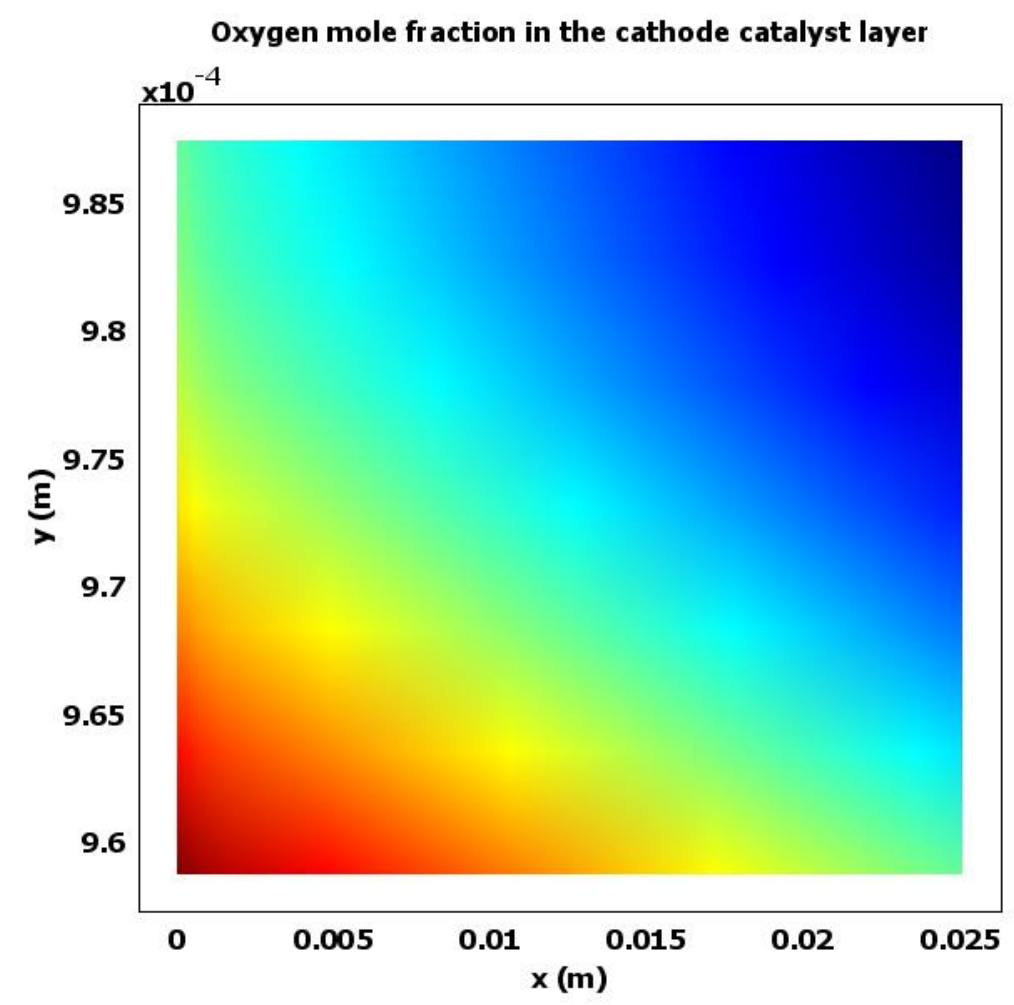

Max: 0.0915
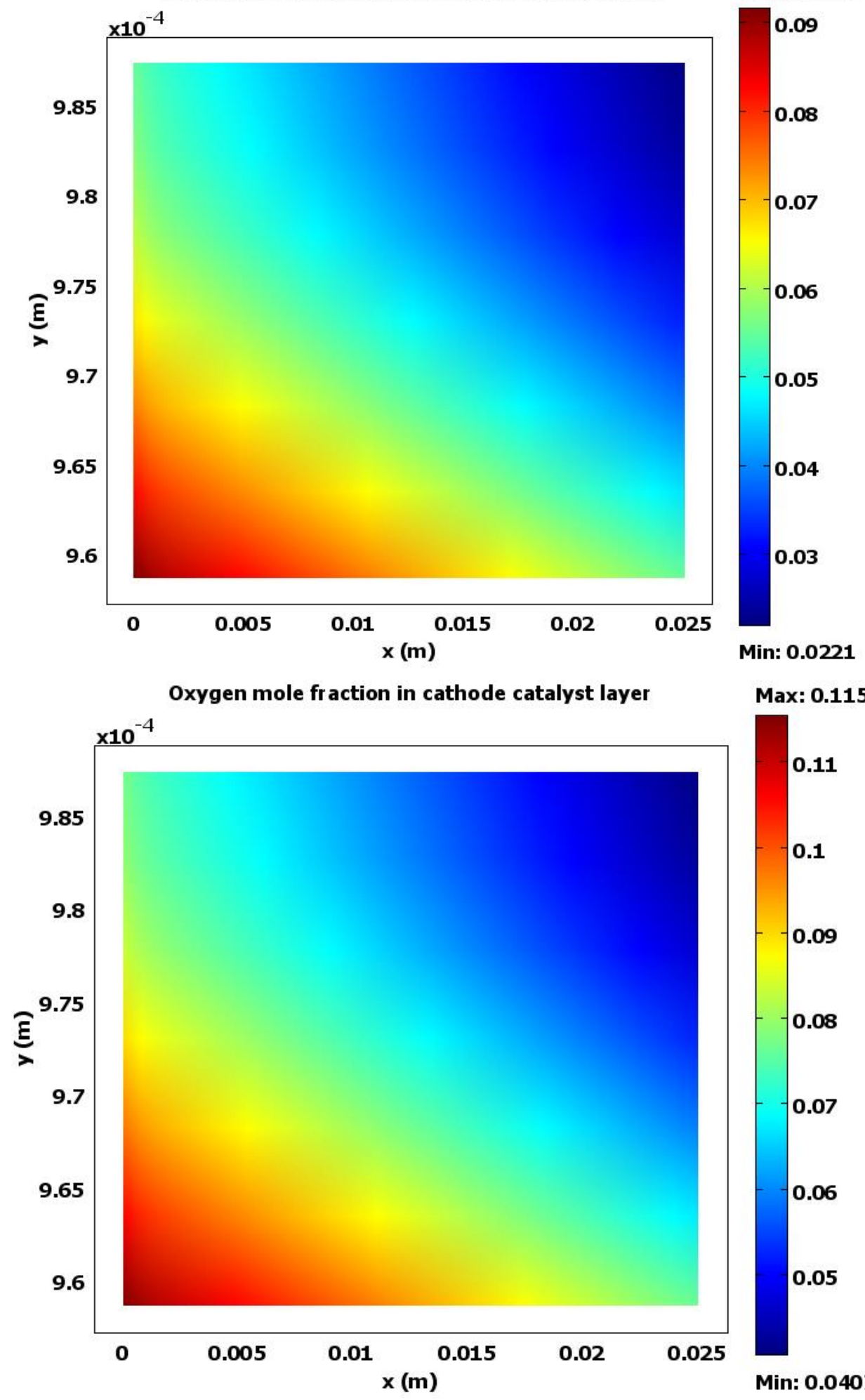

Max: 0.115

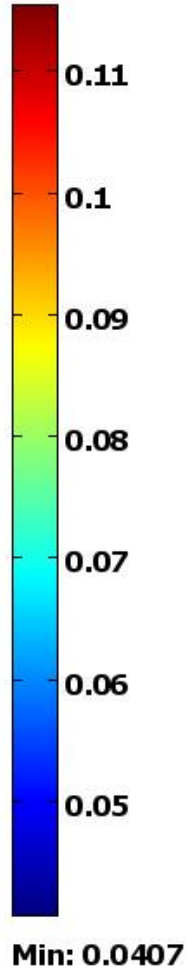

Figure 4.8 Oxygen Mole Fraction Distribution Inside Cathode Catalyst Layer with Different GDL Porosities: $\varepsilon_{g}=0.2$ (Top) and $\varepsilon_{g}=0.4$ (Bottom) at Cell Voltage $0.4 \mathrm{~V}$ 


\subsection{The Effect of the Effective Porosity of the Catalyst Layer}

The effect of the effective porosity of catalyst layer have been numerically studied in this work. The porosity of catalyst layer (CL) can impact the fuel cell performance since the oxygen transport resistance depends on it. With higher effective porosities of $\mathrm{Cl}$, more oxygen can transfer with less resistance and reach the reactive area of $\mathrm{Cl}$ allowing for a more complete electrochemical reaction, so that a higher current density is generated as shown in Figure 4.9.

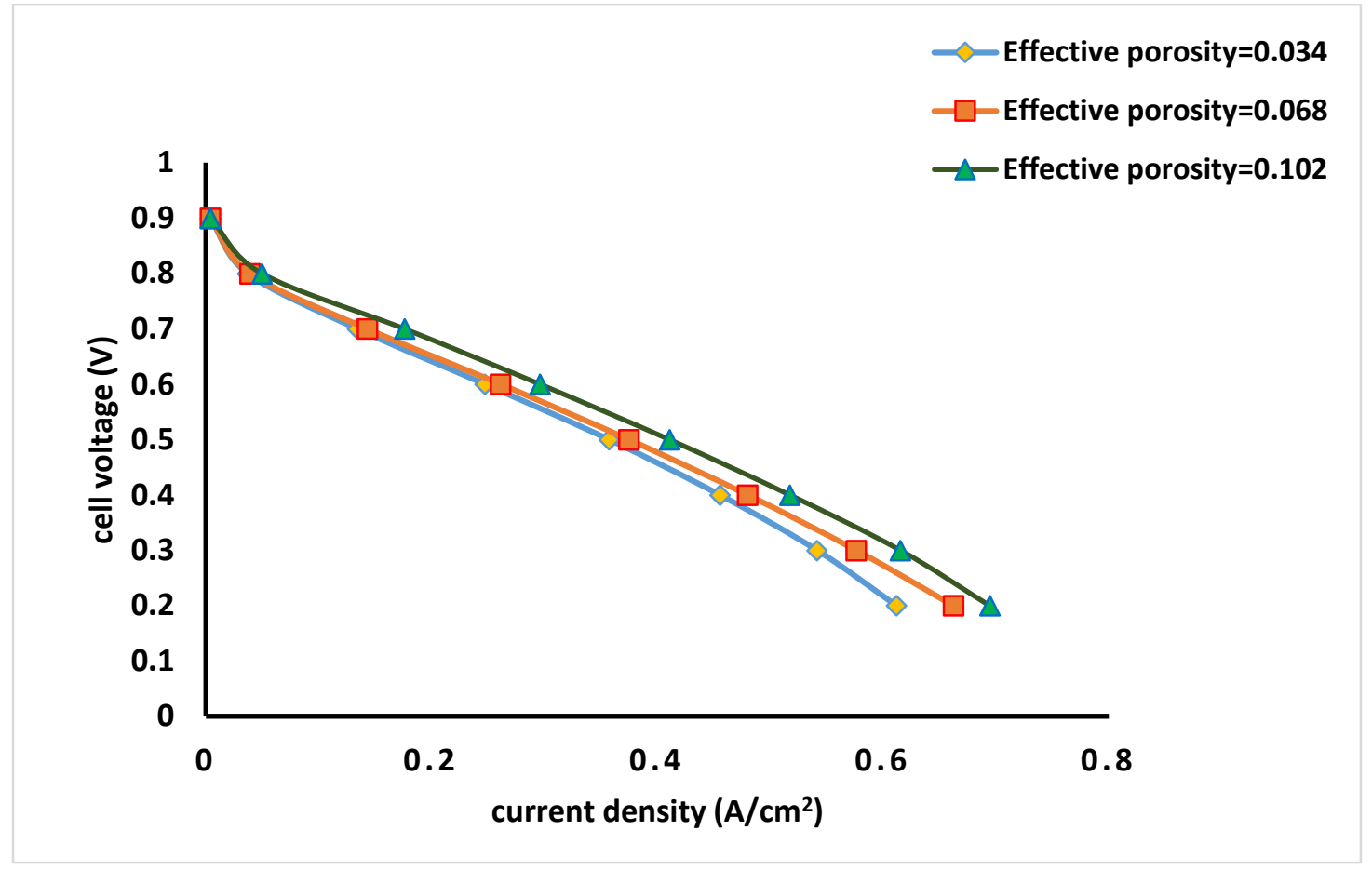

Figure 4.9 The Influence of Effective Porosity of the Catalyst Layer on the Performance of the PEM Fuel Cell.

The effects of the effective porosity of CL on the fuel cell performance are shown in Figure 4.9 using polarization curves. The polarization curves, corresponding to a three different effective porosity $\varepsilon_{c t}: 0.034,0.068$, and 0.102 for different volume fractions of the membrane in the catalyst layer: 0.2, 0.4 and 0.6, respectively. The effective porosities are calculated according to Eq. (2.7) where the membrane porosity is 0.17 . 
Figure 4.10 illustrates the oxygen mole fraction distribution inside the cathode catalyst layer. It can clearly demonstrates that when the effective porosity of catalyst layer rises, the oxygen mole fraction decreases from 0.104 to 0.102 . Oxygen is quickly consumed with effective porosity $\varepsilon_{c t}=$ 0.14 , hence more area of catalyst layer become active with higher porosity, while with effective porosity $\varepsilon_{c t}=0.034$, a small portion of the cathode catalyst layer can serve actively. The results of this numerical study are in contract with the experimental study of [18]. 


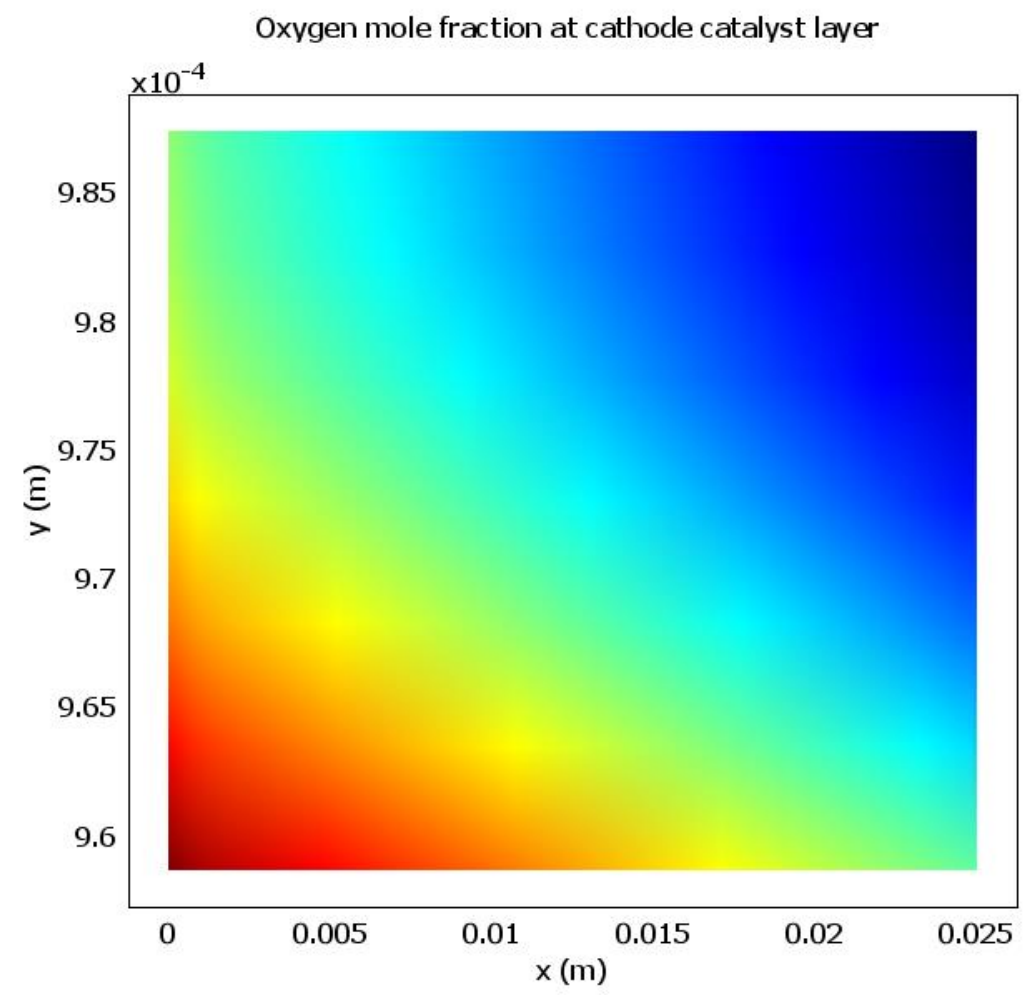

Max: 0.104

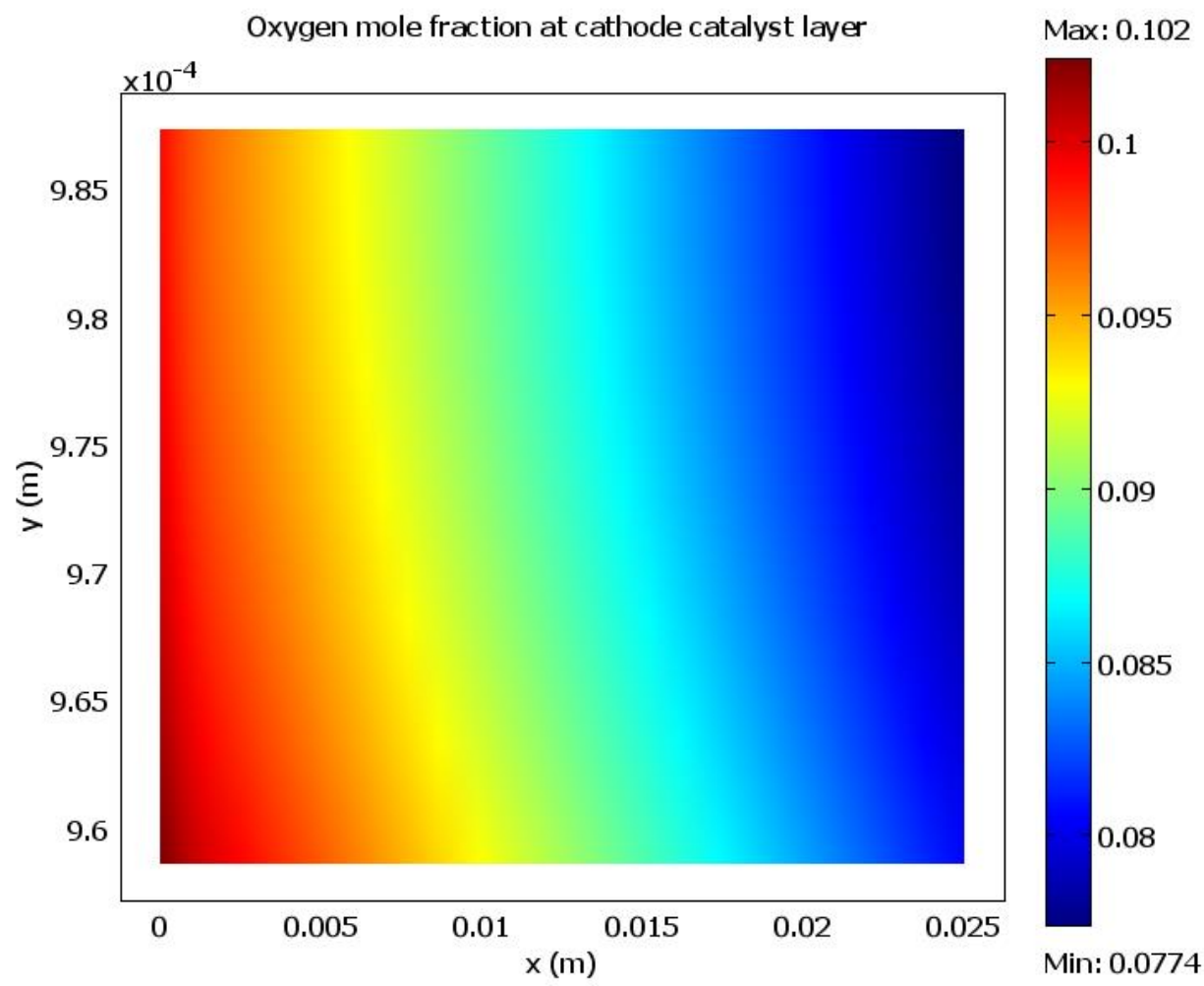

Figure 4.10 Oxygen Mole Fraction Distribution in the Cathode Catalyst Layer with Different Effective Porosity of the Catalyst Layer: $\varepsilon_{c t}=0.034$ (Top), and $\varepsilon_{c t}=0.102$ (Bottom) at Cell Voltage 0.6V. 


\subsection{Effect of Proton Conductivity}

Proton conductivity is one of the most important criteria used to evaluate the membrane as well as the cell performance of the PEM fuel cell. Polymer electrolyte membrane (PEM) fuel cells employ a polymer membrane to conduct protons from the anode to cathode. Although water and proton transport in the polymer electrolyte occurs concurrently, a simple effect of proton conductivity is studied assuming the proton conductivity to be constant inside MEA.

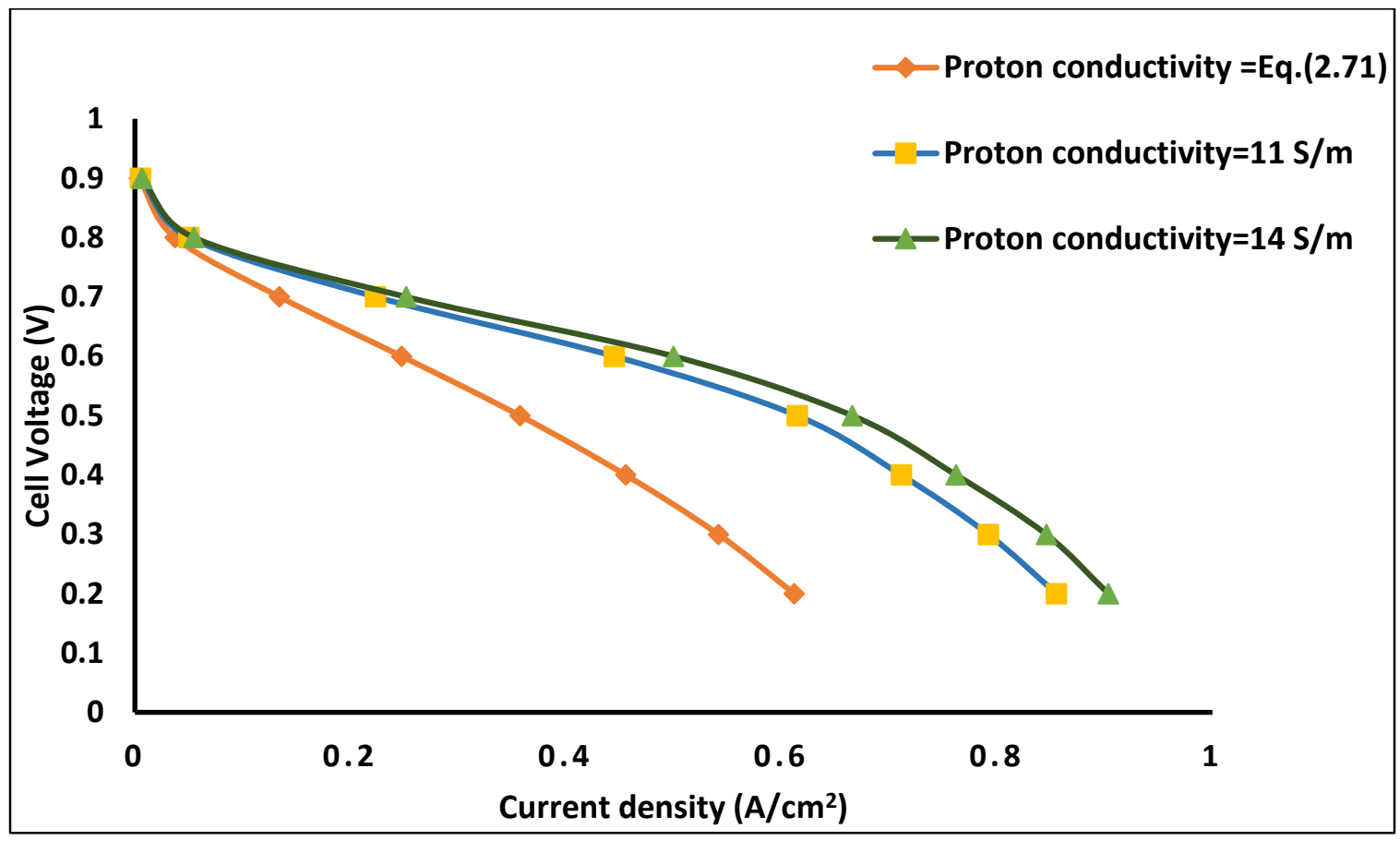

Figure 4.11 Effect of Proton Conductivity on PEM Fuel Cell Performance.

Figure 4.11 depicts the polarization curves for two constant proton conductivities, $11 \mathrm{~S} / \mathrm{m}$ and 14 $\mathrm{S} / \mathrm{m}$, and altering proton conductivity based on Eq. (2.71). It is shown that with lower current density, the changing in the constant proton conductivity of $10 \mathrm{~S} / \mathrm{m}$, and $14 \mathrm{~S} / \mathrm{m}$ has no significant influence, while the influence is very significant with higher current density. The comparison shown in Figure 4.11 indicates that with a lower proton conductivity the current density is decrease and the fuel cell can better perform if a higher proton conductivity of $14 \mathrm{~S} / \mathrm{m}$ is employed. Increasing water content, which is mainly related to operating conditions and another design parameter, ionomer fraction in the catalyst layer, leads to Increasing the proton conductivity. 
To achieve a desired current density, various potential losses should be reduced. Due to ohmic resistance, protons passing through the membrane faces resistance that results in potential loss. Figure 4.12 demonstrates the membrane-phase potential loss in membrane for two constant proton conductivities at $11 \mathrm{~S} / \mathrm{m}$ to $14 \mathrm{~S} / \mathrm{m}$, respectively. The membrane phase potential loss decreases from $0.158 \mathrm{~V}$ to $0.153 \mathrm{~V}$ with the increase of proton conductivity from $11 \mathrm{~S} / \mathrm{m}$ to $14 \mathrm{~S} / \mathrm{m}$. Figure 4.13 shows the membrane-potential loss across the membrane $(\mathrm{M})$ at $\mathrm{x}=0.0118 \mathrm{~m}$. This clearly shows that the potential loss decreases with an increase in the protonic conductivity, which indicates that higher proton conductivity can reduce the proton resistance in the membrane. 

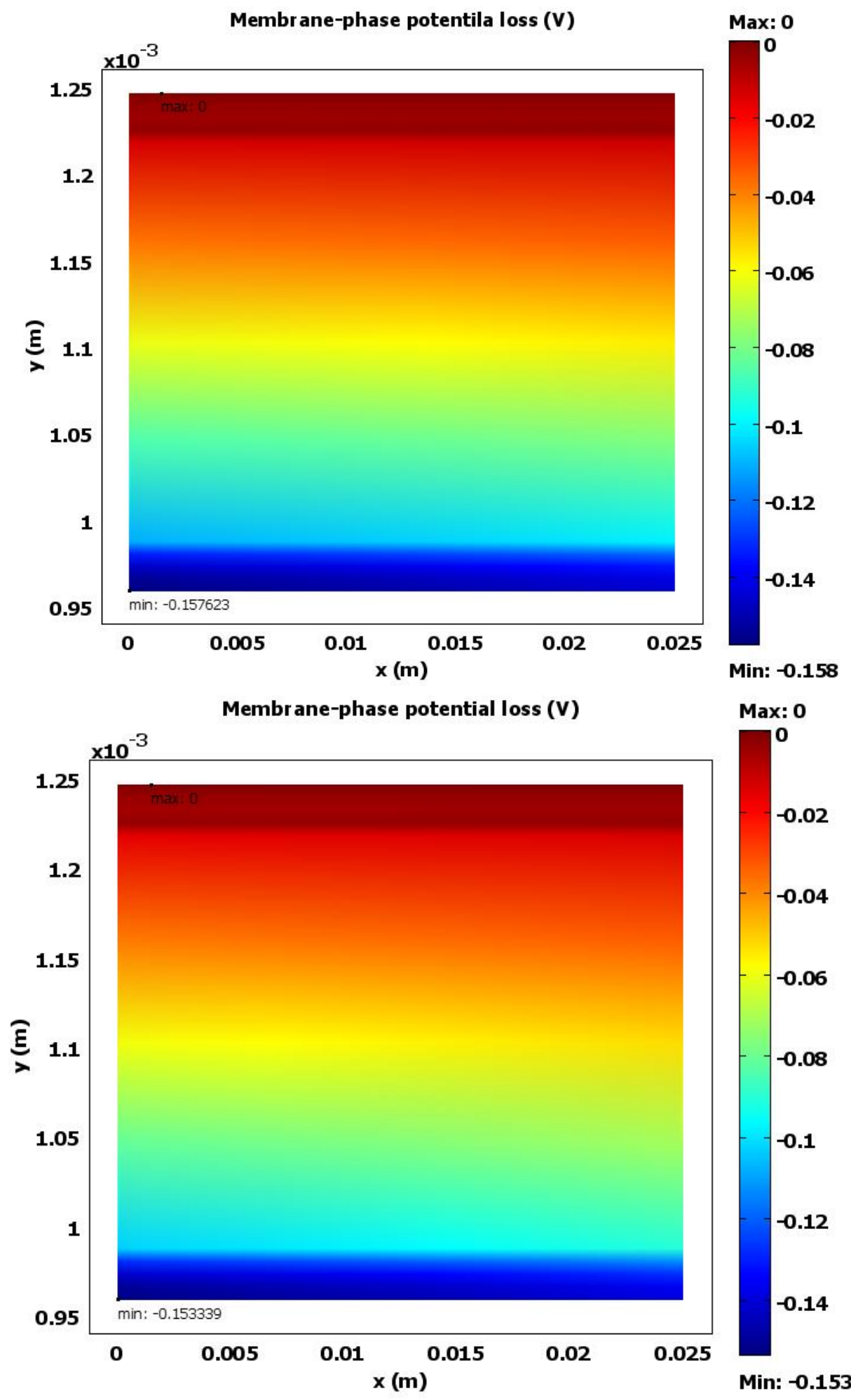

Figure 4.12 Membrane-Phase Potential Losses for Different Proton Conductivities: $11 \mathrm{~S} / \mathrm{m}$ (Top) and $14 \mathrm{~S} / \mathrm{m}$ (Bottom), at Cell Voltage 0.6V 


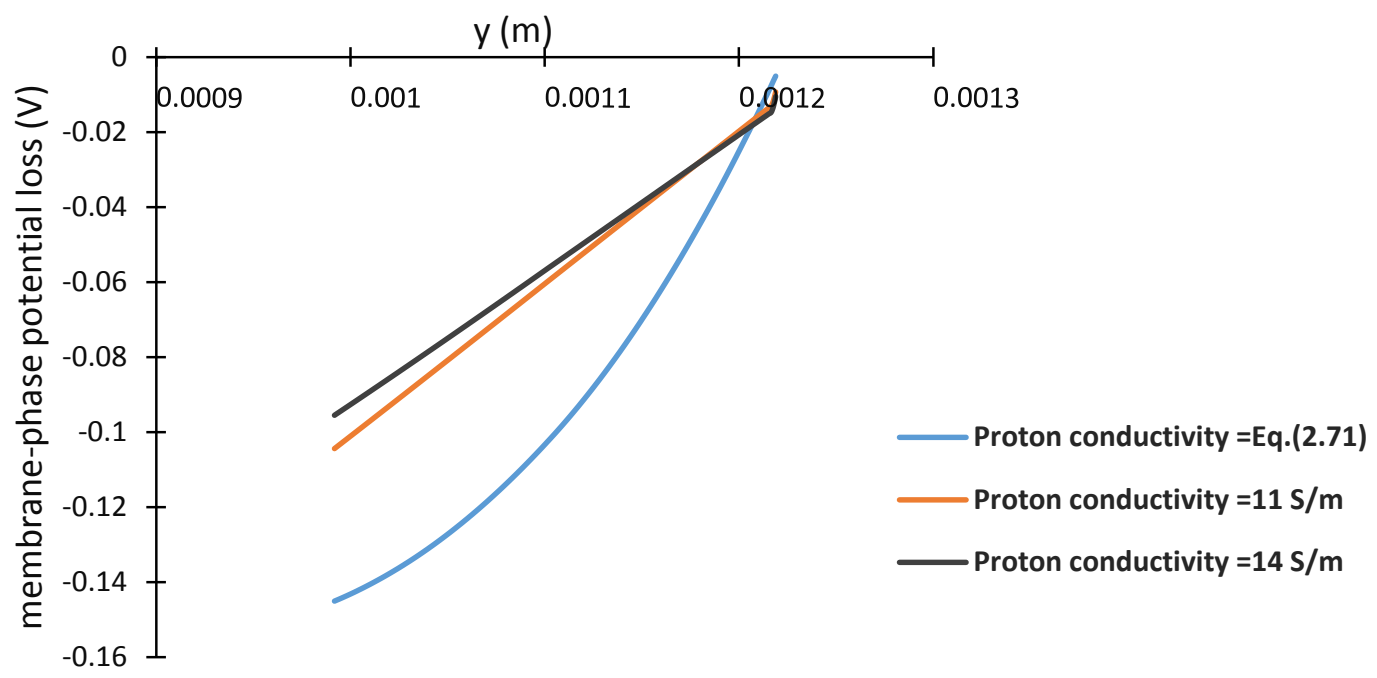

Figure 4.13 Membrane-Phase Potential Losses for Different Proton Conductivities: at $\mathrm{x}=0.0118 \mathrm{~m}$, for Cell Voltage $0.6 \mathrm{~V}$

\subsection{Effect of Operating Pressure}

Pressure is another operating parameter that plays an important role in the cell performance. A PEM fuel cell may be operated at ambient pressure or using pressurized gas supplies upto 6atm and at temperatures between $50-90^{\circ} \mathrm{C}$ [68]. In this section, the fuel cell parameters are kept as specified for a base case in Table 2.2, while varying the operating pressure. Figure 4.14 displays polarization curves for four different pairs of testing pressure conditions: P (1-1), that is, 1atm at both anode and cathode sides; P (2-2), which is 2atm at both sides of the anode and the cathode, and P (1-3), which 3atm at cathode side and is 1atm at the anode side, and P (3-5) representing $5 \mathrm{~atm}$ at the cathode side and $3 \mathrm{~atm}$ at the anode side. Figure 4.14, shows that a higher performance can be achieved when fuel cell operated with higher pressure, and differences in current density are most pronounced for low pressure operation, and that is, properly pressurized reactant gas streams will help increase the limit current density. When highly pressurized oxygen and hydrogen are supplied more reactant gases can be provided to the electrochemical reaction, resulting in a 
higher electrode current density and a better cell performance. Figures 4.15 and 4.17 show the hydrogen and oxygen mole fraction inside the anode and cathode side respectively. Figure 4.15 illustrates that when pressure value rises the minimum value of the hydrogen mole fraction at anode side will increase from 0.652-0.684. At the same time as on the cathode side the maximum values of oxygen mole fraction increases from 0.131 to 0.132 as well as the minimum value increases from 0.0665 to 0.0705 as shown in Figure 4.17. The water vapour mole fraction at the anode side and the cathode side decreases with a higher reactants pressure, indicating that the more reactants are supplied at higher pressure the less water vapour concentration is produced as shown in Figures 4.16 and 4.18. It is clearly observed that more reactants are supplied at the higher pressure, allowing for more complete electrochemical reaction and better performance for fuel cell.

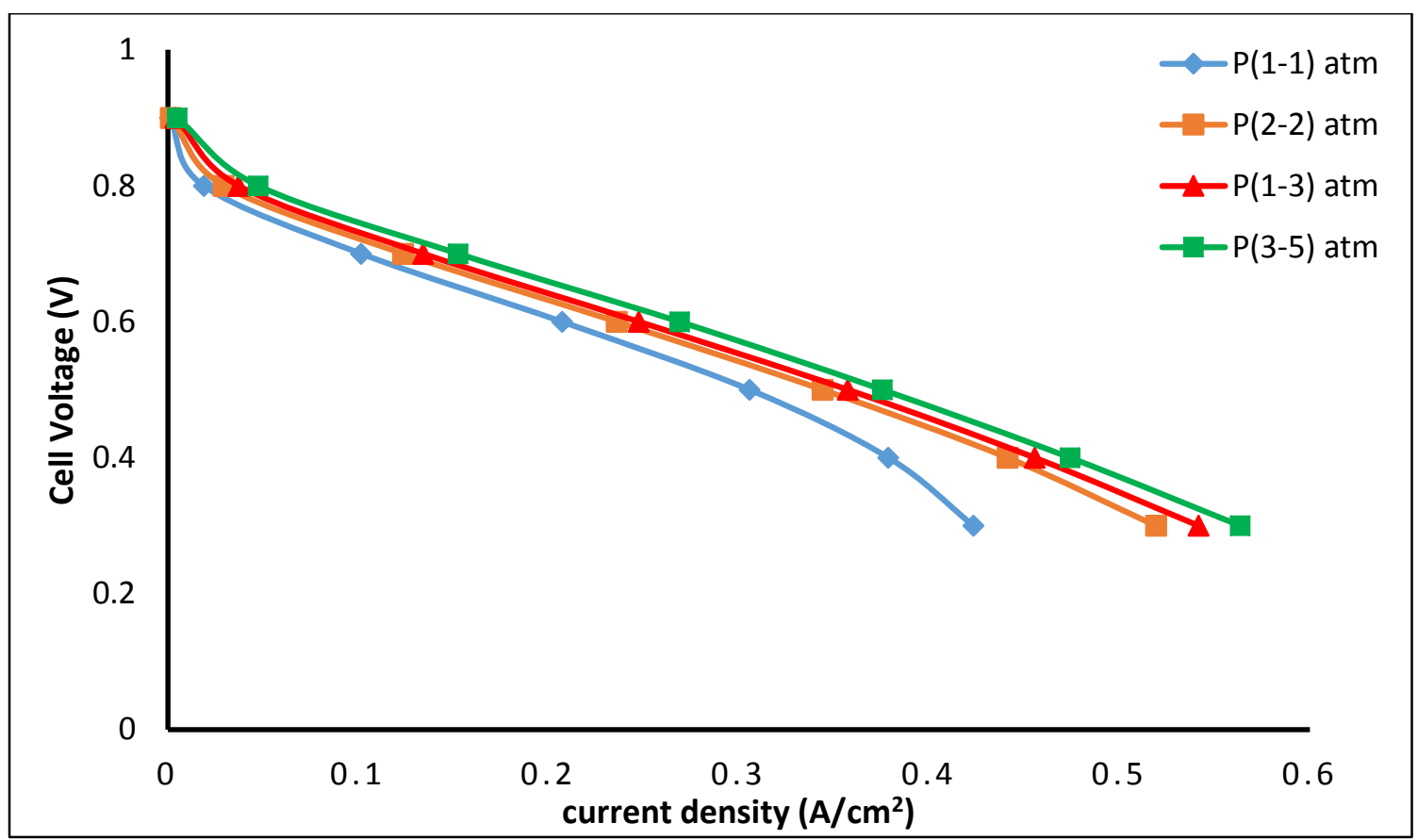

Figure 4.14 Cell Performance at Different Operating Pressure Loading 

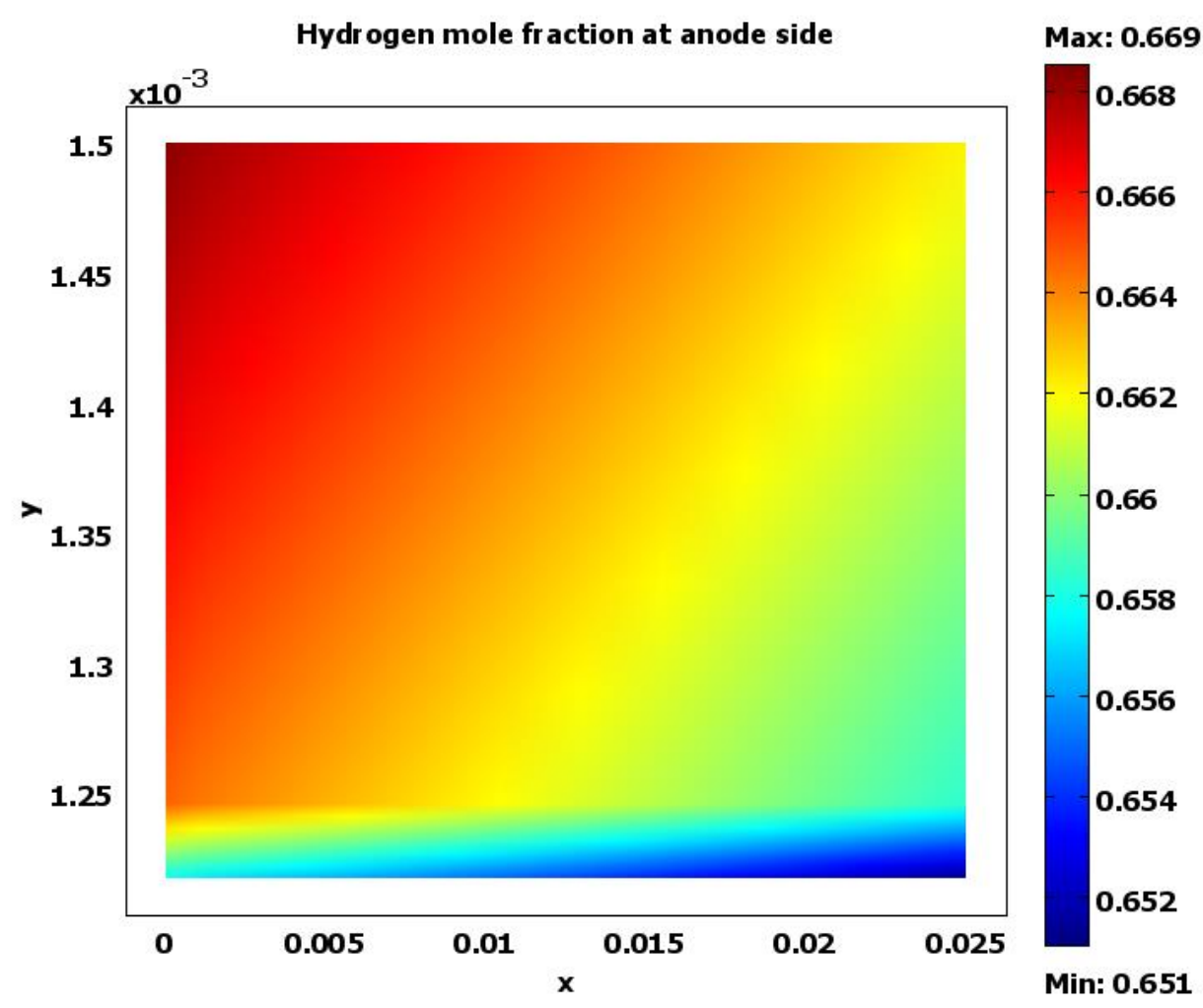

Hydrogen mole fraction at anode side

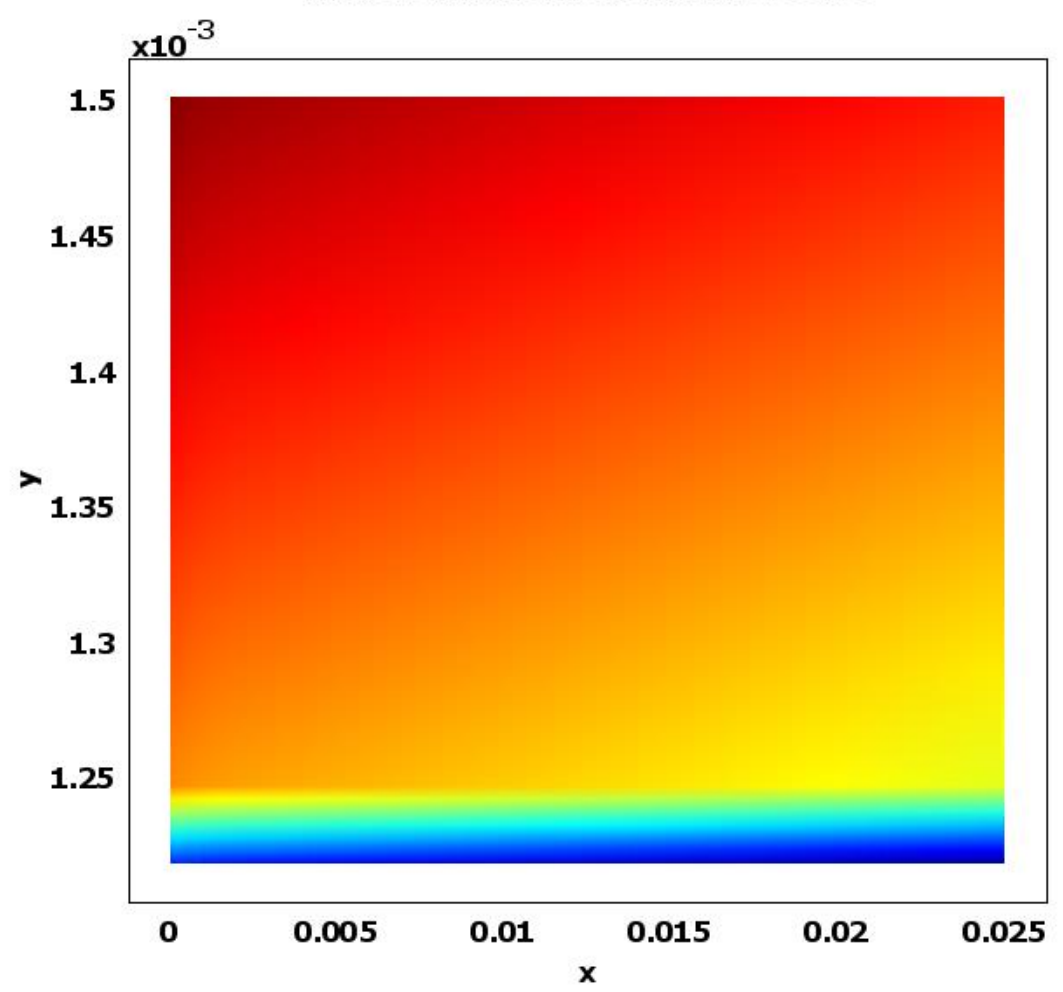

Max: 0.696

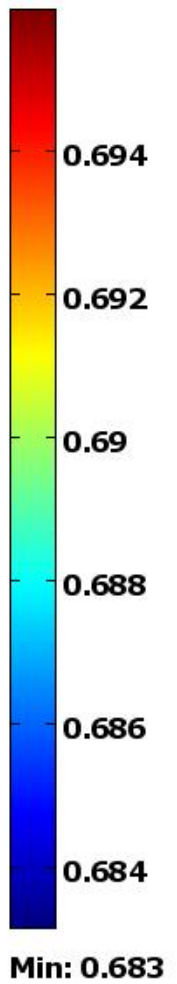

Figure 4.15 Hydrogen Mole Fraction Distribution at Anode Side under Different Operating Pressure Conditions: $\mathrm{P}(1-3)$ top and P (3-5) bottom, at the Cell Voltage 0.6V 


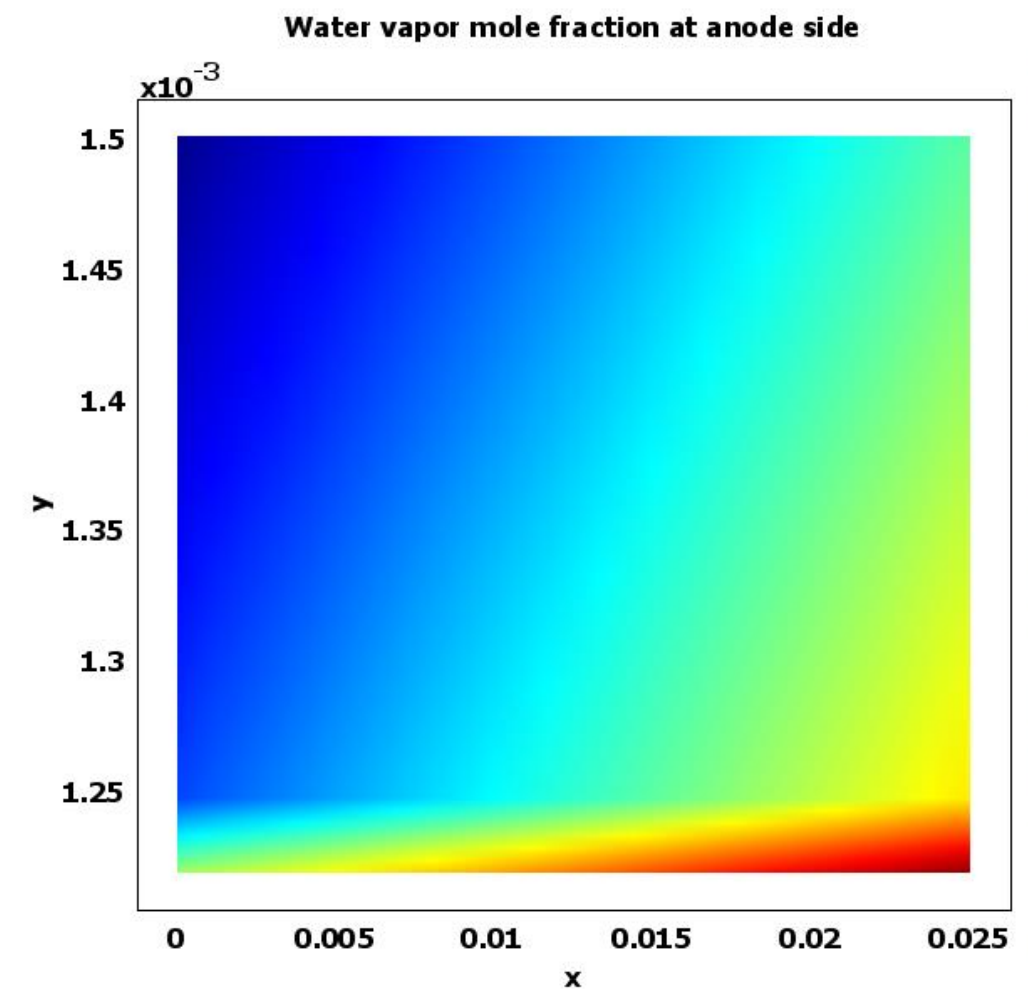

Max: 0.102

0.102

0.101

0.101

0.1

0.1

0.099

0.099

Water vapor mole fraction at anode side

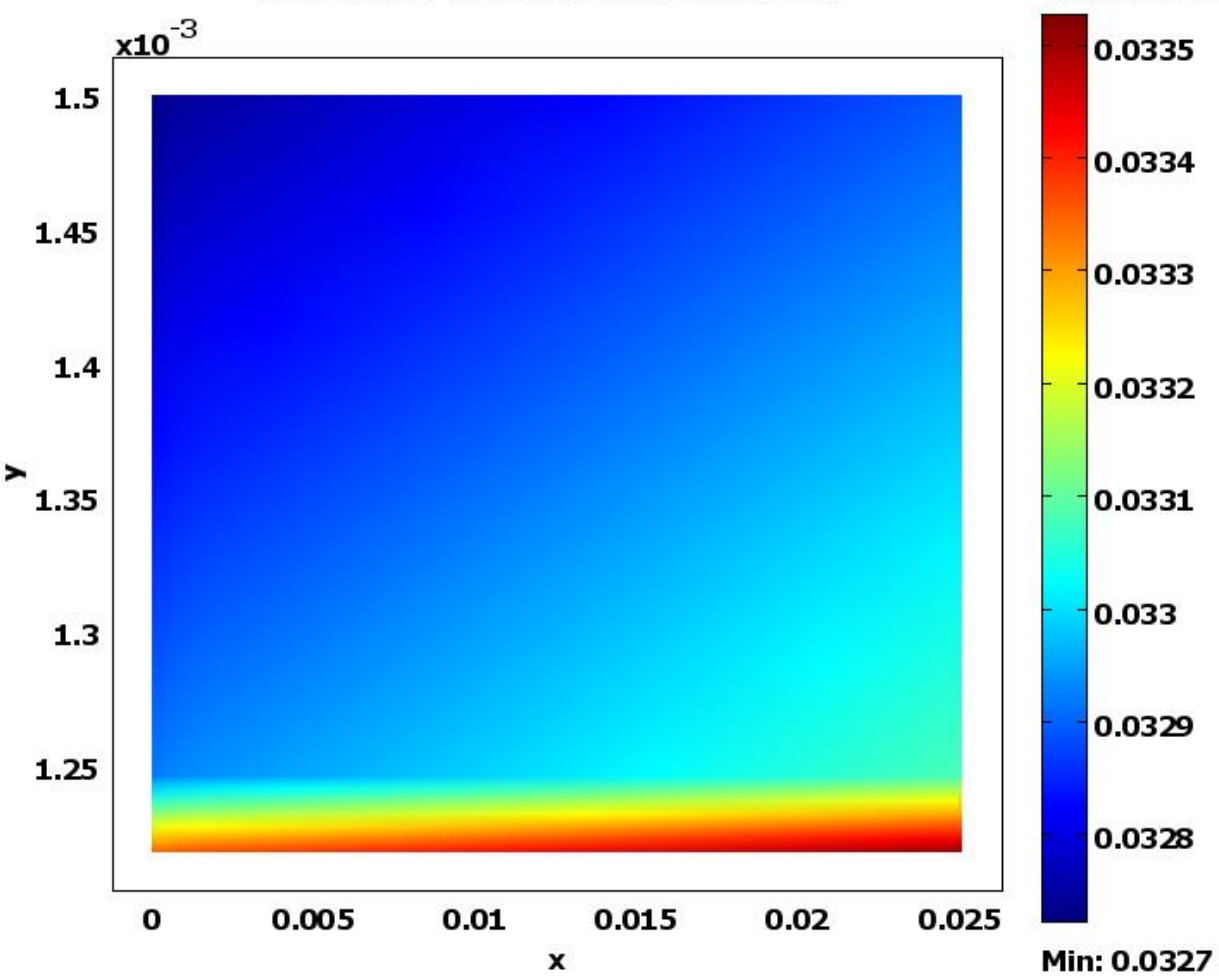

Figure 4.16 Water Vapor Mole Fraction Distribution at Anode Side under Different Operating Pressure Conditions: P (1-3) top and P (3-5) bottom, at the Cell Voltage 0.6V 


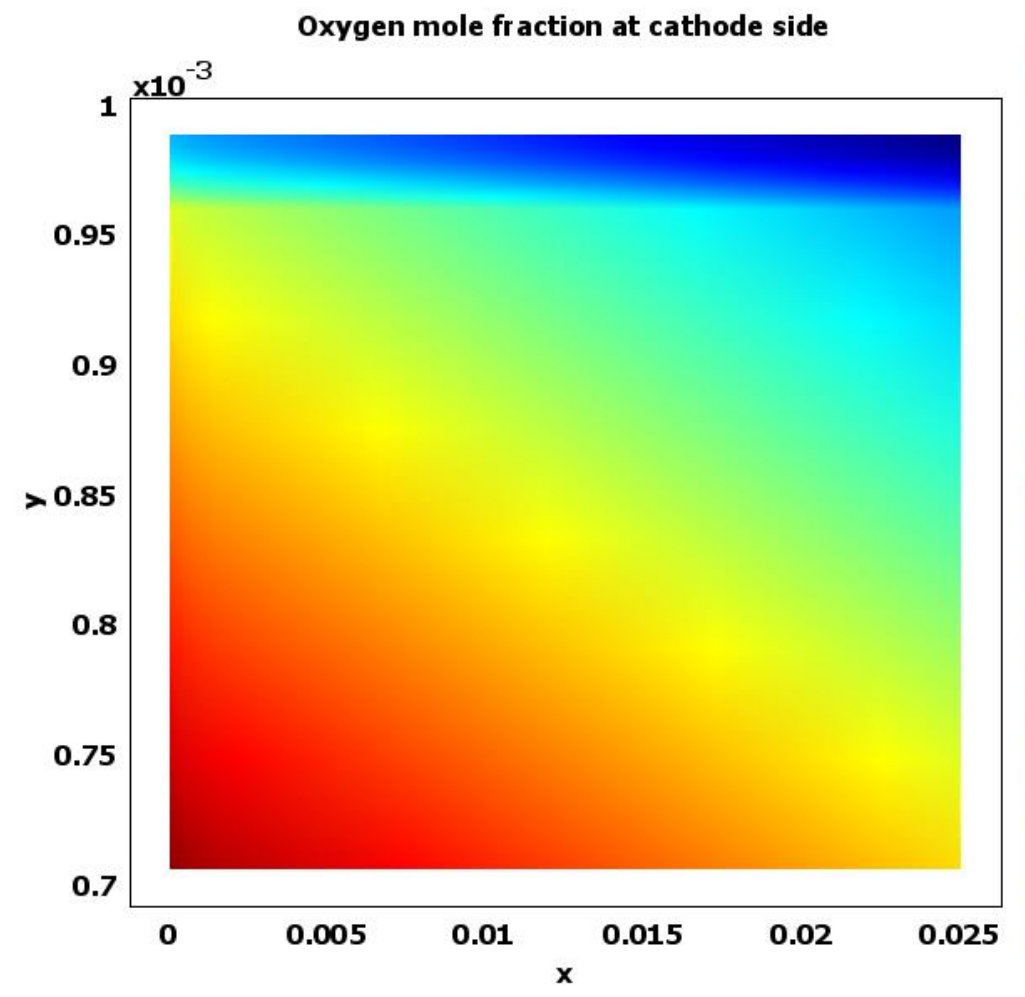

Max: 0.131

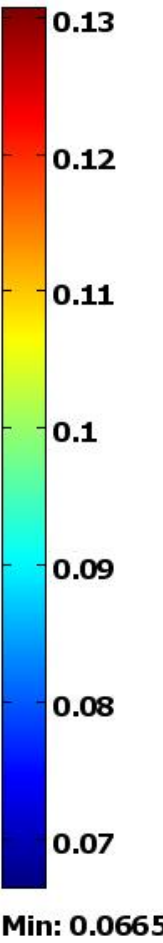

Oxygen mole fraction at cathode side

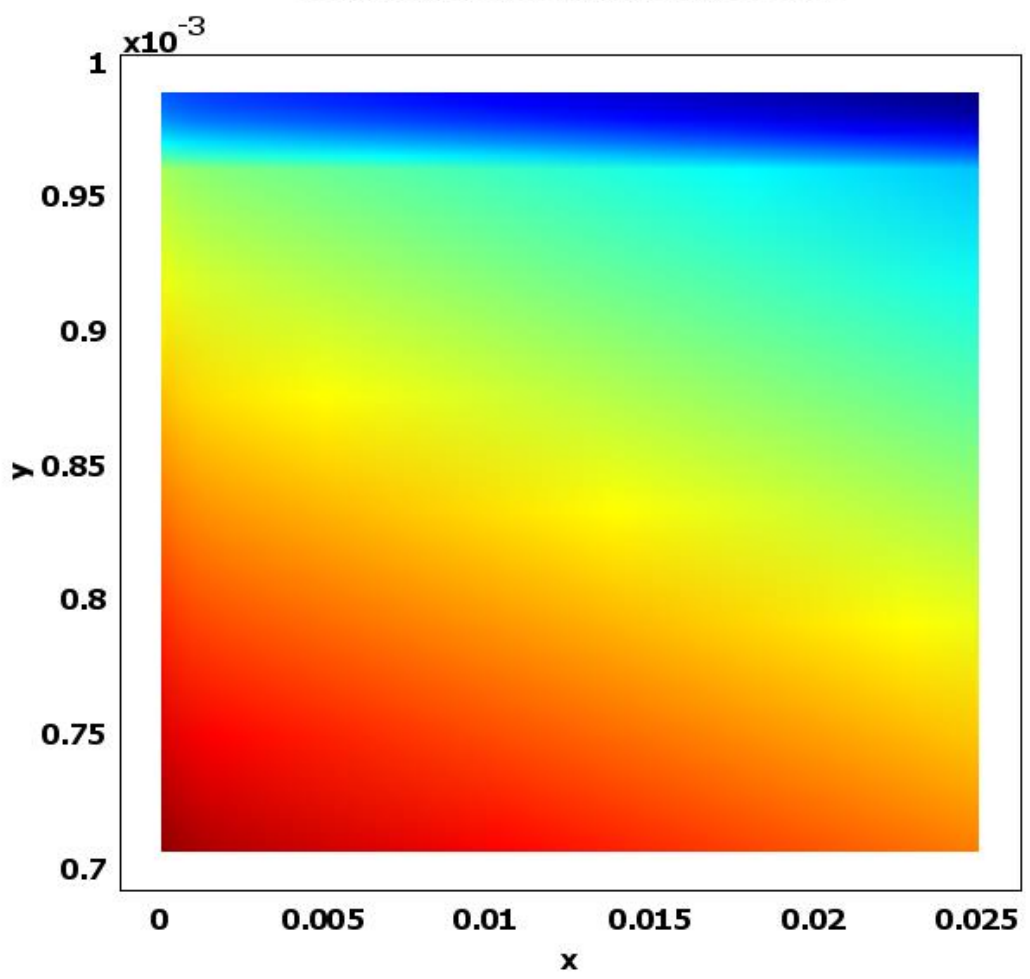

Max: 0.132

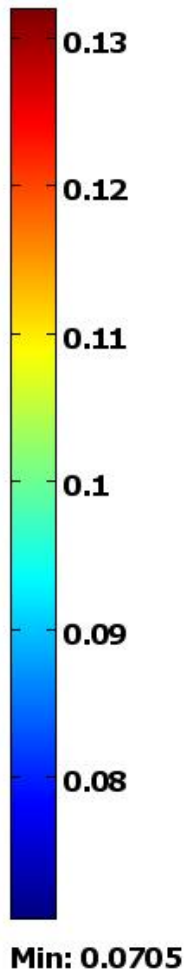

Figure 4.17 Oxygen Mole Fraction Distribution at Cathode Side under Different Operating Pressure Conditions:

$\mathrm{P}(1-3)$ top and $\mathrm{P}(3-5)$ bottom, at the Cell Voltage $0.6 \mathrm{~V}$ 


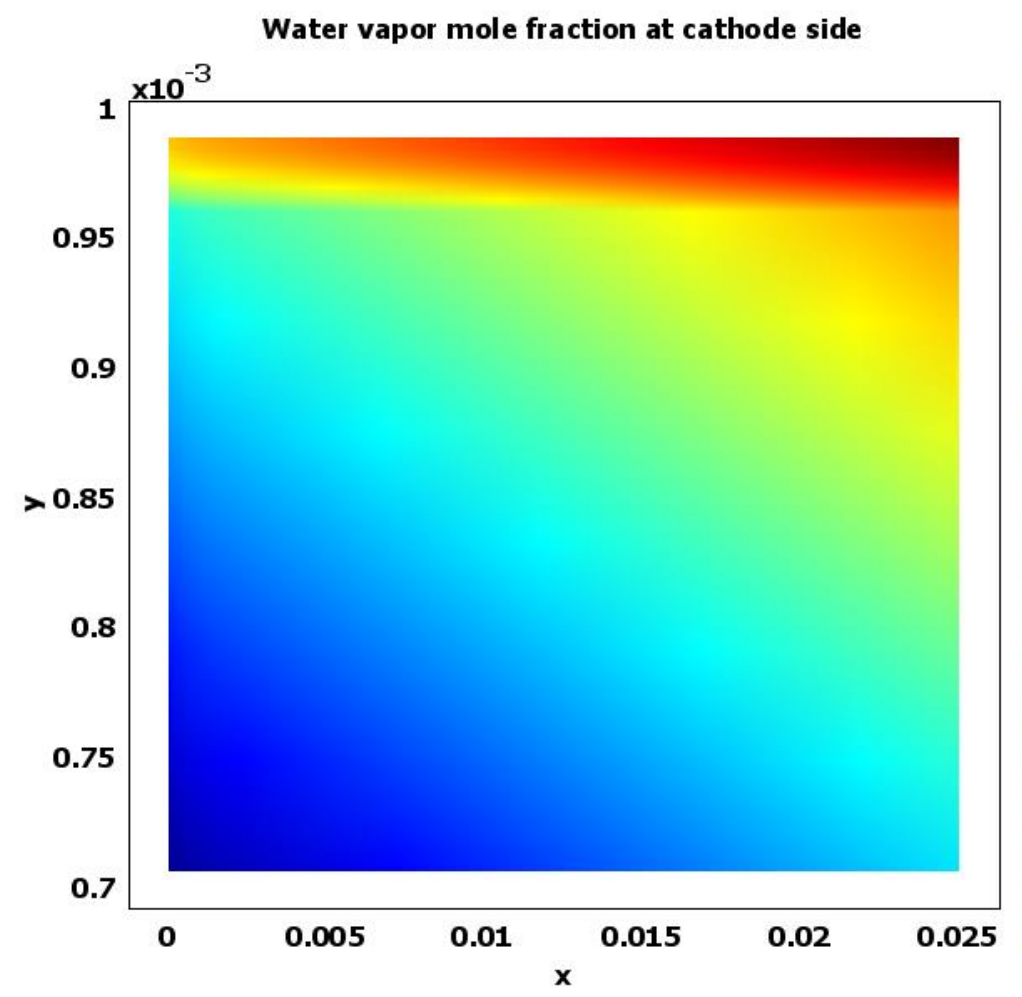

Max: 0.174

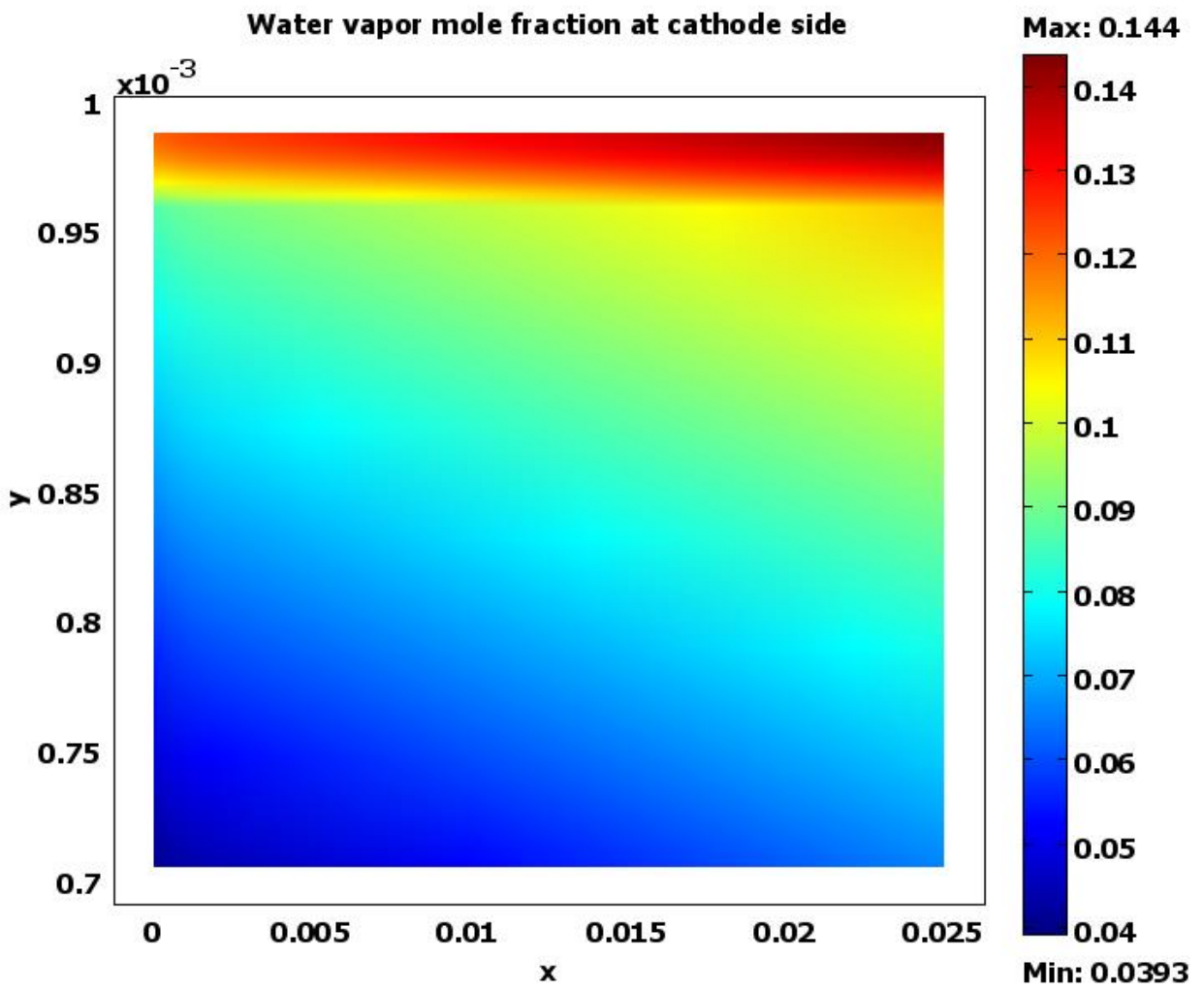

Figure 4.18 Water Vapor Mole Fraction Distribution at Cathode Side under Different Operating Pressure Conditions: P (1-3) Top and P (3-5) Bottom, at the Cell Voltage 0.6V 


\subsection{The Effect of Membrane (M) Porosity}

The membrane is a porous media that liquid water and protons can pass through its pores. Membrane is bonded with two porous catalyst layers into each side, thus the membrane separates the anode and cathode catalyst layers. The membranes main function is to conduct hydrogen ions $H^{+}$(protons), but not electrons to avoid short circuit in fuel cell, and the membrane must only allow liquid water to pass to the other side, not gas to avoid the gas crossover problem that could happened in the fuel cell. Selecting the suitable porosity for the membrane is very important for the processes occurring in a membrane layer. To understand the effects of the membrane porosity in the fuel cell performance, two membrane porosities have been chosen $\varepsilon_{m}=0.17$ and $\varepsilon_{m}=0.28$.

Figure 4.19 shows the effect of the different porosity of membrane on the polarization curves. The obtained results show that the porosity variation in membrane layer has no significant influence on polarization curve with a low current density, however a slight influence can be notice with higher current density.

The diffusion of dissolved oxygen to the reaction side of cathode catalyst layer and the mass transport losses that results from the diffusion of oxygen across the porous electrode at the cathode side determines the performance of a PEM fuel cell [27]. Figure 4.20 shows the oxygen mole fraction distribution inside fuel cells with different $M$ porosities. With higher membrane porosity 0.28 the mass transport of the reactant and product water is not inhibited. The more oxygen mole fraction with higher membrane porosity indicates less consumption of oxygen and thus less producing of water mole fraction as shown in Figure 4.21.

Due to the effects of the electro-osmatic drag in the membrane, membrane layers containing larger porosity 0.28 leads to less water content in the membrane and since less proton conductivity leading to higher membrane-phase potential loss, as a results of that less water content can be found in the membrane and catalyst layers with higher porosity, as shown in Figures 4.22 and 4.23 


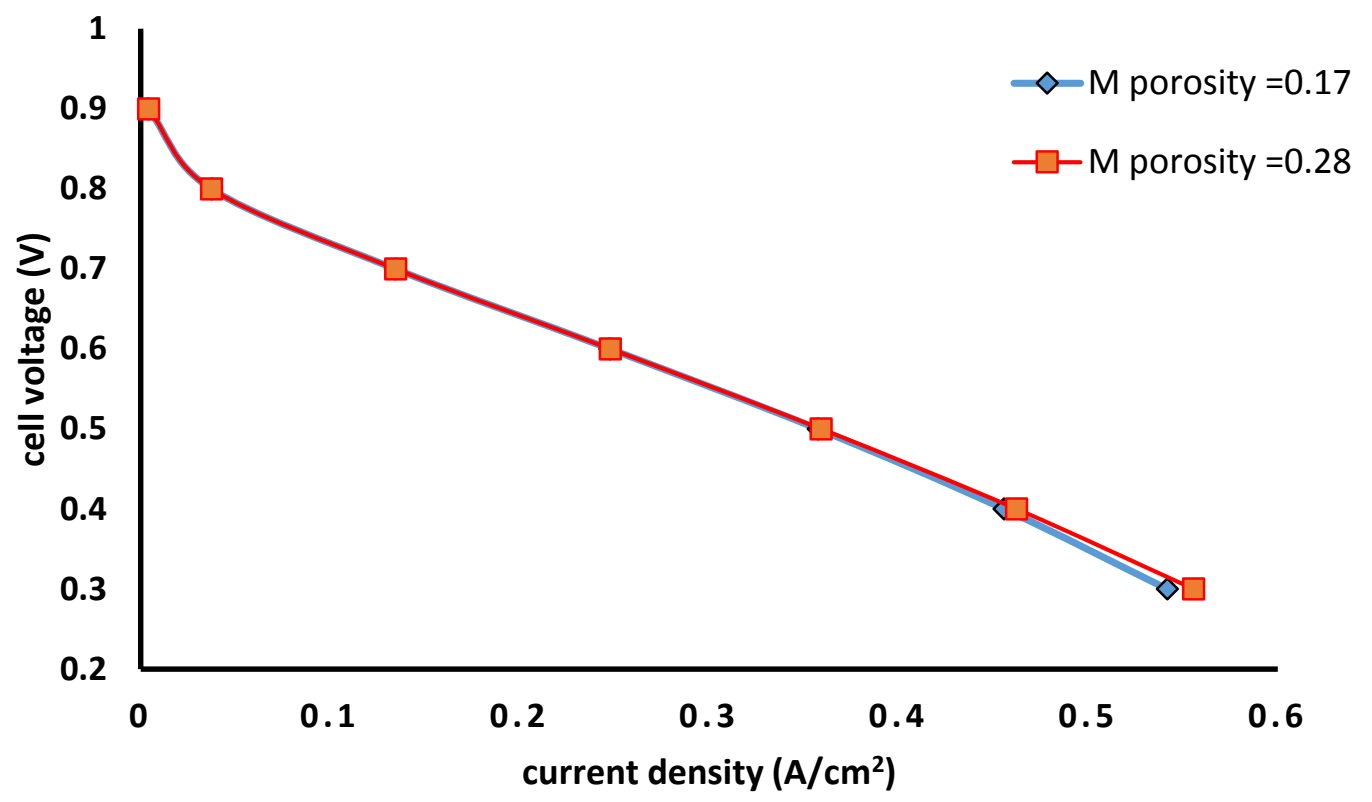

Figure 4.19 Effects of Membrane Porosity on PEM Fuel Cell Performance

The proton conductivity is directly associated with water content in the membrane, thus an appropriate water content balance is desirable in the membrane to avoid dehydration the membrane or flooding the electrode. Considerable effects have been noticed for the membrane porosity in the water content in the membrane and further study is recommended. 


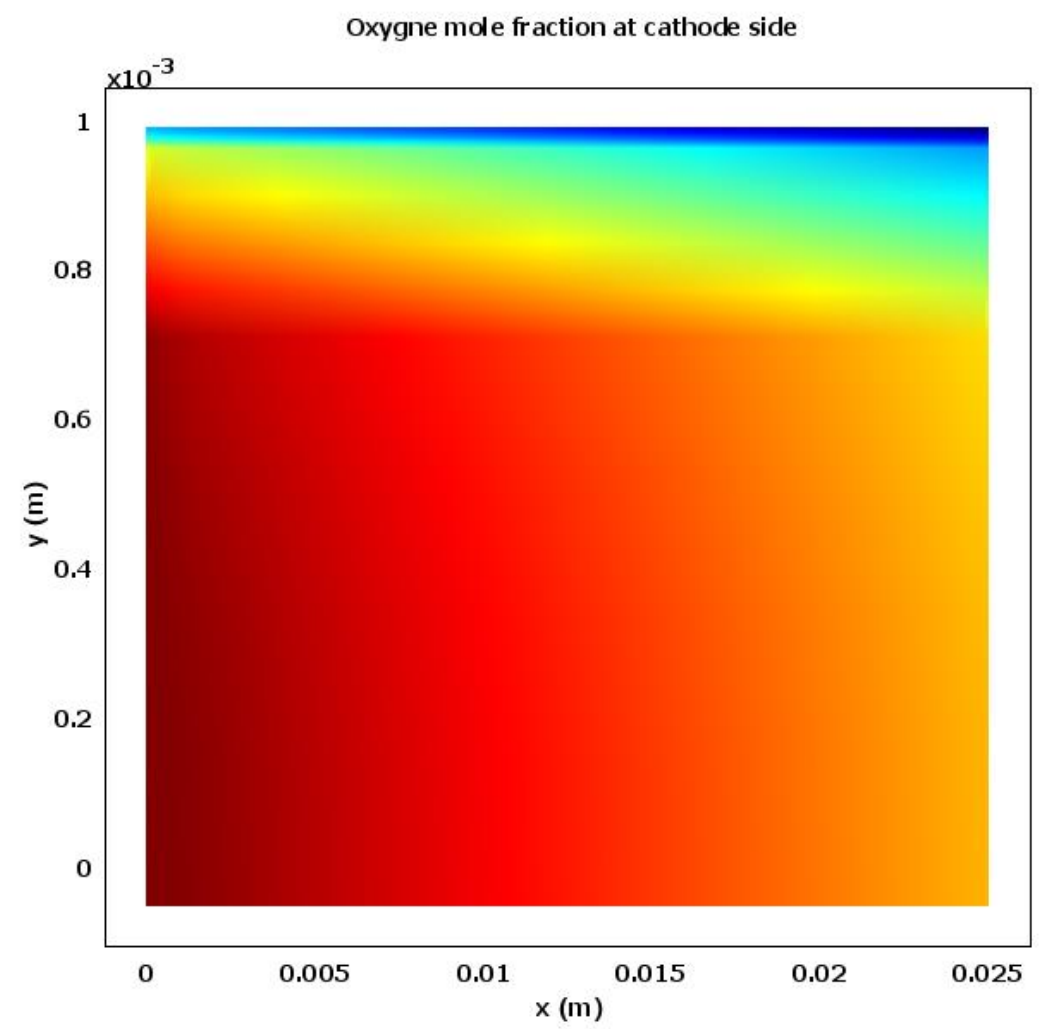

Max: 0.131

0.13

0.12

$-0.11$

0.1

$-0.09$

Oxygen mole fraction at cathode side

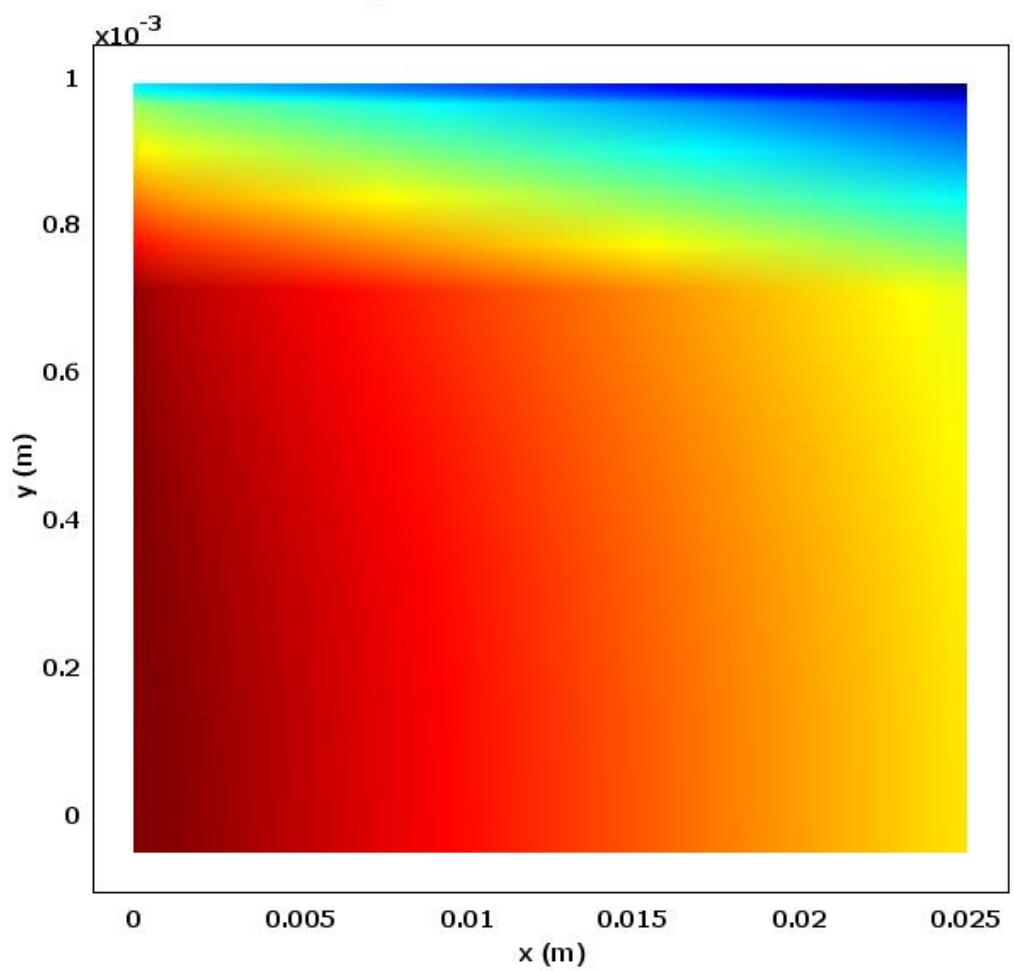

Max: 0.131

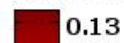

$-0.12$

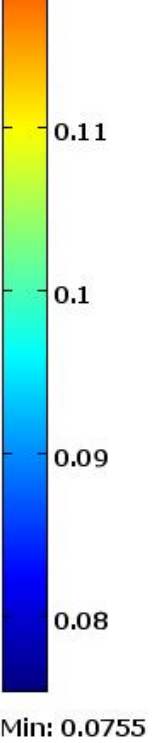

Figure 4.20 Oxygen Mole Fraction Distribution inside Fuel Cells with Different Membrane Porosities: $\varepsilon_{m}=0.17$ (Top), and $\varepsilon_{m}=0.28$ (Bottom), at Cell Voltage 0.6V. 


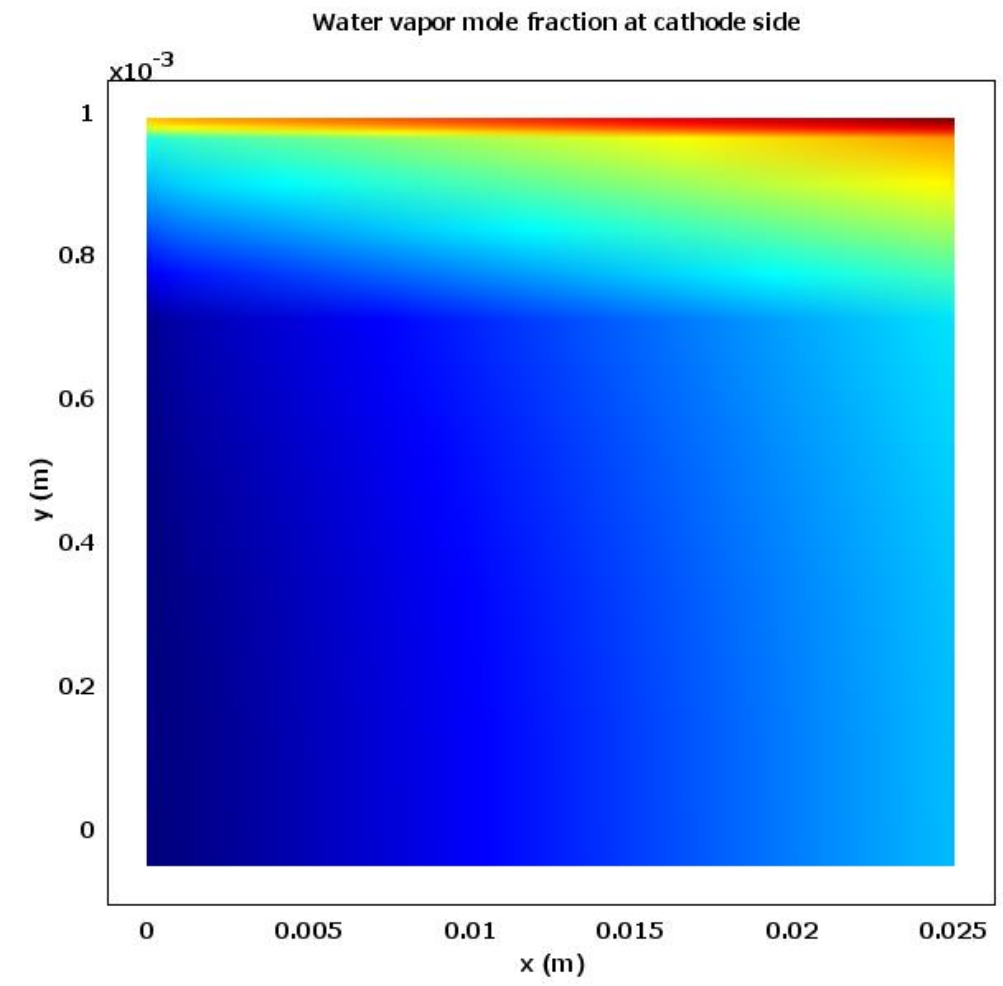

Max: 0.174

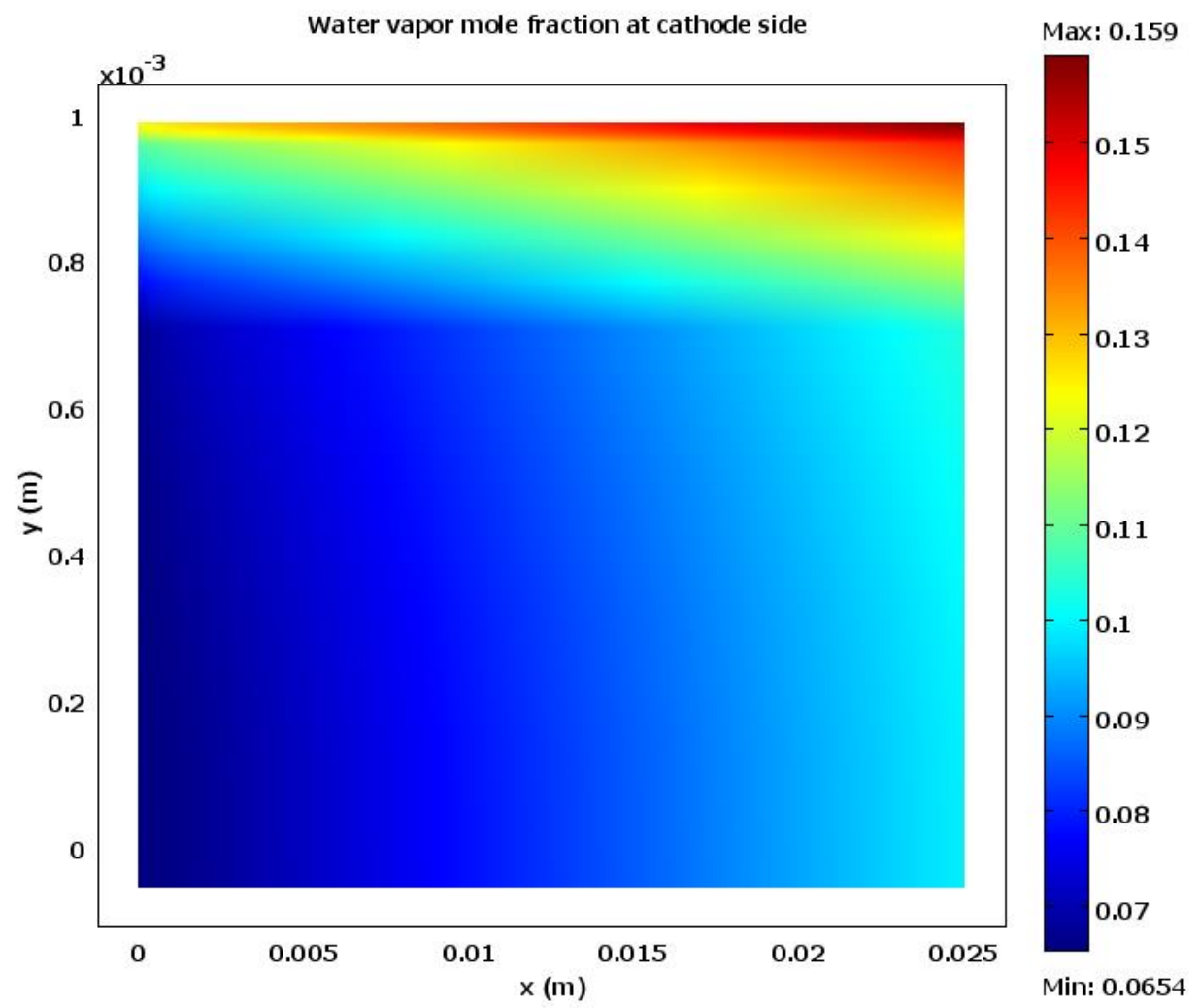

Figure 4.21 Water Vapor Mole Fraction Distribution at the Cathode Side with Different Membrane Porosities: $\varepsilon_{m}=0.17$ (Top), and $\varepsilon_{m}=0.28$ (Bottom), at Cell Voltage 0.6V. 

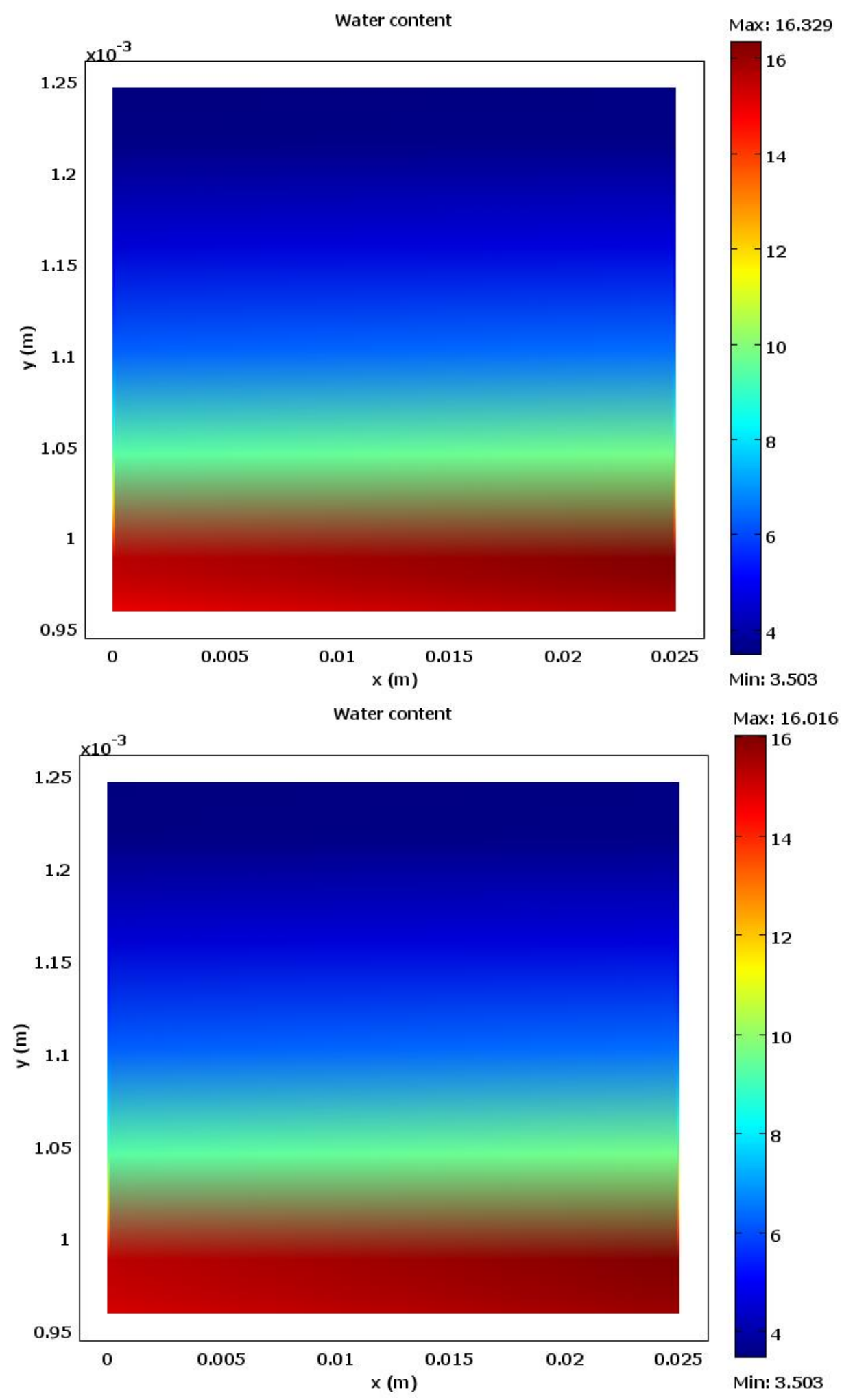

Figure 4.22 Water Content at Cell Voltage 0.6V with Different Membrane Porosities: $\varepsilon_{m}=0.17$ (Top), and $\varepsilon_{m}=0.28$ (Bottom), 

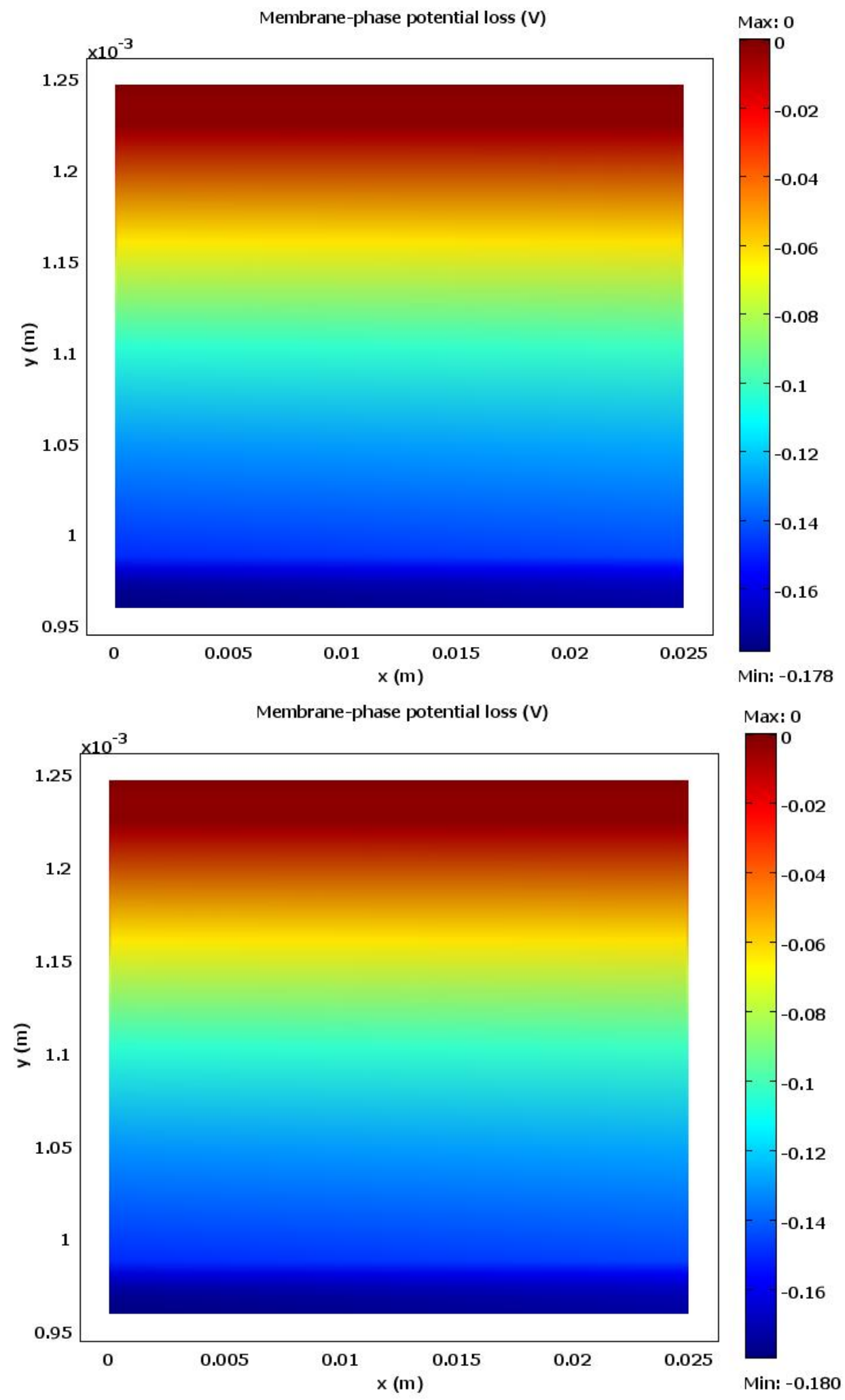

Figure 4.23 Membrane-Phase Potential Loss for Different Membrane Porosities: $\varepsilon_{m}=0.17$ (Top), and $\varepsilon_{m}=0.28$ (Bottom), at Cell Voltage $0.6 \mathrm{~V}$. 


\subsection{Effects of Air Inlet Velocity at Cathode Side}

Air supplies oxygen to the cathode side of PEM fuel cell to participate in the electrochemical reaction to generate electric energy. Another function of the air is to remove the excess water from the fuel cell system, or in a detrimental case dry the cell out [74]. Thus it is essential to select the right airflow to avoid drying the member out. In this section, the effects of changing the air inlet velocity at the cathode side on the fuel cell performance have been numerically investigated in this study. Figure 4.24 illustrates the polarization curves, corresponding to two different velocities $U_{c}=0.1185 \mathrm{~m} / \mathrm{s}$ and $U_{c}=1.45 \mathrm{~m} / \mathrm{s}$. Changing the air inlet velocity does not change the polarization curve significantly at lower current densities, however lowering the air flowrate would reduce cathode performance and thus reduce the PEM fuel cell performance, at higher current densities as shown in Figure 4.24.

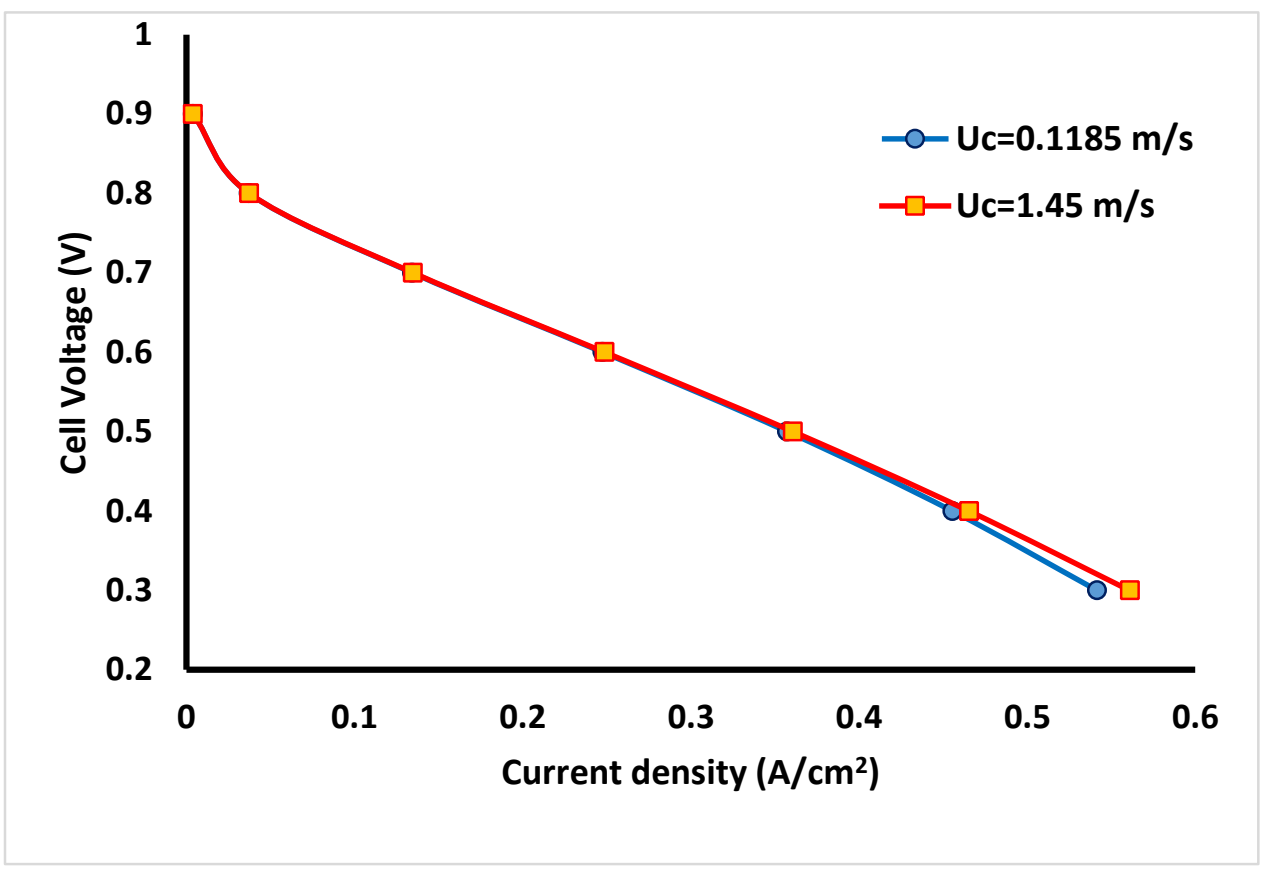

Figure 4.24 Effect of Air Inlet Velocity on PEM Fuel Cell Performance 
The energy equation that is employed in this model considers the heat transfer by convection in the gas channels and the heat transfer by conduction in the entire domains. The obtained results show that the pathway of the convective heat flux is identical to the flow pathway, (refer to Figure 3.4 for the $x-y$ plane, Ch.3), while the temperature gradient determines the pathway of the conductive heat flux [75], which is in this case in the perpendicular direction to the flow towards the boundaries of gas channels, as shown in Figure 4.26. The influence of the forced convection heat transfer in the gas channels (GCs) is significant in comparison with the total heat rejection. The relationship between the effects of drying air velocity and temperature is so non-linear [75], thus increasing air velocity at the inlet has a significant effect on the temperature distribution inside the fuel cell as shown in Figure 4.25. With higher inlet air velocity, the inlet air is cold with low humidity, so the temperature inside the fuel cell is dropped, as shown in Figure 4.25. As expected, a noticeable dropping in cell temperature in conjunction with increasing the air inlet velocity. Air velocity is a critical factor in the thermal management of fuel cell as the simulation result shows that temperature distribution in fuel cell is highly effected by the air velocity. The obtained results of this study is in contract with the work of Larminie et al [9].

The air is always fed through the cathode side to supply the demanded oxygen. Figure 4.27 illustrates the oxygen mole fraction distribution across the gas diffusion layer and catalyst layer in the cathode side. It can clearly demonstrates that when the air inlet velocity increases the minimum value of oxygen mole fraction increases from 0.0665 to 0.0830 . The faster rate of air supply to the cathode side increases the oxygen concentration as expected.

With temperatures higher than $333 \mathrm{~K}$, it suffices to say that the air will continuously dry out the excess water in the electrodes faster than the production of water by the electrochemical reaction at the catalysts layers [9]. Figure 4.28 shows the water content distribution inside fuel cell with different air inlet velocity; it is obvious that with higher flow rate less water content can be found, as the air that flows through the cell at higher rate would reduce the humidity and remove more of the product water. 


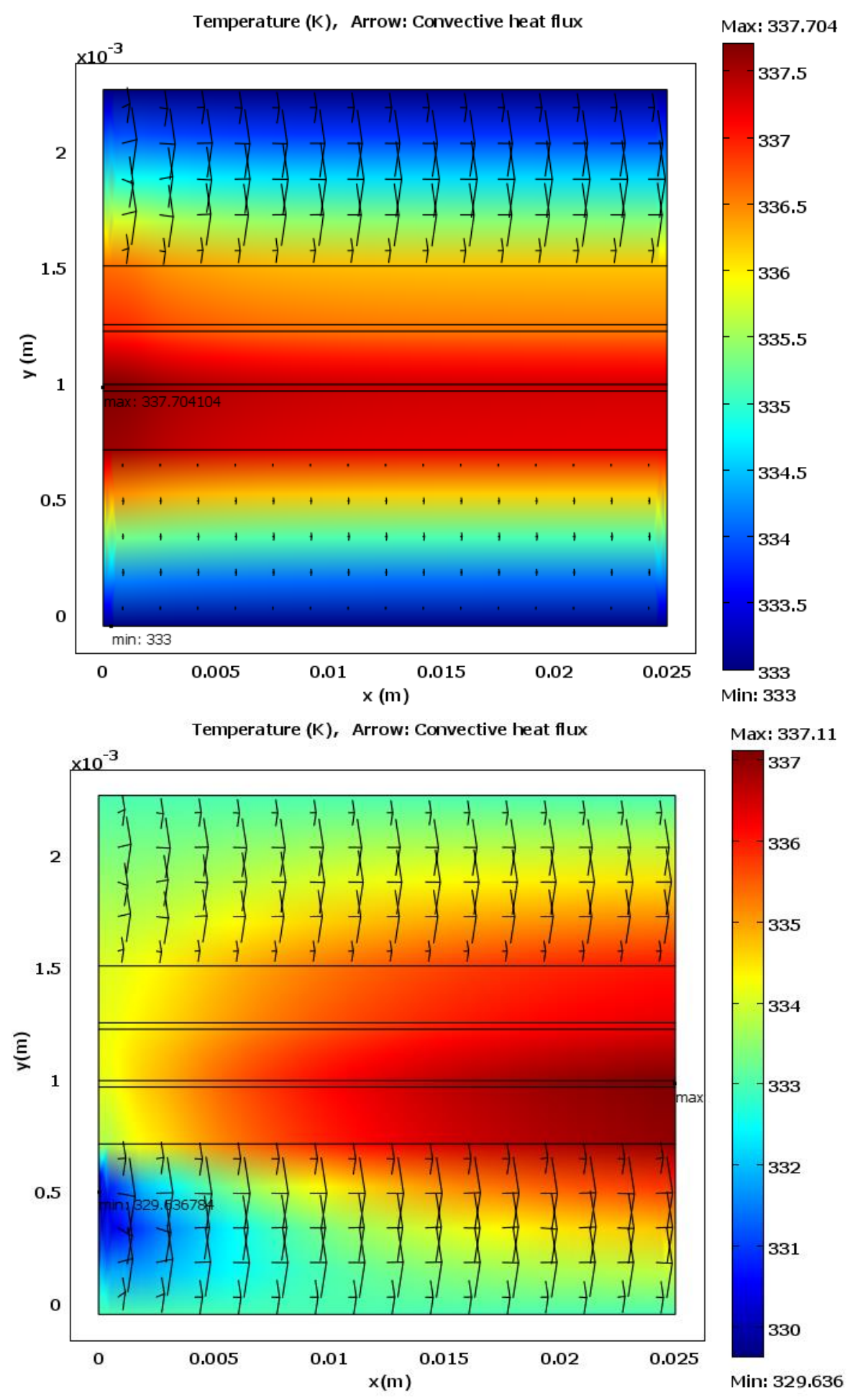

Figure 4.25 Temperature Distribution (Surface Plot) and Convective Heat Flux (Arrow Plot) in the Fuel Cell with Different Air Inlet Velocity $U_{c}=0.1185 \mathrm{~m} / \mathrm{s}$ (Top), and $U_{c}=1.45 \mathrm{~m} / \mathrm{s}$ (Bottom), Operating at Cell Voltage $0.6 \mathrm{~V}$. 


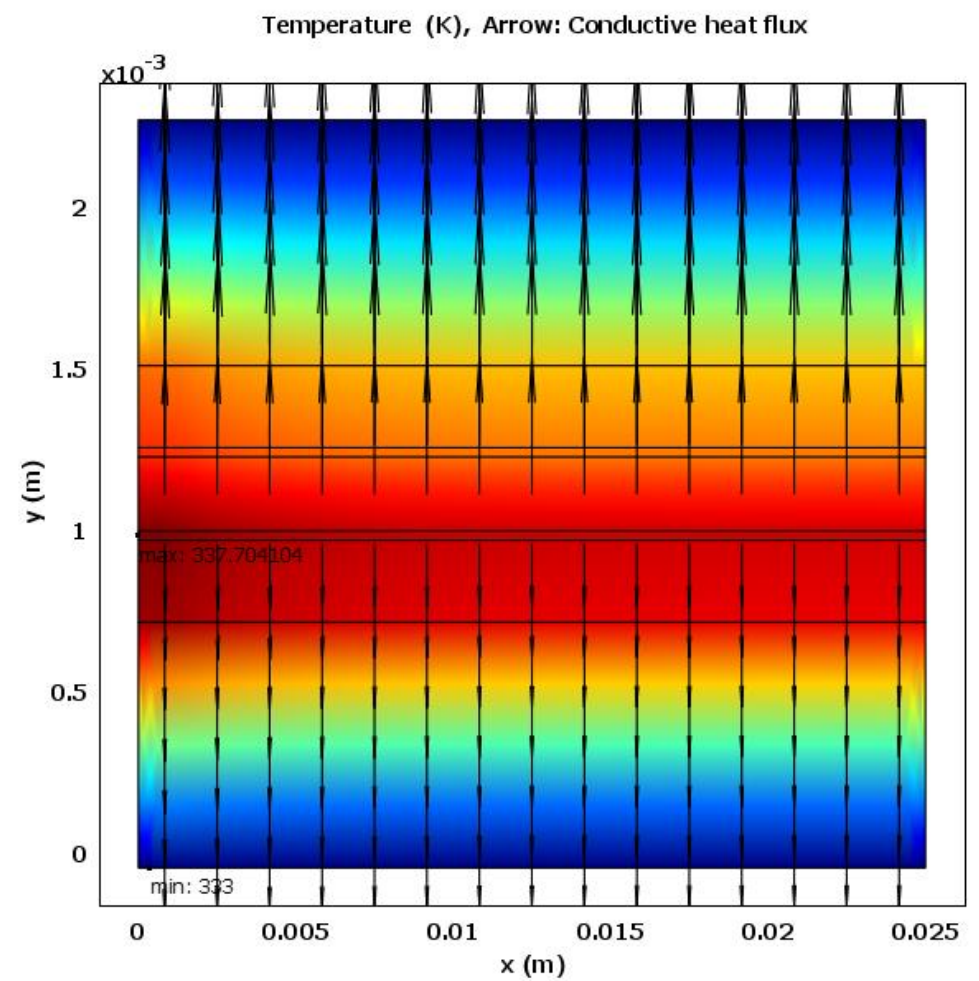

Max: 337.704

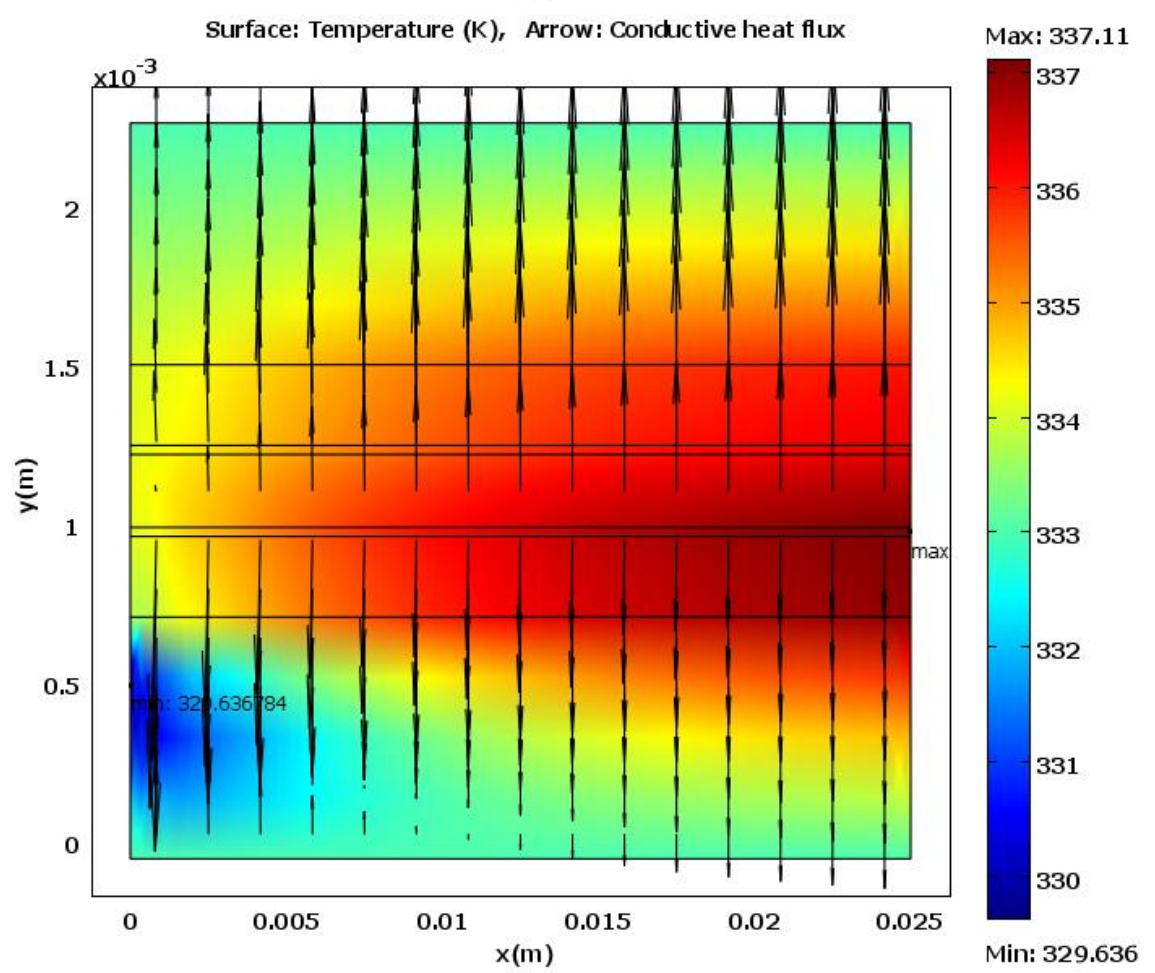

Figure 4.26 Temperature Distribution (Surface Plot) and Conductive Heat Flux (arrow plot) in the Fuel Cell with Different Air Inlet Velocity $U_{c}=0.1185 \mathrm{~m} / \mathrm{s}$ (Top), and $U_{c}=1.45 \mathrm{~m} / \mathrm{s}$ (Bottom), operating at Cell Voltage $0.6 \mathrm{~V}$. 


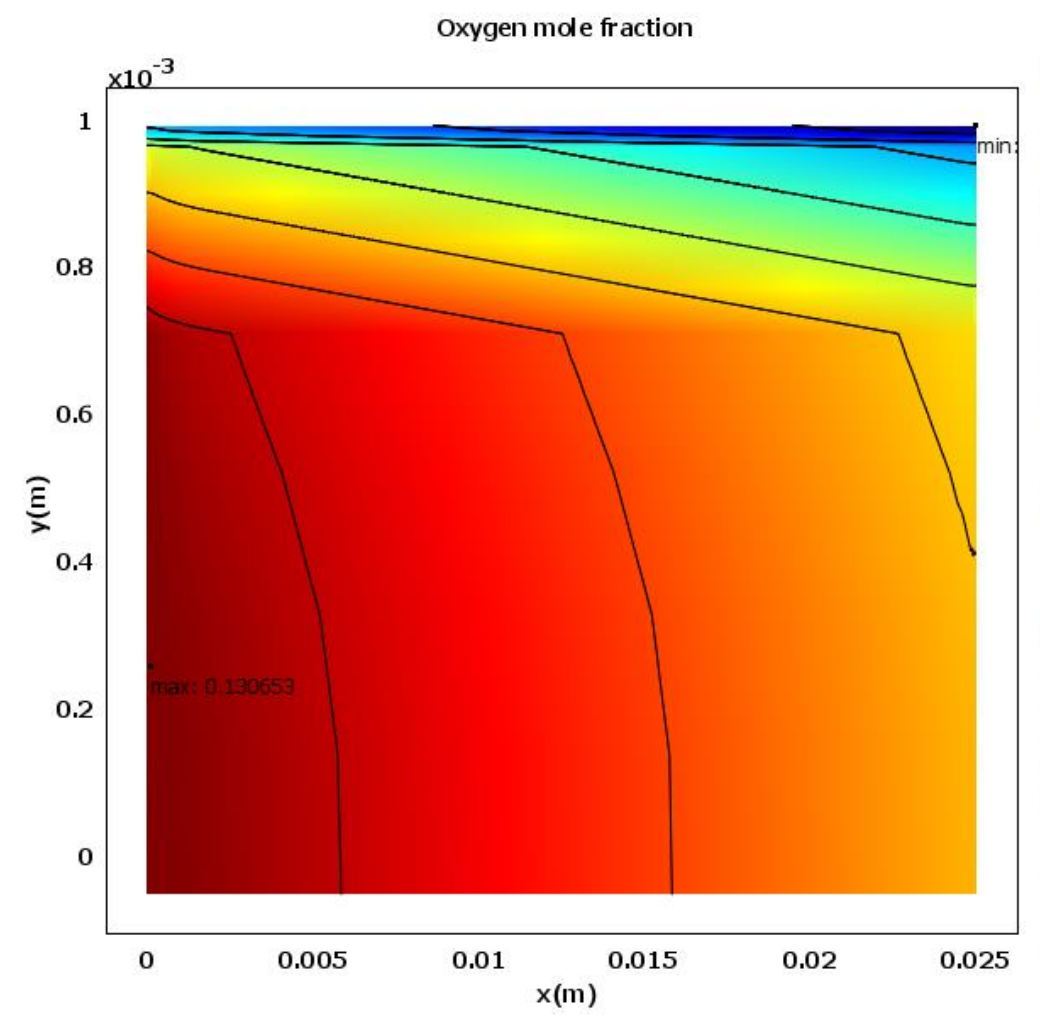

Max: 0.131
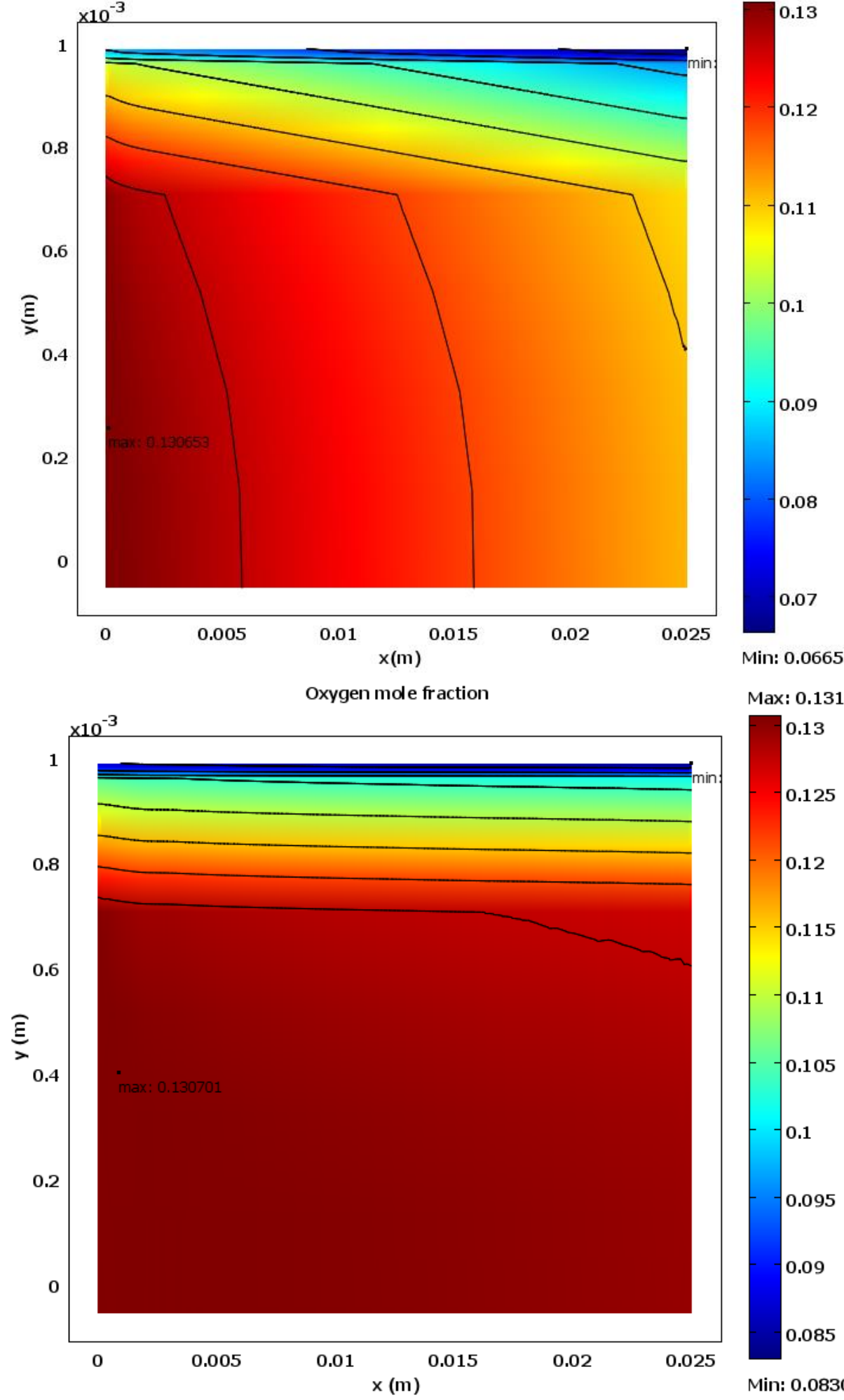

Max: 0.131

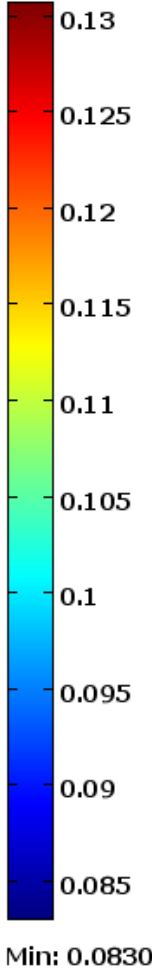

Figure 4.27 Oxygen Mole Fraction Distribution at the Cathode Side with Different Air Inlet Velocity $U_{c}=0.1185 \mathrm{~m} / \mathrm{s}$ (Top), and $U_{c}=1.45 \mathrm{~m} / \mathrm{s}$ (Bottom), at Cell Voltage of $0.6 \mathrm{~V}$. 


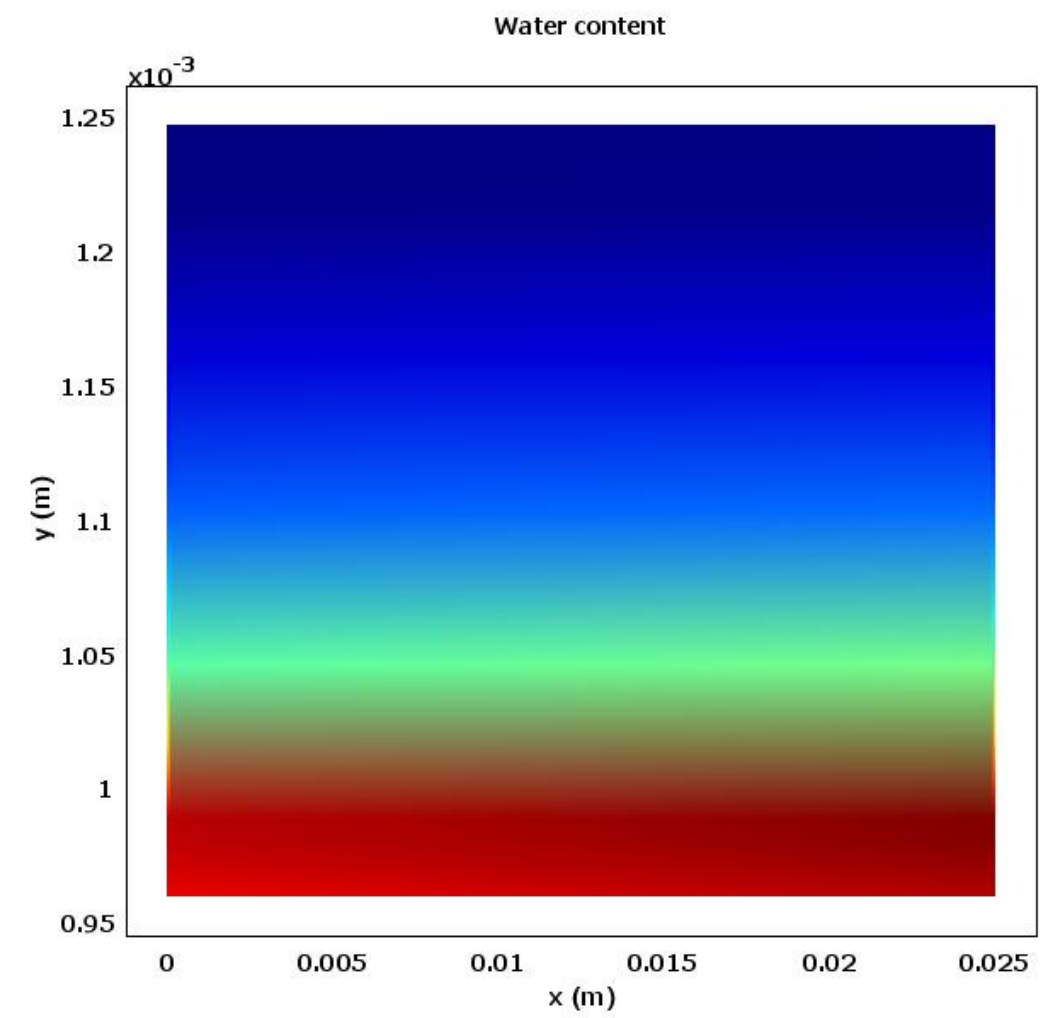

Max: 16.329
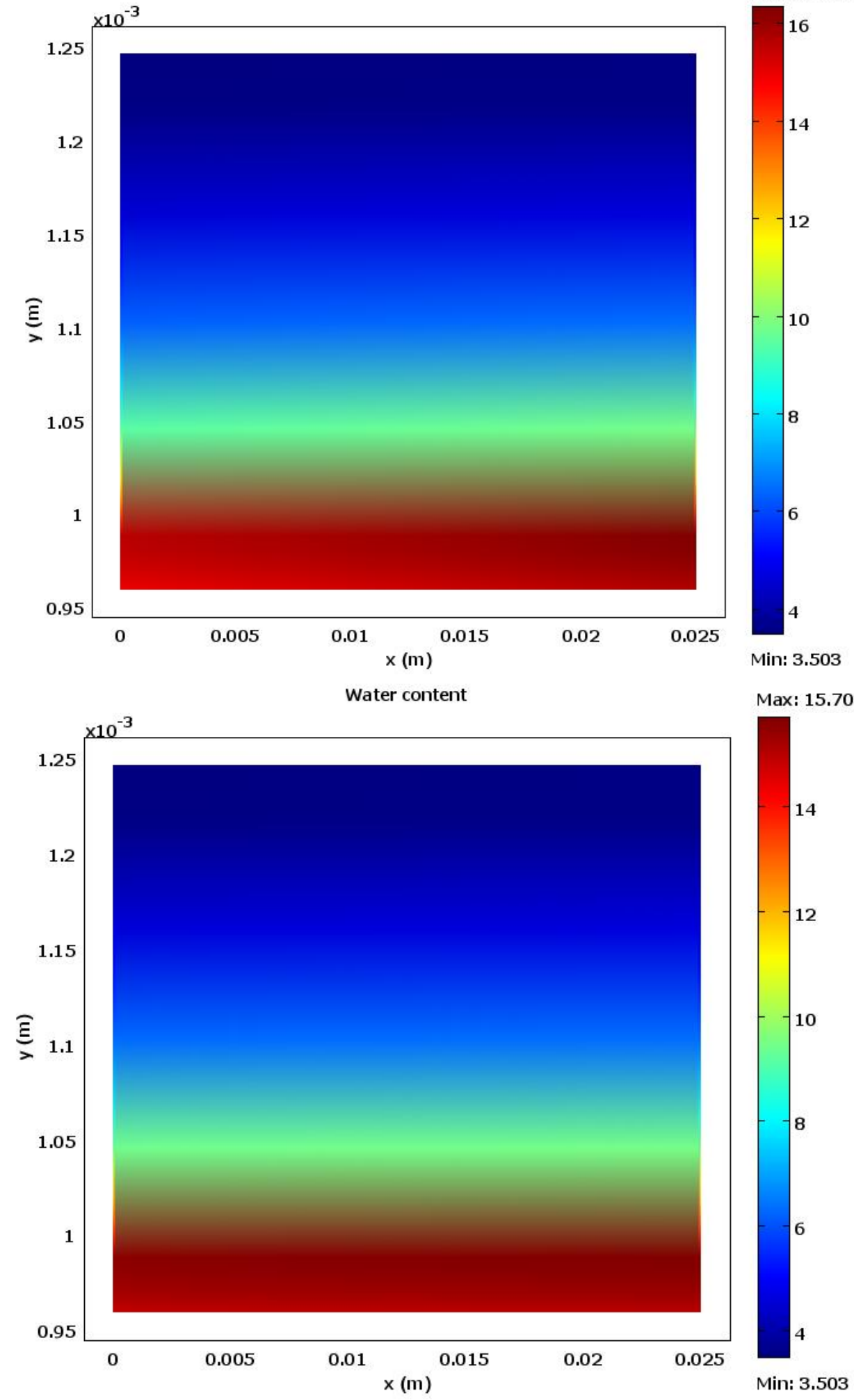

Max: 15.703

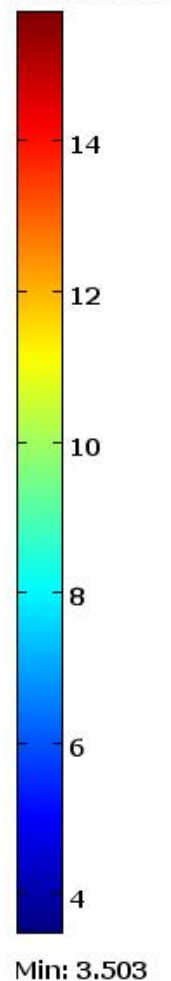

Figure 4.28 Water Content Distribution inside Fuel Cell with Different Air Inlet Velocity $U_{c}=0.1185 \mathrm{~m} / \mathrm{s}$ (Top), and $U_{c}=1.45 \mathrm{~m} / \mathrm{s}$ (Bottom), at Cell Voltage of $0.6 \mathrm{~V}$. 


\subsection{The optimization model}

The optimum founding parameters from the parametric study that were carried out in previous sections have been examined for optimization of the PEM fuel cell. Figure 4.29 shows a significant improvement in the current density, which was reached by updating the old model that corresponded to the base case condition in Table (2.2) with the new parameters. Table (4.1) listed the current densities that came from updating the $x-y$ plane model with the optimum parameters, i.e. the protonic conductivity has been changed from the form of Eq. 2.71 for the base case and replaced with the optimum value of $14 \mathrm{~S} / \mathrm{m}$ that was found in section 4.5 . For a given cell voltage of $0.7 \mathrm{~V}$, Table (4.1) illustrates that updating the new model with the optimum parameters increases the current density from $0.13417 \mathrm{~A} / \mathrm{cm}^{2}$ to $0.48998 \mathrm{~A} / \mathrm{cm}^{2}$, which is more than triple the value of the base case. Also, Table (4.1) shows that the protonic conductivity, which is strongly associated with water content in the membrane, and the operating temperature have the biggest influence on the current density. This indicates that the water management and temperature management are the key to the success of the performance of PEM fuel cell. Further experimental investigation is recommended to examine the new findings of this research.

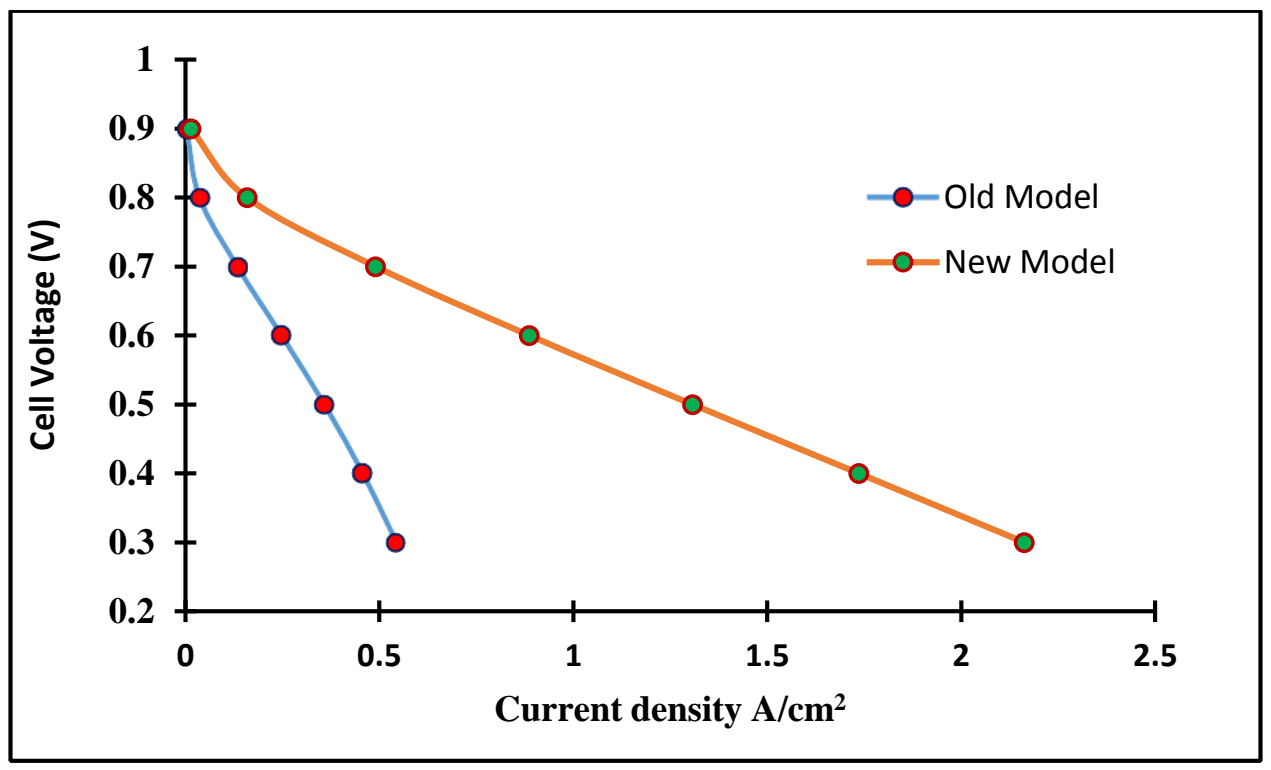

Figure 4.29 The Polarization Curves of the New and Old Models 
Table 4.1: The Current Density Corresponding to the Optimum Parameters at Cell Voltage of 0.7V

\begin{tabular}{|l|l|}
\hline Optimization parameters (cell voltage $\mathbf{= 0 . 7}$ V) & $\begin{array}{l}\text { Current density } \\
\text { (A/cm }\end{array}$ \\
\hline Relative humidity $=100 \%$ & $\mathbf{0 . 1 3 4 1 7}$ \\
\hline Proton Conductivity (changed from Eq. (2.71) to 14 (S/m) & $\mathbf{0 . 2 5 1 6 5}$ \\
\hline GDL porosity (changed from 0.17 to 0.4) & 0.26132 \\
\hline CL effective porosity (changed from 0.034 to 0.102) & 0.31906 \\
\hline Operating pressure (changed from (1-3) atm to (3-5) atm) & 0.37380 \\
\hline Operating Temperature ( changed from 333K to 353 K) & $\mathbf{0 . 4 7 8 4 1}$ \\
\hline Membrane porosity (changed from 0.17 to 0.28) & 0.48036 \\
\hline Inlet air velocity (changed from $0.1185 \mathrm{~m} / \mathrm{s}$ to $1 \mathrm{~m} / \mathrm{s}$ ) & $\mathbf{0 . 4 8 9 9 8}$ \\
\hline
\end{tabular}




\section{Chapter 5 \\ Conclusions and Recommendations}

\subsection{Conclusion}

In the work presented in this thesis, a comprehensive model was developed in a two-dimensional non-isothermal PEM fuel cell in $\mathrm{x}-\mathrm{y}$ and $\mathrm{y}-\mathrm{z}$ planes. In last few years much research effort has been paid towards developing more physically complex analytical models with less assumptions. The comprehensive fuel cell model developed in this study can be used to examine details of complex flow patterns, mass and heat transport encountered as well as the membrane-phase and solid-phase potential distributions in an operational PEMFC, which are usually unobservable by the three-dimensional model due to oversimplification. The computational fluid dynamics (CFD) framework was applied in this study to solve the governing equations of transport species, momentum, charge conservation and energy. Instead of treating catalyst layers as interfaces of nil thickness, the model presented here features a finite thickness employed for catalyst layers, allowing for a more realistic description of electrochemical reaction kinetics arising in the operational PEM fuel cell. To account for the membrane swelling effect, the membrane water content balance is modeled in this study.

Parametric studies were performed using the $\mathrm{x}-\mathrm{y}$ plane, which revealed the effects of a number of operating conditions and material properties, including the effect of inlet reactant relative humidity, the effect of operating temperature, the effect of gas diffusion porosity, the effect of effective porosity of the catalyst layer, the effect of proton conductivity, the effect of operating pressure, the effect of membrane porosity and the effect of air inlet velocity at cathode side on the PEM fuel cell performance. The equations governing the flow of air and distribution of the reactants concentration in all layers were derived considering the effects of porosity of layers together with all other parameters. The effects of porosities change in membrane (M), gas diffusion layers (GDLs) and catalyst layers (CLs) on the performance of the fuel cell have been numerically deliberated. The results revealed that higher volume porosity of GDL, M, and CL, have positive effects on the performance of PEM fuel cell. One of the main contributions of this work that provided insight into the design of the membrane with proper porosity to improve water management based on the transport behaviour of liquid water in the membrane. Considerable 
effects have been noticed for the membrane porosity in the water content in the membrane. The parametric simulation results illustrate that the air velocity is a critical factor in the thermal management of the cell. Also, it is found that a PEM fuel cell can perform better with reasonably high operating pressure and temperature, as well as a supply of fully humidified gaseous reactants.

The models results were validated against experimental data and good overall agreement was achieved. The simulation results of this study provides insights that may assist practitioners in optimizing PEMFC design and reducing the manufacturing cost.

\subsection{Contributions}

Three main contributions made in this thesis work are summarized as follows:

1. A set of detailed two-dimensional non-isothermal computational models for PEM fuel cells in $x-y$ and $y-z$ planes are developed, which circumvents the 3D modeling complexity and the increased computational expenses, to examine details of complex flow patterns, mass and heat transport encountered as well as water content in membrane, the membrane-phase and solid-phase potential distributions in an operational PEMFC

2. Previous single-phase non-isothermal two-dimensional PEM fuel cell models [47-49] were refined. During this thesis study, these models have been refined by:

- Taking into account the Ohmic heating loss in the electrodes to the $\mathrm{x}-\mathrm{y}$ plane model that developed by Yin et al. [47] for more realistic results.

- Refined the author pervious model $[48,49]$ by excluding the thermodiffusion term of the Maxwell-Stefan equation, since the overall performance of a steady-state PEM fuel cell does not exhibit significant changes after adding it. Changes made to the existing model led to increase the computation speed and reduce the cost.

3. A detailed parametric study was conducted using the refined two-dimensional model of PEM fuel cell in the $x-y$ plane with more details as presented in Chapter 4, have not been published yet, which constitutes an original contribution. 


\subsection{Recommendations}

The results presented in this thesis are in good agreement with experimental data, and the model is capable of examining details of transport phenomena in PEM fuel cell which are hard to capture through experiments. However, there are still a number of improvements that may enhance the present model to achieve more accurate and better prediction of all major physically realistic phenomena for optimization of PEM fuel cell design and reduction of its manufacturing cost, so the future work may be carried out such as the following:

1. Develop a two-phase flow model that can account for liquid water transport in the porous electrodes to gain a more realistic understanding of the fuel cell operation mechanism

2. Making variables time-dependent, to provide more valuable insights to all types of over potential of the PEM fuel cell.

3. Three dimensional model that includes all the components of the PEM fuel cell with more physical complexities is recommended for full understanding of the non-isothermal effects on performance of PEM fuel cell.

4. Further study of the relation between the membrane porosity and water accumulation is needed to improve the present investigation. 


\section{REFERENCES}

1. Frano Barbir: "PEM Fuel Cells Theory and Practice". Elsevier Inc, 2005.

2. Pu, Hongting: "Polymers for PEM Fuel Cells". Hoboken, New Jersey: John Wiley \& Sons. , 2014.

3. http://en.wikipedia.org

4. Kerry-Ann Adamson: "Stationary Fuel Cells- An Overview" Elsevier,2007.

5. http://www.enterpriserobotics.com/ER_Details.asp?ID=735

6. Vladimir S. Bagotsky: "Fuel Cells- Problems and Solutions" Second Edition, Wiley, 2012.

7. Sossina M. Haile, Dane A. Boysen, Calum R. I. Chisholm \& Ryan B. Merle: "Solid acids as fuel cell electrolytes". Nature 410: pp.910-913, 2001.

8. Steele, B.C.H. and A. Heinzel: "Materials for fuel-cell technologies," Nature 414: pp.345352, 2001.

9. James Larminie and Andrew Dicks: "Fuel Cell Systems Explained" John Wiley \&Sons, Ltd, Chichester, England, 2000.

10. Jung-Ho Wee: “Applications of Proton Exchange Membrane Fuel Cell Systems”, Renewable and Sustainable Energy Reviews Vol (1): pp. 1720-1738, 2007.

11. Leonard W. Fine, Herbert Beall, and John Stuehr: "Chemistry for Scientists and Engineers". Preliminary Edition, Saunders Golden Sunburst Series, 2000.

12. http://kids.britannica.com/comptons/art-106689/The-proton-exchange-membrane-fuel-cellis-one-of-the

13. Hui Li, Shanna Knights, Zheng Shi, John W. Van Zee, Jiujun Zhang: "Proton Exchange Membrane Fuel Cells, Contamination and Mitigation Strategies". 2010.

14. James Larminie and Andrew Dicks: "Fuel Cell Systems Explained". John Wiley \& Sons, Ltd, Chichester, England, 2000.

15. M. W. Verbrugge, R. F. Hill: "Ion and Solvent Transport in Ion-Exchange Membranes". $J$. Electrochem. Soc., Vol.140 (5): pp.1218-1225, 1993.

16. Inzelt, G., Pineri, M., Schultze, J. W. and M. A. Vorotyntsev: "Electron and proton conducting polymers: recent developments and prospects". Electrochimica Acta, Vol. 45 (15): pp.2403-2421, 2000.

17. Alexander Kabza: "Fuel Cell Formulary”, 2015 
18. Chris Rayment and Scott Sherwin: "Introduction to Fuel Cell Technology", Department of Aerospace and Mechanical Engineering- University of Notre Dame, U.S.A, 2003.

19. P.D. Beattie, F.P. Orfino, V.I. Basura, K. Zychowska, J.F. Ding, C. Chuy, J. Schmeisser and S. Holdcroft:. "Ionic conductivity of proton exchange membranes". J. Electroanalytical Chemistry, Vol. 503: pp.45-56, 2001.

20. D. M. Bernadi and M. W. Verbrugge: "A Mathematical Model of the Solid Polymer Electrolyte Fuel Cell”. J. Electrochem. Soc., Vol. 139(9): pp.2477-2491, 1992.

21. D. M. Bernardi and M. W. Verbrugge: "Mathematical Model of a Gas Diffusion Electrode Bonded to a Polymer Electrolyte". AIChE J., Vol. 37(8): pp.1151-1162, 1991.

22. T. E. Springer, T. A. Zawordzinski, and S. Gottesfeld: "Polymer Electrolyte Fuel Cell Model". J. Electrochem. Soc., Vol. 138(8): pp.2334-2342, 1991.

23. T. F. Fuller, J. Newman:"Water and Thermal Management in Solid Polymer Electrolyte Fuel Cells”. J. Electrochem. Soc., Vol. 140(5): pp.1218-1225, 1993.

24. T. V. Nguyen, R. E. White: "A Water and Heat Management Modle ofr Proton Exchange Membrane Fuel Cells”. J. Electrochem. Soc., Vol. 140(8): pp.2178-2186, 1993

25. J. S. Yi, T. V. Nguyen: “An Along-the Channel Model for Proton Exchange Membrane Fuel Cells”. J. Electrochem. Soc., Vol. 145(4): pp.1149-1159, 1998.

26. J. S. Yi, T. V. Nguyen: "Multicomponent Transport in Porous Electrodes of Proton Exchange Membrane Fuel Cells Using the Interdigitated Gas Distributors”. J. Electrochem. Soc., Vol. 146(1): pp.38-45, 1999.

27. J.C. Amphlett, R.M. Baumert, R.F. Mann, B.A. Peppley, P.R. Roberge: "Performance Modeling of Ballard Mark IV Fuel Cell’. J. Electorchem. Soc., Vol. 142(1): pp.1-15, 1995.

28. J.Kim, S.M. Lee, S. Srinivasan: "Modeling of Proton Exchange Membrane Fuel Cell Performance with an Empirical Equation”. J. Electorchem. Soc., Vol. 142(8): pp.2670-2674, 1995.

29. V. Gurau, H. Liu, and S. Kakac: "Two-Dimensional Model for Proton Exchange Membrane Fuel Cells". AIChE J, Vol. 44(11): pp.2410-2422, 1998.

30. S. Um, C. Y. Wang, and K. S. Chen: "Computational Fluid Dynamics Modeling of Proton Exchange Membrane Fuel Cells”. J. Electrochem. Soc., Vol. 147(12): pp.4485-4493, 2000.

31. Z. H. Wang, C. Y. Wang, K. S. Chen: "Two Phase Flow and Transport in the Air Cathode of Proton Exchange Membrane Fuel Cells". J. Power Sources, Vol. 94(1): pp.40-50, 2001. 
32. T. Berning, D. M. Lu, N. Djilali: “Three-Dimensional Computational Analysis of Transport Phenomena in a PEM Fuel Cell”. J. Power Sources, Vol. 106(1-2): pp.284-292, 2002.

33. S. Dutta, S. Shimpalee, J. W. Van zee: "Three-dimensional Numerical Simulation of Straight Channel PEM Fuel Cells”. J. Appl. Electrochem., Vol. 30: pp.135-146, 2000.

34. S. Dutta, S. Shimpalee, J. W. Van zee: "Numerical Prediction of Mass Exchange between Anode and Cathode Channels in a PEM Fuel Cell”. Int. J. Heat Mass Transfer, Vol. 44: pp.2940, 2001.

35. S. Um, C.Y. Wang: "Three-Dimensional Analysis of Transport and Electrochemical Reactions in Polymer Electrolyte Fuel Cells”, J. Power Sources, Vol. 125: pp.40-51, 2004.

36. C.Y. Wang: "Fundamental models for fuel cell engineering". Chem. Rev. Vol. 104: pp.47274765, (2004).

37. L. You, H.T. Liu: "A two-phase flow and transport model for the air cathode in PEM fuel cells”. Int. J. Heat Mass Transfer Vol. 45: pp.2277-2287, 2002.

38. L. You, H.T. Liu: "A two-phase and multicomponent model for the cathode of PEM fuel cells". ASME Congress and Exhibition, New York, 2001.

39. S. Mazumder, V. Cole: "Rigorous 3-D mathematical modeling of PEM fuel cells". J. Electrochem. Soc. Vol. 150 (11): pp. A1510 - A1517, 2003.

40. T. Berning, N. Djilali: “A 3D, multiphase, multicomponent model of the cathode and anode of a PEM fuel cell”. J. Electrochem. Soc. Vol. 150: pp.A1589-A1598, 2003.

41. Min-Hsing Chang, Falin Chen, and Hong-She Teng: "Effects of two-phase transport in the cathode gas diffusion layer on the performance of a PEMFC". Journal of Power Sources Vol. 160: pp.268-276, 2006.

42. A. S. Bansode, T. Sundararajan, and Sarit K. Das: "An Analytical Solution to Predict the Inception of Two-Phase Flow in a Proton Exchange Membrane Fuel Cell”. J. Fuel Cell Sci. Technol., 7(6), pp. 064502-064502-5, 2010.

43. T. Zhou, H. Liu: “A General Three-Dimensional Model for Proton Exchange Membrane Fuel Cells”. Int. J. Transport Phenom., Vol. 3: pp.177-198, 2001.

44. T. Zhou, and H. Liu: "Effects of the electrical resistance of the GDL in the PEM fuel cell". $J$. Power Sources, Vol. 151(11): pp.A1954-A1960, 2006.

45. J.S. Yi and T.V. Nguyen: "Proton Conducting Membrane Fuel Cells I". The Electrochemical Society Proceeding Series, Vol. 23: pp.66-75, 1995. 
46. Jun Cao and N. Djilali: "Numerical Modeling of PEM Fuel Cells under Partially Hydrated Membrane Conditions”. ASME J. Energy Resources Technology, Vol. 127: pp.26-36, 2005.

47. Jianghui Yin and Jun Cao: "Modeling of PEM fuel cell with finite- thickness catalysts". Modern Physics Letters B, 23: 537, 2009.

48. Rihab Jaralla, Jun Cao and Ziad Saghir: "Numerical Investigation of Thermodiffusion Effects on PEM Fuel Cell Performance”. Modern Physics Letters B, 24:pp. 1329, 2010.

49. Rihab Jaralla, Mama Chacha, Tawfiq J. Jaber and Jun Cao: “An Enhanced Model for Numerical Investigation of Mass Transport in an Operational PEM Fuel Cell”. AHU $J$. of Engineering \& Applied Sciences, Vol. 5(1): pp.43-64, 2013.

50. Utku Gulan, Hasmet Turkoglu, and Irfan Ar: "The Effect of Inlet Parameters on Fluid Flow and Cell Performance at Cathode of a Proton Exchange Membrane Fuel Cell'. J. Fuel Cell Sci. Technol., Vol. 7(4): pp.041002-041002-8, 2010.

51. P.C. Sui, S. Kumar, N. Dijlali: “Advanced computational tools for PEM fuel cell design, Part 1. Development and base case simulations". Journal of Power Sources Vol. 180: pp.410-422, 2008.

52. Faycel Khemili, Mustapha Najjari, and Sassi Ben Nasrallah: "Transient Thermal Model for Proton Exchange Membrane Fuel Cells”. J. Fuel Cell Sci. Technol., Vol. 9(2): pp.021008021008-10, 2012.

53. A. Verma and R. Pitchumani: "Analysis and Optimization of Transient Response of Polymer Electrolyte Fuel Cells”. J. Fuel Cell Sci. Technol., Vol. 12(1): pp.011005-011005-10, 2015.

54. Nima Ahmadi, Sajad Rezazadeh, Mirkazem Yekani, Alireza Fakouri, Iraj Mirzaee: "Numerical Investigation of the Effect on Inlet Gases Humidity on Polymer Exchange Membrane Fuel Cell (PEMFC) Performance," Transactions of the Canadian Society for Mechanical Engineering, Vol. 37(1), 2013.

55. Qi-fei Jian, Guang-qing Ma, Yang Zhao, and Kai Xiao: "Humidification Effects of Proton Exchange Membrane Fuel Cell with Conventional and Interdigitated Flow Field," J. Fuel Cell Sci. Technol., Vol. 10(6): pp.061007-061007-10, 2013.

56. Yok-Sheung Li, Yi Han and Jie-Min Zhan: "Uniformity Analysis in Different Flow-Field Configurations of Proton Exchange Membrane Fuel Cell’. J. Fuel Cell Sci. Technol Vol.10 (3): pp.031003, 2013. 
57. A. Iranzo1, A. Salva, E. Tapia and F. Rosa:"Effect of the Membrane Thermal Conductivity on the Performance of a Polymer Electrolyte Membrane Fuel Cell”. J. Fuel Cell Sci. Technol., Vol. 11(3): pp.031007-031007-7, 2014.

58. Dario Maggiolo, Andrea Marion and Massimo Guarnieri: "Lattice Boltzmann Modeling of Water Cumulation at the Gas Channel-Gas Diffusion Layer Interface in Polymer Electrolyte Membrane Fuel Cells". J. Fuel Cell Sci. Technol., Vol. 11(6): pp.061008-061008-6, 2014.

59. Paola Costamagna: 'Transport phenomena in polymeric membrane fuel cells". Chemical Engineering Science Vol. 56: pp.323-332, 2001.

60. T. Zhou and H. Liu: "Effects of the electrical resistance of the GDL in the PEM fuel cell". Journal of Power Sources, Vol. 161(1): pp. 444-453, 2006.

61. 59 T. V. Nguyen, R. E. White:“A Water and Heat Management Model for Proton Exchange Membrane Fuel Cells". J. Electrochem. Soc., Vol. 140(8): pp. 2178-2186, 1993.

62. H. Ju, and C.Y. Wang: "Experimental Validation of a PEM Fuel Cell Model by Current Distribution Data”. Journal Electrochemical Society, Vol. 151(11): pp.1954-1960, 2004.

63. D. Singh, D. M. Lu, and N. Djilali: "A Two-Dimensional Analysis of Mass Transport in Proton Exchange Membrane Fuel Cells”. Inter. J. of Eng. Sci., Vol.37: pp. 431-452, 1999.

64. L. Wang, A. Husar, T. Zhou, H.Liu: "A Parametric Study of PEM Fuel Cell Performances" International Journal of Hydrogen Energy, Vol. 28, pp. 1263-1272, 2003.

65. Q. Yan, H. Toghiani, and H. Causey: "Investigation of water transport through membrane in a PEM fuel cell by water balance experiments" Journal of Power Sources, Vol.158 (1): pp.316325, 2006.

66. Wu Bi and Thomas. F. Fuller: "Temperature Effects on PEM Fuel Cells Pt/C Catalyst Degradation" ECS Trans, Vol. 11(1): pp.1235-1246, 2007.

67. Bhaskar Balasubramanian, Frano Barbir and Jay Neutzler:"OI"HMAL OPERATING TEMPERATURE AND PRESSURE OF PEM FUEL CELL”. Energy Partners, L.C., pp. 977981, 1998.

68. Qiangu Yan, Hossein Toghiani, Junxiao Wu: "Investigation of Water Transport through Membrane in a PEM Fuel Cell by Water Balance Experiments" Journal of Power Sources, Vol. 158, pp. 316-325, 2006.

69. D. Natarajan and T.V. Nguyen: "Three-dimensional effects of liquid water flooding in the 
cathode of a PEM fuel cell” Journal of Power Sources, Vol. 115(1), pp. 66-80, 2002.

70. T. Berning, N. Dijiali: “A 3D, multiphase, multicomponent model of the cathode and anode of a PEM fuel cell” Journal of Electrochemical Society, Vol. 150(12), pp.1589-1598, 2003.

71. John M. Stockie, Keith Promislow, Brian R. Wetton: "Afinite volume method for multicomponent gas transport in a porous fuel cell electrode" International Journal for Numerical Methods in Fluids. Vol.41 (61), pp.577-599, 2003.

72. R. Roshandel, B. Farhanieh, E. Saievar-Iranizad: "The effects of porosity distribution variation of PEM fuel cell performance” Renewable Energy, Vol. 30, pp.1557-1572, 2005.

73. Ai Suzuki1, Tatsuya Hattori, Ryuji Miura, Hideyuki Tsuboi, Nozomu Hatakeyama, Hiromitsu Takaba, Mark C. Williams, and Akira Miyamoto: "Porosity and Pt content in the catalyst layer of PEMFC: effects on diffusion and polarization characteristics" International Journal of Electrochemical Science, Vol. 5, pp. 1948-1961, 2010.

74. Setareh Shahsavari, Andrew Desouza, Majid Bahrami, and Erik Kjeang: "Thermal analysis of air-cooled PEM fuel cells”, International Journal of Hydrogen Energy Vol. (37): pp.1826118271, 2012.

75. Colleen Spiegel: "Designing and Building Fuel Cells", McGraw Hill, 2007

76. Frano Barbir: "PEM Fuel Cells Theory and Practice". $2^{\text {nd }}$ Edition, Elsevier Inc, 2012.

77. T. Zhou, H. T. Liu: “A general three-dimensional model for proton exchange membrane fuel cells”, Int. J. Transport Phenom. Vol. (3):pp.177-198, 2001 